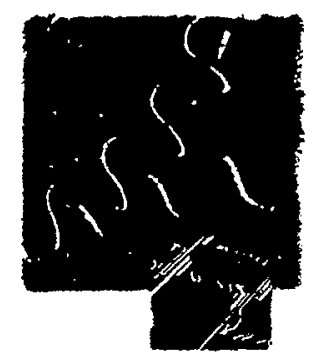

\title{
Seaport Liquid Natural Gas Study
}

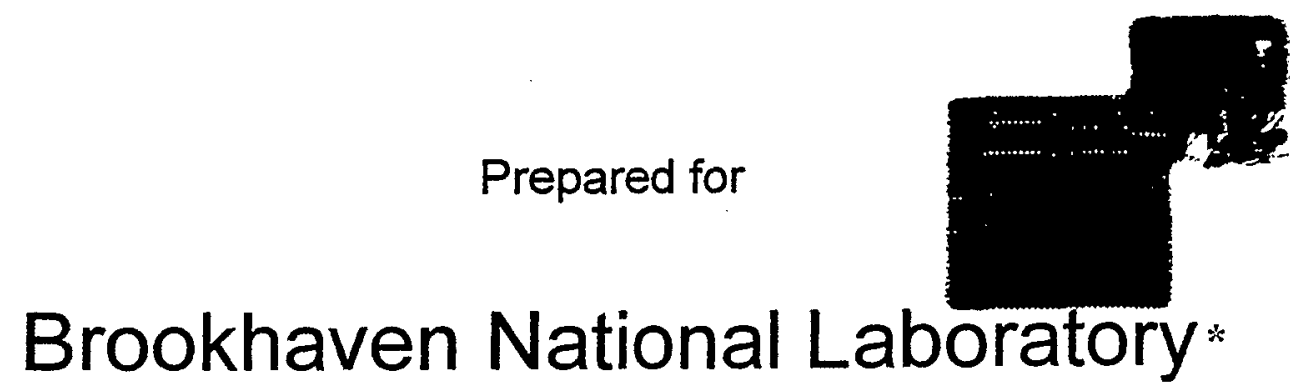

Contract No. 725091

Submitted by:

Zak Cook

CALSTART-WestStart

3360 E. Foothill Blvd.

Pasadena, CA 91107

February 1999

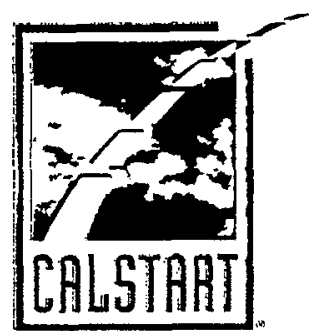

Clean Transportation Solutions"

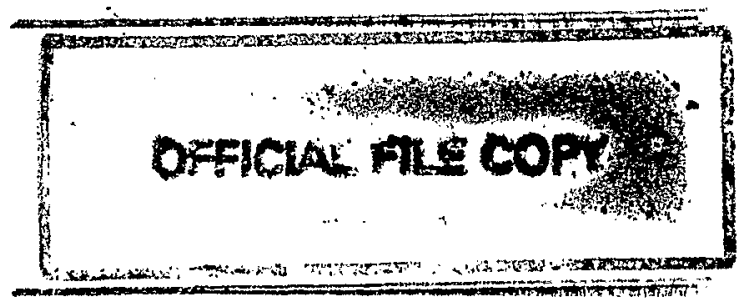




\section{Seaport Liquid Natural Gas Study}

Prepared for

\section{Brookhaven National Laboratory}

Contract No. 725091

Submitted by:

Zak Cook

CALSTART-WestStart

3360 E. Foothill Blvd.

Pasadena, CA 91107

February 1999 


\section{Acknowledgements}

This report was prepared by CALSTART-WestStart under contract to Brookhaven National Laboratory. The Port of Los Angeles, the Port of Oakland and the Pacific Gas $\&$ Electric Company also provided co-funding for the project. The research, analysis and writing of this study took place from May of 1998 through February of 1999. All statements and conclusions expressed herein are those of CALSTART-WestStart, and do not necessarily reflect the position of either the Brookhaven National Laboratory or the co-funding organizations.

Zak Cook of CALSTART-WestStart served as the project manager and principal investigator. Therese Costa, William T. Elrick, Mark Kragen, Angel Mandoky, Kevin Nesbitt, Marion L. Walsh and Jack R. Witz of CALSTART-WestStart provided substantial assistance with data collection, analysis and presentation. Many other individuals within CALSTART-WestStart also assisted in the shaping and refinement of this report. Joyce Peterson of the Public Policy Institute of California supplied invaluable editorial assistance and peer review.

CALSTART also wishes to acknowledge the support of Michael Gurevich of the Department of Energy's Office of Heavy Vehicle Technologies.

James E. Wegrzyn was the program manager at the Brookhaven National Laboratory. 
TABLE OF CONTENTS

\section{EXECUTIVE SUMMARY}

CHAPTER 1 INTRODUCTION.

1.1 STUDY GOALS ................................................................................................ 1-1

1.2 BACKGROUND .................................................................................... 1-1

1.2.1 Why Ports? ..............................................................................

1.2.2 Why LNG? ......................................................................... 1-3

1.3 ASSESSING THE FEASIBILITY OF LNG USE OF THE PORTS......................1-4

1.3.1 Report Structure...................................................................... 1-4

1.3.2 Methodology and Data Collection ........................................... 1-5

\section{CHAPTER 2 PORT OPERATIONS ANALYSIS ........................................................................}

2.1 OVERVIEW OF PORT OPERATIONS …........................................................ 2-1

2.2 PORT-RELATED TRUCKING OPERATIONS .................................................. 2-2

2.2.1 Organizational Structure.......................................................2-4

2.2.2 Economics of Port Trucking .......................................................2-2

2.2.3 Vehicle Profiles .....................................................................2-6

2.2.4 Vehicle Fueling .....................................................................2-2-8

2.2.5 Vehicle Maintenance ...............................................................2-9

2.2.6 Trip Ranges and Daily Mileage Patterns .................................2-11

2.2.7 Gross Vehicle/Combination Weights and Related Issues...... 2-12

\subsection{ENGINE-POWERED VEHICLE AND EQUIPMENT OPERATIONS AT}

\section{SHIPPING AND RAIL TERMINALS ......................................................................2-13}

2.3.1 Equipment Types, Function and Population..........................2-14

2.3.2 Equipment Specifications and Operations............................ 2-15

2.3.3 Hours of Operation ............................................................2-16

2.3.4 Refueling and Maintenance .............................................2-17

2.3.5 Fuel Costs ............................................................................2-17

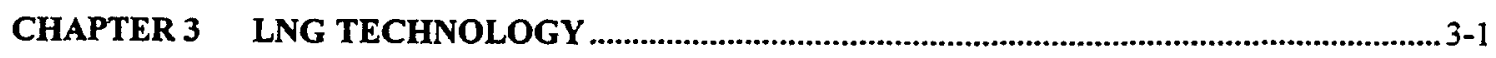

3.1 ENGINE TECHNOLOGY........................................................................... 3-1

3.1.1 Engine Availability..........................................................3-1

3.1.2 Incremental Costs ............................................................ 3-3

3.1.3 Engine Efficiency .................................................................3-4

3.1.4 Maintenance and Reliability ...................................................3-4

3.1.5 Engine and Chassis Pairings ..................................................... 3-4

3.2 REFUELING INFRASTRUCTURE ...............................................................

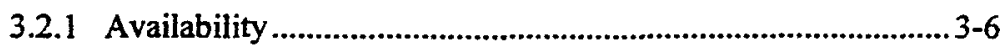

3.2.2 Infrastructure Providers and System Costs ..............................3-6 
3.3.1 Current Prices

CHAPTER 4 FEASIBILITY ANALYSIS...........................................................................

4.1 TECHNOLOGICAL FEASIBILITY ........................................................... 4-1

4.1.1 Availability of Suitable Engine Systems ................................ 4-1

4.1.2 Technological Maturity ...........................................................4-3

4.1.3 LNG Refueling Infrastructure ............................................... 4-3

4.2 ECONOMIC FEASIBILITY ........................................................................... 4-4

4.2.1 Capital Costs of LNG Engine and Refueling Systems ............. 4-4

4.2.2 Operational Costs ....................................................................... 4-6

4.3 ENVIRONMENTAL FEASIBILITY ................................................................ 4-12

4.3.1 On-Road Trucking............................................................. 4-13

4.3.2 Emissions from Port Terminal Operations ............................. 4-15

4.3.3 Summary of Environmental Feasibility ................................. 4-19

4.4 OTHER FACTORS IMPACTING FEASIBILITY OF LNG USE..................... 4-20

4.4.1 Characteristics of Port Trucking Operations ..........................4-20

4.4.2 Characteristics of Terminal Operations ...................................4-22

4.4.3 Legislative and Regulatory Action ...........................................4-23

4.4.4 Characteristics of Ports...........................................................4-24

4.4.5 Competing Technologies ...................................................... 4-25

4.4.6 Ancillary Benefits.............................................................. 4-28

4.4.7 Safety Issues ....................................................................... 4-29

4.4.8 Permitting ........................................................................... 4-30

4.4.9 Summary of Additional Factors ............................................... 4-30

4.5 FEASIBILITY SUMMARY ....................................................................4-31

CHAPTER 5 MITIGATING BARRIERS, LEVERAGING OPPORTUNITIES ..........................5-1

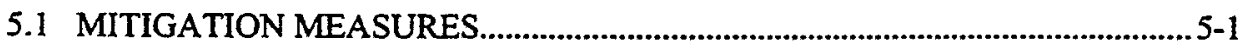

5.2 SUMMARY OF KEY MITIGATION STRATEGIES ............................................. 5-9

CHAPTER 6 CONCLUSIONS AND RECOMMENDATIONS ….......................................... 6-1

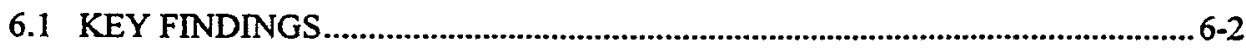

6.1.1 Port Operations........................................................................6-2

6.1.2 LNG: Technology and Marketplace........................................6-3

6.1.3 Assessing Feasibility, Identifying Barriers and Benefits.........6-4

6.1.4 Mitigation Measures....................................................................6-5

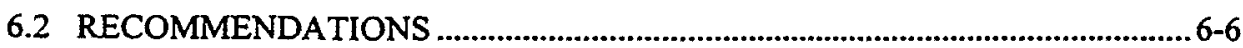




\section{APPENDICES}

APPENDIX A - Current U.S. LNG Refuse Hauler \& Trucking Programs.

A-1

APPENDIX B - Cost Effectiveness Calculations. B-1

APPENDIX C - Cost Parity Model Inputs. C-1

APPENDIX D - LNG to Diesel Gallon Equivalent Price Conversion. D-1

APPENDIX E - Emissions Factors and Calculations E-1

APPENDIX F - Legislation, Regulations and Funding .F-1 APPENDIX G - Estimated Daily LNG Fuel Demand at Various Penetration Levels....... G-1 


\section{LIST OF TABLES}

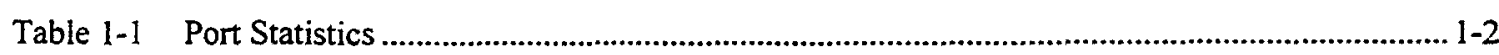

Table 1-2 Survey Sample ........................................................................................................

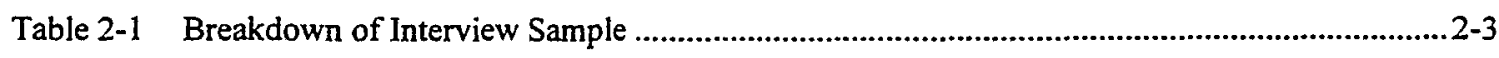

Table 2-2 Critical Factor in Determining Company and Driver Profitability ........................................2-5

Table 2-3 Vehicle Profile (Used Only) ............................................................................................. 2-8

Table 2-4 Trip Ranges and Average Daily Mileage..........................................................................2-11

Table 2-5 Terminal Equipment Types, Functions and Locations ....................................................2-14

Table 2-6 Equipment Inventories.............................................................................................2-15

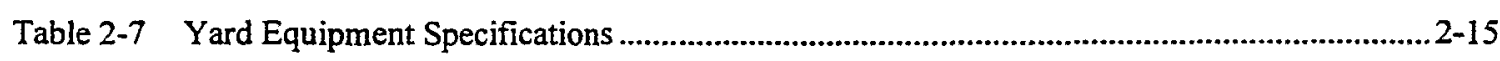

Table 2-8 Average Annual Hours of Use Per Unit .....................................................................2-16

Table 3-1 Heavy-Duty LNG Engine Characteristics and Availability ..................................................3-2

Table 3-2 Heavy-Duty LNG Vehicles Operating or Ordered, U.S. Only .............................................3-3

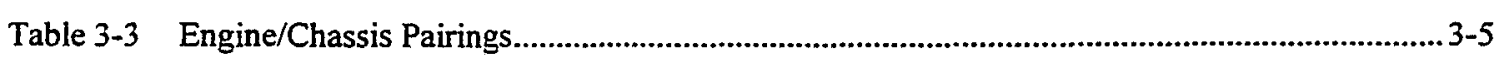

Table 3-4 Contracting Teams and Completed Projects ........................................................................3-7

Table 3-5 Projected Station Sizes and Costs ................................................................................. 3-8

Table 4-1 Heavy-Duty Natural Gas Engines Suitable for Port Trucking .................................................4-2

Table 4-2 Natural Gas Engines Suitable for Use in Terminal Applications............................................ 4-2

Table 4-3 Diesel and LNG Prices, Per Diesel Gallon Equivalent.........................................................4-7

Table 4-4 Emission Factors For On-Road Heavy-Duty Vehicles .....................................................4-13

Table 4-5 Emissions from Port-Related Trucking Fleet.................................................................4-13

Table 4-6 Emission Factors/Standards For Off-Road, Heavy-Duty Diesel Units.................................. 4-16

Table 4-7 Port of Los Angeles Shipping and Rail Terminals ............................................................... 4-16

Table 4-8 Port of Oakland Shipping and Rail Terminals......................................................................4-17

Table 4-9 Characteristics of Port Trucking .................................................................................4-20

Table 5-1 Preferred Means of Incentivizing AFV Use .......................................................................... 5-4

Table 5-2 Critical Barriers and Mitigation Strategies ....................................................................5-10 


\section{LIST OF FIGURES}

Figure 1-1 Key California Diesel Regulations ........................................................................... 1-3

Figure 1-2 Comparative Emissions ............................................................................................ $1-4$

Figure 2-1 Percent of Business Dedicated to Port Work ................................................................2-3

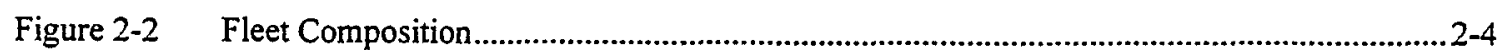

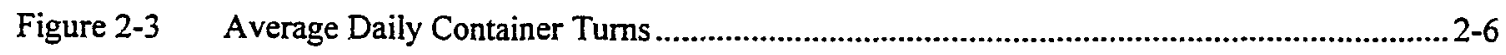

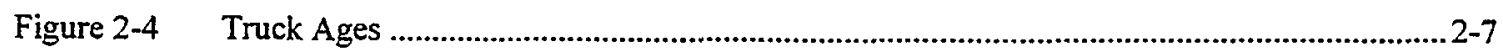

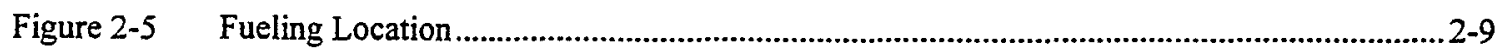

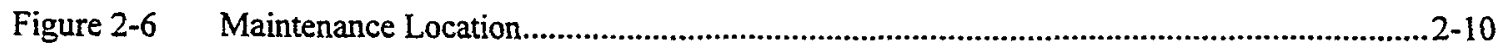

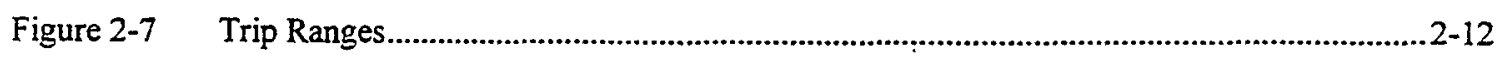

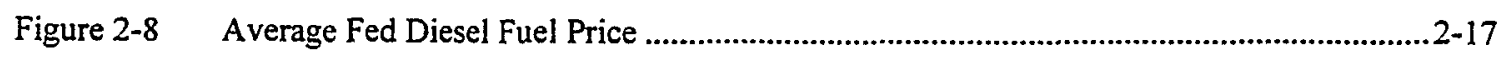

Figure 3-1 Composition of California LNG Prices .......................................................................3-9

Figure 3-2 Projected Wellhead Natural Gas Prices .......................................................................3-10

Figure 3-3 Federal Excise Tax Rates, Per Diesel Gallon Equivalent .............................................. 3-11

Figure 4-1 Factors Impacting Technological Feasibility .....................................................................4-4

Figure 4-2 Retail Diesel Prices in California, 1997-1998 ................................................................. 4-7

Figure 4-3 Crude Oil Price Projections ..................................................................................... 4-8

Figure 4-4 Operational Cost Parity Scenarios ............................................................................ 4-10

Figure 4-5 Factors Impacting Economic Feasibility....................................................................... 4-12

Figure 4-6 Vehicle Emissions, Actual Diesel and Potential LNG..................................................4-14

Figure 4-7 Potential NOx and PM Reductions, Port of Los Angeles Trucking....................................4-14

Figure 4-8 Potential NOx and PM Reductions, Port of Oakland Trucking .......................................4-15

Figure 4-9 Potential NOx and PM Reductions, Port of Los Angeles Yard Tractors ............................ 4-18

Figure 4-10 Potential NOx and PM Reductions, Port of Oakland Yard Tractors.................................. $\overline{4}-18$

Figure 4-1 1 Factors Impacting Environmental Feasibility ................................................................4-19

Figure 4-12 Other Factors Impacting Feasibility ............................................................................4-31

Figure 4-13 Feasibility Overview: Key Variables and Their Impacts ................................................... 4-32

Figure 5-1 Potential LNG Fuel Demand, Port of Los Angeles......................................................5-5

Figure 5-2 Potential LNG Fuel Demand, Port of Oakland ..................................................................5-6 
This page intentionally left blank 


\section{Executive Summary}

\section{Project Overview}

Within California, diesel emissions have been subject to increasing scrutiny and regulatory action. Most recently, the California Air Resources Board (CARB) named the particulate matter in diesel exhaust as a toxic air contaminant (TAC). The regulatory implications of this listing are not yet clear; but at a minimum, it has increased the liability associated with concentrated diesel emissions. In addition to this action, several high profile lawsuits have been initiated against four of the State's largest supermarket chains, alleging that diesel emissions from their distribution facilities violate Proposition 65 statutes. These and other developments have heightened public awareness of the potential health risks associated with diesel fuel and spurred renewed interest in a variety of low emission technologies.

The Seaport Liquid Natural Gas (LNG) Study evaluates the feasibility of using LNG as a heavyduty vehicle and equipment fuel--that is, as an alternative to diesel--at the Ports of Los Angeles and Oakland. The Ports appear to contain a broad range of potentially suitable applications for LNG; however, this analysis focuses exclusively on the Class 7 and 8 trucking operations, and the heavy-duty shipping and rail terminal container handling equipment that are associated with the two facilities. At present, all of these activities are heavily dependent on diesel-powered, heavyduty vehicles and equipment, the utilization of which contributes significantly to the overall emissions inventory stemming from port-related activities.

At present, LNG is considered the most viable alternative to diesel for heavy-duty applications. The use of this alternative fuel in place of diesel typically results in substantial reductions of key criteria pollutant emissions. Because LNG is domestically produced, its use at ports and elsewhere would also support the Department of Energy's stated goal of reducing reliance on imported energy sources. In addition, under certain circumstances, the overall operational costs associated with the fuel's use can be competitive with those of diesel. At the same time, on-going technological advancements continue to expand the range of potential applications for the fuel. Yet, in spite of both LNG's potential and the Ports' emissions profiles, the fuel has not found use in this setting. These conditions provide both the backdrop and the impetus for this feasibility study.

CALSTART's feasibility analysis contains a number of distinct components. These are as follows:

- Characterization of the Ports' trucking and terminal operations, including equipment inventories and identification of key features with respect to alternative fuel use (Chapter 2);

- Assessment of the current state of LNG technology, including discussion of engine, refueting and small-scale liquefaction systems, as well as selected case studies (Chapter 3);

- Comparison of the characteristics of port operations and LNG technology, and identification of critical barriers to and benefits of LNG use in this setting (Chapter 4);

- Description of actions that could aid in overcoming the key obstacles to LNG use (Chapter 5);

- Summary of key findings and recommendations (Chapter 6). 


\section{魚}

\section{Findings and Recommendations}

The findings of CALSTART's research effort are mixed. Under current conditions, LNG use at the Ports appears to be -

1) Technologically feasible: suitable LNG engine and refueling technologies are presently available for most of the potential port applications detailed in this study.

2) Environmentally beneficial: most equipment currently in use at the ports is highly polluting. Utilization of LNG technologies in place of existing diesel systems would generally result in at least a $50 \%$ per unit decrease in NOx and PM emissions. Therefore even limited penetration of LNG technologies could produce significant aggregate emissions reductions.

3) Logistically problematic: the organization and composition of both terminal and trucking fleets have a number of characteristics that pose obstacles to the use of LNG. Conversely, the Ports and their operators also have certain features that are extremely amenable to LNG use.

4) Economically questionable: the current price relationship between LNG and diesel in California does not offer a clear economic incentive to utilize the alternative fuel in the applications evaluated here. Moreover, in certain sectors of port operations, LNG use would result in significant operational cost penalties, relative to diesel. Incremental vehicle and refueling station costs, and the inherent efficiency penalties associated with natural gas engines only augment the economic barriers posed by current fuel prices.

Based upon these findings, use of LNG at the Ports faces significant obstacles and it would, therefore, be premature for the Ports to promote exclusive utilization of the fuel and its associated technology at this time. However, the magnitude of the potential emissions reductions, the heightened focus on diesel fuel and the apparent conditionality of many of the current barriers to LNG use all suggest that it is worthwhile to attempt to address these barriers, and premature to dismiss the fuel as a viable alternative. CALSTART therefore recommends that several critical steps be taken that would benefit the Ports and their surrounding communities, without committing them to a particular technology pathway. These are as follows:

- Both Ports should move immediately to develop general alternative fuel incentive programs, incorporating provisions such as priority access for AFVs and AFV-friendly lease agreements. Such measures are critical if low-emission technologies are to find application at the Ports.

- The Ports should carefully monitor the evolving liability risks associated with concentrated diesel fuel use. This information should be shared with tenants in an ongoing strategy group dedicated to addressing air quality issues at the Ports.

- The Ports should begin to identify those fleets and operations that might prove more receptive and amenable to utilizing non-conventional, low emission technologies. These potential early-adopters should be given the opportunity to help shape incentive programs and encouraged to work with the Ports in developing appropriate demonstration projects.

- The Ports, in conjunction with regulatory and planning agencies, should design modernization and expansion projects in such a way as to facilitate and encourage the utilization of low-emission technologies such as LNG. Many of the barriers and mitigation strategies (priority lanes for low emission vehicles, space constraints, etc.) are best addressed during facility construction or modification.

- The Ports should capitalize on new and existing funding sources, and initiate a variety of technology evaluation projects. One extremely viable project could be the testing of a 
small-scale liquefaction system in conjunction with a LNG vehicle or equipment application. Such a project would be exceptionally valuable in assessing the ability of small-scale systems to deliver on their potential for low-cost local LNG production. Alternatively, the Ports could attempt to coordinate with the Pacific Gas and Electric Company (PG\&E) and The Gas Company of Southern California's (So. Cal. Gas) ongoing small-scale liquefaction program, concentrating their own efforts on finding appropriate vehicle and equipment users. 


\section{표}

\section{This page intentionally left blank}




\section{Introduction}

\subsection{Study Goals}

Liquid natural gas (LNG) is currently being used as a low emission 'alternative' fuel in a variety of vehicular applications across the country, including heavy-duty trucking, transit and refuse hauling, but has not yet found use in the port arena. The Seaport Liquid Natural Gas (LNG) Study presents and analyzes the key technological, economic, environmental and institutional variables that affect the potential utilization of LNG in this setting. As originally conceived, the study's principal goal was to evaluate the feasibility of using LNG as a transportation fuel in the heavyduty, on-road trucking operations associated with the Ports of Los Angeles and Oakland. In response to early findings, however, CALSTART has expanded the scope of the study to include like analysis of the heavy-duty ground vehicles and equipment operating at the shipping and rail terminals located on or near these ports.

\subsection{Background}

\subsubsection{Why Ports?}

Modern port facilities such as those in Los Angeles and Oakland are simultaneously conduits and engines of local, regional and national economic activity. The Ports of Los Angeles and Oakland directly and indirectly employ hundreds of thousands of people in California, while the economic worth of the 1997 goods movement through the two ports was valued at $\$ 73.8$ billion and $\$ 25$ billion, respectively.'

As major economic hubs, ports are both home to and the nexus of a vast array of equipment and vehicle operations. The most obvious and dominant constituents of this system are the shipping, rail and trucking operations. However, ports may also house power generation facilities, liquid and dry bulk terminals, pleasure cruise lines, fishing fleets, warehousing and consolidation stations, and food and material processing sites. The vast majority of these operations rely on vehicles and equipment powered by internal combustion engines running on conventional fuels such as gasoline and diesel. Consequently, ports are also a major point source for regional criteria pollutant emissions. This is particularly true for large ports such as those in Los Angeles and Oakland, whose extraordinarily high volumes of containerized and bulk cargo require myriad distribution and support operations.

The statistics in Table 1-1 below provide a snapshot of the current Port operations. In fact, both the Ports included in this study are growing in terms of facility size and cargo tonnage. Annual growth projections for total cargo throughput at the Ports of Los Angeles and Oakland are $6 \%$ and $5 \%$, respectively. Although the precise emissions impact of this cargo handling and facility expansion is difficult to predict, a direct, if not strictly linear relationship between cargo activity levels and emissions from port operations must be assumed. And while some trends in port operations and infrastructure development may slightly off-set the impact of increased cargo activity, most notably the expansion of on-dock rail facilities and subsequent elimination of shorthaul dock to rail terminal truck trips, they will neither mitigate present emission levels nor prevent their overall growth.

\footnotetext{
'Per conversations with Jeff Leung, Public Affairs Officer, Port of Los Angeles and Dan Westerlin, Manager, Strategic Marketing, Port of Oakland, February 1999.
} 


\section{Table 1-1: Port Statistics}

\begin{tabular}{|c|c|c|}
\hline & $\begin{array}{c}\text { Port of Los } \\
\text { Angeles }\end{array}$ & Port of Oakland \\
\hline $\begin{array}{c}\text { Throughput (twenty unit } \\
\text { equivalents) }\end{array}$ & $3,145,529$ & $1,575,406$ \\
\hline $\begin{array}{c}\text { \% of Cargo Tonnage } \\
\text { Containerized }\end{array}$ & $77 \%$ & $98 \%$ \\
\hline $\begin{array}{c}\text { Annual Cargo Ship } \\
\text { Arrivals }\end{array}$ & 2,569 & $1,677^{\star}$ \\
\hline $\begin{array}{c}\text { Daily } \\
\text { Truck Trips }\end{array}$ & $\sim 7,500$ & $\sim 4,000$ \\
\hline $\begin{array}{c}\text { "1996 Figure } \\
\text { Source: Port of Los Angeles and Port of Oakland Public Affairs Offices. }\end{array}$
\end{tabular}

It would appear then, that there is a significant conflict between regional economic and environmental health. This tension, however, is not necessarily intractable. A broad range of strategies exist that may aid in the uncoupling of cargo activity and emissions growth at the Ports. This study examines the viability and potential impact of just one of these strategies - the utilization of LNG fuel and technology in place of diesel - in a limited, but extremely significant subset of port operations - on-road heavy-duty trucking and off-road heavy-duty container handling equipment.

On-road heavy-duty trucks are integral to the movement of containerized and bulk cargo to, from and within each of the Ports. Although no exact figure is available, the Port of Los Angeles supports a truck population of approximately 3500 vehicles, which generate 7500 average daily trips. ${ }^{2}$ The Port of Oakland truck population is significantly smaller at approximately 2000 vehicles, and generates an average of 4000 daily trips. ${ }^{3}$ The off-road heavy-duty equipment included in this study is used in the handling and maintenance of containerized cargo at the onport and port-associated shipping and rail terminals. The total population of these diverse units at the Ports of Los Angeles and Oakland is approximately 800 and 500, respectively. ${ }^{4}$

CALSTART has elected to focus on these two sectors of port operations for several reasons, chief among these being their reliance on and high consumption of diesel fuel. Exhaust resulting from the combustion of diesel fuel produces substantial amounts of two of the most serious criteria pollutants, oxides of nitrogen (NOx) and particulate matter (PM), and is suspected of causing a

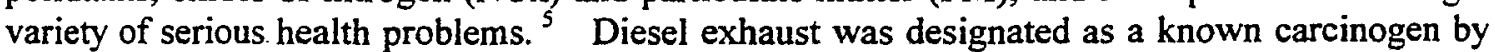
the State of California in 1990, while diesel exhaust particulate matter was listed as a Toxic Air Contaminant (TAC) by the California Air Resources Board (CARB) in 1998. In addition, several

\footnotetext{
${ }^{2}$ In actuality, the truck population serving the Port of Los Angeles is closer to 7,000 vehicles; however, these same vehicles also service the contiguous and similarly sized Port of Long Beach. On any given day, this population will be roughly split between the two facilities. The overall estimate is based on information gathered from interviews with port trucking operators and corresponds closely with estimates provided by Port officials.

${ }^{3}$ Again this data is based on estimates provided by port trucking operators. It should be noted, however, that this figure differs considerably from the estimate of 1000 vehicles provided by Port of Oakland officials.

${ }^{4}$ Totals based on interviews with port terminal operators. See Chapter 4 for exact figures.

${ }^{5}$ U.S. Environmental Protection Agency, Final Regulatory Impact Analysis: Control of Emissions of Air Pollution from Highway Heavy-Duty Engines, September 1997.
} 
lawsuits were filed in 1998 against four of California's largest supermarket chains, in connection with diesel emissions from their distribution facilities. These lawsuits have raised serious concerns within the transportation community regarding the liability associated with concentrated diesel. The Ports could prove similarly vulnerable. Emissions from heavy-duty vehicles emissions are heavily concentrated in the immediate area of the facilities, both of which are embedded in densely populated urban areas.

Figure1-1: Key California Diesel Regulations

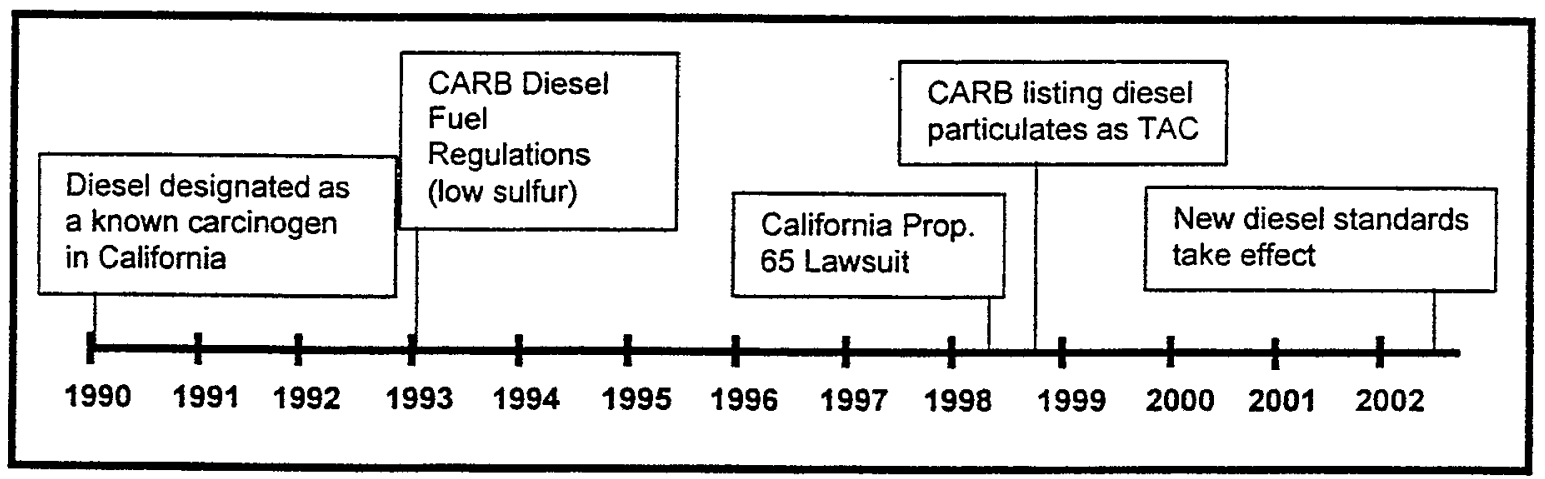

In addition to their emissions characteristics, the heavy-duty diesel vehicles and equipment involved in the movement of containerized cargo also appear well-suited to utilize the current and near-term LNG technology. Duty-cycles and power demands appear to match available technology. Moreover, although both off-road and on-road heavy-duty vehicles have been the subject of considerable evaluation with respect to their potential for LNG use, little if any research has been done on port-specific applications. As discussed in later sections, this arena presents unique opportunities and challenges to the use of LNG, or any other alternative fuel.

\subsubsection{Why LNG?}

Liquid natural gas is currently used in a wide variety of stationary and mobile applications throughout the world. In the U.S., stationary power generation is the most common consumer of the fuel; however, LNG is finding increasing use in the transportation sector. ${ }^{6}$ This alternative fuel is garnering increased interest in transportation applications for three principal reasons:

- The fuel is domestically produced and therefore an important component in the effort to ease reliance on foreign energy sources.

- On an energy equivalent basis, the price of LNG may be highly competitive with or favorable to conventional fuels in certain applications.

- Because of its relatively simple molecular structure, the fuel is extremely clean burning in comparison to diesel and gasoline.

Of the three, it is the emissions characteristics of LNG technologies that provide the primary initial impetus to examine their potential for use in port applications. NOx and PM emissions from heavy-duty LNG engines are significantly lower than those produced by comparable diesel units. Carbon monoxide ( $\mathrm{CO}$ ) emissions may also be reduced depending on the application and engine type. Figure 1-2 below shows the emission standards for a representative +300 horsepower (hp) on-road diesel truck engine, an off-road, diesel-powered container handling unit engine and a comparable LNG system.

\footnotetext{
${ }^{6}$ Nimocks, Bob, LNG: Downstream Market Review, presented at 'LNG: Prospecting Downstream Markets' conference, May 1998.
} 
Figure1-2: Comparative Emissions

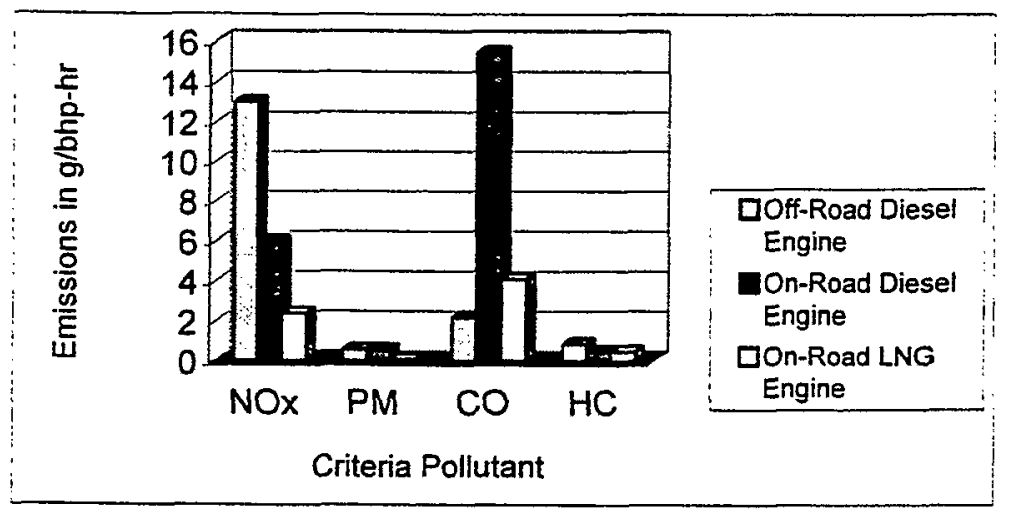

In addition to its emission advantages, LNG has several other characteristics that make it an attractive alternative to diesel in heavy-duty applications. Because it is a liquid fuel, the refueling process is rapid and comparable to that of diesel or gasoline, albeit with some additional safety precautions due to the fuel's cryogenic state. This liquid character also gives LNG systems a particular advantage over compressed natural gas (CNG) units with respect to heavy-duty use. Although both systems use the same engines and deliver similar emissions benefits, LNG's higher energy density means less fuel storage volume is required to achieve a given range. This is a critical consideration in heavy-duty applications where fuel consumption is high and weight and storage space are at a premium. In total, these characteristics make LNG, as a fuel and a technology family, the most viable current or near-term alternative to diesel in the types of heavyduty applications found at the Ports.

\subsection{Assessing the Feasibility of LNG Use at the Ports}

\subsubsection{Report Structure}

Despite its promise, LNG has not penetrated the port arena. This study has attempted to assess the critical factors in LNG use at the Ports, with the goal of determining the overall feasibility of its utilization in this sector. The process and organization of this assessment is as follows:

- Chapter 2 presents an analysis of the trucking and container handling operations at the Ports of Los Angeles and Oakland, including an inventory of existing equipment and estimations of their current emissions impact.

- Chapter 3 offers a concise overview of the current and near-term heavy-duty LNG engine, refueling and small-scale liquefaction systems, as well as a discussion of LNG fuel prices. This chapter also includes a review of relevant case studies.

- Chapter 4 synthesizes data from the previous two chapters and evaluates the technical and economic feasibility of using LNG in particular port applications covered here. A variety of additional factors that may impact LNG feasibility, ranging from regulatory measures to competing technologies, are also discussed.

- Chapter 5 discusses actions that could be taken by the Ports and other interested parties to encourage the use of LNG in lieu of traditional diesel technologies. Each of the critical barriers identified in Chapter 4 is revisited. Appropriate policy actions and mitigation measures are then presented.

- Chapter 6 summarizes the report's key findings, identifies areas where further research is needed and suggests a variety of paths that may be taken to encourage the use of alternative fuels and low emission advanced transportation technologies at the Ports. 


\subsubsection{Methodology and Data Collection}

The data used in this feasibility analysis is drawn from a variety of sources. Virtually all of the operational data on trucking and container handling activity was gathered directly through interviews with relevant personnel at each firm or facility. Table 1-2 below characterizes the sample that CALSTART was able to obtain.

Table 1-2: Survey Sample

\begin{tabular}{|c|c|c|c|}
\hline & Trucking & Shipping & Rail \\
\hline $\begin{array}{c}\text { Port of Los } \\
\text { Angeles }\end{array}$ & 19 firms & 4 of 6 terminals & 3 of 5 facilities \\
\hline $\begin{array}{c}\text { Port of } \\
\text { Oakland }\end{array}$ & 29 firms & 7 of 9 terminals & 3 of 3 facilities \\
\hline
\end{tabular}

Although it proved impossible to interview all relevant port tenants and operators (participation was voluntary) and the level of detail supplied by interviewees varied significantly from facility to facility, this appears to be the most complete data set available at present.

In general, because the Ports act only as landlords, they have what one port official described as "a wealth of ignorance" regarding the day-to-day operations at and around the terminals. " Various port officials were interviewed, however, and provided valuable statistics regarding the overall operations at their respective facilities. Officials at the South Coast and Bay Area air quality management districts (AQMDs) and transportation planning agencies were also interviewed. While extremely helpful and forthright regarding emissions methodologies and planning, they proved similarly uninformed about the day-to-day operations at the ports and their air quality impacts. This is to be expected, given that these facilities are not regulated as distinct entities; however, the dearth of information necessitated reliance on primary data drawn from the interview process. Where relevant, the possible biases of the data are noted.

In-use operational data from current LNG users also proved difficult to obtain. Comparison of the operational costs of $L N G$ versus diesel units requires a level of detail and analytical rigor that is beyond the interests of most users. At present, little detailed cost comparison data exists. Moreover, it is extremely problematic to generalize from what data is available, given that small differences in duty-cycles or operational types may significantly affect the comparison. As a result, the discussion of these variables is often more qualitative than quantitative in nature.

Finally, it should be noted that feasibility is not a static assessment. Many of the critical variables and factors identified by CALSTART are highly and rapidly mutable. In keeping with the original project proposal, CALSTART has attempted to assess not only the current potential for LNG use at the Ports, but also the likely impact of a range of possible actions and future industry developments: Although highly speculative, this exercise serves to highlight the very significant impact that the Ports and other relevant parties could have on the present, near and long-term viability of low emission, advanced transportation technology use in the applications discussed here.

\footnotetext{
${ }^{7}$ Per conversation with anonymous Port of Los Angeles official, December 1998.
} 


\section{This page intentionally left blank}




\section{Port Operations Analysis}

\subsection{Overview of Port Operations}

Virtually all sectors of port operations - massive container ships, tug boats, pleasure cruisers, locomotives, trucks, back-up power generators, workers' and tourists' personal automobiles utilize conventional fuels and internal combustion engines, and therefore produce various amounts of criteria pollutants. For ports to achieve and maintain significant emission reductions, it will be necessary to address all of these disparate sources. Such an effort, however, is beyond the scope of this report. Rather, CALSTART's research has focused primarily on two sectors of vehicle and equipment activity - on-road heavy-duty trucks and off-road, heavy-duty rail and shipping terminal container handling equipment. These sectors are linked by two characteristics critical to this study: a near total reliance on diesel power systems; and their shared dedication to the movement of containerized freight to, from, and within the Ports of Los Angeles and Oakland.

Containerized freight refers to cargo transported in large, steel rectangular boxes. Earlier generations of these units, many of which are still in use, are typically $20^{\prime}$ long, 8' $6^{\prime \prime}$ high and 8' wide. (Container throughput is generally measured in terms of these models, known as twenty equivalent units, or TEUs.) Forty-foot and 9'6" high units are increasingly the standard, however, with some as long as $48^{\prime}$. Due to safety and weight restrictions, it is unlikely that these units will get any larger. Loaded weights vary according to cargo type, but are typically in the range of 10-25 tons. Due to handling and consolidation efficiency, containerization has become the predominant means of transporting non-bulk cargo and represents approximately $77 \%$ and $98 \%$ of the total cargo tonnage passing through the Ports of Los Angeles and Oakland, respectively. More importantly, container transport and handling accounts for over $90 \%$ of all hecovy-duty truck trips and virtually all on-terminal heavy-duty equipment usage at the Ports. ${ }^{\prime}$

Three types of operations - shipping, rail and trucking - are intimately linked in the movement of containerized freight. Containers arrive at the port's waterside via massive container ships, some capable of carrying as many as 5,000 TEUs. These vessels are then unloaded via container cranes. Though earlier generations of these cranes were diesel-powered, all units currently in operation at the Ports of Oakland and Los Angeles are electrically-powered and have therefore been excluded from this analysis. Unloaded containers are placed onto chassis pulled by yard tractors and either transported to storage areas on the shipping terminal or taken directly to ondock rail facilities for loading onto rail cars. Depending on the operation, stored containers may either be stacked four to five high using equipment pieces such as reach stackers, transtainers and top picks, or simply parked on their chassis while awaiting transport.

Trucks arrive at the terminals empty (bobtailed) or carrying a container for export. After waiting for entry at the terminal gates, these vehicles are then directed to a parked chassis or a container stack for unloading/loading. After a container has been obtained, the trucks are then weighed, inspected and cleared for departure. Approximately 50\% of all containers at the Port of Los Angeles and $40 \%$ at the Port of Oakland are then transported to rail facilities for loading onto rail cars, in a process referred to as a land bridge. ${ }^{2}$ Depending on the port and the rail company, rail

\footnotetext{
${ }^{1}$ Per conversation with Mr. Matthew Goldman, Sr. Port Planner, Port of Los Angeles.

${ }^{2}$ Port of Los Angeles data: ibid.

Port of Oakland data: Multitrans Transportation Consultants, Intermodal Report, prepared for the Metropolitan Transportation Commission, December 1994.
} 
terminals may be within a mile of the shipping terminal or as far as 20 miles. The remaining containers are carried directly to their destination by truck. Typically the threshold mileage for rail transport is 400-500 miles, although this varies depending on the container's exact destination and other factors. For export, this chain of events is essentially reversed.

The following sections contain a more detailed analysis of the vehicles and equipment utilized in the movement and handling of containerized cargo. Trucking operations are evaluated first, followed by a joint analysis of rail and shipping terminal operations.

\section{Omitted Fleets}

Although this study analyzes a broad range of vehicle and equipment operations, several very obvious components of the port system have been omitted from the current discussion, most notably switcher and line locomotives, marine applications and port authority vehicles. LNG switchers were operating in demonstration programs at two LA rail facilities as recently as a year ago; however, both have now been discontinued. Nonetheless, these units represent an extremely viable application for LNG use and could help to expand the demand base for the fuel. Marine units such as ferries, tugs and pilot boats also represent potentially viable candidates for natural gas use, particularly LNG. Though no natural gas marine units are currently operating at either port, CALSTART, in cooperation with the Maritime Administration and the Federal Transit Administration, is currently conducting a feasibility study for a natural gas ferry service in the Golden Gate National Recreation Area. This study is part of a larger effort to evaluate the potential for natural gas ferry service in the Bay Area. If such a project were initiated it could also spur fuel demand and provide excellent synergies with other port alternative fuel efforts. Despite their potential, however, evaluation of these technologies is beyond the scope of this study.

Both the Port of Oakland and Los Angeles maintain sizable fleets of light-, medium- and heavyduty vehicles. CALSTART was able to obtain detailed data on the operation and duty cycles of these vehicles. Based upon this data, it was concluded that these units were not amenable to LNG utilization, primarily due to their very limited mileages and hours of operation. Certain of these vehicles could, however, prove excellent applications for CNG, where downtime and subsequent fuel warming and boil-off are not a concern. In fact, the Port of Los Angeles already operates numerous light-duty CNG vehicles and has plans to purchase 30 new CNG units, including 17 medium-duty utility/maintenance trucks. With these purchases, roughly $30 \%$ of its entire fleet will be natural gas powered. ${ }^{3}$ Most LNG refueling stations can also be configured to dispense CNG. Therefore, were the fuel introduced to the setting, Port vehicles could provide a complimentary CNG application.

\section{$2.2 \quad$ Port-Related Trucking Operations}

As noted above, the movement of freight to and from the Ports of Los Angeles and Oakland is heavily dependent on the utilization of on-road, heavy-duty trucks. This section details the operation of these vehicles. Data is presented on a broad range of variables related to this particular sector of the trucking industry, including economic and organizational structure, equipment specifications, use patterns, refueling and maintenance procedures, purchase considerations, and attitudes regarding alternative fuels.

Except where otherwise noted, the following data are drawn directly from interviews with trucking operators at the two ports. Although CALSTART had hoped to rely heavily on existing

${ }^{3}$ Per conversation with T.L. Garrett, Environmental Scientist, Port of Los Angeles, December 1998. 
sources of data for this analysis, initial investigations revealed a near complete lack of reliable and comprehensive information on port trucking. As a result, CALSTART found it necessary to conduct a battery of in-person and telephone interviews with trucking firms at the two ports. A total of 48 companies, representing a population of approximately 3,500 vehicles, were interviewed. Of the sampled vehicle population, approximately 2,500 were considered to be port dedicated. Table $2-1$ below contains the breakdown between the two ports, as well as an estimate of the total port truck population covered by interview process.

Table 2-1: Breakdown of Interview Sample

\begin{tabular}{|l|c|c|c|c|}
\hline & $\begin{array}{c}\text { \# of firms } \\
\text { interviewed }\end{array}$ & $\begin{array}{c}\text { Total \# of } \\
\text { trucks } \\
\text { represented }\end{array}$ & $\begin{array}{c}\text { Number of } \\
\text { port- dedicated } \\
\text { trucks } \\
\text { represented }\end{array}$ & $\begin{array}{c}\text { Estimated \% of total } \\
\text { port truck population } \\
\text { included in sample }\end{array}$ \\
\hline Port of Los Angeles & 19 & 2116 & 1493 & $43 \%$ \\
\hline Port of Oakland & 29 & 1352 & 944 & $47 \%$ \\
\hline
\end{tabular}

Column four of Table 2-1 indicates that CALSTART was able to obtain a relatively large sample size, in both absolute and proportional terms. The estimation of sample coverage is based on information provided by both port officials and trucking operators regarding the total truck fleet serving the various facilities. These percentages should be considered approximate. Moreover, while CALSTART made every attempt to interview a broad variety of companies, there is no way to guarantee that the sample is truly representative of the population as a whole. If there is a sample bias, it is most likely in favor of higher end firms, as these would be the most visible and accessible to researcher efforts.

Finally, for the following analysis, all calculations have been based on the port-dedicated portion of the fleet sample. This value is obtained by multiplying the total reported fleet size for each company by the percentage of its business devoted to port activities. As Figure 2-1 below suggests, the majority of those fleets interviewed were focused on port-related freight handling.

\section{Figure 2-1: Percent of Business Dedicated to Port Work}

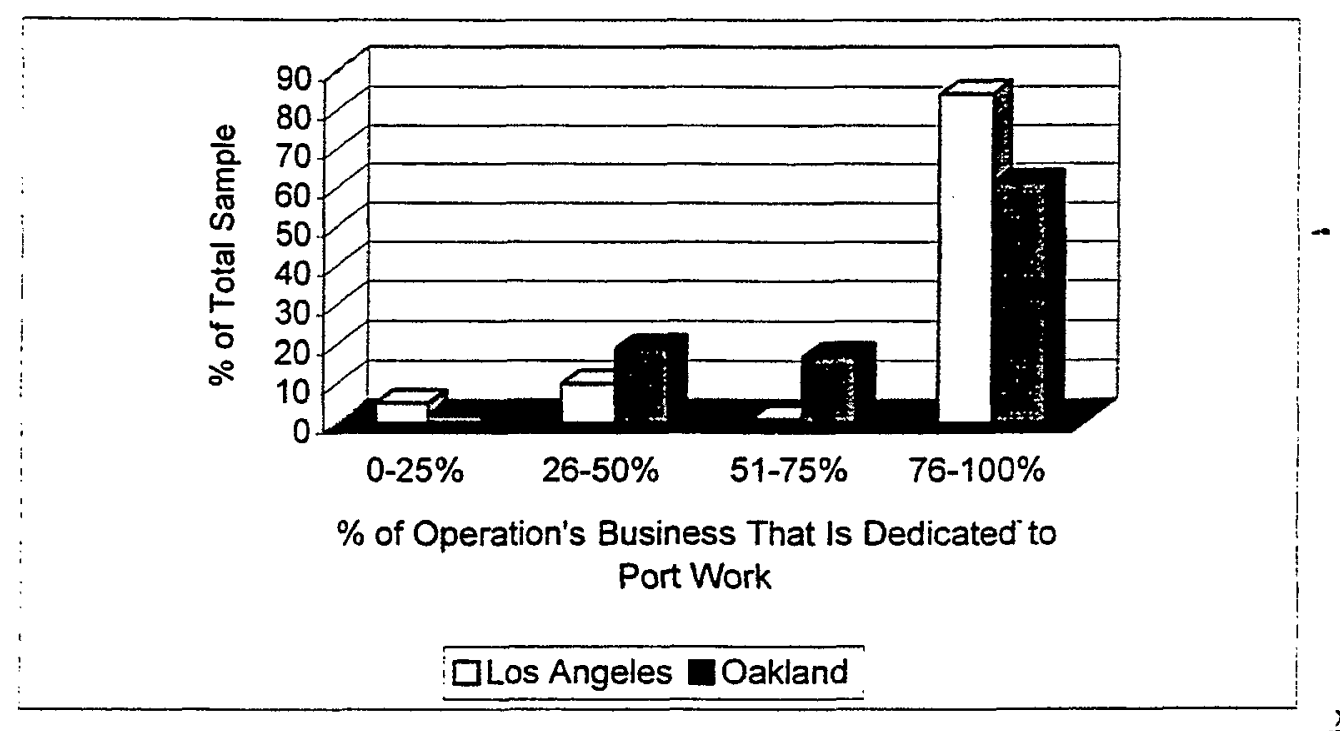

Seaport Liquid Natural Gas Study - Final Report 
In the following section, information is presented on a wide variety of variables relating to trucking operations at the two ports. Traditionally, the critical operational variables used to assess potential LNG utilization have included vehicle performance demands, use patterns, vehicle ranges, refueling behavior and maintenance patterns. These are all addressed. In addition, however, CALSTART has gathered extensive information on a number of factors specific to port-related trucking operation, that might also impact the feasibility and penetration of LNG technologies. These include the economic and organizational structure of port trucking operations, equipment purchase habits and port logistics.

\subsubsection{Organizational Structure}

Unlike traditional, long-haul trucking operations, which typically feature a preponderance of company-owned/leased vehicles and staff drivers, port trucking operations rely heavily on owner/operators employed on an independent contractor basis. Figure 2-2 below indicates that, while there is a good deal of variability among the different operators at the two ports, the vast majority of freight carried by truck to and from both ports is done so by owner/operators.

Figure 2-2: Fleet Composition

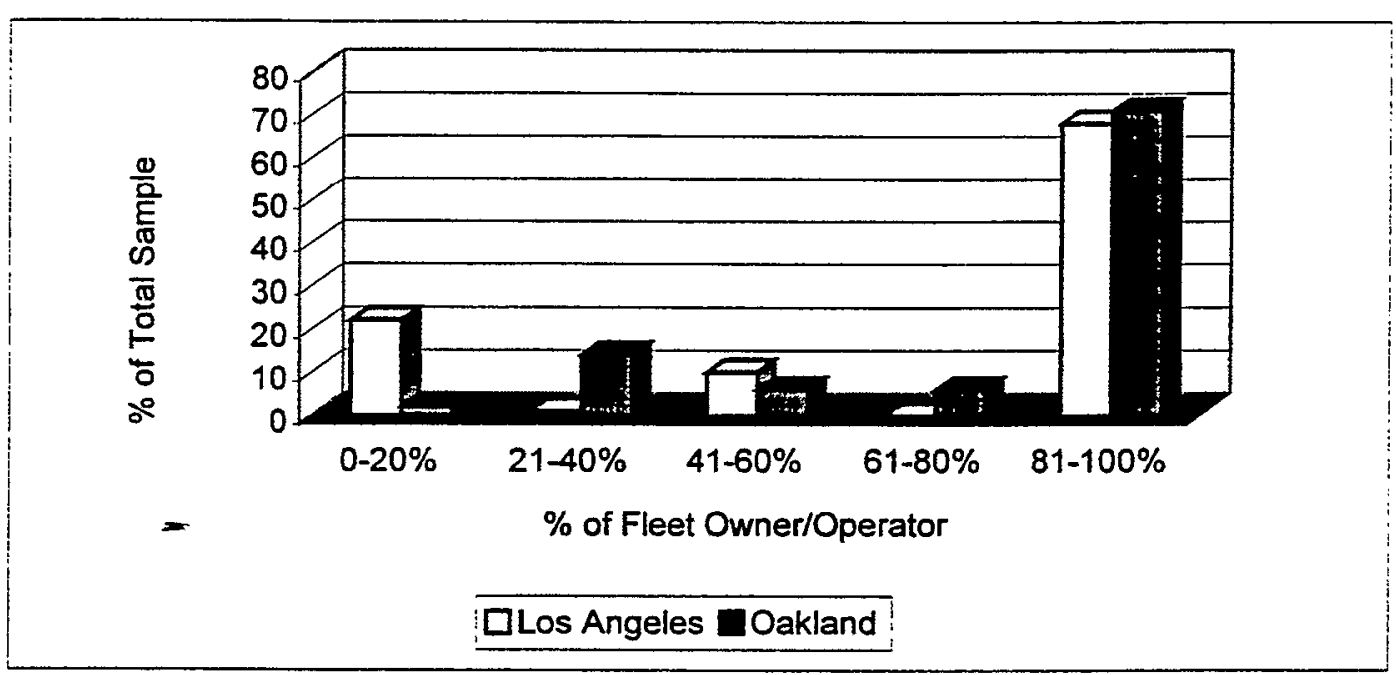

The data gathered by CALSTART indicate that the percentage of freight carried by owner/operators at the Ports of Los Angeles and Oakland is $71 \%$ and $82 \%$, respectively. While these percentages are clearly high, they fall considerably short of estimations provided by other sources. Stephanie Williams, Environmental Affairs Director for the California Trucking Association (CTA) thought the percentage of owner/operators to be "over 95\%." Other sources at the Ports of Oakland and Los Angeles gave estimates in the $90 \%$ range. Although CALSTART's research effort is perhaps the most comprehensive survey to date of port-related trucking, there is a strong likelihood that it underestimates this particular variable. As noted earlier, the smaller, less visible trucking operations were extremely difficult to include in the survey. However, they are also the most likely to employ high percentages of owner/operators. 
According to the company managers interviewed by CALSTART, the owner/operator population servicing the Ports is an exceptionally fluid one, with high rates of entry/exit and movement between firms. While some drivers do develop long-term relationships with a particular company, this does not appear to be the norm. The owner/operator population is further characterized by high percentages of recent immigrants, particularly from Latin America. For many of these drivers, port trucking provides an initial economic toehold, but one that is often leveraged and left behind.

Both the fluidity and the make-up of the Ports' owner/operator population have made labor organization in this sector a problematic undertaking. Although the Teamsters' Union routinely canvasses the Ports, membership is generally limited to the few company drivers employed in this arena. According to trucking company managers, the percentage of company drivers has been decreasing over time, principally in response to competitive pressure from non-unionized operations and cost-reduction efforts by shipping companies.

\subsubsection{Economics of Port Trucking}

The economics of port trucking - what determines profitability and why-are critical in assessing the potential for LNG use and identifying appropriate pathways to encourage utilization of the technology. Containerized freight hauling out of the port is paid on a per load basis, with the specific charge being a function of distance augmented by over-weight and delay time penalties. In contrast to traditional long haul operations, however, profit margins are not highly dependent on maintaining a low per-mile operation cost. This is, of course, an important factor, particularly on longer deliveries, but it is not the critical one for most port truckers. (See Table 2-2) Of greater significance to roughly $90 \%$ of these operators and the companies they work for is the number of container carries that they are able to complete in a given day.

\section{Table 2-2: Critical Factor in Determining Company and Driver Profitability}

\begin{tabular}{|c|c|c|c|c|}
\hline & $\begin{array}{c}\text { Container } \\
\text { turns per } \\
\text { day }\end{array}$ & $\begin{array}{c}\text { Cost per } \\
\text { mile of } \\
\text { operation }\end{array}$ & Both & Other \\
\hline Port of Oakland & $86 \%$ & $3 \%$ & $11 \%$ & 0 \\
\hline $\begin{array}{c}\text { Port of Los } \\
\text { Angeles }\end{array}$ & $96 \%$ & 0 & 0 & $4 \%$ \\
\hline
\end{tabular}

Container carries, or "turns" as they are more commonly referred to, are a function of both the delivery/pick-up distance and waiting times at the port terminals. As Figure 2-3 indicates, average daily turns vary greatly from one company to the next, with those companies focused on short-haul, ship-to-rail container transfers having the highest daily averages. 
Figure 2-3: Average Daily Container Turns

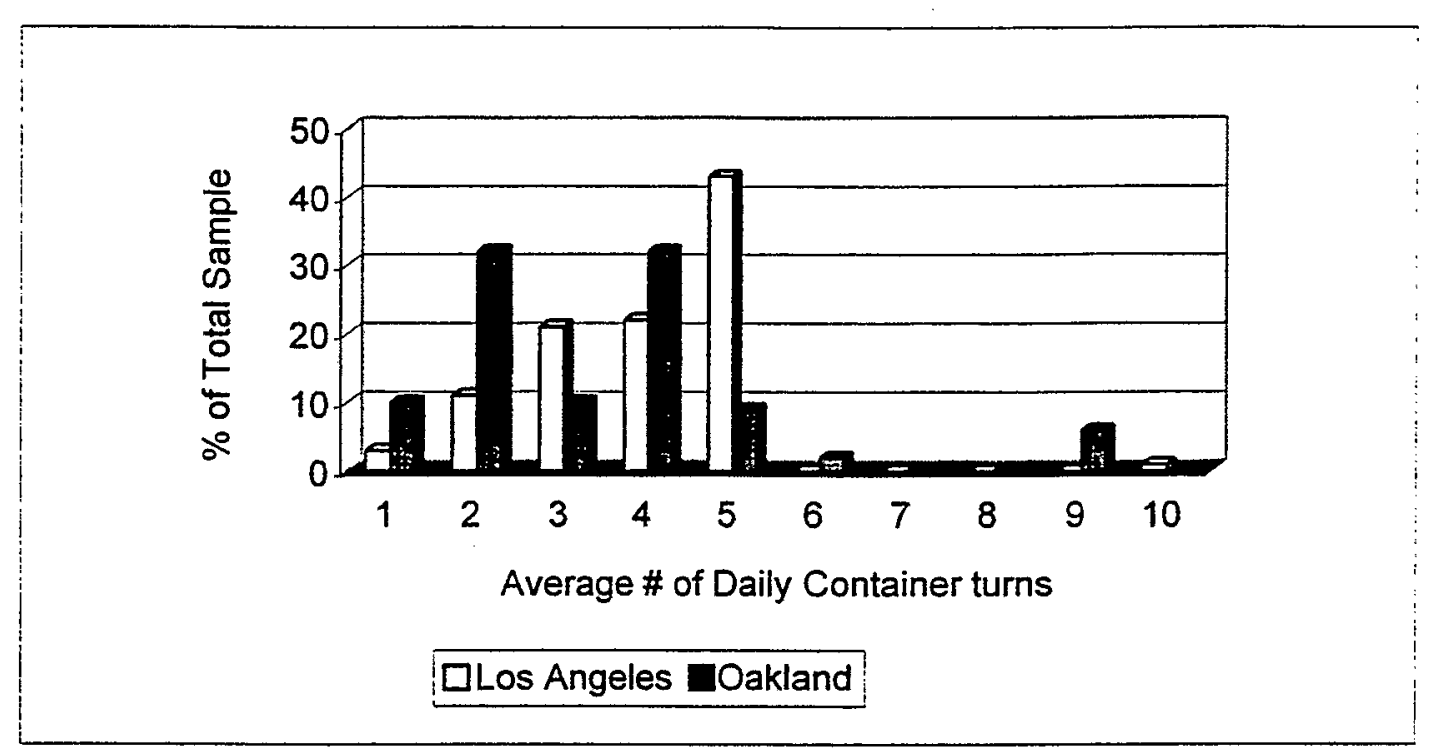

The number of daily turns appear to vary little between the two ports, with Oakland and Los Angeles operators averaging 3.2 and 3.9, respectively. Paradoxically, however, average reported waiting times at the two port differ dramatically. Oakland trucking operations estimated an average waiting time of 2.0 hours, while their Los Angeles counterparts encounter average waiting times of 3.4 hours.

Given that Los Angeles operators report both higher turn averages as well as longer waiting times, the above data should be treated warily. However, the central point remains valid: time (as measured in daily container turns), not cost per mile of operation is the critical determinant in the profitability of port trucking operations. And while it is unlikely that any company or owner/operator with a significantly higher operational cost per mile could survive in the long term, the more intense focus on time suggests some relatively low-cost options for encouraging the use of LNG.

In general, port trucking is considered to be the lowest tier of the trucking industry. Profit margins are extremely narrow $(1-5 \%)$ and drivers are among the least experienced in the industry. As previously noted, many of the surveyed managers described their drivers as recent immigrants and economically marginalized. Moreover, due to the long delay times at the ports and the absence of an effective labor organization promoting the interests of owner/operators, wages tend to be very low. Although no questions regarding wages were included in the official survey, numerous managers estimated the average hourly earnings of their drivers at approximately $\$ 8-10$ per hour. These wage levels have a clear impact on the quality of equipment being used by port truckers, as will be detailed in following sections, but also diminish the ability of this group to absorb the higher incremental cost of alternative fuel technologies.

\subsubsection{Vehicle Profiles}

Vehicle Age

Vehicle age data are used to determine the emissions profile of current port equipment, as well as to characterize the potential for LNG penetration. Port-dedicated trucks are routinely described 
as the oldest and dirtiest on the road, by the operators themselves as well as port officials and air quality control personnel. Data gathered in CALSTART's survey process appear to support this assertion. Figure $2-4$ below presents the model year distribution for a 200 -vehicle subset of the overall surveyed population. ${ }^{4}$

Figure 2-4: Truck Ages

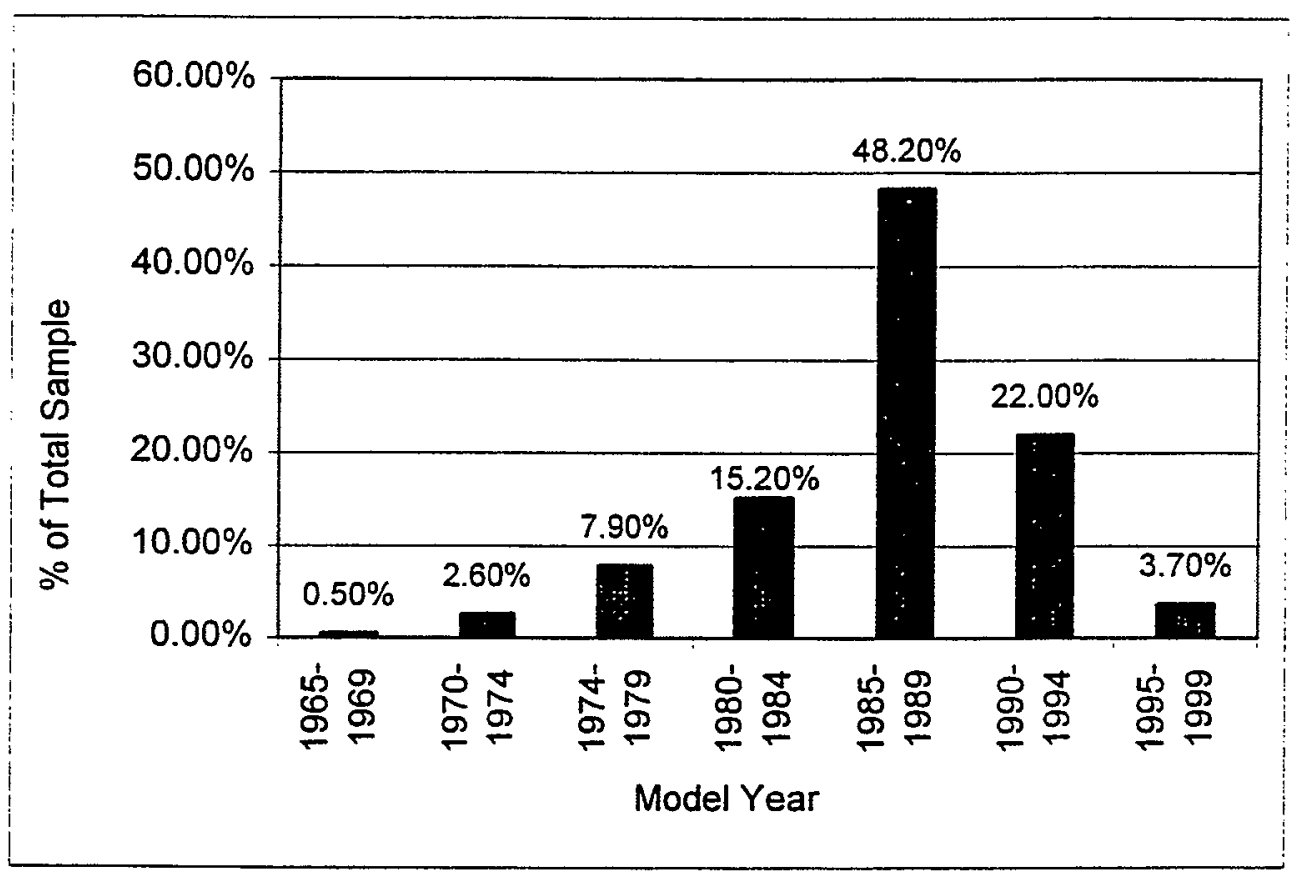

According to this sample, the vast majority of trucks servicing both Ports are 10 years old or more, with the mean age being 13 years (1986 model year). Although NOx emissions from diesel vehicles do not inherently increase with vehicle age, older units have generally been subject to less stringent emissions regulations. Moreover, tampering with vehicle emissions control devices and inadequate engine maintenance, both of which are common in older vehicles, may also result in emissions increases. Therefore, vehicle age is an indirect determinate of emissions levels.

\section{Purchase Habits and Vehicle Characteristics}

The characteristics of current port trucks, and the means by which they entered the port fleet are critical data in determining the compatibility of LNG technologies. Performance characteristics such as horsepower and torque provide performance benchmarks for LNG equipment. Purchase habits indicate the market channels through which LNG units must pass to reach the port fleets. According to the survey data, $18 \%$ of the vehicles operating at the Port of Oakland and only $4 \%$ of those at the Port of Los Angeles were purchased new by port trucking operators themselves. The former percentage appears to be high compared to anecdotal evidence, and there is no obvious explanation for the difference between the two ports. Despite these uncertainties, these data do begin to suggest a more diverse population than had previously been postulated.

${ }^{4}$ The sample is drawn from data provided by two large firms working at the Port of Los Angeles. Although limited, this sample is very likely representative of the truck populations at both Ports. In general, trucking operators were unable to provide this level of detail regarding their fleets. 
Nonetheless, the vast majority of port truckers do purchase their vehicles used. Certain key characteristics for these used vehicles are presented below in Table 2-3, including vehicle age, mileage, purchase price, horsepower requirements and fuel efficiency.

Table 2-3: Vehicle Profile (Used Only)

\begin{tabular}{|c|c|c|}
\hline & Port of Oakland & Port of Los Angeles \\
\hline $\begin{array}{c}\text { Avg. vehicle age } \\
\text { at time of } \\
\text { purchase (range) }\end{array}$ & 7 years & $\begin{array}{c}7 \text { years } \\
(1-15)\end{array}$ \\
\hline $\begin{array}{c}\text { Avg. mileage at } \\
\text { time of purchase } \\
\text { (range) }\end{array}$ & $\begin{array}{c}391,000 \text { miles } \\
(150,000-600,000)\end{array}$ & $\begin{array}{c}376,000 \mathrm{miles} \\
(100,000- \\
1,000,000)\end{array}$ \\
\hline $\begin{array}{c}\text { Avg. cost at time } \\
\text { of purchase } \\
\text { (range) }\end{array}$ & $\$ 14,000$ & $\begin{array}{c}\$ 17,000 \\
(\$ 5-40,000)\end{array}$ \\
\hline $\begin{array}{c}\text { Preferred power } \\
\text { rating (range) }\end{array}$ & $350 \mathrm{hp}$ & $350 \mathrm{hp}$ \\
\hline Average fuel & $(300-400 \mathrm{hp})$ & $(350-400 \mathrm{hp})$ \\
\hline efficiency (range) & $5.72 \mathrm{mpg}$ & $6.21 \mathrm{mpg}$ \\
$(4-7.5)$ & $(4-8)$ \\
\hline
\end{tabular}

There are a number of critical features to note in Table 2-3. Most important perhaps is the broad range of values otherwise masked in the above averages. Port truckers are a diverse group, both in terms of the equipment they utilize and how they operate. Again, anecdotal evidence from officials at the CTA, the Ports and the Air Districts suggested a far more homogeneous port trucking population than that portrayed as a result of CALSTART's survey effort. This diversity, including the small, but significant percentage of operators purchasing new vehicles, has important implications for the potential utilization of LNG at the ports. The port 'market' may, in fact, contain a number of niche operations amenable to the use of LNG. This said, however, it is also clear that the vast majority of operators are purchasing the second, third or even fourth life of a given vehicle. Preferred sources of second-hand vehicles, for those operators that can afford them, are the large, interstate trucking companies such as Schneider and J.B. Hunt. These firms routinely purchase/lease new vehicles and sell them off for $\$ 20,000-30,000$ after 2-4 years, generally with $200,000-400,000$ miles. From there, these vehicles filter down through the various operations at the port. Vehicles with over $1,000,000$ miles and costing approximately $\$ 3,000$ 5,000 are not at all uncommon.

\subsubsection{Vehicle Fueling}

Due to the lack of established, public LNG refueling infrastructure, on-site fueling is traditionally considered a prerequisite for LNG utilization. Figure 2-5 below presents information on the fueling behavior of trucking operators at the two ports. 
Figure 2-5: Fueling Location
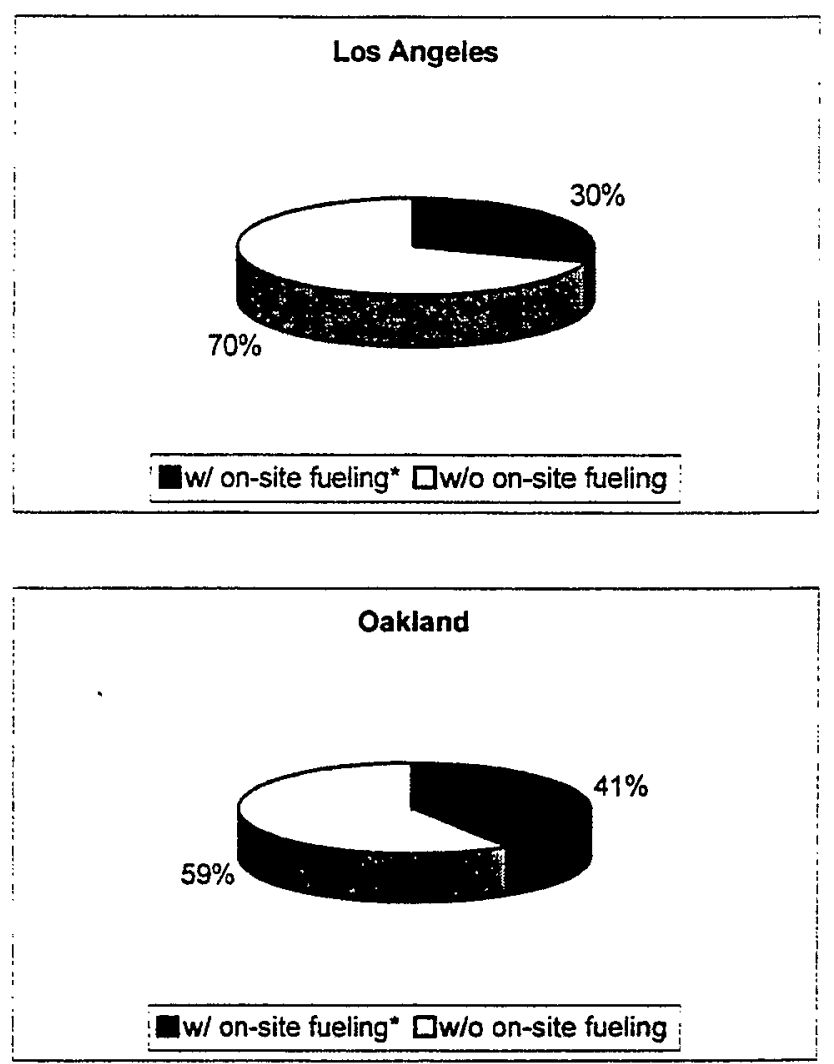

* Includes those operations with wet-hosing-where fuel is delivered by truck and pumped directly into vehicles.

Theoretically, the relatively low percentage of vehicles with access to on-site fueling facilities represents another impediment to the utilization of LNG in port trucking operations. This barrier could be circumvented if the ports were to support the development of local LNG provision, either through direct funding of refueling facilities or subsidization of the fuel's cost, and would become entirely moot if port policies led to substantial demand for the fuel. In the latter case, public providers would inevitably emerge.

Because they are buying their fuel from public or card lock facilities, the majority of port truckers pay market price for diesel $(\$ 1.20-\$ 1.40 /$ gallon). Those with on-site fueling, however, are typically able to secure a $\$ .05-\$ .12$ gallon cost savings.

\subsubsection{Vehicle Maintenance}

Vehicle maintenance patterns and the presence of well-trained, on-site mechanics are often considered another important criterion in evaluating the feasibility of LNG utilization. As with on-site fueling, however, the real impact of this variable with respect to port trucking is unclear. In the short term, any effort by the ports to encourage LNG use would have to take into account the specialized nature of the technology, ideally through the training of mobile and/or staff 
mechanics. In the long term, however, any policies that effectively encourage LNG use would also stimulate market demand for mechanics and shops capable of servicing the technology. The relatively concentrated nature of port operations and the size of the potential market for repair services could also stimulate this demand.

At present, state law in California establishes certain minimum maintenance standards (typically relating to vehicle safety) for commercial, on-road trucks. Individual operators or companies often elect to exceed these minimum standards in order to reduce likelihood of breakdown and extend vehicle life. It was not possible, however, to establish representative maintenance or repair intervals and costs for the two port trucking populations. This issue of maintenance costs will be more thoroughly addressed in the cost comparison between LNG and diesel technologies to be contained in subsequent chapters. CALSTART was, however, able to establish the percentage of operations where maintenance is performed on-site, generally by staff mechanics. This information is presented below in Figure 2-6.

Figure 2-6: Maintenance Location

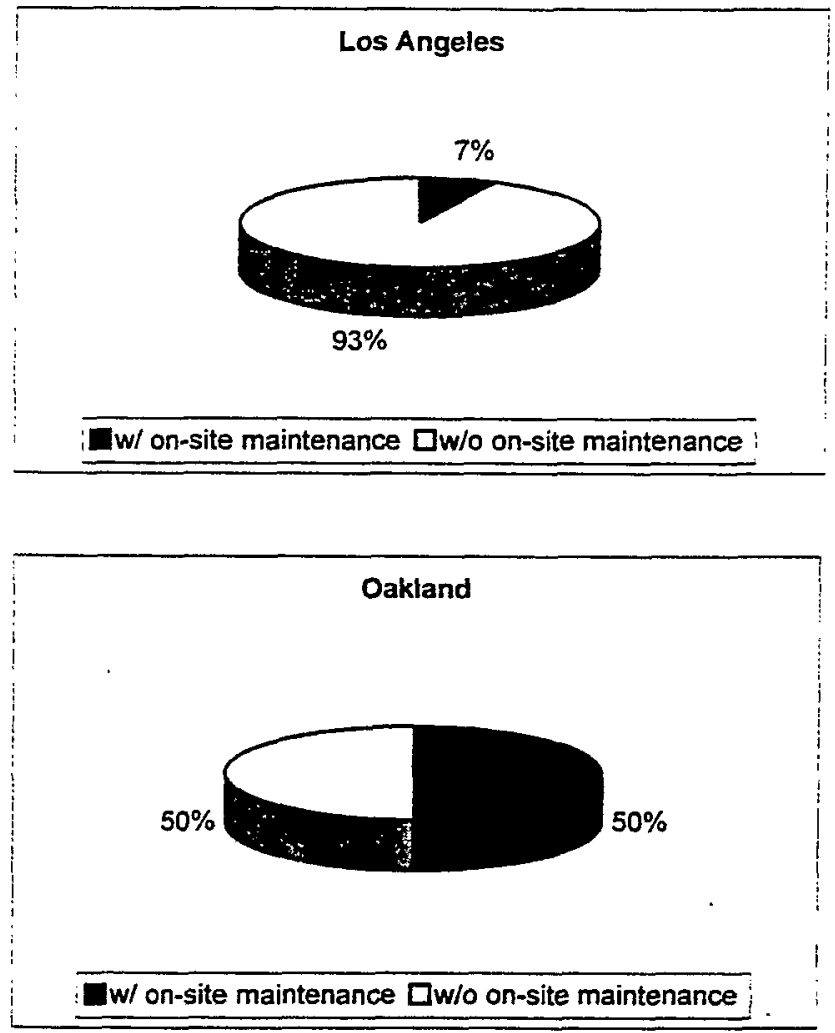

The two ports appear to differ markedly with regard to on-site maintenance. There is, however, little additional data to account for this difference. In the case of both ports, the 'with on-site maintenance' category denotes any operation with an on-site mechanic, even if only minor service (oil changes, brake adjustments, etc.) is performed. Typically though, most operations will contract out major service (engine overhauling, body work, etc.) to specialized repair operations, or even to dealers. 


\subsubsection{Trip Ranges and Daily Mileage Patterns}

Trip ranges and daily mileage patterns represent vital criteria in the assessment of potential LNG use by port trucking operators. The issue of where, or more specifically, how far trucks range after leaving the vicinity of the port itself provides vital information on infrastructure requirements. Average daily mileage provides similar information, but also assists in calculating the economics associated with LNG use. Because the cost savings associated with this alternative fuel are presently nominal at best, in comparison to diesel, only fleets with consistently high daily mileage have been considered appropriate users. While this economic picture is highly mutable and could be significantly affected by port policies, daily mileage remains an important factor in determining operational economics. It is also a critical variable in determining the emissions impact of port trucking. Table 2-4 and Figure 2-7 below present data on trip ranges and average daily mileage patterns at the two ports. In addition to cumulative information for each of the two ports, trip ranges and daily mileage are also broken out for different operation types at the Ports, in this case those operations with greater than/less than $50 \%$ owner/operators.

Table 2-4: Trip Ranges and Average Daily Mileage

\begin{tabular}{|c|c|c|c|c|c|c|}
\hline & \multicolumn{3}{|c|}{ Port of Los Angeles } & \multicolumn{3}{|c|}{ Port of Oakland } \\
\hline & $\begin{array}{c}\text { fleets with } \\
>50 \% \\
\text { owner/ } \\
\text { operators }\end{array}$ & $\begin{array}{c}\text { fleets with } \\
<50 \% \\
\text { owner/ } \\
\text { operators }\end{array}$ & $\begin{array}{l}\text { all } \\
\text { fleets }\end{array}$ & $\begin{array}{c}\text { fleets with } \\
>50 \% \\
\text { owner/ } \\
\text { operators }\end{array}$ & $\begin{array}{c}\text { fleets with } \\
<50 \% \\
\text { owner/ } \\
\text { operators }\end{array}$ & $\begin{array}{l}\text { all } \\
\text { fleets }\end{array}$ \\
\hline $\begin{array}{l}\% \text { of trips } 0-50 \\
\text { miles from } \\
\text { port (one way) }\end{array}$ & $39 \%$ & $61 \%$ & $47 \%$ & $51 \%$ & $54 \%$ & $51 \%$ \\
\hline $\begin{array}{l}\% \text { of trips } 51- \\
100 \text { miles from } \\
\text { port (one way) }\end{array}$ & $39 \%$ & $15 \%$ & $36 \%$ & $28 \%$ & $37 \%$ & $30 \%$ \\
\hline $\begin{array}{l}\% \text { of trips }> \\
100 \text { miles from } \\
\text { port (one way) }\end{array}$ & $23 \%$ & $22 \%$ & $17 \%$ & $20 \%$ & $10 \%$ & $19 \%$ \\
\hline $\begin{array}{l}\text { Average Daily } \\
\text { Mileage }\end{array}$ & 241 & 332 & 272 & 212 & 355 & 235 \\
\hline
\end{tabular}


Figure 2-7: Trip Ranges

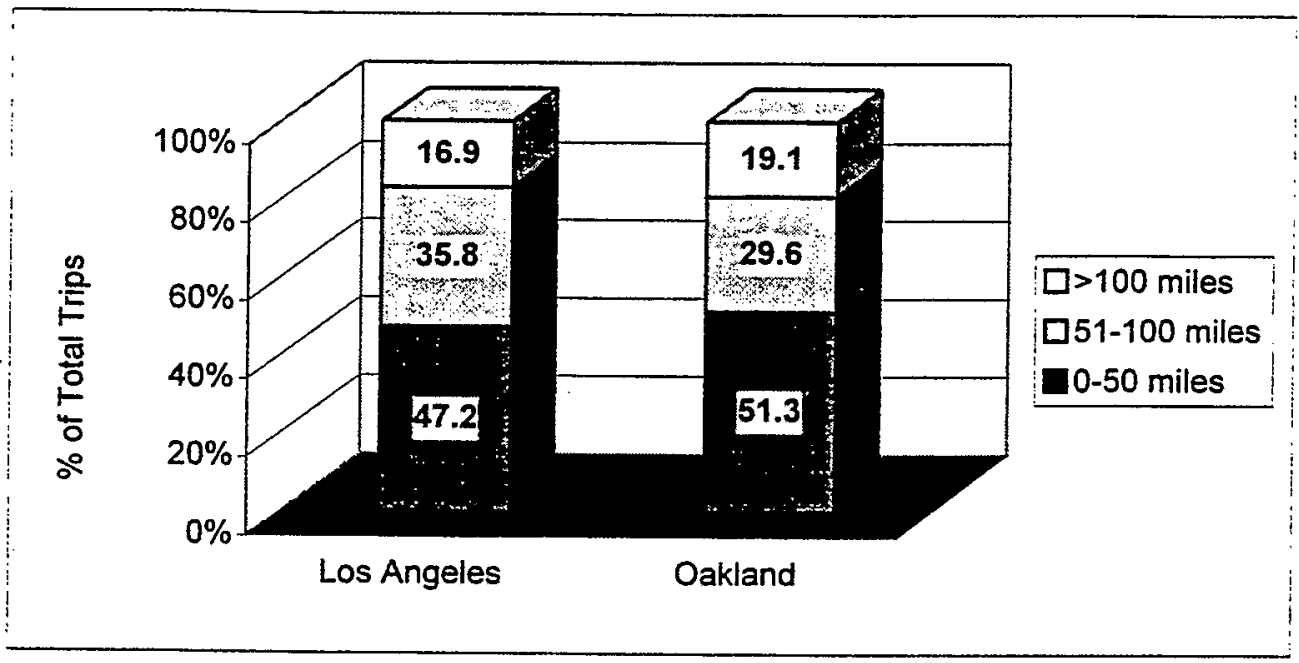

In general, operators at the two ports display very similar trip ranges and daily mileage patterns. Not surprisingly, short trips under 50 miles one way represent the most significant portion of port truck trips. According to officials at the Ports of Oakland and Los Angeles, as well as trucking operators, many of these short trips are shipping to rail terminal transfers. Depending on the location of the rail facility, these trips are as short as one mile, but not more than twenty [to the Burlington Northern Santa Fe (BNSF) facility in Richmond, or the East Los Angeles Union Pacific (UP) and BNSF yards.]

The predominance of short- to medium- range trips (0-100 miles from the ports), combined with relatively high average daily mileage is well-suited to the utilization of LNG. Even if refueling infrastructure was initially limited to the vicinity of the ports, a relatively high percentage of vehicle trips could be serviced. It is important to note, however, that specific drivers and vehicles are generally not dedicated to particular routes and that there is a high degree of variability in trip patterns from day to day. Some companies do concentrate on serving particular regions (Silicon Valley, Sacramento, etc.) or operations (rail to ship transfer). Identifying and encouraging LNG use among operations with such service or route predictability would enhance the opportunities for successful implementation of LNG.

The data above also suggest clear differences in the operational characteristics of owner/operated versus company vehicles. Those fleets that rely less heavily on owner/operators tend to have far higher daily mileages. Contrary to what might be expected, this does not appear to be due to different route characteristics (i.e. making longer or shorter trips) between the two groups. Longer work days could potentially account for this differential mileage.

\subsubsection{Gross Vehicle/Combination Weights and Related issues}

Gross vehicle weight (GVW) refers to the total weight of a loaded vehicle, including chassis, body and payload. Gross combination weight (GCW) refers to the total weight of a loaded tractor-trailer combination. Both ratings are used to assign vehicles to particular classes (1-8, in order of ascending weight). In CALSTART's original proposal, it was indicated that researchers would investigate the potential for using LNG in the Class 7 and 8 trucking operations associated with the Ports of Oakland and Los Angeles. In California, Class 7 and 8 trucks have upper GCW limits of $64,000 \mathrm{lbs}$. and $80,000 \mathrm{lbs}$., respectively. Through both direct observation and the 
interview process, CALSTART has determined that there is, in fact, no significant Class 7 vehicle activity associated with port operations. Virtually all respondents indicated their typical GCW to be in the $72,000-80,000 \mathrm{lbs}$, range. Moreover, a number indicated that they routinely exceed this upper weight limit. Although illegal, this practice poses little risk to drivers when moving containers within the bounds of port property. On-highway, however, overweight vehicles are subject to and commonly assessed considerable penalties.

With respect to the utilization of LNG by port trucking operators, this issue of weight has important implications. A number of operators indicated that they presently buy certain makes of vehicle, Kenworth and Freightliner in particular, because of their lighter weight and/or that they modify their vehicles (removal of passenger seat, partial fueling, aluminum rims, etc.) towards a similar end. As a result they are able to carry heavier payloads than competitors and avoid overweight penalties. At present, most LNG power systems (engine and fueling system) for Class 8 trucks have an incremental weight penaity of approximately $300-500 \mathrm{lbs}$.

Gross vehicle/combined weights also have a bearing on power demands. Specific power demands are dependent on both payload weight and route topography. As previously indicated, port operators generally demand engines with a power rating of at least $350 \mathrm{hp}$. Obviously, any alternative technology will need to meet or exceed the power requirements of port truckers in order to gain broad acceptance.

\subsection{Engine-Powered Vehicle and Equipment Operations at Shipping and Rail Terminals}

The container shipping terminals and rail facilities associated with the Ports of Los Angeles and Oakland are home to a broad array of engine-powered equipment and vehicles. All of these units are essentially bound to their respective company facilities. In this section, information is presented on the types of units operating at these sites, their operating characteristics and a variety of other parameters relevant to the potential utilization of LNG. Given the current study's focus on LNG, only diesel-powered, heavy-duty vehicles and equipment have been included in the analysis.

Except where otherwise noted, all the operational information presented below is drawn directly from interviews with maintenance and repair managers and/or terminal managers at the various facilities. CALSTART researchers were able to interview and collect data from relevant personnel at seven of nine container terminals located at the Port of Oakland and all three major rail facilities. At the Port of Los Angeles, four of six container terminals participated, as did the largest three of its four associated rail yards.

It is critical to note that the quality of data obtained from the different operations varied greatly. Although most operations have access to the level of detail sought by CALSTART, few were willing or able to provide more than estimates, and many questions went unanswered by the majority of the sample population. Unfortunately, CALSTART was not in a position to push for greater detail. Furthermore, data aggregation was one of the conditions stipulated by interviewees for their participation. Although averaging and aggregation mask much of the variation among port operations, the information presented below appears to be the most comprehensive available at the current time.

Finally, it should be noted that CALSTART has elected to include in its operational analysis and emissions calculations not only those rail facilities that are within or adjacent to the Ports, but 
also several outlying rail facilities, including the East Los Angeles BNSF and UP yards and the Richmond BNSF yard. The heavy-duty equipment operations at these facilities are dominated by containerized cargo movement and therefore inextricably linked to the overall operation of the Ports.

\subsubsection{Equipment Types, Function and Population}

The basic pieces of equipment used in the loading, unloading and arrangement of freight containers vary little between the different facilities and operation types. The largest discrepancy in equipment use exists not between rail and shipping terminals, but rather between "grounded" and "on-chassis" shipping terminal operations. A grounded operation is one where containers are stacked, up to six high and in rows of varying width, while awaiting ship or truck transport. Such operations are well-suited to space constrained facilities, but require more container movements and are therefore less efficient. In "on-chassis" operations, containers never touch the ground, but rather are unloaded directly from ships onto on-road chassis. These chassis are then pulled to an appropriate spot on the yard, stored and eventually taken away by an on-road Class 8 tractor. In container drop-offs the process is simply reversed. Although space intensive, this operation is by far the most efficient, requiring the least container moves and less yard equipment. In reality, most operations utilize elements of both systems. Table 2-5 below lists the most common pieces of rail and shipping terminal equipment, along with a brief description of their function.

\section{Table 2-5: Terminal Equipment Types, Functions and Locations}

\begin{tabular}{|c|c|c|}
\hline Equipment Type & Function & Common Location \\
\hline $\begin{array}{l}\text { Transtainer or } \\
\text { gantry crane }\end{array}$ & $\begin{array}{c}\text { Rail mounted or rubber tired, straddles multiple } \\
\text { stacks of containers, loads/unloads containers } \\
\text { directly onto/from waiting trucks and yard } \\
\text { tractors }\end{array}$ & $\begin{array}{l}\text { Grounded shipping } \\
\text { terminals }\end{array}$ \\
\hline $\begin{array}{l}\text { Straddle crane or } \\
\text { straddle carrier }\end{array}$ & $\begin{array}{l}\text { Similar to gantry crane but narrower and } \\
\text { usually shorter, moves and stacks empty and } \\
\text { full containers, straddles containers and grasps } \\
\text { from top, critical piece in all rail operations }\end{array}$ & $\begin{array}{l}\text { Predominantly rail } \\
\text { terminals, some grounded } \\
\text { shipping terminals }\end{array}$ \\
\hline $\begin{array}{l}\text { Reach stacker (also } \\
\text { referred to as } \\
\text { packer, flipper, } \\
\text { wedge) }\end{array}$ & $\begin{array}{c}\text { Moves and stacks empty and full containers, } \\
\text { can reach across another row of containers, } \\
\text { grasps from top, can load/unload directly from } \\
\text { truck or yard tractor }\end{array}$ & $\begin{array}{l}\text { Grounded shipping } \\
\text { terminals, rail terminals }\end{array}$ \\
\hline Top pick & $\begin{array}{l}\text { Moves and stacks full and empty containers, up } \\
\text { to six high, grasps from top, can load/unload } \\
\text { directly from truck or yard tractor }\end{array}$ & Shipping terminals \\
\hline Side pick & $\begin{array}{l}\text { Moves and stacks empty containers only, up to } \\
\text { six high, grasps from side, can load/unload } \\
\text { directly from truck or yard tractor }\end{array}$ & $\begin{array}{l}\text { Predominantly grounded } \\
\text { shipping terminals }\end{array}$ \\
\hline $\begin{array}{l}\text { Heavy forklift (15- } \\
25 \text { ton) }\end{array}$ & Movement of empty and full containers & $\begin{array}{l}\text { Predominantly grounded } \\
\text { shipping terminals }\end{array}$ \\
\hline $\begin{array}{l}\text { Yard tractor/yard } \\
\text { hostler/yard goat }\end{array}$ & $\begin{array}{l}\text { Move containers and chassis around yard, } \\
\text { pivotal role in all operation types }\end{array}$ & $\begin{array}{l}\text { All shipping and rail } \\
\text { terminals }\end{array}$ \\
\hline Diesel generator & $\begin{array}{l}\text { Auxiliary power source, most commonly used } \\
\text { to power refrigerated containers while awaiting } \\
\text { shipment, }\end{array}$ & $\begin{array}{l}\text { Grounded and on-chassis } \\
\text { shipping terminals }\end{array}$ \\
\hline
\end{tabular}


Table 2-6 below presents the cumulative vehicle and equipment inventories for those shipping and rail terminals interviewed by CALSTART. These inventories will be used in later sections to determine the emissions profile of current terminal equipment.

Table 2-6: Equipment Inventories

\begin{tabular}{|l|cc|cc|cc|cc|}
\hline & \multicolumn{3}{|c|}{ Port of Los Angeles } & \multicolumn{4}{c|}{ Port of Oakland } \\
\cline { 2 - 9 } & \multicolumn{2}{|c|}{ Counted } & \multicolumn{2}{c|}{ Extrapolated } & \multicolumn{3}{c|}{ Counted } & \multicolumn{2}{c|}{ Extrapolated ${ }^{+}$} \\
& Shipping & Rail & Shipping & Rail & Shipping & Rail & Shipping & Rail \\
\hline Transtainer & 12 & - & 18 & - & 8 & - & 10 & - \\
Straddle crane & - & 25 & - & 42 & 5 & 6 & 6 & 6 \\
Reach stacker & - & 3 & - & 5 & 6 & 5 & 8 & 5 \\
Top pick & 17 & - & 25 & - & 35 & - & 45 & - \\
Side pick & 13 & 6 & 19 & 10 & 22 & 1 & 28 & 1 \\
Heavy forklift & 8 & 2 & 12 & 3 & 14 & - & 18 & - \\
Yard tractor & 270 & 164 & 405 & 273 & 232 & 33 & 298 & 33 \\
Diesel generator & 3 & - & 4 & - & 22 & - & 28 & - \\
\hline
\end{tabular}

† Extrapolations for Rail based on 3 of 5 terminais sampled, extrapolations for Shipping based on 4 of 6 terminals sampled ¥ All 3 Rail terminals were sampled; extrapolations for Shipping based on 7 of 9 terminals sampled

\subsubsection{Equipment Specifications and Operations}

\section{Equipment Specifications}

In an attempt to further characterize the yard equipment summarized above, CALSTART collected data on an array of specifications associated with these technologies, including preferred manufacturers, typical power ratings, approximate purchase cost and typical fuel efficiencies. Each of these categories, with the possible exception of preferred manufacturer, has relevance with respect to assessing the potential utilization of LNG. This information is presented below in Table 2-7. Because these particular specifications differ little between the two ports or among the various operation types, the data below have been aggregated.

Table 2-7: Yard Equipment Specifications

\begin{tabular}{|c|c|c|c|c|c|}
\hline $\begin{array}{c}\text { Equipment } \\
\text { Type }\end{array}$ & $\begin{array}{c}\text { Representative } \\
\text { Engine Models }\end{array}$ & $\begin{array}{c}\text { Representative } \\
\text { Power Rating }\end{array}$ & $\begin{array}{c}\text { Approximate } \\
\text { Cost of New } \\
\text { Unit }\end{array}$ & $\begin{array}{c}\text { Average } \\
\text { Fuel } \\
\text { Efficiency }\end{array}$ & $\begin{array}{c}\text { Common } \\
\text { Manufacturers }\end{array}$ \\
\hline Transtainer & $\begin{array}{c}\text { Cummins L10C } \\
\text { DDC 6V92 }\end{array}$ & $300 \mathrm{hp}$ & $\$ 1,000,000 \mathrm{plus}$ & $\mathbf{5 g p h}$ & $\begin{array}{c}\text { Paceco, Sisu, Tayior, } \\
\text { Crupp }\end{array}$ \\
\hline Straddle crane & DDC671 & $300 \mathrm{hp}$ & $\$ 1,000,000$ & $5 \mathrm{gph}$ & MiJack, Vaimet, Taylor \\
\hline Reach stacker & $\begin{array}{c}\text { Volvo TD100 } \\
\text { Cummins L10C }\end{array}$ & $300 \mathrm{hp}$ & $\$ 450,000$ & $4 \mathrm{gph}$ & $\begin{array}{c}\text { Taylor, Kalmar, } \\
\text { Hyster, MiJack }\end{array}$ \\
\hline Top pick & $\begin{array}{c}\text { Volvo TD100 } \\
\text { Cummins 6BT }\end{array}$ & $275 \mathrm{hp}$ & $\$ 350,000$ & $4 \mathrm{gph}$ & $\begin{array}{c}\text { Taylor, Kaimar, } \\
\text { Hyster, Rego }\end{array}$ \\
\hline Side pick & Cummins 6BT & $225 \mathrm{hp}$ & $\$ 200,000$ & $3 \mathrm{gph}$ & Taylor, Kalmar, Hyster \\
\hline Heavy forklift & Volvo TD71 & $275 \mathrm{hp}$ & $\$ 130,000$ & $3 \mathrm{gph}$ & $\begin{array}{c}\text { Komatsu, Taylor, } \\
\text { Hyster, Caterpillar, }\end{array}$ \\
\hline Yard tractor & Cummins 6BT & $200 \mathrm{hp}$ & $\$ 48,000$ & $2 \mathrm{gph}$ & Sisu/Ottawa, Capacity \\
\hline $\begin{array}{c}\text { Diesel } \\
\text { generator }\end{array}$ & Caterpillar 3406 & $220 \mathrm{hp}$ & $\$ 100,000$ & $8 \mathrm{gph}$ & Caterpillar, Volvo, \\
\hline
\end{tabular}


Despite the exceptional load demands placed on these pieces of equipment, the engines are standard off-road models, with horsepower ratings similar to or smaller than those found in the Class 8 vehicles discussed earlier. This would appear to suggest that commercially available LNG products might be able to provide adequate performance for a number of these applications. Obviously torque and duty cycle requirements would also have to be evaluated; however, no data is currently available on these parameters. Given their role in port operations though, it is reasonable to expect that the duty cycles and torque requirements of yard tractors would most closely match the performance parameters of on-road engines.

As a result of their high degree of specialization and the intense performance demands placed on them, most of these units carry a large capital cost. This could act as a significant barrier to the penetration of $L N G$ technologies in most applications. In addition, given the relatively small numbers of units found at any given facility, terminal operators would undoubtedly be reluctant to experiment with relatively untried technologies, unless guaranteed back-up equipment were available. This risk aversion stems from the extremely high operational costs associated with the terminals. Again, yard tractors are an obvious exception to these cost and scarcity constraints. With relatively large per terminal populations, these units could provide a relatively low-risk means of demonstrating new technologies.

Two other characteristics of terminal equipment provide opportunities for LNG utilization. Because of its high capital costs, most terminal equipment has a very long life expectancy. Most terminal managers were unable to give life expectancies for their equipment, noting that vehicles were simply refurbished, repowered with new engines and replaced only when obsolete. In terms of both cost and convenience, engine repowering might represent an excellent opportunity to evaluate LNG technology in terminal applications, without purchasing new equipment. In addition, the long life span of terminal equipment could also represent an extended opportunity to recoup the incremental expense of LNG equipment and accrue savings, assuming the technology could reduce operational costs.

\subsubsection{Hours of Operation}

In terms of assessing the potential for LNG use, annual hours of operation have similar bearing to annual miles traveled for on-road equipment. High levels of use increase the speed at which the initial investment in an alternative fuel technology may be recovered and cost savings accrued, assuming of course there is some operational cost savings associated with the system. While the potential operational cost savings associated with LNG in these applications are still unclear, high use levels remain an important filter in assessing appropriateness of use. Although there is some periodicity associated with the activity levels at both the rail and shipping terminals, equipment usage tends to be intensive. Table 2-8 below presents data on the annual hours of operation associated with the various equipment classes at both operation types.

Table 2-8: Average Annual Hours of Use Per Unit

\begin{tabular}{|c|c|c|c|c|}
\hline & \multicolumn{2}{|c|}{ Port of Los Angeles } & \multicolumn{2}{c|}{ Port of Oakland } \\
\hline Equipment type & Shipping & Rail & Shipping & Rail \\
\hline Transtainer & 500 & N/A & 2,000 & N/A \\
\hline Straddle carrier & N/A & 5,900 & 3,500 & 3,800 \\
\hline Reach stacker & N/A & 2,300 & 3,000 & 3,000 \\
\hline Top pick & 2,400 & N/A & 2,500 & N/A \\
\hline Side pick & 750 & N/A & 1,700 & 1,400 \\
\hline Heavy forklift & 1,000 & 700 & 700 & N/A \\
\hline Yard tractor & 2,500 & 5,600 & 2,000 & 3,500 \\
\hline Diesel generator & No data & N/A & 4,800 & N/A \\
\hline
\end{tabular}


Annual hours of operation also provide some indication of frequency of equipment use. Due to boil-off issues, LNG is generally not considered a suitable fuel for vehicles that experience long 'out-of-use' periods. According to the above data and direct testimony from interviewees, this does not appear to be an issue with the majority of equipment classes. It is highly unusual for any piece of equipment to go a week without use and only the relatively low hours associated with the heavy forklifts would appear to suggest any cause for concern.

\subsubsection{Refueling and Maintenance}

As would be expected, given the size and use schedules of the equipment, all the shipping and rail facilities interviewed by CALSTART had both on-site fueling and maintenance facilities. With very few exceptions, terminal vehicles are completely bound to their particular facility as offroad vehicles may not be driven on public roads. Therefore refueling must take place on-site, either at stationary pumps or via a mobile fuel truck. Specific personnel are dedicated to vehicle refueling and drivers generally do not refuel their own vehicles. In addition, minor diagnostics and adjustments are often performed in conjunction with fueling. Typically, all maintenance, including major service is also performed on-site by staff mechanics, although some terminals contract out for engine overhauls and body work. Maintenance schedules are fixed and typically conservative.

\subsubsection{Fuel Costs}

Because all terminal equipment operations are classified as off-road, terminal operators are allowed to purchase and use 'red diesel'. Tainted with a red dye for easy identification, this fuel is intended exclusively for off-road use and does not carry any on-road fuel tax. This amounts to a price reduction of roughly $\$ .45 /$ gallon ( $\$ .42$ from waived state and federal fuel tax and $\$ .03$ gallon in reduced sales tax). Figure 2-8 below presents average fuel prices paid by terminal operators at the Ports of Los Angeles and Oakland.

Figure 2-8: Average Red Diesel Fuel Price

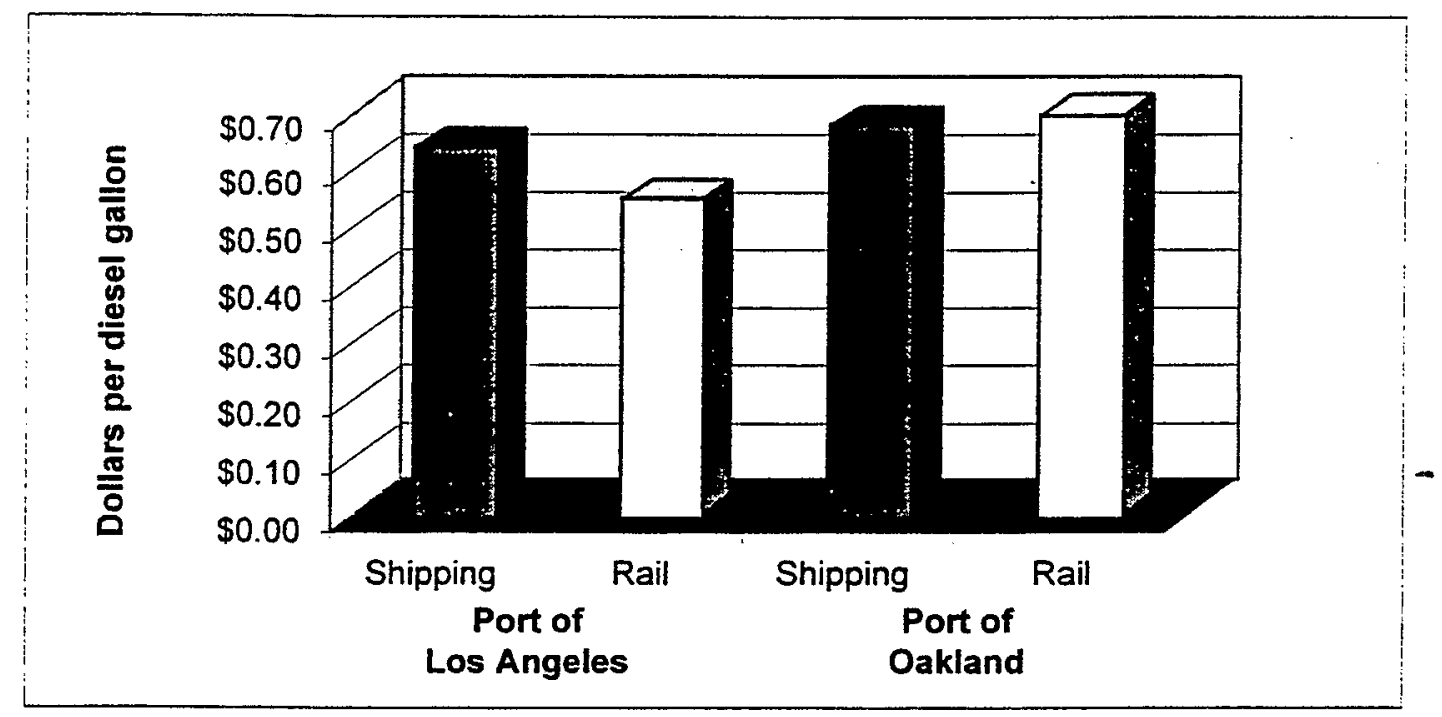




\section{This page intentionally left blank}




\section{LNG Technology}

This section presents an overview of the current state of LNG engines, refueling and small-scale liquefaction technologies. These data are critical in the feasibility analysis contained in subsequent chapters, where the state of LNG technology and LNG market factors will be compared to findings from the previous port operations analysis in order assess their compatibility. Towards this end, information is presented on system costs, availability and performance. In addition to this technology review, the section also contains a discussion of LNG fuel pricing and an examination of future price projections. Finally, the chapter concludes with a brief review of relevant case studies.

\subsection{Engine Technology}

\subsubsection{Engine Availability}

The availability of engine systems that are suitable for use in port applications is the keystone of determining the technological feasibility of LNG use in this setting. Without appropriately powered and configured engine systems, there is no possibility of the fuel or its associated technologies being used at the Ports. A list of current and near-term heavy-duty natural gas engine product offerings and specifications is presented in Table 3-1 on the following page. It differs from the Gas Research Institute (GRI) ${ }^{1}$ and National Renewable Energy Laboratory $\left(\mathrm{NREL}^{2}\right.$ inventories in that the engines listed in this report are currently being produced, or have established future production dates. It was discovered during the data gathering effort of this report that some of the engines listed in the GRI and NREL tables are in fact available, but new product is not being built.

As Table 3-1 indicates, there is a broad range of natural gas engine product available. With the exception of the Caterpillar/Power Systems Associates (PSA) engines, all of these units are sparkignited (SI) systems, run exclusively on natural gas and are compatible with either LNG or CNG fuel systems. Caterpillar/PSA's dual-fuel engine is a compression ignition (CI) system that operates primarily ( $\sim 85 \%$ ) on natural gas (CNG or LNG), but uses diesel fuel for pilot ignition. In addition, it can run exclusively on diesel in a reduced-efficiency "limp-home" mode.

Discussions with the various engine original equipment manufacturers (OEMs) regarding the direction of their firms development efforts and the state of the industry as a whole produced very similar responses. All of the OEMs offering a dedicated LNG product have withdrawn considerably from their pursuit of the heavy-duty truck market and are instead concentrating research, development and marketing capital on transit and, to a limited extent, refuse applications. According to the alternative fuels groups within the OEMs, this retrenchment stems from decreasing research and development funding for their units and a subsequent desire to focus on areas of greatest immediate potential. Table 3-2 shows the distribution of heavy-duty LNG vehicles currently operating in the U.S, by sector.

\footnotetext{
${ }^{1}$ Gas Research Institute, Medium and Heavy Duty Vehicles, January 1998.

2 Norton, Paul, An Overview of Heavy-Duty Alternative Fuel Engines and Vehicles, presented at Clean Cities Conference, June 1998.
} 
Table 3.1 - Heavy-Duty LNG Engine Characteristics and Availability

\begin{tabular}{|c|c|c|c|c|c|c|c|c|c|c|c|c|}
\hline \multirow{2}{*}{ Manufacturer } & \multirow{2}{*}{ Englne } & \multicolumn{4}{|c|}{ g/bhp-hr } & \multirow{2}{*}{$\begin{array}{l}\text { CARB Optlonal Low } \\
\text { NOx Certiflcation }\end{array}$} & \multirow{2}{*}{$\begin{array}{c}\text { With } \\
\text { Catalyst? }\end{array}$} & \multirow{2}{*}{ Displacement } & \multirow{2}{*}{ Power (HP) } & \multirow{2}{*}{ Torque $(\mathrm{lb} / \mathrm{ft})$} & \multirow{2}{*}{ Availability } & \multirow{2}{*}{ Incremental Cost } \\
\hline & & NMHC & co & NOx & PM & & & & & & & \\
\hline Cummins & $\begin{array}{l}\text { B5.9G } \\
\text { C8.3G } \\
\text { L10G }\end{array}$ & $\begin{array}{l}0.1 \\
0.6 \\
0.1 \\
\end{array}$ & $\begin{array}{l}2.6 \\
0.9 \\
4.6 \\
\end{array}$ & $\begin{array}{l}1.8 \\
1.8 \\
1.8 \\
\end{array}$ & $\begin{array}{l}0.02 \\
0.02 \\
0.02 \\
\end{array}$ & $\begin{array}{c}2.5 \\
2.5 \\
2 \\
\end{array}$ & $\begin{array}{l}Y \\
Y \\
Y\end{array}$ & $\begin{array}{l}359 \mathrm{Cl}, 5.9 \mathrm{~L} \\
505 \mathrm{Cl}, 8.3 \mathrm{~L} \\
611 \mathrm{Cl}, 10 \mathrm{~L} \\
\end{array}$ & $\begin{array}{r}150-230 \\
250-275 \\
280-300 \\
\end{array}$ & $\begin{array}{c}375-500 @ 1600 \mathrm{rpm} \\
660-750 @ 1400 \mathrm{rpm} \\
900 @ 1300 \mathrm{rpm} \\
\end{array}$ & $\begin{array}{l}\text { now } \\
\text { now } \\
\text { now }\end{array}$ & $\$ 35-45 k$ (total system) \\
\hline Detrolt Diesel & $\begin{array}{l}50 G \\
60 G\end{array}$ & $\begin{array}{l}0.6 \\
0.6\end{array}$ & $\begin{array}{l}2.3 \\
1.6\end{array}$ & $\begin{array}{l}2.2 \\
2.2\end{array}$ & $\begin{array}{l}0.01 \\
0.02\end{array}$ & $2.5^{1}$ & $\begin{array}{l}Y \\
Y\end{array}$ & $\begin{array}{l}519 \mathrm{Cl}, 8.5 \mathrm{~L} \\
778 \mathrm{Cl}, 12.7 \mathrm{~L}\end{array}$ & $\begin{array}{c}275 \\
330-400\end{array}$ & $\begin{array}{l}890 @ 1200 \mathrm{rpm} \\
1400 @ 1200 \mathrm{rpm}\end{array}$ & $\begin{array}{c}\text { now } \\
\text { pre-production }\end{array}$ & $\begin{array}{l}\text { \$12k (engine only) } \\
\text { \$40-45k (engine only) }\end{array}$ \\
\hline John Dearn b & \begin{tabular}{|l|l|}
$6.8 \mathrm{~L}$ \\
$8.1 \mathrm{~L}$ \\
\end{tabular} & $\begin{array}{l}0.3 \\
0.5 \\
\end{array}$ & $\begin{array}{l}2.4 \\
2.8 \\
\end{array}$ & $\begin{array}{l}2.2 \\
3.2 \\
\end{array}$ & $\begin{array}{l}0.06 \\
0.07 \\
\end{array}$ & $:$ & $\begin{array}{l}\mathrm{N} \\
\mathrm{N}\end{array}$ & $\begin{array}{l}6.8 \mathrm{~L} \\
8.1 \mathrm{~L} \\
\end{array}$ & $\begin{array}{r}225-250 \\
250-280 \\
\end{array}$ & $\begin{array}{l}640-660 @ 2400 \mathrm{rpm} \\
800-900 @ 1300 \mathrm{rpm}\end{array}$ & $\begin{array}{l}\text { now } \\
\text { now } \\
\end{array}$ & $\begin{array}{l}20 \% \text { more than diesel (engine } \\
\text { only) }\end{array}$ \\
\hline Mack & $\begin{array}{l}E 7 G 325 \\
E 7 G 350\end{array}$ & $\begin{array}{l}n / a \\
0.66\end{array}$ & $\begin{array}{l}2.8 \\
1.36\end{array}$ & $\begin{array}{l}2.5 \\
2.5 \\
\end{array}$ & $\begin{array}{l}0.1 \\
0.03 \\
\end{array}$ & $\begin{array}{c}2.5^{2} \\
2^{2}\end{array}$ & $\begin{array}{l}\mathbf{N} \\
\mathbf{N}\end{array}$ & $\begin{array}{l}728 \mathrm{Cl} .12 \mathrm{~L} \\
728 \mathrm{Cl}, 12 \mathrm{~L}\end{array}$ & $\begin{array}{l}325 \\
350 \\
\end{array}$ & $\begin{array}{l}1180 @ 1250 \mathrm{rpm} \\
1260 @ 1250 \mathrm{rpm} \\
\end{array}$ & $\begin{array}{l}\text { now } \\
\text { now } \\
\end{array}$ & $\begin{array}{l}\$ 40,000 \mathrm{w} / 150 \text { gal capacity } \\
\text { (total system) }\end{array}$ \\
\hline $\begin{array}{l}\text { Power Systems } \\
\text { Associates ' (CAT) }\end{array}$ & $\begin{array}{l}3126 \mathrm{~A}^{\mathrm{d}} \\
3126 \mathrm{~B}^{\circ} \\
3176 \mathrm{BG}^{\mathrm{d}} \\
\mathrm{C} 10 \\
\mathrm{C} 12 \\
3406 \mathrm{EG}^{\circ}\end{array}$ & $\begin{array}{l}1.1 \\
0.5\end{array}$ & $\begin{array}{l}7.4 \\
4.1\end{array}$ & $\begin{array}{l}2.4 \\
2.4\end{array}$ & $\begin{array}{c}0.06 \\
0.1\end{array}$ & $\begin{array}{l}2.5 \\
2.5 \\
2.5 \\
2.5 \\
-\end{array}$ & $\begin{array}{l}\mathrm{N} \\
\mathrm{N} \\
\mathrm{N} \\
\mathrm{N} \\
\mathrm{N} \\
\mathrm{N}\end{array}$ & $\begin{array}{l}139 \mathrm{Cl}, 7.2 \mathrm{~L} \\
439 \mathrm{Cl}, 7.2 \mathrm{~L} \\
629 \mathrm{Cl}, 10.3 \mathrm{~L} \\
629 \mathrm{Cl}, 10.3 \mathrm{~L} \\
732 \mathrm{Cl}, 12 \mathrm{~L} \\
893 \mathrm{Cl}, 14.6 \mathrm{~L}\end{array}$ & $\begin{array}{l}190-250 \\
190-250 \\
270-350 \\
275-350 \\
360-425 \\
400-475 \\
\end{array}$ & $\begin{array}{c}700 @ 1500 \mathrm{rpm} \\
700 @ 1500 \mathrm{rpm} \\
800-1050 @ 1200 \mathrm{rpm} \\
1050 @ 1200 \mathrm{rpm} \\
1250 @ 1200 \mathrm{rpm} \\
1450 @ 1200 \mathrm{rpm}\end{array}$ & $\begin{array}{c}\text { slated for } 1999 \\
\text { now } \\
\text { now } \\
\text { now } \\
\text { now } \\
\text { slated for } 2000\end{array}$ & \begin{tabular}{|l}
$\pi / a$ \\
$\$ 16-19,000$ (lotal system) \\
$\$ 19-21,000$ (total system) \\
$\$ 19-21,000$ (total system) \\
$\$ 20-22,000$ (total system) \\
n/a
\end{tabular} \\
\hline
\end{tabular}

a - CARB HD Truck Optional NOx certification pending, number is estimaled certification level

$b$ - currently only in CNG option

c- dual-fuel engine (diesel and LNG)

$d$ - retrofit of provious model

- new model

$t$ - certified to urban bus cycle only 
Table 3-2: Heavy-Duty LNG Vehicles Operating or Ordered, U.S. Only

\begin{tabular}{|cc|}
\hline Sector & $\begin{array}{c}\text { Heavy-Duty LNG Vehicles } \\
\text { ( in use or on order) }\end{array}$ \\
\hline Transit & 768 \\
\hline Refuse & 43 \\
\hline Trucking (Class 8) & 60 \\
\hline
\end{tabular}

Caterpillar/PSA appears to be the one exception to this transit focus. Their units' lower incremental costs and the added security of diesel fuel compatibility give these dual-fuel systems a distinct advantage over dedicated systems in on-road trucking applications. Moreover, their C12 model is the only natural gas engine with sufficient power for most Class 8 trucking applications to be certified to CARB's optional oxides of nitrogen (NOx) standard ( $2.5 \mathrm{~g} / \mathrm{bhp}-\mathrm{hr}$ ). Collectively, these characteristics make the units particularly well-suited for heavy-duty trucking. As part of their settlement in the aforementioned Proposition 65 lawsuits, several large supermarket chains have agreed to purchase over 100 Class 8 LNG tractors. Not surprisingly, all of these units will be equipped with the $\mathrm{C}-12$ engine.

In general, engine manufacturers do not appear to be as active in their pursuit of the off-road vehicle and equipment market. At present, utilization of natural gas engines is still driven primarily by emissions concerns. Prior to 1996, however, no emission standards existed for offroad units and even now, standards are considerably less stringent than for on-road ones. Hence, there has been less impetus to develop and market off-road systems. What off-road natural gas units are available have considerably higher emissions levels than their on-road counterparts. However, with refinement of mountings and electronic controls, the on-road engine systems detailed in Table 3-1 could also be suitable for use in many off-road applications. Where technically feasible, the use of on-road versions of natural gas engines in off-road equipment would maximize emissions reductions and therefore be a preferable alternative.

\subsubsection{Incremental Costs}

Incremental costs refer to the difference in price between a conventional, baseline unit and its (generally more expensive) alternative. This added expense represents a barrier to the use of many alternative fuel technologies, especially where the anticipated operational costs do not suggest a strong likelihood for a return on this additional investment. All of the natural gas systems carry a significant incremental cost over conventional diesel systems. (The figures presented in Table 3-1 are approximations only. Actual costs will depend on order volume.) According to engine manufacturers, there are no inherent technological reasons for this increased cost. Rather, it is the extremely low production volumes, the 'customized' nature of the engine installations and the price of on-board LNG fuel storage systems that account for much of the differential cost. Incremental costs have already decreased by approximately $50 \%$ over the last 6 years and should continue to diminish as the natural gas engine market expands. ${ }^{3}$

The cost of LNG fuel tanks has displayed a similar trend to that of natural gas engines, although less dramatic. On-board LNG storage tanks are double-walled stainless steel, vacuum-jacketed and equipped with a variety of pressure relief devices. This design is inherently more expensive than a conventional, single-walled aluminum system. At present, a 190 LNG gallon unit (112

\footnotetext{
${ }^{3}$ Zeus Development Corporation, LNG Vehicle Markets and Infrastructure, prepared for the Gas Research Institute, March 1998.
} 
diesel equivalent gallons) typically costs $\$ 7,000-8,000$, compared to approximately $\$ 750$ for a similarly sized diesel tank.

\subsubsection{Engine Efficiency}

Engine efficiency refers to the degree to which the potential energy contained in a given fuel (often measured in British thermal units, or Btus) is converted into work by a given engine system. This measurement has a direct impact on operational economics as it is also an indication of the amount of work, in miles vehicle miles traveled (VMT) or hours of operation, that can be obtained from a given fuel purchase. Both dedicated and dual-fuel natural gas systems are inherently less efficient than their diesel counterparts. Optimum efficiencies are $\sim 95 \%$ and $\sim 85 \%$, respectively, relative to diesel systems. Under real world conditions, however, actual efficiencies are highly variable. While data from some projects finds natural gas vehicles operating at essentially optimum efficiencies, other results have been far less encouraging, with efficiencies as low as $65 \%$ being recorded. ${ }^{4}$

At present, too little systematic data has been gathered to generate reliable 'average' efficiencies for natural gas systems versus diesel. However, this variability does highlight the relative immaturity of natural gas engine technologies in comparison to diesel ones. Further refinement of engines for specific applications such as on-road trucking should help to bring these units closer to their optimum efficiency levels. This already appears to be occurring in transit applications. Until that time, however, the increased operational costs associated with these efficiency losses must be factored into the overall economics of LNG use.

\subsubsection{Maintenance and Reliability}

Maintenance costs and reliability are also critical components of the overall operational economics associated with a given engine system, and important measures in comparing various technologies. Because natural gas is a simpler and therefore cleaner fuel to burn than diesel, both dedicated and dual-fuel natural gas engines require less frequent oil changes and may prove to have longer operational lives than diesel-powered units. Conversely, dedicated engines require regular spark plug replacements-an incremental expense over engines. Additionally, the relative immaturity of natural gas engines has resulted in an increased incidence of mechanical failure and equipment downtime in many LNG projects. As with engine efficiency, too little in-use data is available to produce a reliable quantitative comparison to diesel systems. Evidence from transit applications appears to indicate maintenance cost parity, but less refined applications such as trucking are experiencing steep refinement curves at present. ${ }^{5}$ NREL, in conjunction with Battelle, is currently undertaking a series longitudinal studies of comparative operational costs for diesel and LNG vehicles in a range of applications. This effort promises to provide critical real world data; however, official results were unavailable at the time of this report's publication.

\subsubsection{Engine and Chassis Pairings}

There have been a wide variety of heavy-duty LNG engine and truck chassis pairings to date. With the exception of MACK, truck manufacturers do not appear to have exclusive relationships with any engine OEM. Instead, customer demand, engine availability, power/torque compatibility and funding sources have driven the pairings to date.

\footnotetext{
${ }^{4}$ Per conservation with Kevin Chandler, Principal Research Scientist, Battelle, regarding performance of natural gas engines in Raley's supermarket fleet, November 1998.

${ }^{5}$ Ibid.
} 
Table 3-3: Engine/Chassis Pairings

\begin{tabular}{|c|c|c|}
\hline Chassis Manufacturer & Engine Manufacturer & Engine Model \\
\hline Freightliner & $\begin{array}{l}\text { Cummins } \\
\text { Detroit Diesel } \\
\text { Power System Associates }\end{array}$ & $\begin{array}{l}\text { B5.9G } \\
\text { C8.3G } \\
\text { L10G } \\
\text { Series } 50 G \\
3126 \\
C-10 \\
C-12\end{array}$ \\
\hline Spartan & Cummins & B5.9G \\
\hline Kenworth & $\begin{array}{l}\text { Cummins } \\
\text { Power System Associates }\end{array}$ & $\begin{array}{l}\text { L10G } \\
3126 \\
C-10 \\
C-12 \\
\end{array}$ \\
\hline Peterbuilt & Power System Associates & $\begin{array}{l}3126 \\
C-10 \\
C-12\end{array}$ \\
\hline Ford - Sterling & Power System Associates & $\begin{array}{l}3126 \\
C-10 \\
C-12\end{array}$ \\
\hline Crane Carrier & Power Systems Associates & $\begin{array}{l}3126 \\
C-10 \\
C-12\end{array}$ \\
\hline GMC & Power System Associates & 3126 \\
\hline Chevy & Power System Associates & 3126 \\
\hline Western Star & Power System Associates & $\begin{array}{l}C-10 \\
C-12\end{array}$ \\
\hline Navistar & Power System Associates & $\begin{array}{l}C-10 \\
C-12 \\
\end{array}$ \\
\hline MACK & MACK & $12 \mathrm{~L} \mathrm{E7G}$ \\
\hline Ottawa/Sisu & Cummins & B5.9G \\
\hline
\end{tabular}

Based on GRI, NREL and CALSTART research, the above listing would appear to suggest that numerous engine/chassis partnerships have been developed and that a diverse group of vehicles are available on demand. This, however, is not the case. In conversation with relevant heavyduty vehicle manufacturers, CALSTART established that the majority of engine/chassis pairings were prototypes and should not be considered commercially available. Moreover, a number of the vehicle manufacturers listed above, including Spartan, Crane Carrier, Ford-Sterling, GMC, and Chevy have suspended LNG vehicle development and withdrawn from market.

Responses from manufacturers did indicate that the technology is available to develop functional engine/chassis pairings. With the extremely limited demand, however, economies of scale remain elusive and incremental costs continue to be prohibitively high. In addition, limited demand retards the investment in LNG technology refinement, which is vital if it is to compete effectively with diesel. It is important to note, however, that technological development and vehicle availability are not just market dependent, but also customer dependent. Mr. Stephen Ginter of MACK trucks indicated that his company had received inquiries from a large customer regarding the purchase of 50 LNG $\mathrm{CH}$-tractors. ${ }^{6}$ Although such a vehicle has never been built, if

\footnotetext{
${ }^{6}$ Per conversation with Stephen Ginter, Vocational Product Manager, Mack Trucks, Inc., June 1998.
} 
the order were placed, the vehicles would be delivered and on the road in 10 months. Similarly, other chassis builders have both indicated and exhibited a strong willingness to meet the demands of their large customers, even if it requires new product development.

\subsection{Refueling Infrastructure}

A recent study commissioned by GRI noted that, within the transportation community, "the lack of refueling infrastructure is (considered) the most critical constraint affecting the growth of LNG as a transportation fuel." To date, fuel providers such as Amoco and Mesa Pacific have been unwilling to shoulder the entire expense and risk of establishing retail fueling stations, citing the small number of vehicles and inadequate demand for fuel. Conversely, potential users have generally been unwilling to commit to significant vehicle purchases because of the dearth of refueling facilities and the high cost of building and operating their own. This classic "chicken or egg" dilemma has stymied the growth of the LNG industry and limited the list of users to centrally fueled fleets with adequate resources to construct and sufficient demand to support an on-site fueling facility.

Although the self-contained terminal operations fit this centrally fueled fleet model, the Ports also present an opportunity to develop new models for LNG infrastructure provision. Because the Ports function as hubs for very large populations of on-road and off-road vehicles, limited commitments by individual firms to use LNG systems could quickly translate into a substantial aggregate demand for the fuel. This in turn could motivate the development of commercial/retail refueling infrastructure. This possibility will be discussed in greater detail in Chapters 4 and 5 .

\subsubsection{Availability}

Because of its cryogenic nature, LNG requires a unique set of refueling technologies. Although the actual use and performance of LNG refueling infrastructure closely resembles that of diesel and gasoline systems, the technology has a number of distinct characteristics. Perhaps the most critical of these is its relative scarcity. Although the vehicle refueling infrastructure for LNG has increased in the last few years, less than 15 operational facilities currently exist in the State of California. None of these stations are commercial/retail operations, but are instead associated with individual LNG fleets. Traditionally, public access has been a stipulation for receiving public costsharing funds; however, actual access by outside fleets has proved problematic. The net effect is that for a fleet to use LNG, it must either be strategically located near an obliging existing facility, or build a fuel station itself. At present, there are no LNG refueling facilities located in the near vicinity of either the Port of Los Angeles or the Port of Oakland. Therefore, any LNG program at the Ports. would require the development of local infrastructure.

\subsubsection{Infrastructure Providers and System Costs}

At the time of this report, $\mathrm{LNG}$ infrastructure is available through various teaming arrangements with MVE, Inc., Jack B. Kelley, Inc., CVI, Inc., NorthStar Inc., CH-IV and Mesa Pacific LNG. Although many other firms are involved in the LNG refueling infrastructure industry, these are the core contractors and hardware suppliers. Moreover, all are actively involved in infrastructure development at present. Some of the projects these companies have been involved with are shown in Table 3-4.

\footnotetext{
${ }^{7}$ Zeus Development Corporation, LNG Vehicle Markets and Infrastructure, prepared for the Gas Research Institute, March 1998.
} 
Table 3-4: Contracting Teams and Completed Projects

\begin{tabular}{|cc|}
\hline Contracting Teams & Examples of Projects \\
\hline MVE, Inc./NorthStar, Inc. & Taormina Industries, Inc. Anaheim, CA \\
Perrier, Ontario, CA & Sun Metro, El Paso, TX \\
MVE,Inc./Mesa Pacific LNG & Olympic Station, Los Angels, CA \\
Jack B. Kelley, Inc/Cryenco & UPS/Ontario Station, Ontario, CA \\
& Bloomfield, New Mexico \\
Jack B, Kelley, Inc/Drexel & Edinburgh, Scotland \\
CH-IV Cryogenics LP & Houston Metro, Houston, TX \\
& William H. Martin, Inc., Washington \\
CVI, Inc. & Pennsylvania \\
\hline
\end{tabular}

All of the above companies were contacted for product and pricing information in the context of this project. Table 3-5 lists estimated costs for a variety of station scenarios. It should be noted that in all cases, these prices represent very rough estimations. Actual costs may vary greatly depending on site preparation, permitting delays and system configuration. In general, systems can be configured to dispense both LNG and CNG, albeit at additional expense. In addition, stations are typically modular and scalable in size and dispensing capacity. 
Table 3-5: Projected Station Sizes and Costs

\begin{tabular}{|c|c|c|}
\hline Provider & Features & Price \\
\hline MVE, Inc. & $\begin{array}{l}\text { Scenario 1: small scale station } \\
\text { less than } 6,000 \text { gallons with con- } \\
\text { tainment (considered temporary) } \\
\text { Scenario } 2 \text { : full size station with } \\
1-13,000 \text { gallon LNG storage } \\
\text { tank and single LNG dispenser }\end{array}$ & $\begin{array}{c}\$ 300,000 \\
\\
\$ 400,000 \\
+ \text { civil work } \\
(\sim 100,000) \\
\end{array}$ \\
\hline $\begin{array}{l}\text { CH-IV } \\
\text { Cryogenics LP }\end{array}$ & $\begin{array}{l}\text { Scenario 1: small scale station with one } \\
\text { LNG dispenser and 3,000 gallons of fuel } \\
\text { storage } \\
\text { Scenario 2: } 2 \text { LNG dispensers and 1- } \\
\text { 13,000 gallon LNG storage tank } \\
\end{array}$ & $\begin{array}{l}\$ 370,000 \\
\$ 500,000- \\
525,000\end{array}$ \\
\hline CVI, Inc. & $\begin{array}{l}\text { Scenario 1: 1-13,000 gallon } \\
\text { underground storage tank, } 1 \text { LNG } \\
\text { dispenser } \\
\text { Scenario 2: } 2-30,000 \text { gallon } \\
\text { underground storage tank, } 4 \text { LNG } \\
\text { dispensers, } 1 \text { CNG dispenser }\end{array}$ & $\begin{array}{l}\$ 700,000 \\
\$ 2.5 \mathrm{M}\end{array}$ \\
\hline NorthStar, Inc. & $\begin{array}{l}\text { Scenario } 1: 1-13,000 \text { gallon } \\
\text { tank and single LNG dispenser } \\
\text { Scenario } 2: \text { add an additional } \\
13,000 \text { gallon storage tank }\end{array}$ & $\begin{array}{l}\$ 450,000 \\
\$ 120,000 \\
+ \text { labor }\end{array}$ \\
\hline
\end{tabular}

It is important to emphasize that although this appears to be a competitive market, it is still in early stages of development. Both cryogenic storage and liquid fuel dispensing are proven technologies. However, the marriage of the two has had its share of difficulties. For example, in the teaming effort between Jack B. Kelley and Drexel in the construction of the UPS Ontario facility, there were numerous problems resulting from Drexel being unable to provide the field support required of a new, unproven system. This created extreme customer dissatisfaction on this and other station projects in which they were involved. As a result, Drexel has not been involved in the construction of any subsequent stations. Therefore, it is imperative to be aware of not only the industry experience each team member can contribute to the construction of a fuel station, but also who is going to maintain the station and provide the field support. This has been a critical shortfall to date and has made it difficult for end-users to embrace this technology.

\subsection{LNG Pricing}

The following section discusses prices and pricing forces for LNG in California. These data will be used in subsequent chapters to calculate the comparative operational costs of diesel- and LNGpowered vehicles. Current diesel prices are discussed as part of that later cost comparison.

\subsubsection{Current Prices}

LNG fuel prices exhibit a high degree of geographic variability. At present, California lacks any significant local LNG production, causing suppliers to import fuel from large-scale liquefaction 
facilities located in Wyoming, Kansas and Colorado. This has a pronounced effect on fuel price, with typical transportation costs ranging from $\$ 1.35-\$ 1.80 / \mathrm{mile} / \mathrm{load}$. As a result, delivered LNG prices in California range from a low of \$0.43/ LNG gallon at the Los Angeles International Airport to upwards of $\$ 1.00 / \mathrm{LNG}$ gallon for smaller industrial users. The three primary LNG suppliers to California - Amoco, J.B. Kelly, Mesa Pacific - estimate a near-term pre-tax price of $\$ 0.45$ to $\$ 0.55 / \mathrm{gal}$ for delivery to Los Angeles, assuming that a full tanker load of 10,000 gallons is taken. Partial loads typically incur a penalty of \$.03-.06/LNG gallon. Prices to the Port of Oakland would be comparable or slightly higher, depending on the supplier.

Jack B. Kelley Inc. has recently completed a new liquefaction facility, located in Arizona, very near to the California border. This plant has a total production capacity of 86,000 LNG gallons/day and is currently producing 30,000-40,000 LNG gallons daily. According to Steve Bartlett, Cryogenic Equipment and Operations Manager, Jack B. Kelley, fuel costs are $\$ 0.35 / \mathrm{LNG}$ gallon at the source. Additional transportation costs would be figured at $\$ 1.80$ per mile for partial loads and $\$ 1.50$ per mile for full loads of fuel. This would translate into about $\$ 0.44-.45 / \mathrm{LNG}$ gallon for full load deliveries to the Port of Los Angeles and \$.53/LNG gallon to the Port of Oakland. Although it was originally hoped that this plant might significantly reduce the cost of LNG in California, this does not appear to be the case. Despite its relative proximity to the Bay Area and Los Angeles markets and reduced transportation charges, the plant's feedstock gas costs and production efficiency preclude any real undercutting of current LNG prices.

\subsubsection{Composition of LNG Prices}

As noted above, transportation costs are a significant contributor to the overall cost of LNG in California. Figure 3-1 below presents the elemental breakdown of LNG price. This breakdown is California specific and assumes delivery from a generic liquefaction facility in the Rocky Mountain area.

Figure 3-1: Composition of California LNG Prices

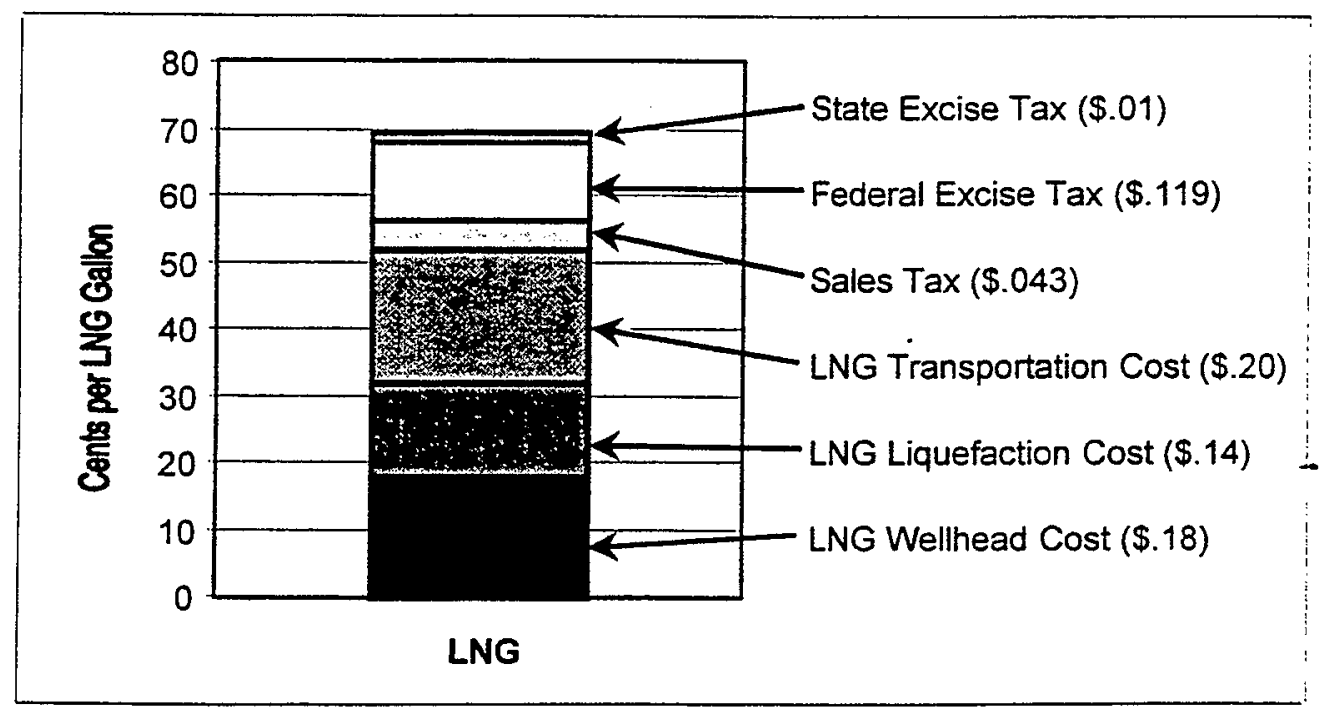




\section{Wellhead Price}

Wellhead price represents the base cost of natural gas and the de facto price of feedstock gas used at most liquefaction facilities (owing to their proximity to gas fields). In general, natural gas prices are considered to be extremely stable, with only slight increases predicted over the next two decades (see Figure 3-2 below). There is, however, significant regional variation in the price of wellhead and pipeline gas owing to differential production and distribution costs. As Figure 32 below indicates, California wellhead gas is considerably more expensive than the national average.

Figure 3-2: Projected Wellhead Natural Gas Prices

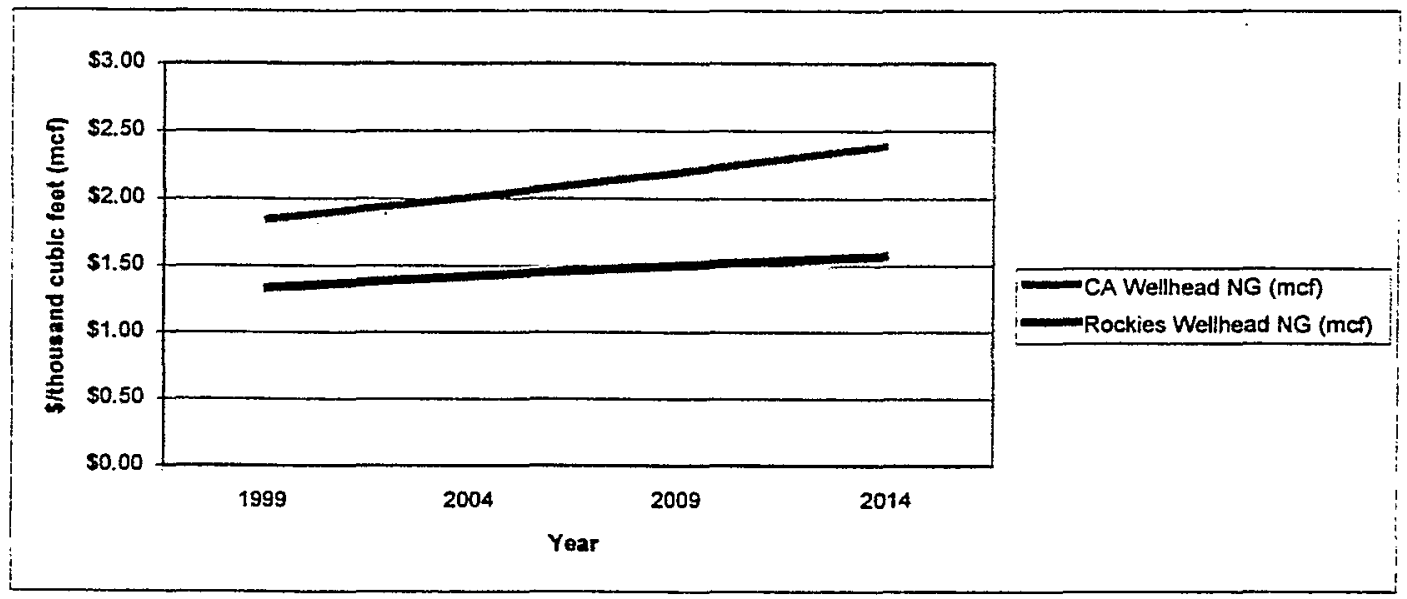

Source: Energy Information Administration, Annual Energy Outlook 1998, http://www.eia.doe.gov.

\section{Liquefaction Costs}

Large-scale liquefaction facilities are considered to be highly refined technologies. A number of different liquefaction systems exist, each with their own advantages and disadvantages. However, technology advances are not expected to significantly alter the cost of large-scale liquefaction.

As a result of the stability of liquefaction technology and natural gas wellhead prices, LNG suppliers are able to offer 2-3 year fixed-price contracts on delivered fuel. In theory, this stability is highly beneficial to the cost planning process of an operation using the fuel. However, where LNG prices are higher than diesel, it also reduces the likelihood of a reversal in the two fuel's competitive relationship.

Federal and State Excise Taxes, State Sales Tax

At present, federal and state excise taxes on LNG are \$.119 and \$.06/LNG gallon, respectively. State excise tax may also be paid as a lump sum of $\$ 168 /$ vehicle/year. Up-front payment would result in a $\sim \$ .05 / L N G$ gallon tax decrease for high mileage fleets. Application of the $8.25 \%$ California sales tax to LNG purchases appears to uneven and problematic. For the purposes of all cost calculations in this study, sales tax has been included and state excise tax is calculated at \$.01/LNG gallon.

On an energy equivalent basis, LNG currently enjoys a significant tax advantage over diesel, though it is taxed at a higher rate than CNG. Lobbying efforts by the natural gas industry have succeeded in reducing the federal tax on LNG from its previous high of \$.315/DEG and work 
continues to bring the fuel's tax rate in-line with CNG. Figure 3-3 below shows the federal tax for the three fuels, based on a diesel equivalent gallon (DEG) basis. State excise taxes are even more favorable to LNG. Assuming state excise tax is paid as a lump sum of $\$ 168 /$ vehicle/year, and that the vehicle travels approximately 65,000 miles annually, the tax on $L N G$ is only \$.017/DEG, compared to $\$ .18 /$ gallon on diesel.

Figure 3.3: Federal Excise Tax Rates, Per Diesel Gallon Equivalent

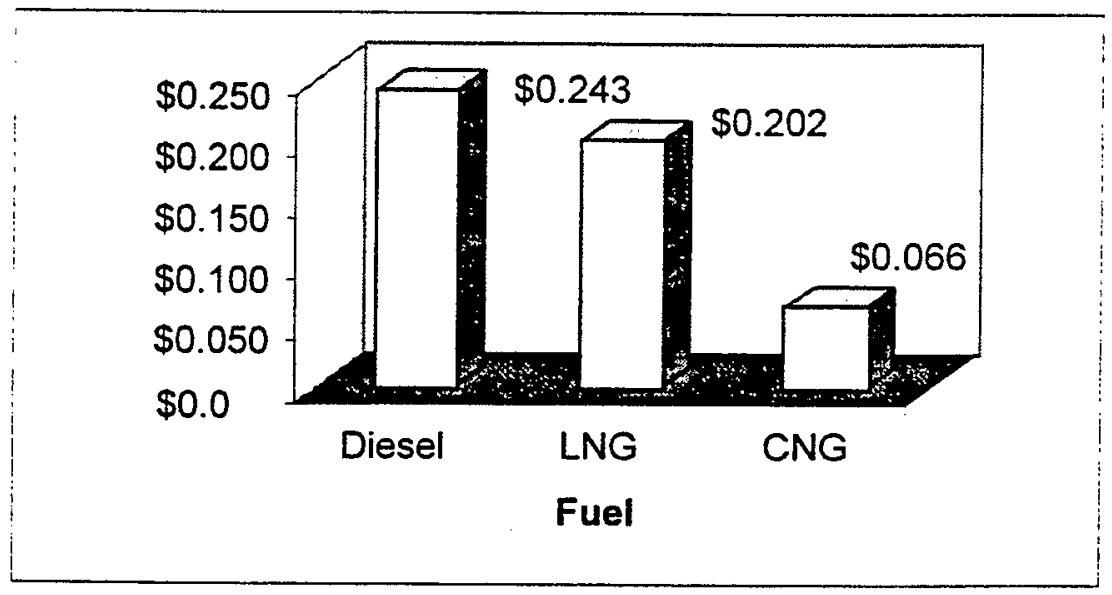

\subsection{Small-Scale Liquefaction}

One potential solution to the high cost of delivered LNG is the construction of distributed, smallscale liquefaction systems that may either be integrated with or located in proximity to vehicle refueling stations. Although generally less efficient than large-scale units, small-scale systems may offer a number of advantages with respect to LNG use in transportation applications. Most importantly, they can be located so as to minimize or even eliminate the high costs associated with LNG transportation. Alternately (or additionally in the case of refuse applications) they can be situated at or in close proximity to sources of low-cost feedstock gas, such as landfills and sewage treatment plants. Finally, smaller facilities may simply be far easier to fund, permit and build. As part of the Seaport Liquid Natural Gas Study, CALSTART was asked to identify developers of small-scale liquefaction technologies. For the purposes of this study, only those organizations actively working to develop and commercialize liquefaction systems capable of producing between 500-10,000 diesel equivalent gallons (DEG) per day have been included. At present, this produces an extremely limited group, consisting of only six organizations.

\section{Cryenco, Inc. , Denver, Colorado}

A division of Chart Industries and sister company of infrastructure provider CVI knc., Cryenco is developing two small-scale liquefaction technologies; the TADOPTR, or thermoacoustic driver orifice pulse tube refrigerator, and the LOPTR, or linear motor driver pulse tube refrigerator. Prototypes of each, capable of producing $100 \mathrm{LNG}$ gallons per day, have already been built, and the company is currently seeking funding to build larger-scale versions, capable of producing 500 LNG gallons per day. Eventually the TADOPTR may be scaled to produce 10,000-20,000 LNG gallons per day. According to Dr. John Wollan, director of Cryenco's acoustic liquefaction program, a 500 LNG gallon per day TADOPTR will cost approximately $\$ 130,000$, assuming some level of production, with a $10,000 \mathrm{LNG}$ gallon per day unit falling in the $\$ 1,000,000$ range. Both 
these prices could drop considerably with further technology refinement. LOPTR prices would be roughly similar, with a 500 LNG gallon per day unit costing an estimated $\$ 100,000-140,000$, depending on the configuration, but are less likely to decrease due to technology advances. A 500 -gallon version of either system could be produced in approximately one year from order time. Cryenco could potentially pair with sister company CVI to eventually produce an integrated liquefaction and refueling system.

\section{Cryofuel Systems Inc., Redmond, Washington}

The company's development efforts are currently focused on the production of $850-4250$ LNG gallon/day integrated liquefaction and vehicle refueling systems. Smaller prototypes have been built and two 850 LNG gallon/day systems are expected to be completed in 1999. According to Dr. John Barclay, CEO and president, a 2550 LNG gallon/day unit with 3,000 gallons of storage, two LNG and four CNG dispensing hoses and all necessary safety equipment would cost approximately $\$ 725,000$ installed. The company will also produce and sell the purification and liquefaction elements of the systems individually for use in non-fueling applications. Estimated turnaround time on a liquefaction and refueling station order would be six to nine months.

\section{Institute of Gas Technology (IGT), Des Plaines, Illinois}

This research institute began work in March of 1998 on the development of a small-scale LNG liquefaction system. The goal of the project is to produce a $300-500 \mathrm{LNG}$ gallons per day unit, using a mixed refrigerant cycle and off-the-shelf technologies. According to Mr. Ken Koontz, IGT's principal investigator, it is far too early to project costs or performance characteristics for the system. The unit is scheduled to be completed and fully tested by September of 1999 .

\section{Idaho National Engineering and Environmental Laboratory (INEEL), Idaho Falls,} Idaho

NEEL is currently working on a number of LNG related technologies including refueling systems and a small-scale liquefaction unit. The liquefaction system under development at INEEL is intended to be a low-cost, high-efficiency option, with the end goal being a unit in the $\$ 350,000$ range, capable of producing 5,000 LNG gallons per day. According to Mr. Bruce Wilding, Alternative Fuel Program Project Manager, the system is still in the design stages and is expected to be completed in 1.5-2.5 years.

Two of California's largest gas utilities, Pacific Gas and Electric (also one of the cofunders of this study) and So. Cal. Gas. are cooperatively evaluating the feasibility of using this technology in a network of small local liquefaction facilities. Although the fuel would initially be used for PG\&E's fleet, commercial transportation applications are also considered a potential market. According to PG\&E, the target price for LNG from facilities in the Bay Area would be $\sim \$ .30 / \mathrm{LNG}$ gallon, pre-tax and transportation. ${ }^{8}$

\section{Liberty Fuels (formerly U.S. Natural Gas Vehicles), Santa Cruz, California}

The company has developed and built a $2,150 \mathrm{LNG}$ gallon/day liquefaction and refueling unit, making it the only one of this group with a full-scale working system. With 2,150 gallons of storage, a single $\mathrm{LNG}$ and $\mathrm{CNG}$ dispenser and all necessary safety equipment the unit costs $\$ 650,000$, according to chief engineer, $\mathrm{Mr}$. Youbert Alcaldo. Installation and site preparation would be additional. The hardware could be scaled to produce up to

\footnotetext{
${ }^{8}$ Per conversation with Brian Stokes, Senior Research Associate, PG\&E, February 1999.
} 
$10,725 \mathrm{LNG}$ gallon/day. Although the system is operational, additional units will not be commercially available until mid- 1999.

\section{KM Energy, Mt. Shasta, California}

KM Energy is an official distributor of Liberty Fuels' 2150 LNG gallon/day system; however, they are also actively working to develop several larger systems, capable of producing 3,000-20,000 LNG gallons per day. These systems are currently in the design stage and would utilize different refrigeration cycles depending on their size. According to Chairman, Mr. Robert Kline, the larger units would be best suited to on-site liquefaction of capped well gas, while the smaller systems would be appropriate for vehicle refueling stations.

As the limited amount of technology development suggests, the small-scale liquefaction industry is perhaps the least developed of the LNG technology sectors discussed in this report. This nascence and the complete lack of in-use performance data make it nearly impossible to compare the systems, whether to one another or to traditional delivery and storage models. Obviously, one of the most important criteria in evaluating these different technologies is the final cost of the LNG (and CNG) that they produce. Unfortunately, assumptions regarding amortization periods, throughput and feedstock cost vary widely, making comparison of manufacturers' estimated LNG prices problematic at best, and meaningless at worst. It is worth noting, however, that several developers estimate their systems' wholesale fuel cost to be in the range of $\$ 0.30-.35 /$ LNG gallon, depending on the source and cost of feedstock gas. These price goals could be met or even improved on by tapping low-cost sources of feedstock gas such as landfills, sewage treatment facilities or capped wells.

As the considerable upheaval in the LNG storage and refueling business indicates, reliability and service are also critical criteria in comparing technologies. Currently there is no information on the various systems and companies presented here, with respect to these characteristics.

Finally, it is important to note that, although only six organizations have been identified as actively working on the development of small-scale liquefaction systems, other areas of the U.S. cryogenics industry are well developed. If demand for LNG in the transportation sector were to grow substantially, it is likely that a number of larger, more established cryogenics firms would enter the liquefier market. Similarly, natural gas utilities and distributors could also play a pivotal role in the development and/or installation of small-scale stations, as evinced by the So. Cal. Gas. and PG\&E partnership. Both the growth in demand and the subsequent entry of well-capitalized firms into this technology area could significantly alter the economics and developmental pace of small-scale liquefaction.

\subsection{Case Studies}

One of the difficulties in assessing LNG as heavy-duty vehicle fuel and technology is the dearth of in-use data. Although the fuel and its associated technologies have seen service in a broad range of applications, very little systematic, longitudinal information has been gathered on the relative performance of these systems compared to diesel ones.

To date, the majority of in-use information that is available comes from transit applications. This sector served as the initial test bed for heavy-duty LNG and CNG. engine systems, with demonstration programs first beginning in the early 1990's. Due to the extreme immaturity of the technology, most early demonstrations were plagued with reliability and performance problems. 
Most notably, early engines were not able to control the air-fuel mix. As a result, misfires, incomplete burning of the fuel and seriously compromised engine efficiencies were common.

By the mid-90's, however, OEMs all began to introduce the enhanced electronic engine controls that are now standard on all heavy-duty natural gas engines. These and other technological refinements have resulted in substantial performance and reliability improvements, allowing natural gas systems to compete more effectively with diesel in transit applications. This is reflected in the increasing market share claimed by natural gas technologies. At present, natural gas vehicles account for $4.8 \%$ of all transit units operating in the U.S. This number is expected to increase to $7.3 \%$ by the end of 1999 , based on current orders. LNG units represent only $1 \%$ of the current U.S. transit fleet; however, they account for $7 \%$ of the total new vehicles ordered. ${ }^{9}$

The experience gained from the transit sector benefits and informs all uses of LNG, and the resulting technology refinement has significantly broadened the range of potential applications for the fuel. However, port trucking and terminal operations differ markedly from transit in terms of duty cycles, operational characteristics and power requirements. The following sections present operational information from a range of applications more closely resembling those at the port. These case studies include two on-road LNG trucking operations, one LNG refuse project and a CNG yard tractor fleet. (Appendix A outlines the remaining LNG refuse and trucking projects in the U.S.) As previously mentioned, there is little quantitative data available from these vehicle programs. As a result, the following studies are primarily qualitative in nature. NREL, in cooperation with Battelle, is currently undertaking longitudinal studies of a number of LNG fleets, including the Raley's vehicles discussed below. This study is expected to produce a wealth of detailed information on the comparative operational costs associated with heavy-duty diesel and LNG engine systems. However, results were not available at the time of this report's preparation.

\section{H.E Butt Supermarkets}

The Texas-based HEB Grocery Company began using Class 8 LNG trucks at their Houston Retail Support Center in January 1998. These vehicles operate along normal company routes and average about 400 miles per day, or 125,000 miles annually. So far, 18 of the company's 61 vehicles have had their existing Caterpillar C-10 diesel engines modified to operate as dual-fuel, at a cost of $\$ 17,762$ per engine. These 10.3 liter engines are rated with 300 horsepower and 1050 $\mathrm{lb}-\mathrm{ft}$ of torque at $1200 \mathrm{rpm}$. The remaining vehicles, equipped with both $\mathrm{C}-10$ and $\mathrm{C}-12$ engines, will be converted by the end of this year, according to company officials. To support the fleet, a 19,000 gallon on-site LNG refueling facility was built by MVE. LNG is supplied by an Amoco liquefaction facility, located only 30 miles from the HEB facility. All refueling station costs are incorporated into the fuel price, which is $\$ 0.60$ per diesel gallon equivalent, pre-tax. Due to the proximity of the liquefaction facility, the base fuel price is only $\$ .32 / \mathrm{LNG}$ gallon, or $\$ .54 / \mathrm{DEG}$. No public funding was available for either the vehicle or fueling station costs.

In its first year of operation the LNG fleet has shown significant cost savings while simultaneously maintaining the minimum standards of operation required from all of HEB's fleet vehicles. The time between oil change intervals has more than doubled and fuel costs have been reduced using $\mathrm{LNG}$. HEB estimates their engine efficiency penalty to be only $5 \%$, relative to diesel. Collectively, over the 6-year life of the vehicles, these factors are expected to result in maintenance cost savings of $\$ 1,135 /$ unit and fuel cost savings of $\$ 14,949 /$ unit. In addition, PSA has guaranteed a one-year life extension on the engines, from 5 to 6 years. This results in an additional $\$ 11,200$ savings per vehicle. At the end of their service, the units will likely be

${ }^{9}$ American Public Transit Association, Transit Vehicle Data Book, 1994, 1996, 1998. 
reconverted to diesel and sold. The LNG tanks and dual-fuel parts will then be reinstalled on the next generation of HEB vehicles. This reinstallation and upgrade of electronic engine controls will cost as estimated $\$ 3,500$, compared to almost $\$ 18,000$ for the original units. Assuming that fuel prices stay relatively constant, HEB will then be able to accrue even greater cost savings.

\section{Raley's Supermarkets}

The Raley's supermarket chain introduced California's first commercial over-the-road fleet of LNG-powered trucks in April of 1997. Operating eight LNG trucks, or 20\% of its fleet, Raley's has one of the largest Class $8 \mathrm{LNG}$ fleets in the country. Each vehicle currently operates 16 hours a day, 6 days a week, and has a range of 600 miles per fueling. The Kenworth T800 trucks are equipped with Cummins L10-300G LNG engines, which offer 300 horsepower and $900 \mathrm{lb}-\mathrm{ft}$ of torque at $1300 \mathrm{rpm}$. The fueling system on the vehicles includes two 87 gallon MVE saddle tanks. In addition to these trucks, Raley's also operates two Ottawa LNG yard tractors, equipped with 195 horsepower Cummins B-5.9G engines. In order to support its LNG fleet, Raley's installed a temporary 6,000 gallon fueling station, while also constructing a permanent 13,000 gallon station. Both units are built by MVE. Raley's fuel is supplied by J.B. Kelley, at a pre-tax cost of $\$ .53 / \mathrm{LNG}$ gallon or $\$ .90 / \mathrm{DEG}$. Raley's received a total of $\$ 600,000$ in public funding to cover the incremental cost of the LNG units as well as part of the fueling station costs.

Although Raley's officials are among the most vocal supporters of LNG technology and will very likely expand their LNG fleet, the units' performance has been mixed. The L-10 engines appear to be underpowered for this particular application, having $15 \%$ less torque than their diesel counterparts. As a result, the engines are forced to run harder, which lowers their overall efficiency compared to diesel units. According to Mr. Kevin Chandler, Principal Research Scientist at Battelle and project manager on the NREL LNG study, the LNG units have consistently experienced $34-37 \%$ efficiency penalties relative to the fleet's conventional trucks. In addition, several vehicles have broken down while en route, resulting in significant towing charges. Overall, comparative maintenance costs appear to be roughly equal. While the oil change interval has been lengthened on the LNG units, they also require spark plug changes, at a cost of $\$ 163 /$ set. Neither diesel nor dual-fuel engines have spark plugs. At the time of this writing, Mr. Chandler was not able to provide a comprehensive operational cost comparison; however, there is clearly a cost penalty associated with the LNG units.

On a more positive note, Raley's has received tremendous publicity due to its use of LNG vehicles. The supermarket chain has also avoided incurring any legal problems associated with diesel exhaust at its distribution facility. And despite the problems experienced to date, the company remains committed to maintaining, and very likely expanding its LNG fleet.

\section{William H. Martin Inc.}

William H. Martin Inc., a waste management company in Washington, Pennsylvania, began operating LNG-powered refuse haulers in July of 1997 after a consortium came together to develop the project. The consortium consisted of Gas Research Institute, NREL, ATA, Mack and the Pennsylvania Department of Environmental Protection, and provided the funds for an on-site 13,000 gallon underground LNG station. The station was built by CVI of Columbus, Ohio while Mack provided the vehicles at no incremental cost.

Currently four vehicles are in operation, with others to arrive in 1999. The vehicles are Mack MR and LE models, equipped with E7G $325 \mathrm{hp} \mathrm{LNG} \mathrm{engines.} \mathrm{These} \mathrm{refuse} \mathrm{trucks} \mathrm{operate} \mathrm{on}$ normal residential pickup routes, covering $65-80$ miles a day in 11-12 hour shifts. Each vehicle is equipped with two LNG saddle tanks, one holding 100 gallons the other 50 gallons of LNG. The 
project is designed to examine both the environmental and economic characteristics of the vehicles; however, this data is not yet available. Mr. Ben Woods, District Manager of Waste Management of Pennsylvania, expressed support for the project, indicating that the efficiency penalty relative to diesel has only been $15 \%$ and that there have been "no real operational problems."

\section{USF Reddaway}

USF Reddaway operates 57 full-service trucking terminals in nine western states. At the company headquarters in Portland, Oregon they operate over $50 \mathrm{CNG}$ vehicles, including 40 forklifts, one Ford F250 pickup and 8 yard tractors (with two more on their way). Although the vehicles operate on CNG the engine systems for CNG and LNG are basically the same. The yard tractors being used at this facility have proved to be a successful off-road application of natural gas, suggesting similar possibilities for port terminal applications. The yard tractors are Ottawa units, equipped with Cummins B5.9G engines. The tractors were OEM purchases and each carried an incremental cost of $\$ 6000$ over the price of an equivalent diesel vehicle. Most of the trailers USF Reddaway pulls are $28 \mathrm{ft}$. with a maximum load of $28,000 \mathrm{lbs}$.. Because Oregon law permits trailers to be pulled in triples, the load on these yard tractors can be quite heavy. Even under these excessive loads, the yard tractors have never had insufficient power to do the job.

To support their CNG activities, USF Reddaway leases a CNG station from North West Pump, which was built by IMW Atlas. When the natural gas project was initially undertaken, USF Reddaway estimated that the overall natural gas project would save them about $\$ 130,000$ per year. As a result of dropping diesel prices, this savings has been reduced to about $\$ 120,000$ per year.

\section{Case Study Summary}

These various projects suggest both the promise and peril of natural gas use in heavy-duty applications. Clearly, the experience of HEB is an important example, suggesting the very substantial cost savings that can be realized with access to locally produced LNG and a long-term commitment to the fuel's utilization. Just as importantly, USF Reddaway's successful utilization of natural gas yard tractors, albeit CNG ones, demonstrates the potential for similar applications at the Ports. On a more sobering note, the very large efficiency penalties experienced by the Raley's fleet evince the need for further engine refinements and, moreover, careful matching of engine systems and duty cycles. 


\section{Feasibility Analysis}

This chapter presents the formal feasibility analysis of LNG use at the Ports of Los Angeles and Oakland. The basis of this evaluation is the ability of LNG, as a fuel and a technology family, to compete technically, economically, environmentally and logistically with the diesel-powered equipment currently in use in this setting. Each of these general categories will be examined, as will a range of other relevant factors, towards the end of identifying the overall potential for using LNG in the port arena. The chapter concludes with a summary of this potential and a formal identification of the critical barriers and benefits to the fuel's use. Measures to mitigate barriers and capitalize on these benefits are then discussed in Chapter 5.

\subsection{Technological Feasibility}

\subsubsection{Availability of Suitable Engine Systems}

The keystone of technological feasibility is the availability of engine systems that are compatible with current and near-term port operations. Comparison of the engine and equipment specifications provided by port terminal and trucking operators to the current inventory of LNG engine technologies suggests that, with some provisions, the use of LNG systems at the ports is technically feasible.

\section{Port Trucking}

CALSTART's analysis of port trucking operations revealed that the vast majority of port truckers utilize vehicles with engines $350 \mathrm{hp}$ or higher and torque ranges on the order of 1300-1500@ $1200 \mathrm{rpm}$. As Table 4-1 indicates, there are currently two commercially available natural gas engines and one prototype unit that can approach or meet these power requirements. However, certain limitations of this group must be noted.

- The Mack engine cannot be purchased as an individual component, but rather, must be integrated into a new Mack vehicle by the dealer/factory.

- The Detroit Diesel unit is still considered a prototype and therefore carries a $\$ 45,000$ incremental cost (for the engine alone).

- The C-12 is the only of the three engines presented above to be certified to the California Air Resources Board optional oxides of nitrogen (NOx) standard $(2.5 \mathrm{~g} / \mathrm{bhp}-\mathrm{hr})$, and consequently, the only one to qualify for state funding under the new $\$ 25$ million Carl Moyer Air Quality Standards Attainment Program.

In light of these qualifications, the Caterpillar/PSA C-12 dual fuel engine is effectively the only current option for the Class 8 trucks servicing the Ports. The California Air Resources Board has stated that other heavy-duty engine manufacturers intend to apply for certification this year, including in all likelihood, Detroit Diesel. Until that time, however, it is very unlikely that noncertified engines would find use at Ports. The Moyer Program, which is intended to cover the incremental cost of low-emission heavy-duty equipment, is the largest and most significant funding source of its kind in California. Given the economic considerations discussed below (Section 2.2), few users will consider LNG vehicle use without this funding support. 
Table 4-1: Heavy-duty Natural Gas Engines Suitable for Port Trucking

\begin{tabular}{|l|l|l|l|}
\hline \multicolumn{1}{|c|}{ Manufacturer } & \multicolumn{1}{|c|}{ Engine Model } & \multicolumn{1}{|c|}{$\begin{array}{c}\text { Rated Power } \\
\text { (hp@rpm) }\end{array}$} & \multicolumn{1}{c|}{$\begin{array}{c}\text { Peak Torque } \\
\text { (ft-lb@rpm) }\end{array}$} \\
\hline Detroit Diesel & Series 60G & $400 @ 1800-2000$ & $1450 @ 1200$ \\
\hline Mack & E7G (350) & $350 @ 1800$ & $1260 @ 1250$ \\
\hline Power Systems & $\mathrm{C12}$ & $410 @ 2100$ & $1300 @ 1200-1500$ \\
\hline
\end{tabular}

Discussions with engine manufacturers suggest that this range of suitable and certified product offerings should expand considerably over the next year or two. In addition to the Detroit Diesel Series 60G, two new Caterpillar/PSA dual-fuel engines are expected to enter the market in roughly that period: a high-powered version of the $C-12$, rated at $425 \mathrm{hp}$ and $1450 \mathrm{lb}-\mathrm{ft}$ of torque; and the $3406 \mathrm{E}$, rated at $500 \mathrm{hp}$ and $1650 \mathrm{lb}$-ft of torque. All three engines would be suitable for use in port trucking applications.

\section{Shipping and Rail Terminals}

Unlike heavy-duty, on-road trucking applications, there are a broad range of natural gas engine products that would appear to satisfy the power requirements of most of the heavy-duty container handling equipment at the shipping and rail terminals. As noted in Chapter 2 , the vast majority of the power systems for these diverse units fall in $180-300 \mathrm{hp}$ range. The natural gas engine products that could be suitable for these applications are listed below in Table 4-2. With the exception of the Detroit Diesel Series 60G and the two Deere engines (which are CNG certified only), all units are certified and would therefore qualify for funding under the Moyer Program.

Table 4-2: Natural Gas Engines Suitable for Use in Terminal Applications

\begin{tabular}{|l|l|l|l|}
\hline Manufacturer & Engine Model & $\begin{array}{l}\text { Rated Power } \\
\text { (hp@rpm) }\end{array}$ & $\begin{array}{l}\text { Peak Torque } \\
\text { (ft-1b@rpm) }\end{array}$ \\
\hline Cummins & B5.9G & $150-230 @ 2500-2800$ & $375-500 @ 1500-1600$ \\
& C8.3G & $250-275 @ 2400$ & $660-750 @ 1400$ \\
& L-10G & $280-325 @ 2100$ & $900 @ 1300$ \\
\hline Detroit Diesel & Series 50G & $275 @ 2100$ & $890 @ 1400$ \\
& Series 60G & $330-400 @ 2100$ & $1400-1450 @ 1200$ \\
\hline John Deere & PowerTech 6.8L & $225 @ 2400$ & $640 @ 2400$ \\
& PowerTech 8.1L & $250 @ 2200$ & $800 @ 1300$ \\
\hline Caterpillar/Power & 3126 & $190-250 @ 2400$ & $550-660 @ 1500-1550$ \\
Systems Associates & C10 & $305-350 @ 1200-1500$ & $1050-1150 @ 1200-1500$ \\
& C12 & $370-410 @ 2100$ & $1300 @ 1200-1500$ \\
\hline
\end{tabular}

Despite the relative abundance of systems in the required power range for port terminal operations, there may be some technological obstacles to their utilization in these applications. These engines have seen very little use in off-road functions, where duty cycles and use requirements often differ markedly from on-road ones. In most port equipment, engine systems typically function as both propulsion systems and power sources for hydraulic features. Without in-use data, it is difficult to predict how the current generation of natural gas engines, dual-fuel or dedicated, will perform under these conditions. Some positive evidence may be drawn from the successful use of natural gas engines in refuse applications, where the 'stop and go' drive cycles and powering of ancillary hydraulic functions closely mimic terminal applications. Nonetheless, successful use of LNG in terminal equipment will undoubtedly require further refinements to the current engine systems. 


\subsubsection{Technological Maturity}

As noted in Chapter 3, neither dedicated nor dual-fuel natural gas engines have yet achieved the level of technological maturity found in diesel systems. To date this relative immaturity has had two critical manifestations in natural gas-powered heavy-duty vehicle projects: below optimum engine efficiencies; and increased incidence of mechanical/operational failure. Although some efficiency penalty is inherent to natural gas systems, the variance seen among past and present vehicle projects is not. Nor is the increased vehicle downtime witnessed to date. Instead, these factors stem directly from the relative dearth of in-use experience with these technologies. In transit applications, where natural gas has seen the heaviest use, both factors appear to be diminishing. A similar experience and refinement pathway can be expected for heavy-duty offroad and trucking applications, given sufficient usage.

While this experience is being gathered and the necessary refinements are being made, however, users may incur operational cost penalties. These penalties will in turn affect the overall operational economics associated with LNG use. Section 4.3 discusses the potential impact of engine efficiency variations and increased vehicle downtime on operational economics.

\subsubsection{LNG Refueling Infrastructure}

As discussed in Chapter 3, a variety of suitable LNG refueling systems are currently available. Moreover, the potential port applications discussed within this study do not appear to present any unique technological or logistical problems that might affect the utilization of these systems. LNG refueling systems have not achieved the same degree of developmental maturity as their diesel counterparts. In addition, the former are inherently more complex, due to the cryogenic nature of the fuel. However, the current state of refueling technology does not appear to present a barrier to the use of LNG at the Ports.

There are, however, certain issues relating to refueling infrastructure that may present some obstacles to LNG use at the Ports, most notably the lack of an established standard for measuring dispensed LNG and permitting difficulties. At present, the California Bureau of Weights and Measures has not established a protocol for measuring the transfer of LNG from storage receptacles into LNG vehicles. Therefore no stations operating in California carry the Bureau's seal of approval and calibration. Although this is not a problem for private, on-site stations, it could potentially present challenges to the emplacement of the type of retail facility discussed in later chapters. According to various industry sources, this issue is currently being addressed within the Bureau, but a formal policy has yet to emerge. 
Figure 4-1: Factors Impacting Technological Feasibility

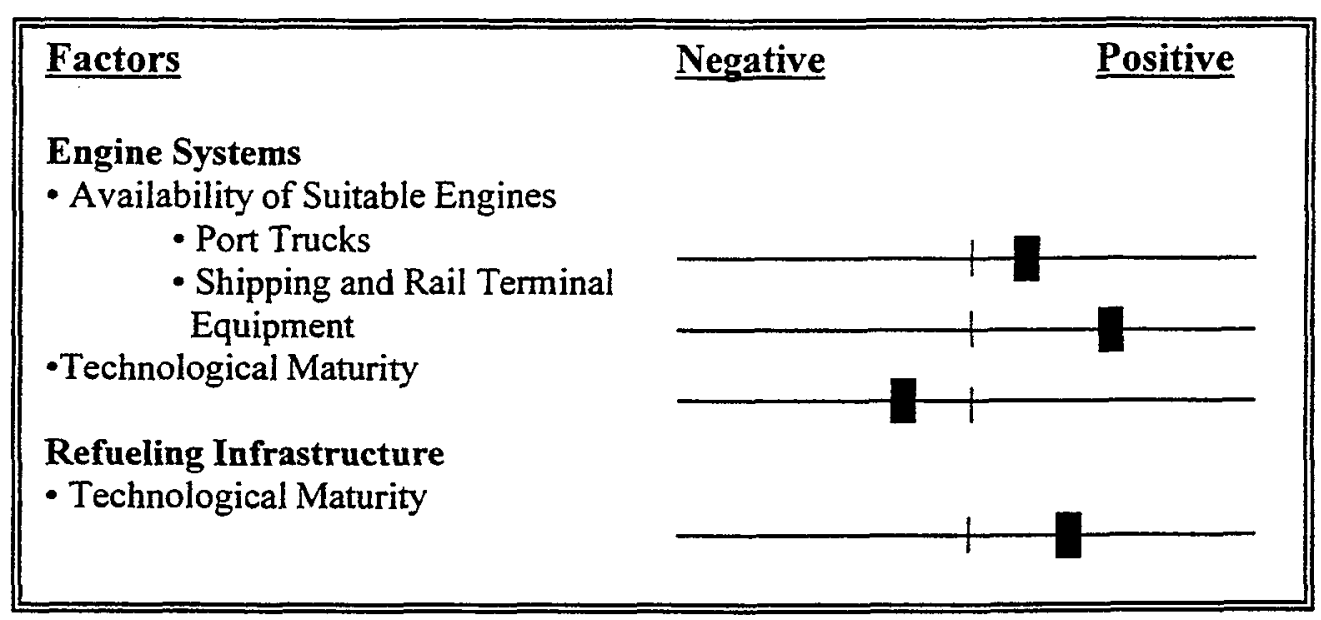

\subsection{Economic Feasibility}

\subsubsection{Capital Costs of LNG Engine and Refueling Systems}

\section{Engine System Costs}

As detailed in Chapter 3, LNG engines and on-board fuel storage systems carry a significant incremental cost over conventional diesel technologies, generally ranging from $\$ 20,000-45,000$. Beyond the price variations between manufacturers and fuel storage options, the exact value of this differential cost would depend on the equipment type, order volume, whether the engine is going into a new or used unit, and in the case of the latter, the exact vehicle age. All incremental cost estimates presented in the engine inventory (Table 3-1) assume a single engine purchase, and that the LNG system is installed on a new vehicle.

Given the reliance on used product within the trucking community, and the high capital cost and exceptionally slow turnover of terminal vehicles, engine repowering, as opposed to new vehicle purchases, represents the most likely means of market penetration for LNG technologies. Repowering refers to the replacement of the current engine system in an existing vehicle with a new(er) and typically lower emission model. Conversations with NGV Ecotrans Inc., one of the few established natural gas repowering specialists operating in California, confirmed that the process is technically feasible for the broad range of port trucks and terminal equipment. ${ }^{1}$ Due to the labor costs associated with the removal of the old engine and the reconfiguration of existing systems, repowering from diesel to LNG is typically more expensive than simply placing a new LNG system in a new vehicle. Mr. Yoshio Coy, a Project Engineer at the firm, estimates the cost of repowering an on-road Class 8 diesel tractor to LNG to be approximately $\$ 50,000-70,000$, depending on the vehicle age and amount of $L N G$ fuel storage required. The approximate cost of repowering a piece of off-road terminal equipment such as a yard tractor would be $\$ 35,000$ 40,000 , assuming that a certified, on-road natural gas engine is used.

Retrofits and conversions of existing diesel engines to dual-fuel or dedicated natural gas use are also technically feasible, but appear to have limited value. At present, a conversion kit exists for the Cummins L10 engine. The unit costs approximately $\$ 12,000$, not including labor. More

\footnotetext{
${ }^{1}$ Per conversation with Yoshio Coy, Project Engineer, NGV Ecotrans Ins., October 1998.
} 
promising is the conversion of existing Caterpillar/PSA C-10 and C-12 engines to dual-fuel operation. The retrofit costs approximately $\$ 16,000-20,000$ per unit. C-12s do not appear to be in heavy use among port trucking or terminal operators and conversion opportunities would be somewhat limited. However, where such opportunities do exist, this retrofit appears to be the most cost-effective pathway for introducing LNG.

Though a variety of other retrofit kits are available, few if any have received certification from air quality regulators. Because certification is essential in order to receive funding and/or credit for emissions reductions, use of these technologies is probably not a viable option for port vehicles and equipment.

These incremental costs clearly represent a powerful barrier to LNG use among port operators. However, there are a variety of state and local funding sources that may be used to defray the incremental cost of low emission technologies for heavy-duty vehicles. Among these, the new Moyer Program will likely be the critical funding mechanism for this sector over the next year and possibly beyond, depending on its initial success. The program focuses on buying emission reductions through the replacement, repowering and retrofit of heavy-duty diesel engines in onroad, off-road, marine and locomotive applications. Projects will be evaluated primarily on the cost-effectiveness of their emission reductions, with a ceiling of $\$ 12,000 /$ ton of NOx reduced annually. Appendix B contains cost-effectiveness calculations for three representative port vehicles, using operations information obtained in surveys of port operators. In all the scenarios, (repower of an existing Class 8 truck, purchase of a new Class 8 LNG truck and repower of an existing yard tractor) the cost-effectiveness of the emission reductions would be within the acceptable range and therefore eligible for funding under the program.

Even prior to the Moyer Program, heavy-duty LNG vehicle projects in California have generally been able to secure incremental cost funding from a variety of state and local agencies. The Moyer Program, however, is expected to streamline and enrich the funding process, while at the same time extending funding to certain regions and equipment groups that were not previously eligible. Although both Ports stand to benefit from this program, it is particularly critical to the Port of Oakland. Prior to the Moyer Program, the Bay Area Air Quality Management District was unable to fund vehicle purchases by private fleets.

In light of the various funding opportunities available for heavy-duty vehicle projects, incremental costs do not appear to represent a decisive impediment to LNG use at the Ports. So long as potential users are able to secure this funding, incremental costs should not have a negative impact on the overall economics associated with LNG. Moreover, as noted in Chapter 3, the differential cost between diesel and LNG technologies has already narrowed significantly and should continue to diminish with increased production experience and volumes. Without incremental cost funding, however, use of LNG technologies will depend on the ability to recoup increased capital costs through reduced operating expenses or other indirect economic benefits. These issues will be discussed in subsequent sections of this chapter.

\section{Refueling System Costs}

As discussed in Chapter 3, LNG refueling infrastructure is both extremely limited and expensive (to purchase and to operate) compared to diesel systems. Typically, those organizations utilizing LNG power systems are required to purchase and maintain their own fueling stations, in contrast to the vast network of commercial diesel refueling stations maintained by fuel providers. Alternatively, the fuel supplier may assume the up-front cost of the station's construction and load that expense into a long-term fuel contract. At present, both of these approaches are common within the industry. In either case, however, the cost of the station is being assumed by an 
individual user. This stands in stark contrast to retail diesel fuel provision, where fuel station costs are essentially irrelevant due to their distribution amongst multiple customers and high fuel volumes. Even in the case of the on-site diesel fueling stations found at shipping and rail terminals, and at some trucking facilities, the cost assumed by the user is far less than with LNG systems. The units are standardized, mass produced and relatively inexpensive, typically costing on the order of $\sim \$ 75,000$, in comparison to $\sim \$ 500,000$ for a comparable LNG unit.

While certain air quality management districts may provide partial funding for refueling facilities, these funds are generally far more difficult to obtain than those for vehicles or engines. (In the case of the California supermarket chains sued under Proposition 65 , only $\sim 30 \%$ of the cost of their planned LNG refueling facilities will be provided through public funding ${ }^{2}$.) Nor is there any indication this trend will change. At present, the Moyer Program does not include funding for refueling infrastructure. Fueling station costs must therefore be factored into the overall economics of LNG use. At roughly $\sim \$ 500,000$ for a suitably sized unit, this cost represents a considerable disincentive to utilize the fuel.

Although fuel station costs impact the likelihood of LNG use by both terminal and trucking operators, the latter are particularly likely to be deterred by this factor. Given their size, annual fuel consumption and other logistical considerations, the majority of trucking operations at both ports are currently unable to support even on-site diesel fueling. For operators such as these, onsite LNG facilities simply do not appear practical. Some larger, higher-end trucking operators, as well as rail and shipping terminals may be able to assume this capital expense, were there clear operational cost reductions associated with LNG use. Operational costs are discussed in the following section.

\subsubsection{Operational Costs}

\section{Diesel and LNG Fuel Costs}

Probably the single most critical factor in assessing the economic feasibility of LNG use in heavy-duty applications at the Ports is the price relationship between LNG and diesel. In addition to its emissions characteristics, LNG has also garnered interest as an alternative fuel due to its potential to reduce operational costs. For most heavy-duty vehicle applications, the largest component of operating costs (excluding labor) is fuel. Based strictly on energy equivalency, LNG is often less expensive than diesel. Theoretically, where this relationship holds true and all other costs are equal, LNG should allow for reduced operational costs.

As noted in Chapter 3, LNG fuel prices generally range from \$.45-.55/LNG gallon (pre-tax). Using the standard energy conversion factor of 1.7 , this price translates to $\$ .77-.94 /$ diesel gallon equivalent. Table 4-3 below compares the cost of LNG to diesel prices quoted by various port operators, as well as to 1998 retail pump prices reported by the California Energy Commission (CEC) ${ }^{3}$ All on-road values include applicable federal and state excise taxes, and $8.25 \%$ salestax. Off-road prices include sales tax only.

\footnotetext{
${ }^{2}$ Per conversation with Bruce Reznik, Policy Analyst, Gladstein and Associates, November 1998.

${ }^{3}$ CEC Web Site, http://www.energy.ca.gov/fuels/weekly/diesel.html
} 
Table 4-3: Diesel and LNG Prices, Per Diesel Gallon Equivalent

\section{Off-Road Applications}

\begin{tabular}{|l|l|l|}
\hline $\begin{array}{l}\text { Off-road LNG } \\
\text { (no excise tax) }\end{array}$ & $\begin{array}{l}\text { Rail } \\
\text { Terminals } \\
\text { (no excise tax) }\end{array}$ & $\begin{array}{l}\text { Shipping } \\
\text { Terminals } \\
\text { (no excise tax) }\end{array}$ \\
\hline$\$ .83-1.02$ & $\$ .63$ & $\$ .66$ \\
\hline
\end{tabular}

\section{On-Road Applications}

\begin{tabular}{|l|l|l|}
\hline $\begin{array}{l}\text { On-road LNG } \\
\text { (Includes state } \\
\text { and federal } \\
\text { excise tax) }\end{array}$ & $\begin{array}{l}\text { Trucking } \\
\text { Operators }\end{array}$ & $\begin{array}{l}\text { CEC Reported } \\
\text { Pump Price } \\
\text { (includes state } \\
\text { and federal } \\
\text { excise tax) }\end{array}$ \\
\hline$\$ 1.23-1.42$ & $\$ 1.08-1.40^{\mathrm{b}}$ & $\$ 1.20$ \\
\hline
\end{tabular}

${ }^{2}$ Represents an average of 1998 retail prices for Southem and Northem Califomia (excludes Central Califomia values).

'Price survey was done as part of CALSTART's interview process, the majority of which took place in August of 1998 . Diesel prices have since decreased, as indicated in Figure 4-2 below.

Diesel prices have displayed considerable volatility in recent years. The general trend, however, has been one of decreasing prices, such that diesel prices, when adjusted for inflation, are at a historical low. Figure 4-2 below displays average California retail diesel prices over the last two years. Although regional prices are dependent on a broad range of factors, the most significant variable is the price of crude oil. Figure 4-3 below, presents recent crude oil price trends and projections from the Energy Information Administration (EIA), the research arm of the Department of Energy.

Figure 4-2: Retail Diesel Prices in California, 1997-1998

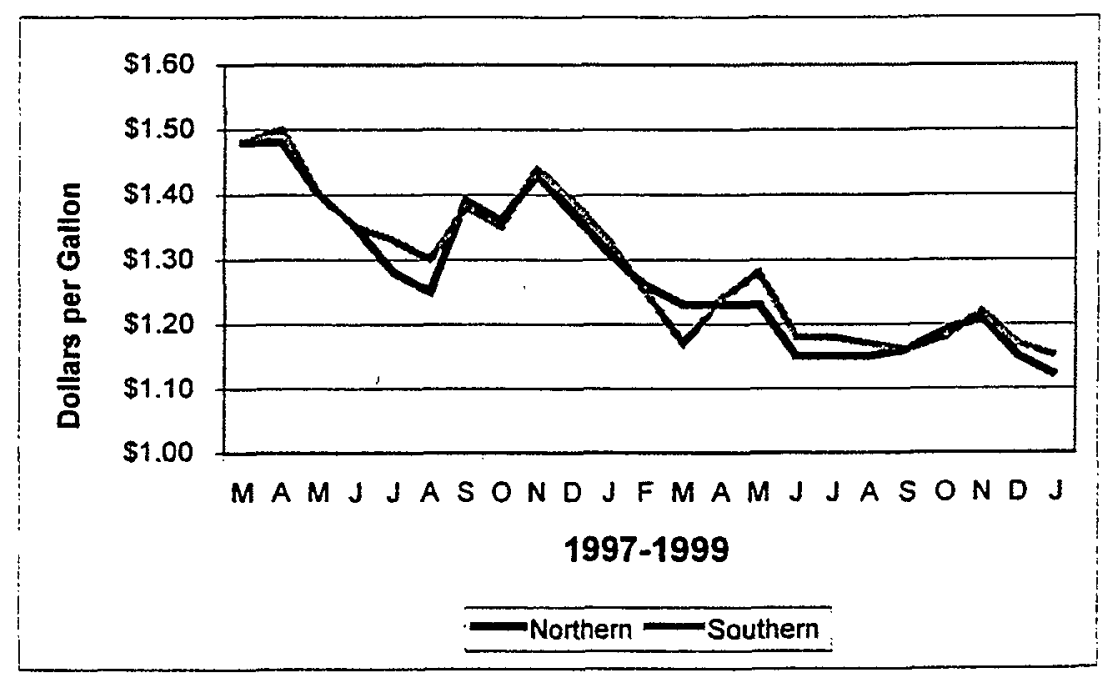

Source: Califomia Energy Commission website http://www.energy.ca.gov/fuels/weekly/diesel.html 
Figure 4-3: Crude Oil Price Projections

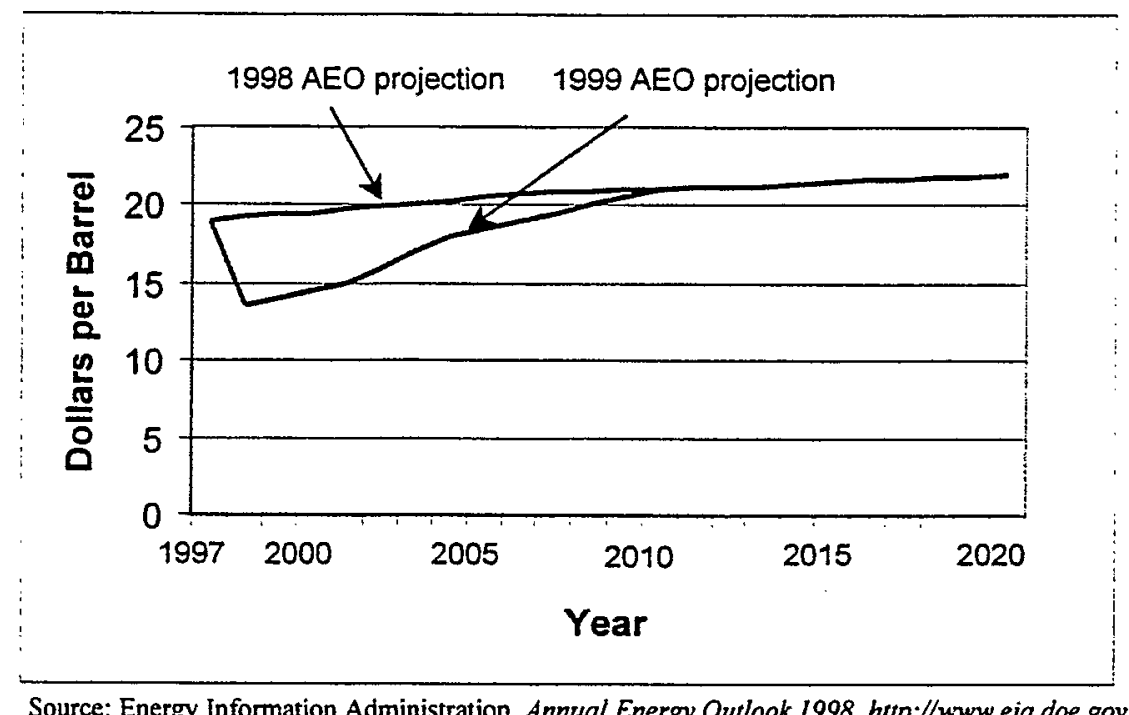

As these figures show, the decline in California diesel prices is in keeping with a similar decrease in the global crude oil prices. Oil prices have traditionally been a subject of tremendous contention and speculation. A critical review of this subject is clearly beyond the scope of this report. The EIA projections utilized here are by no means infallible; however, they represent the U.S. government's official projections and must therefore be considered the "best available data" under the circumstances. The variation between the 1998 projections, actually published in 1997 , and those of the following year are telling. The current price decline was clearly not anticipated. The exact implications of this are unclear; however, these projections would appear to suggest that current prices are anomalous. This does not dictate that a significant upward adjustment in oil prices will occur, but some increase does seem more likely than a continued decline. Obviously, the direction of oil prices will play a critical role in determining the comparative economics of LNG and diesel utilization. Taking what would appear to a conservative approach, near-term diesel prices are considered to remain relatively consistent with 1998 average prices for the purposes of the remaining analysis.

Under current conditions then, and based strictly on an energy equivalent price comparison of diesel and LNG, there does not appear to be a substantive economic incentive to use the alternative fuel in port applications. On the contrary, except in the upper ranges of diesel prices, LNG use would entail an operational cost penalty in comparison to diesel. This penalty would be particularly severe in off-road applications such as the rail and shipping terminals, where the use of (excise tax-free) red diesel negates the differential tax advantage enjoyed by LNG in on-road fuel use.

\section{Efficiency Penalties}

The cost disadvantage of LNG is further intensified by the lower engine efficiencies associated with dedicated and to a lesser extent dual-fuel natural gas engines. As noted in Chapter 3, optimum efficiencies for these units are approximately $85 \%$ and $95 \%$ that of conventional diesel systems, respectively, and actual results may be even lower. This efficiency loss has a direct impact on operational costs, adding, conservatively, another $5-15 \%$ to total fuel consumption and hence to fuel costs. One way of representing this penalty is on a per diesel gallon equivalent 
basis. In other words, if measured in terms of operational rather than energy equivalency, LNG prices in California are actually closer to the following:

- Dual-fuel engine, assuming 5\% efficiency loss - \$1.29-1.49/dge

- Dedicated natural gas, assuming $15 \%$ efficiency loss - \$1.41-1.63/dge

\section{Maintenance Costs}

As noted in Chapter 3, there is not yet sufficient data to reliably establish the comparative lifecycle maintenance costs of diesel and LNG engines. The experience of the HEB fleet clearly provides some evidence for reduced maintenance costs from natural gas engines. Extending oil change intervals and vehicle life can have a very positive effect on LNG operational economics. However, the increased vehicle downtime associated with other LNG projects argues against overly optimistic assessments of overall comparative maintenance costs. In light of these uncertainties, maintenance costs are considered to be equal for diesel, dual-fuel and dedicated natural gas engines. It is important to note, however, that downtime, towing and temporary replacement (rental) charges for heavy-duty vehicles are typically high. Therefore, any significant incidence of vehicle malfunction could quickly negate cost reductions associated with extended oil change intervals or vehicle lifespans.

\section{Refueling Time and Distance}

With proper training of relevant personnel, LNG refueling times should be comparable to those of diesel. Depending on the location of the refueling facility, however, LNG users may incur incremental refueling costs. If LNG refueling requires additional travel in comparison to diesel refueling, this labor time and mileage penalty must be factored into the overall operational costs associated with the alternative fuel.

\section{Projecting Breakeven LNG Prices}

If, as is suggested here, current LNG and diesel prices do not offer sufficient economic incentive to utilize the alternative fuel, the question arises as to what point in the price relationship would do so. Ultimately, this will depend on a wide variety of variables. As discussed above, comparative engine efficiencies, maintenance costs, and the economics and accessibility of refueling infrastructure all impact the operational cost relationship between the two fuels. In addition, the overall cost comparison may be affected by the individual user, the application and myriad other variables discussed in later sections of this chapter.

Given the range of variables and the imprecision of current information, it is not possible to calculate the precise quantitative effect of these factors on the two fuels or to establish a clear trigger price for LNG use. It is both possible and necessary, however, to identify a threshold that must be crossed for LNG use to even begin to appear economically viable. Although this can be done in a variety of ways, CALSTART has elected to utilize a model developed for the Sacramento Metropolitan Air Quality Management District to calculate the operational cost parity price for LNG, as a function of diesel price. ${ }^{4}$ Figure $4-4$ presents estimated cost parity prices of LNG and diesel under three scenarios, based on the operational characteristics of a representative port fleet. ${ }^{5}$ These scenarios are as follows:

Scenario I-All of the incremental vehicle cost has been paid by an outside party. The fuel cost of an on-site $\$ 500,000 \mathrm{LNG}$ fueling station is assumed by the truck fleet.

Scenario 2-All of the incremental vehicle cost and $30 \%$ of the on-site fueling station cost has been paid by an outside party. The remaining $\$ 350,000$ for the station is paid by the truck fleet.

\footnotetext{
${ }^{4}$ All values have been generated using a LNG/diesel cost parity model developed for the Sacramento Metropolitan Air Quality Management District by Arcadis, Geraghty and Miller.

${ }^{5}$ Representative port fleet is 35 vehicles, each operating 250 days/year, traveling 65,000 miles annually, with a fuel efficiency of $6.5 \mathrm{mpg}$.
} 
Scenario 3-All of the incremental vehicle cost has been paid by an outside party. Fuel is obtained from a retail $L N G$ fueling station. Therefore the station cost is assumed to be $\$ 0.00$.

For the purposes of this exercise, maintenance costs, vehicle reliability and accessibility of fueling infrastructure are held constant between diesel- and LNG-powered vehicles in all scenarios; however, dual-fuel and dedicated LNG vehicles are assumed to suffer $5 \%$ and $15 \%$ efficiency penalties, respectively. (For a complete list of model inputs, see Appendix C.) Following industry convention, $L N G$ is given as a pre-tax or delivered fuel price, while diesel is given as a retail price, and includes all applicable taxes. LNG prices can be converted to retail diesel gallon equivalent price using the formula presented in Appendix D.

Figure 4 - 4: Operational Cost Parity

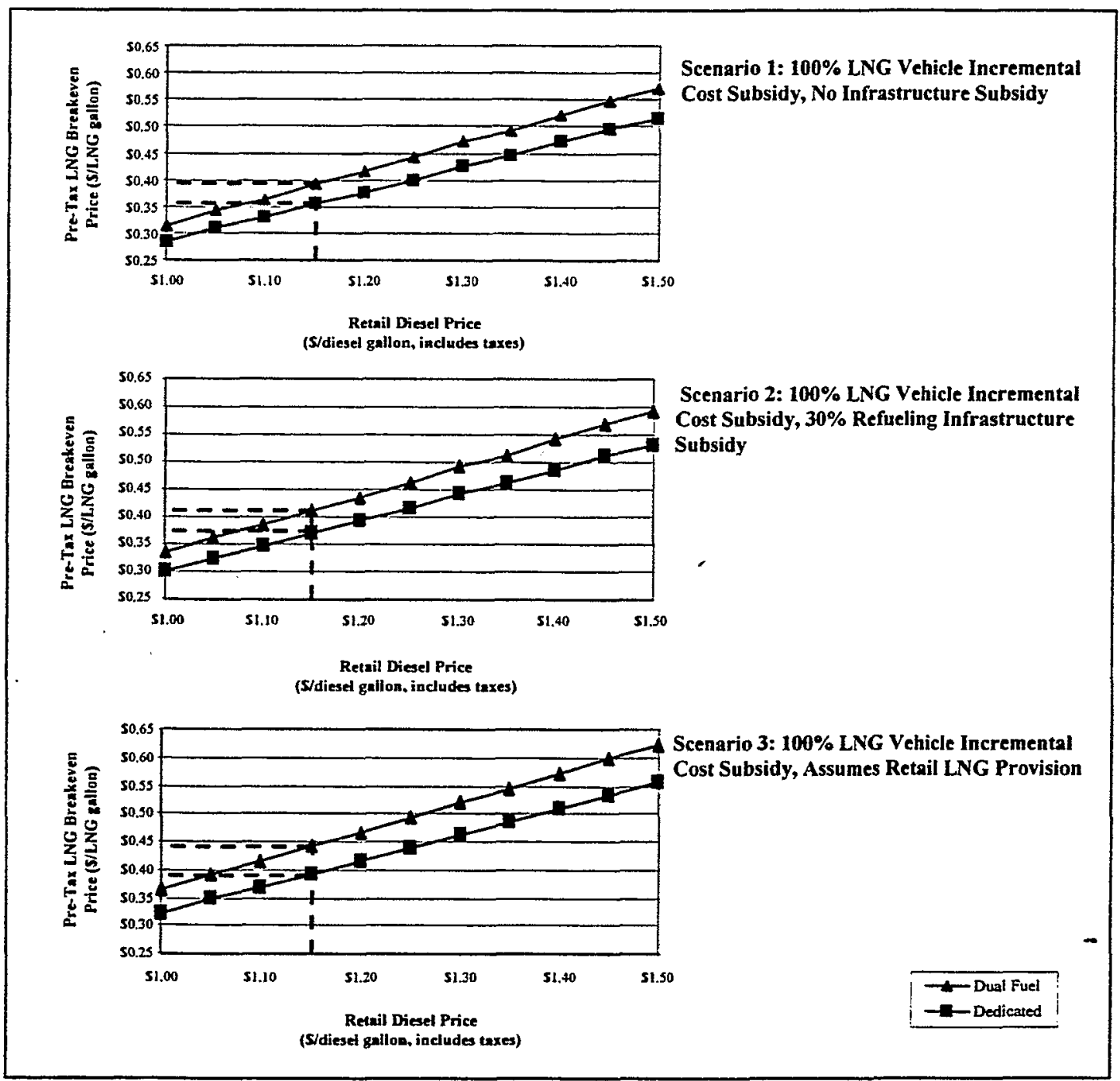

These figures present estimated cost parity fuel prices for just a few of the many plausible scenarios that could be applied to the ports. What the function illustrates; however, is that even under relatively optimistic assumptions such as these, LNG prices must drop considerably below their current state in order to offer even operational cost-parity with diesel, let alone the types of 
savings that might adequately stimulate conversion to a new and unfamiliar technology. Assuming diesel prices remain in the area of $\$ 1.15 /$ gallon, $\$ .35-.40 / \mathrm{LNG}$ gallon appears to the price ceiling for $\mathrm{LNG}$ if it is to compete with diesel on an economic basis. Moreover, these costparity prices apply only to on-road applications. Because of the differential tax advantage enjoyed by LNG in on-road applications, off-road terminal applications would require LNG prices at least $25-30 \%$ cheaper than those for on-road, in order to achieve cost parity.

\section{Summary - Operational Costs}

Under current conditions, the operational costs associated with LNG do not appear to offer any economic incentive to utilize the fuel. Figure 4-5 below summarizes these findings. For on-road trucking operations, LNG may offer some operational cost reductions when diesel prices are at a more elevated state. However, under average conditions, LNG use promises cost parity at best, and may actually result in significant cost penalties. Operational economics are even more unfavorable for off-road terminal applications. In this setting, LNG use would result in substantial cost penalties.

Although diesel prices have shown a good deal of volatility in recent years, there is no reliable evidence to suggest a reversal in the current downward price trend. For the immediate purposes, this variable must be considered relatively fixed. This indicates that, if LNG operational economics are to improve, the fuel's price must decrease and the engines must perform consistently at or near optimum efficiency levels. With respect to LNG prices, it does not appear possible for current suppliers to offer the necessary price reductions. The natural gas feedstock, liquefaction and transportation costs that determine these prices are all relatively stable. Price reductions must therefore come through the identification and use of low-cost, non-traditional feedstock sources and/or reduced transportation charges.

Smaller-scale local liquefaction systems appear to offer some promise in this regard. By tapping landfills, sewage treatment facilities or other low-cost gas sources in the Los Angeles and San Francisco Bay areas, such systems may be able to offer transportation quality LNG at a very competitive price. At present, the necessary technology is still in the prototype stage; however, the Ports could represent an excellent environment in which to test and refine these systems. In addition, as noted in Chapter 3, Bay Area utility PG\&E has teamed with its Los Angeles counterpart So. Cal. Gas to explore the possibility of low-cost, local LNG production. If realized, this effort could help to overcome the current operational cost barriers to LNG use in port applications. 
Figure 4-5: Factors Impacting Economic Feasibility

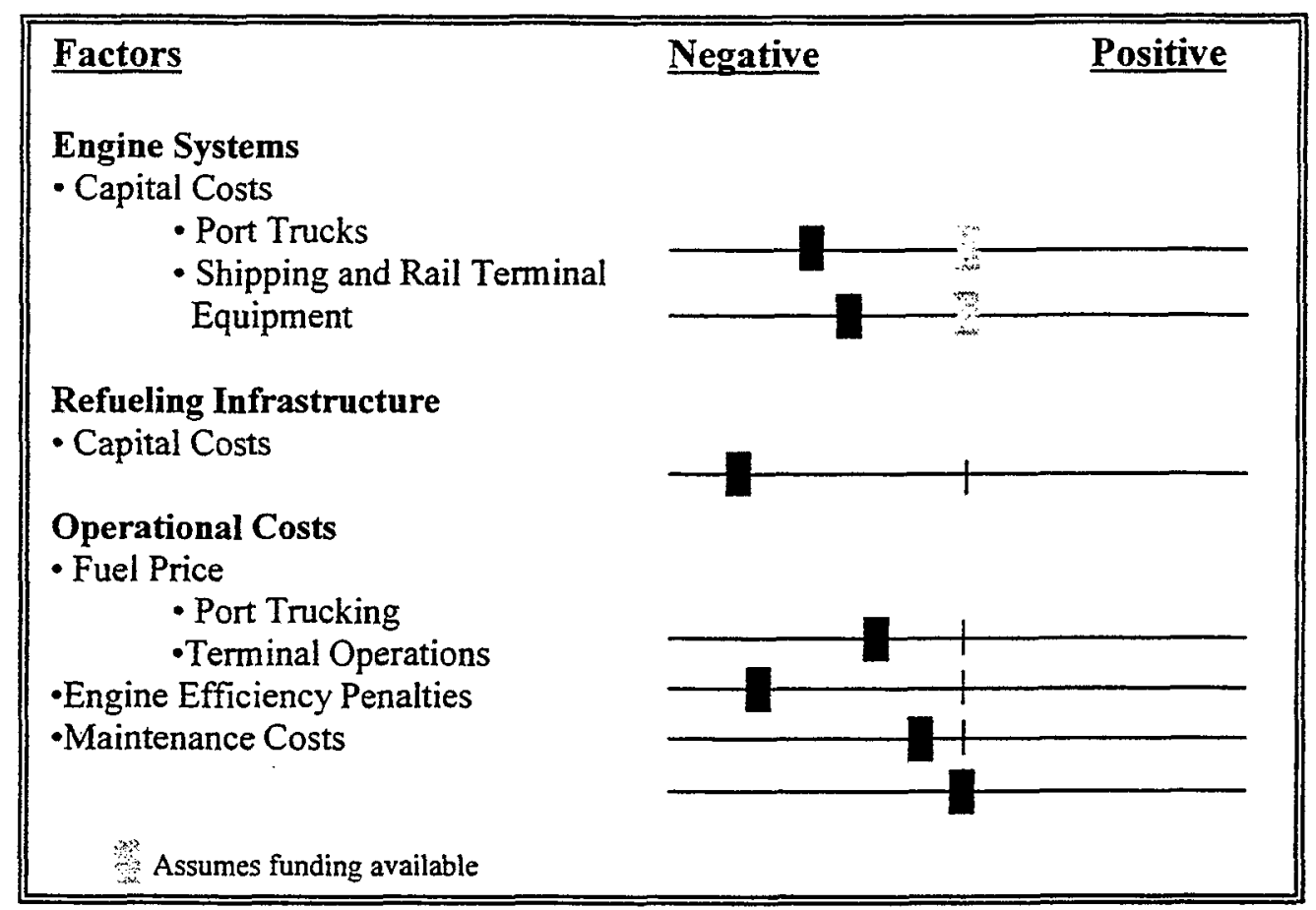

\subsection{Environmental Feasibility}

Emissions concerns represent one of, if not the fundamental motivation for evaluating the potential for LNG use at the Ports and beyond. As earlier noted, LNG engines typically produce significantly fewer NOx and PM emissions than their diesel counterparts. Carbon monoxide (CO) may also decrease, depending on the application and engine, while hydrocarbon (HC) emissions may be slightly increased. In this section, CALSTART presents emissions estimates for the equipment types operating at the Ports, as well as the potential changes in these emissions under various LNG utilization scenarios. These figures are based upon the vehicle operation and specification information contained in Chapter 2, coupled with official emission factors from CARB. The methodologies and factors used to produce these estimates are the same ones utilized by $C A R B$ to determine funding eligibility under the new Moyer Program. (All emissions calculations and methodologies are described in Appendix E).

Although emission estimates are presented for all four of the criteria pollutants presented above, most discussion focuses on the potential for NOx and PM reductions through the use of LNG technologies. These two pollutants are generally considered the most critical and difficult to address, at least within the two air districts housing the Ports of Los Angeles and Oakland. Historically, some trade-off between NOx/PM and $\mathrm{CO} / \mathrm{HC}$ has been considered acceptable by these regulatory agencies, and has not prevented the funding of a broad range of natural gas vehicle projects. 


\subsubsection{On-Road Trucking}

Port-related on-road trucking activities result in the production of substantial quantities of criteria pollutants. Table 4-4 below presents the emission factors for those heavy-duty diesel and LNG engine systems applicable to the port setting. Because of the recent settlement between diesel engine manufacturers, the EPA and CARB regarding illegal alteration of engine software, CARB has stated that a NOx emission factor of $6.0 \mathrm{~g} / \mathrm{bhp}$-hr will be utilized for all on-road heavy-duty diesel engines produced prior to the settlement. However, CALSTART has elected to use the original emission factors. The emission factors utilized to calculate LNG emissions are those of the Caterpillar/PSA C-12 engine.

Table 4-4: Emission Factors for On-Road Heavy-Duty Vehicles

\begin{tabular}{|c|c|c|c|c|c|}
\hline \multicolumn{2}{|r|}{$\begin{array}{l}\text { Model } \\
\text { Year }\end{array}$} & $\begin{array}{l}\text { NOx } \\
\text { (grams }\end{array}$ & \multicolumn{2}{|c|}{ (grams per brake horsepower-hour) } & $\underset{\text { er-hour) }}{\text { NMHC }}$ \\
\hline \multirow{3}{*}{ 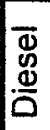 } & pre-1990 & 6 & 0.6 & 15.5 & 0.5 \\
\hline & $1991-1993$ & 5 & 0.14 & 15.5 & 0.5 \\
\hline & $1994+$ & 5 & 0.05 & 15.5 & 0.5 \\
\hline \multicolumn{2}{|c|}{$\mathrm{LNG}^{+}$} & 2.4 & 0.1 & 4.1 & 0.5 \\
\hline
\end{tabular}

† CARB Heavy Duty Trucking Emission Standards

¥ Caterpillar C12 LNG Engine Certification Data

Estimated annual emissions of NOx, PM, CO and $\mathrm{HC}$ from trucking activities at each of the two ports are found in Table 4-5. For the purposes of these calculations, all vehicles are assumed to operate 5 days per week, 50 weeks per year.

Table 4-5: Emissions From Port Related Trucking Fleet

\begin{tabular}{|lcccc|}
\hline & NOx & PM & CO & NMHC \\
\hline Los Angeles & 3,915 & 340 & 10,573 & 341 \\
Oakland & 1,933 & 160 & 5,220 & 169 \\
\hline
\end{tabular}

As these figures indicate, both fleets produce very large quantities of criteria pollutants. Moreover, because the majority of travel by these vehicles occurs within a relatively small radius of the ports (see Table 2-7), emissions will display a similar degree of concentration. Although this clearly has negative implications for the communities surrounding the ports, it also intensifies both the opportunity and need for utilization of a low-emission technology such as LNG. The series of figures below present estimates of the potential emissions reductions that could be achieved through the use of LNG engine technologies in port trucking. Figure 4-6 compares the annual emissions of two vehicles, one diesel-powered and one LNG-powered, using operational data from each of the Ports. Figures 4-7 and 4-8 present the total annual NOx and PM emissions reductions that could be achieved at different levels of LNG utilization in trucking fleets at the two ports. 
Figure 4-6: Vehicle Emissions, Actual Diesel and Potential LNG

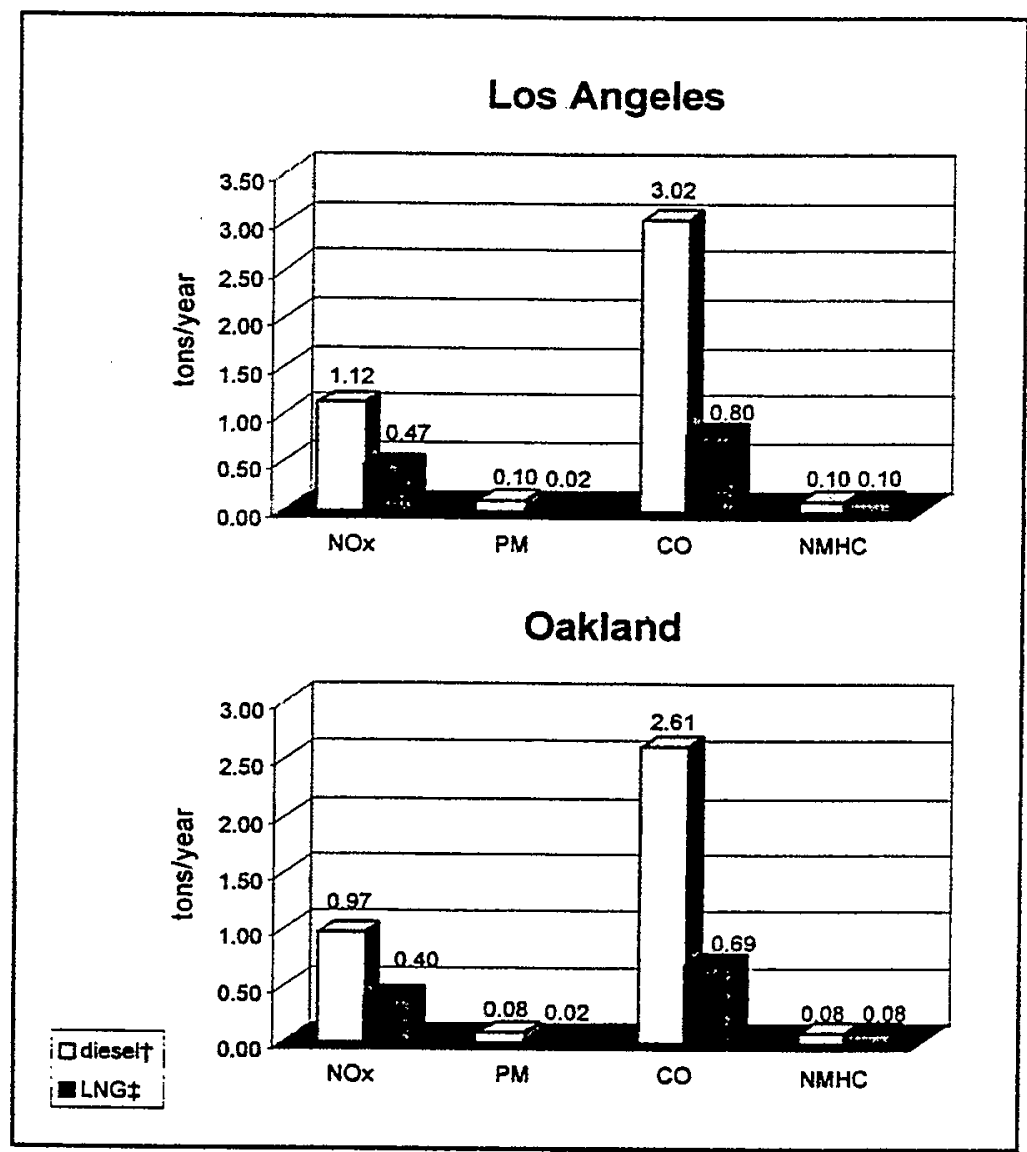

+ Rather than selecting a representative model year and associated emission factors,

total port trucking fleet emissions are divided by the fleet population size

¥ Uses Caterpillar/PSA C-12 engine emission factors combined with port trucking operational data

Figure 4-7: Potential NOx and PM Reductions, Port of Los Angeles Trucking

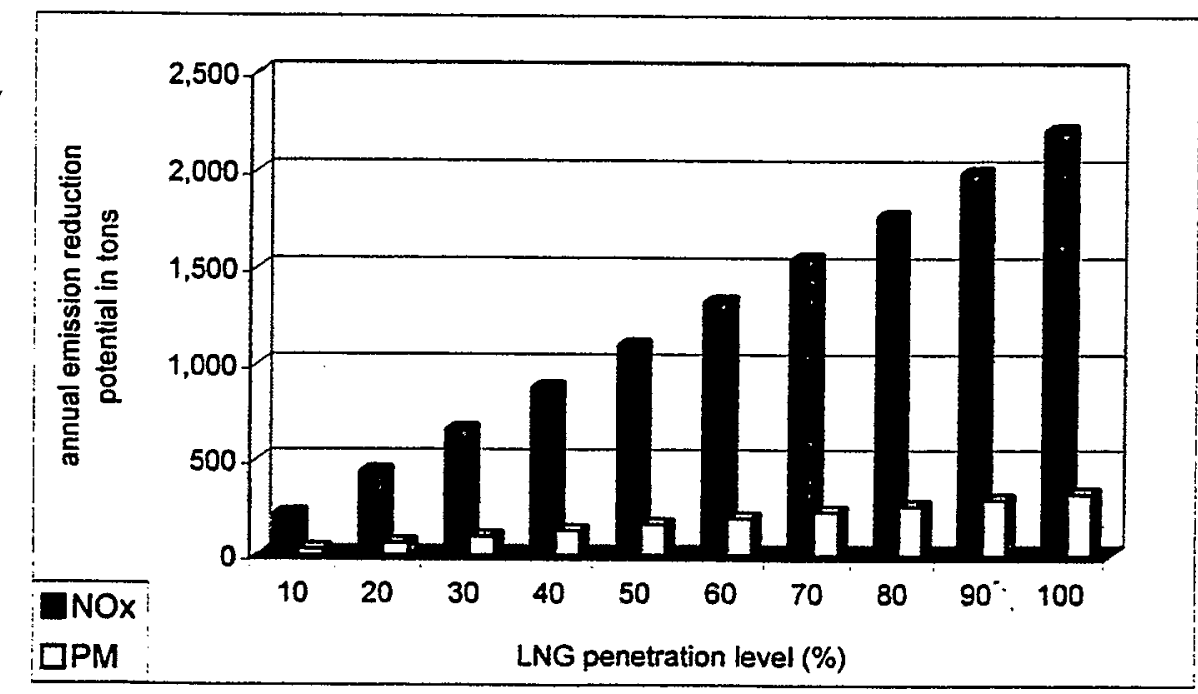


Figure 4-8: Potential NOx and PM Reductions, Port of Oakland Trucking

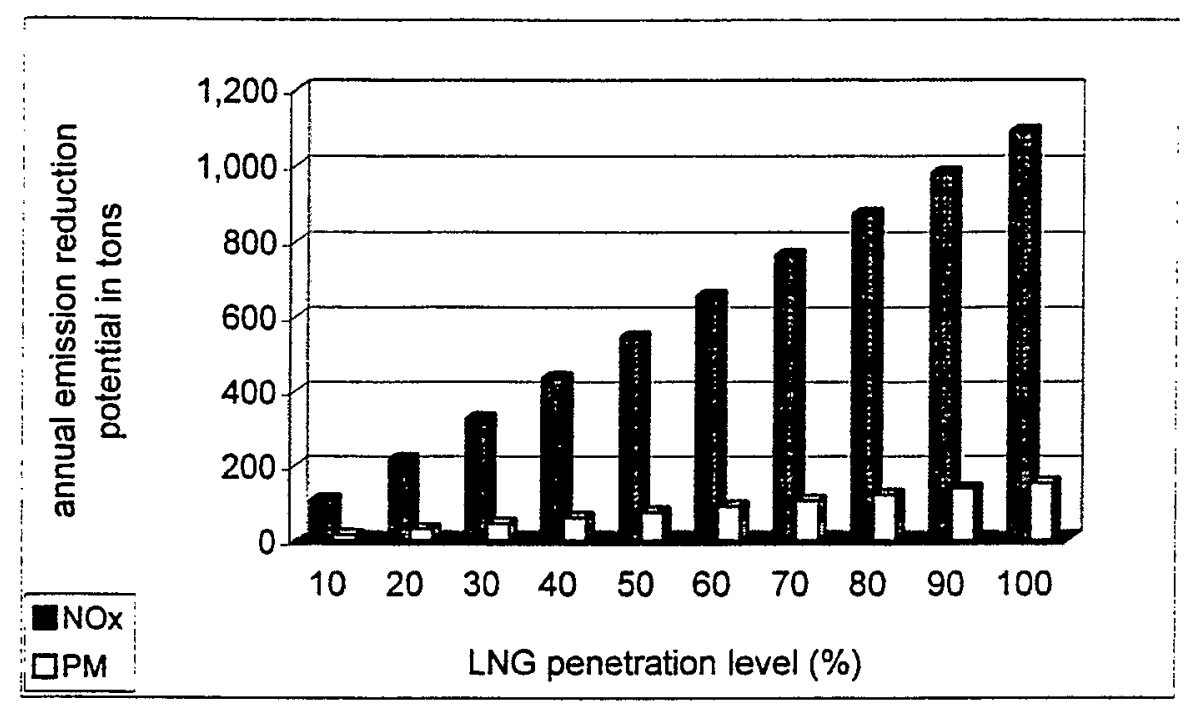

These penetration scenarios evince a number of critical points with respect to the environmental feasibility of LNG use at the Ports. Foremost among these are the very large NOx and PM reductions that would result from LNG use in the port trucking operations. LNG systems offer very substantial emissions advantages over all engine technologies currently in use at the ports, but particularly in comparison to the older diesel units that dominate the port trucking population. Secondly, because of the high emission levels and substantial annual mileages associated with these vehicles, large emission reductions could be achieved even at relatively low levels of LNG utilization. This suggests that the Ports could selectively identify and encourage certain niche operators to use LNG, while still providing tangible emissions reductions. Finally, it is critical to note that these emission reductions could be achieved in a cost-effective manner, as defined by the critical state and local funding sources. Appendix B contains cost-effectiveness calculations for two possible port trucking scenarios: the incremental cost of an LNG system for a new Class 8 truck; and the full LNG repower cost of an existing Class 8 diesel truck. Both scenarios would meet the cost-effectiveness criteria for funding under the Moyer Program.

\subsubsection{Emissions From Port Terminal Operations}

Although the equipment populations utilized in the container handling operations at the shipping and rail terminals are considerably smaller than those of on-road trucks, these units still represent an extremely significant source of criteria pollutants. Prior to 1996, off-road engines were not subject to emissions regulations, allowing manufacturers to concentrate on engine performance without regard for emissions impact. As a result, emissions from off-road units built before 1996 are often twice as much as comparable on-road models. Even after enactment of the 1996 standards, off-road emissions criteria remain far less stringent than on-road ones. Table 4-5 below contains CARB off-road emission factors for heavy-duty diesel equipment, as well as the emissions levels for the Cummins 5.9B dedicated natural gas engine and the Caterpillar/PSA C10 dual-fuel. These engines would fit a broad range of port terminal applications. 
Table 4-6: Emission Factors/Standards for Off-Road, Heavy-Duty Diesel Units

\begin{tabular}{|c|c|c|c|c|}
\hline & \multicolumn{4}{|c|}{$\begin{array}{c}\text { Emission Factor/Standard } \\
\text { (in grams per brake horsepower-hour) }\end{array}$} \\
\hline \multicolumn{1}{|c|}{ Emission Factors } & NMHC & CO & NOx & PM \\
\hline CARB 176-300 HP Standard & 1 & 2.8 & 12 & 0.6 \\
\hline CARB 300+ HP Standard & 0.9 & 2.2 & 13 & 0.6 \\
\hline Cummins B5.9G (150-230 HP) & 0.1 & 2.6 & 1.8 & 0.02 \\
\hline Cummins C8.3G (250-275 HP) & 0.6 & 0.9 & 1.8 & 0.02 \\
\hline CAT C10 (275-350HP) & 1.1 & 7.4 & 2.4 & 0.06 \\
\hline
\end{tabular}

Using the above factors and the standard CARB methodology (described in Appendix E), emissions estimates have been calculated for rail and shipping terminal equipment at the both the ports. Given their different operating parameters, rail and shipping data at each port are presented separately, despite the commonality of equipment types. CALSTART has elected to present emissions estimates for both individual units of each equipment type, as well as a total extrapolated equipment population at each port. These extrapolated populations are generated by calculating the average number of units of each equipment type per facility and using these average fleet sizes for those facilities not included in the original interview survey process. Tables 4-6 and 4-7 below summarize the current emissions from heavy-duty container handling and support equipment used at the various rail and shipping terminals.

Table 4-7: Port of Los Angeles Shipping and Rail Terminals

\begin{tabular}{|c|c|c|c|c|c|c|c|c|c|c|c|}
\hline \multirow{2}{*}{$\begin{array}{l}\text { SHIPPING } \\
\text { EQUIPMENT }\end{array}$} & \multirow{2}{*}{$\begin{array}{l}\text { Typical } \\
\text { HP }\end{array}$} & \multirow{2}{*}{$\begin{array}{c}\text { Annual } \\
\text { Use } \\
\text { Hours }\end{array}$} & \multirow{2}{*}{$\begin{array}{c}\text { Total \# } \\
\text { Vehicles } \\
\text { (extrap.) }^{\mathrm{b}}\end{array}$} & \multicolumn{4}{|c|}{$\begin{array}{c}\text { Emissions per Vehicle } \\
\text { (tons/year) }\end{array}$} & \multicolumn{4}{|c|}{$\begin{array}{c}\text { Fleet Emissions } \\
\text { (tons/year) }\end{array}$} \\
\hline & & & & NOX & PM & NMHC & $\mathrm{CO}$ & NOx & PM & NMHC & co \\
\hline Transtainer & 300 & 500 & 18 & 0.66 & 0.03 & 0.05 & 0.11 & 11.9 & 0.6 & 0.8 & 2.0 \\
\hline Top Pick & 275 & 2400 & 25 & 2.35 & 0.12 & 0.20 & 0.55 & 58.7 & 2.9 & 4.9 & 13.7 \\
\hline Side Pick & 225 & 750 & 19 & 0.55 & 0.03 & 0.05 & 0.13 & 10.5 & 0.5 & 0.9 & 2.4 \\
\hline Heavy Forklift & 275 & 1000 & 12 & 0.73 & 0.04 & 0.06 & 0.17 & 8.8 & 0.4 & 0.7 & 2.1 \\
\hline Yard Tractor & 200 & 2500 & 405 & 1.22 & 0.06 & 0.10 & 0.29 & 495.5 & 24.8 & 41.3 & 115.6 \\
\hline Diesel Generator & 220 & 4750 & 4 & 9.30 & 0.46 & 0.77 & 2.17 & 37.2 & 1.9 & 3.1 & 8.7 \\
\hline TOTAL & & & & & & & & 622.7 & 31.1 & 51.7 & 144.5 \\
\hline
\end{tabular}

\begin{tabular}{|c|c|c|c|c|c|c|c|c|c|c|c|}
\hline \multirow{2}{*}{$\begin{array}{l}\text { RAIL } \\
\text { EQUIPMENT }\end{array}$} & \multirow{2}{*}{$\begin{array}{c}\text { Typical } \\
\text { HP }\end{array}$} & \multirow{2}{*}{$\begin{array}{c}\text { Annual } \\
\text { Use } \\
\text { Hours" }\end{array}$} & \multirow{2}{*}{$\begin{array}{l}\text { Total \# } \\
\text { Vehicles } \\
\text { (extrap.) }\end{array}$} & \multicolumn{4}{|c|}{$\begin{array}{l}\text { Emissions per Vehicle } \\
\text { (tonslyear) }\end{array}$} & \multicolumn{4}{|c|}{$\begin{array}{l}\text { Fleet Emissions } \\
\text { (tons/year) }\end{array}$} \\
\hline & & & & NOx & PM & NMHC & co & NOx & PM & NMHC & co \\
\hline Straddle Crane & 300 & 5900 & 42 & 7.82 & 0.36 & 0.54 & 1.32 & 328.5 & 15.2 & 22.7 & 55.6 \\
\hline Reach Stacker ${ }^{c}$ & 300 & 2300 & 5 & 2.44 & 0.11 & 0.17 & 0.41 & 12.2 & 0.6 & 0.8 & 2.1 \\
\hline Side Pick & 225 & 6000 & 10 & 4.40 & 0.22 & 0.37 & 1.03 & 44.0 & 2.2 & 3.7 & 10.3 \\
\hline Heavy Forklift & 275 & 700 & 3 & 0.51 & 0.03 & 0.04 & 0.12 & 1.5 & 0.1 & 0.1 & 0.4 \\
\hline Yard Tractor & 200 & 5600 & 273 & 2.74 & 0.14 & 0.23 & 0.64 & 748.2 & 37.4 & 62.4 & 174.6 \\
\hline TOTAL & & & & & & & & 1134.5 & 55.4 & 89.7 & 242.9 \\
\hline
\end{tabular}

" Hours use data for Shipping diesel generator and Rail heavy forklift obtained from Port of Oakland data :

${ }^{b}$ Extrapolations for Shipping based on 4 of 6 terminals sampled; extrapolations for Rail based on 3 of 5 terminals

'Also includes flippers, packers and wedges 
Table 4-8: Port of Oakland Shipping and Rail Terminals

\begin{tabular}{|c|c|c|c|c|c|c|c|c|c|c|c|}
\hline \multirow{2}{*}{$\begin{array}{l}\text { SHIPPING } \\
\text { EQUIPMENT }\end{array}$} & \multirow{2}{*}{$\begin{array}{c}\text { Typical } \\
\text { HP }\end{array}$} & \multirow{2}{*}{$\begin{array}{l}\text { Annual } \\
\text { Use } \\
\text { Hours }\end{array}$} & \multirow{2}{*}{$\begin{array}{l}\text { Total \# } \\
\text { Vehicles } \\
\text { (extrap.) }\end{array}$} & \multicolumn{4}{|c|}{$\begin{array}{l}\text { Emissions per Vehicle } \\
\text { (tons'year) }\end{array}$} & \multicolumn{4}{|c|}{$\begin{array}{c}\text { Fleet Emissions } \\
\text { (tons/year) }\end{array}$} \\
\hline & & & & NOx & PM & NMHC & co & NOx & PM & NMHC & CO \\
\hline Transtainer & 300 & 2000 & 10 & 2.65 & 0.12 & 0.18 & 0.45 & 26.5 & 1.2 & 1.8 & 4.5 \\
\hline Straddle Crane & 300 & 3500 & 6 & 4.64 & 0.21 & 0.32 & 0.79 & 27.8 & 1.3 & 1.9 & 4.7 \\
\hline Reach Stacker ${ }^{c}$ & 300 & 3000 & 8 & 3.18 & 0.15 & 0.22 & 0.54 & 25.4 & 1.2 & 1.8 & 4.3 \\
\hline Top Pick & 275 & 2550 & 45 & 2.50 & 0.12 & 0.21 & 0.58 & 112.3 & 5.6 & 9.4 & 26.2 \\
\hline Side Pick & 225 & 1750 & 28 & 1.28 & 0.06 & 0.11 & 0.30 & 36.0 & 1.8 & 3.0 & 8.4 \\
\hline Heavy Forklift & 275 & 650 & 18 & 0.48 & 0.02 & 0.04 & 0.11 & 8.6 & 0.4 & 0.7 & 2.0 \\
\hline Yard Tractor & 200 & 1950 & 298 & 0.95 & 0.05 & 0.08 & 0.22 & 282.7 & 14.2 & 23.7 & 66.4 \\
\hline Diesel Generator & 220 & 4750 & 28 & 9.30 & 0.46 & 0.77 & 2.17 & 260.4 & 13.0 & 21.7 & 60.8 \\
\hline TOTAL & & & & & & & & 779.7 & 38.8 & 64.0 & 177.2 \\
\hline
\end{tabular}

\begin{tabular}{|c|c|c|c|c|c|c|c|c|c|c|c|}
\hline \multirow{2}{*}{$\begin{array}{l}\text { RAIL } \\
\text { EQUIPMENT }\end{array}$} & \multirow{2}{*}{$\begin{array}{c}\text { Typical } \\
\text { HP }\end{array}$} & \multirow{2}{*}{$\begin{array}{l}\text { Annual } \\
\text { Use } \\
\text { Hours" }\end{array}$} & \multirow{2}{*}{$\begin{array}{l}\text { Total \# } \\
\text { Vehicles } \\
\text { (extrap.) }\end{array}$} & \multicolumn{4}{|c|}{$\begin{array}{l}\text { Emissions per Vehicle } \\
\text { (tons/year) }\end{array}$} & \multicolumn{4}{|c|}{$\begin{array}{l}\text { Fleet Emissions } \\
\text { (tons/year) }\end{array}$} \\
\hline & & & & NOX & PM & NMHC & co & NOx & PM & NMHC & co \\
\hline Straddle Crane & 300 & 3800 & 6 & 5.04 & 0.23 & 0.35 & 0.85 & 30.2 & 1.4 & 2.1 & 5.1 \\
\hline Reach Stacker ${ }^{c}$ & 300 & 3000 & 5 & 3.18 & 0.15 & 0.22 & 0.54 & 15.9 & 0.7 & 1.1 & 2.7 \\
\hline Side Pick & 225 & 1400 & 1 & 1.03 & 0.05 & 0.09 & 0.24 & 1.0 & 0.1 & 0.1 & 0.2 \\
\hline Yard Tractor & 200 & 3500 & 33 & 1.71 & 0.09 & 0.14 & 0.40 & 56.5 & 2.8 & 4.7 & 13.2 \\
\hline TOTAL & & & & & & & & 103.7 & 5.0 & 8.0 & 21.2 \\
\hline
\end{tabular}

- Hours use data for Rail reach stacker and side picks obtained from Port of LA rail data

- Extrapolations are based on 7 of 9 terminals sampled

'Also includes flippers, packers and wedges

Although nearly all of the engines currently in use in these terminal applications are off-road models, there are no significant technological barriers to their replacement with certified on-road natural gas systems. These on-road units could be installed on new vehicles coming into port service or during the repowering of existing equipment. This exchange of off-road diesel for onroad natural gas systems would result in very sizable reductions in NOx and PM emissions. Given the high capital costs associated with most container-handling equipment and their very limited populations, however, LNG technologies face serious penetration barriers in most applications at the port terminals, above and beyond the issue of their operational economics. Terminal operators will likely be very reluctant to experiment with costly and scarce units. As a vehicle class, however, yard tractors appear to be an exception to the above characterization and may provide an excellent beachhead for LNG use in the terminal operations. The units are plentiful, relatively inexpensive and have duty cycles that closely match existing LNG applications. Moreover, as a vehicle class, they are responsible for roughly $71 \%$ and $38 \%$ of all NOx emissions at the Port of Los Angeles and Port of Oakland rail and shipping terminals, respectively. Figures 4-9 and 4-10 below show the reductions in NOx and PM emissions that could be achieved at various levels of LNG utilization within this vehicle class. 
Figure 4-9: Potential NOx and PM Reductions, Port of Los Angeles Yard Tractors

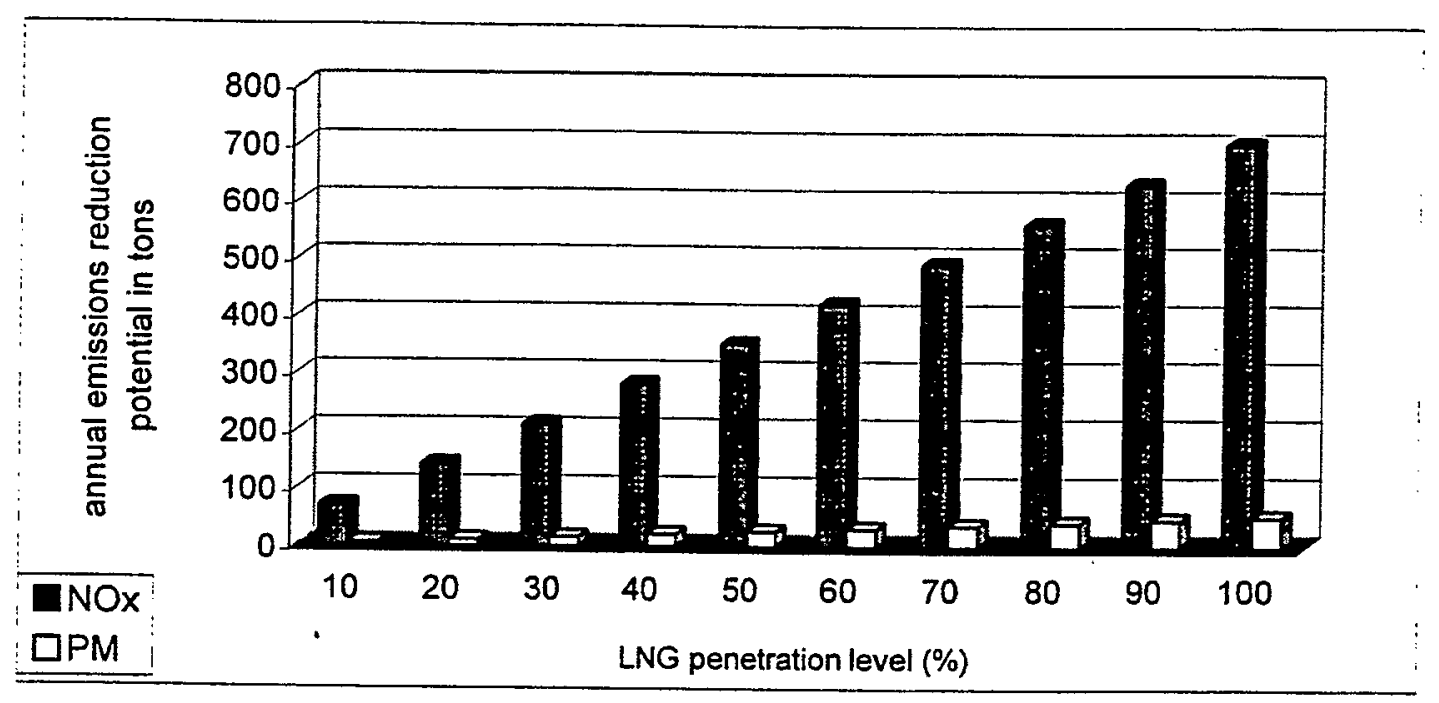

Figure 4-10: Potential NOx and PM Reductions, Port of Oakland Yard Tractors

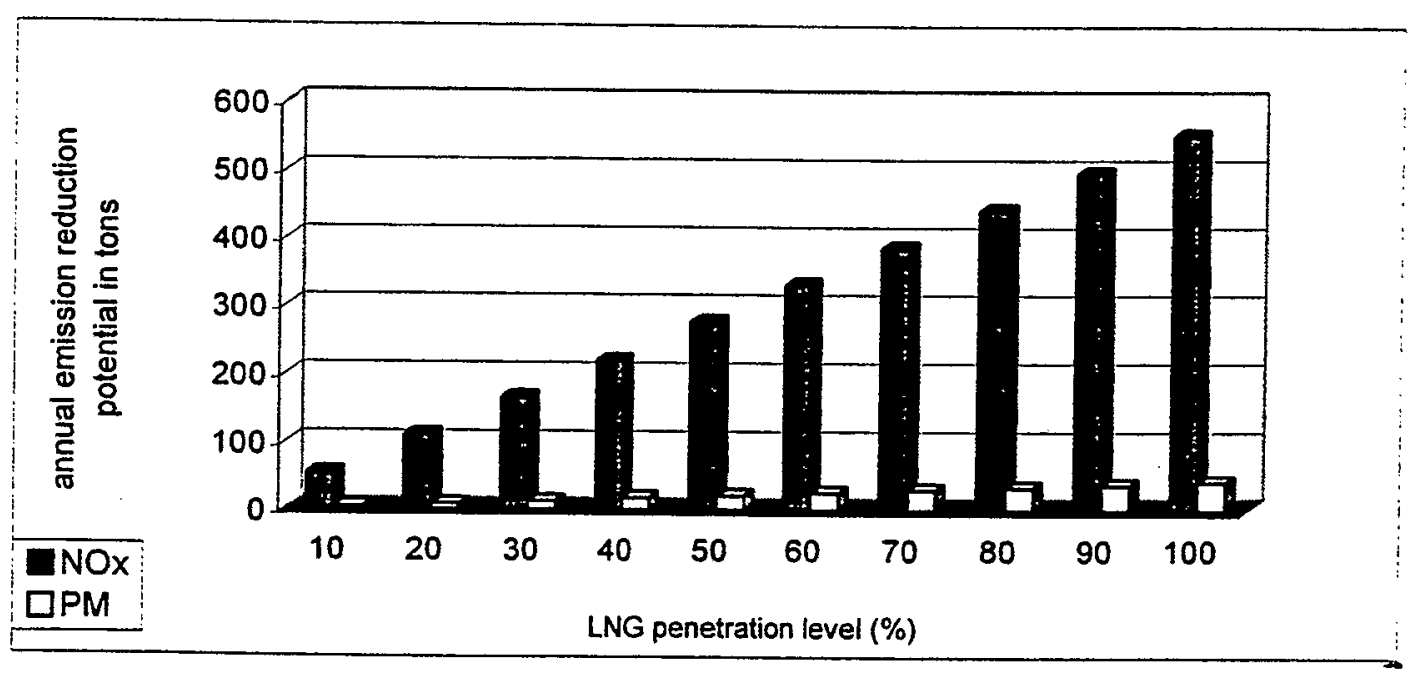

The data above indicates that even limited utilization of LNG equipment in port operations would result in substantial emissions reductions. Operational economics aside, the successful utilization of LNG in yard tractors could also facilitate the transition to a more widespread use of LNG systems in terminal applications and even greater emissions reductions. The emissions characteristics of current terminal units, combined with their high annual hours of operation, also provide the opportunity to realize these reductions in an extremely cost-effective manner. Assuming 3500 hours of use annually, a $\$ 36,000 \mathrm{LNG}$ repower of a diesel yard tractor would 
yield NOx reductions at a cost of $\sim \$ 5300 /$ ton. (See Appendix B for the complete calculation and list of assumptions.) This falls well below CARB's current cost-effectiveness ceiling of $\$ 12,000 /$ ton of NOx reduced.

In addition to being cost-effective, emissions reductions from port terminal vehicles would also be highly concentrated. Unlike on-road vehicles which disperse their emissions, and in the case of LNG trucks their reductions across wide areas, terminal vehicles are bound to the immediate area of the port. Any emissions reductions realized by this vehicle population will directly benefit the communities immediately surrounding the Ports, as well as the larger air cachement areas. Given the recent diesel lawsuits, this localized impact could be an important consideration.

\subsubsection{Summary of Environmental Feasibility}

The preceding data (summarized below in Figure 4-11) indicate that heavy-duty vehicle operations at the Port of Los Angeles and Port of Oakland currently produce significant amounts of criteria pollutants, including approximately 5,672 and 2,816 tons of NOx annually, respectively. Moreover, owing to the confinement of terminal vehicles and the travel patterns of port truckers, the vast majority of these pollutants are emitted within a 50-mile radius of the Ports. In addition to contributing to the overall air quality problems within their respective air basins, these substantial emissions volumes may render port facilities and operators vulnerable to the same type of legal action currently being directed at supermarket distribution facilities. While the vehicles and equipment analyzed here represent only one subsection of port operations and port emissions, they are generally considered the most 'actionable' areas in terms of achieving emissions reductions.

The use of LNG systems in heavy-duty vehicle operations at the Ports could result in substantial emissions reductions, even if the technology's penetration was relatively limited. Emissions of NOx and PM, the most critical mobile source criteria pollutants in the Ports' respective air districts, would generally be reduced by over $50 \%$ on a per vehicle basis with use of LNG. Emissions reductions from LNG use would accrue with particular rapidity in the off-road terminal vehicle sector due to the extremely high pollution allowances traditionally afforded to these classes of equipment.

Figure 4-11: Factors Impacting Environmental Feasibility

\begin{tabular}{|lll|}
\hline Factors & Negative & Positive \\
Potential Emissions Reductions & & \\
- On-Road Trucking & & \\
- Terminal Vehicles \& Equipment & & \\
\hline
\end{tabular}




\subsection{Other Factors Impacting Feasibility of LNG Use}

While the availability and cost of suitable technologies, the comparative cost of their operation and the environmental impact of their use represent the critical feasibility criteria, there are a number of other factors that may also have a significant impact on the potential for LNG use at the Ports. The most salient of these additional factors, including regulatory and legislative measures, the unique characteristics of ports and port operations, competing technologies, safety perceptions and logistical issues relating to LNG infrastructure, are addressed below.

\subsubsection{Characteristics of Port Trucking Operations}

CALSTART's survey efforts revealed a number of characteristics of the port-related trucking industry that might impact the utilization of LNG. Table 4-9 below summarizes some of the key findings regarding this population.

\section{Table 4-9: Characteristics of Port Trucking}

\begin{tabular}{|c|c|c|}
\hline & $\begin{array}{c}\text { Port of } \\
\text { Oakland }\end{array}$ & $\begin{array}{c}\text { Port of Los } \\
\text { Angeles }\end{array}$ \\
\hline $\begin{array}{c}\% \text { of business } \\
\text { performed by } \\
\text { ownerfoperators }\end{array}$ & $82 \%$ & $71 \%$ \\
\hline $\begin{array}{c}\text { \% of vehicles } \\
\text { with access to } \\
\text { on-site fueling }\end{array}$ & $41 \%$ & $30 \%$ \\
\hline $\begin{array}{c}\text { \% of vehicles } \\
\text { with access to } \\
\text { on-site mechanic }\end{array}$ & $50 \%$ & $7 \%$ \\
\hline $\begin{array}{c}\text { Average vehicle } \\
\text { age at time of } \\
\text { purchase }\end{array}$ & 7 years & 7 years \\
\hline
\end{tabular}

\section{Composition of Port Truckers}

The relatively high percentage of owner/operators raises a number of questions regarding the feasibility of LNG use in trucking applications. This population is described by trucking company representatives as having high rates of entry and exit. Because, in the absence of public LNG refueling stations, users of LNG engines are effectively bound to the company fueling station and hence to the company itself, owner/operators would likely be reluctant to utilize the technology. These same constraints apply to vehicle maintenance as well. LNG technologies require skilled and well-trained mechanics familiar with the systems. Without commercial repair facilities, service could only be performed by trained company mechanics, further constraining the mobility of this population and the likelihood of their adopting the technology.

The high percentage of owner/operators at the Ports is reflective of the economics of port trucking operations as a whole. As noted, profit margins are extremely narrow in these operations and most firms are unable to support the costs of maintaining company vehicles and staff drivers. By utilizing owner/operators, trucking firms are able to transfer much of the economic risk and uncertainty inherent to the shipping industry to the drivers. Nor are owner/operators well-rewarded for assuming this risk, typically earning only $\$ 8-10 / \mathrm{hr}$. These factors suggest that the owner/operator population will be unable to utilize any technology that carries a cost or flexibility penalty. If, in fact, this population is to be encouraged to utilize less polluting technologies, be they LNG or any other system, the change will have to be cost-neutral at worst. 
It should also be recognized that the decentralized nature of this group will undoubtedly complicate any outreach efforts that the Ports or other interested parties may wish to undertake. This could prove to be an important consideration. A successful LNG program in this arena would require port authorities to play an active role in addressing various logistical concerns and helping potential users obtain funding.

Despite the predominance of owner/operators, the Ports' trucking populations appear to be far more heterogeneous than was originally assumed. Certain niche operations are far better capitalized and more closely resemble traditional long-haul trucking operations in their use of staff drivers, newer equipment and on-site fueling and maintenance. Firms of this type could provide an excellent entry point for LNG technology at the Ports. An initial focus on higher-end niche operations would also allow for more targeted (and probably more effective) outreach and funding efforts. There may, however, be some equity issues associated with this approach, especially if other incentives are put in place to benefit those firms using alternative fuel technologies. This issue will be discussed in greater detail in the following chapter.

\section{Refueling and Maintenance}

The low percentages of operations with on-site fueling and maintenance facilities also pose a challenge to LNG utilization at the Ports, as these two characteristics have traditionally been considered critical measures of the suitability of particular operations for LNG use. In the case of the Ports, however, this conventional thinking may not apply. Regardless of whether they are using owner/operators or staff drivers, new trucks or old, few port trucking operations would be able to assume the upfront costs associated with LNG refueling infrastructure and maintenance training. A few of the niche operators mentioned above may be able to utilize this conventional centralized system and should be encouraged to do so. However, an alternative strategy that capitalizes directly on the unique aspects of the port trucking population could also be utilized. By securing relatively small commitments to use LNG from a number of different operators, the Ports could quickly aggregate sufficient demand to merit the development of commercial fueling and maintenance facilities. This would distribute the financial risk, ensure equity among trucking operators and provide a solid foundation upon which to build an alternative fuels program at the Ports. This strategy will be discussed in greater detail in the following chapter.

\section{Purchase Habits}

Current purchase habits, in particular the reliance on used equipment, pose a significant barrier to LNG use by port trucking operators. Nor is there reason to expect any alteration of this behavior, given the economics of port sector. Numerous port operators asserted that without a secondhand LNG market, they could not hope to access or utilize the technology. At present, however, there is no used LNG vehicle market, due to an absence of both supply and demand. This could potentially change, but only following significant expansion of the new LNG vehicle market.

As noted earlier, it is technically feasible to repower existing diesel vehicles with LNG engines, at a cost of $\$ 50,000-70,000$ per vehicle. Even at this price, most repowers of port trucks would be deemed cost-effective under the current Moyer Program funding criteria. (See Appendix B for a sample calculation.) This does not, however, ensure that they would receive funding. Other scenarios postulated here - the LNG repower of an existing yard tractor and the incremental cost of a new LNG Class 8 tractor - would be far more cost-effective from a pollution reduction perspective. Ultimately, the viability of Class 8 repowers will depend on the competitiveness of funding applications within the individual AQMDs.

Again, the diversity of the port trucking populations may provide opportunities to overcome the barrier posed by reliance on used equipment. If the Ports were able to enlist early adopters 
among some of the higher-end niche operators, their fleets could eventually become a source of used LNG product. Conversely, having a ready market demand for their used LNG vehicles (which would otherwise have to be converted back to diesel for resale) could also provide a measure of resale security to purchasers of new vehicles. However, this could severely limit the pace of LNG technology penetration in port trucking operations.

The barrier posed by the port trucking community's current reliance on used product is not insurmountable. It does, however, pose serious challenges to the use of LNG equipment in this arena. Whether through repowering, development of an 'internal' used vehicle market or other measures discussed in the following chapter, this must be specifically addressed as part of any effort to foster LNG use at the Ports.

\subsubsection{Characteristics of Terminal Operations}

In many respects, the terminal operations represent an ideal application for LNG. All vehicles remain completely terminal-bound, are fueled and maintained on-site and have power demands within the range of available LNG equipment. All equipment sees heavy and regular use, thereby reducing potential fuel losses from boil-off and venting. Moreover, the terminals are highly visible sources of diesel emissions and could therefore be vulnerable to legal attacks from the surrounding communities. LNG use, particularly in on-road engines, could dramatically reduce emissions from and improve the public image of a port terminal operation. Despite these positive attributes, there are certain aspects of port terminal operations, above and beyond the aforementioned economic issues, that could represent barriers to the use of LNG in these applications. Most important among these are the high cost and low per class populations of terminal equipment, the high cost of training maintenance personnel on new technology and space constraints.

\section{Characteristics of Terminal Vehicle Populations}

As detailed in Chapter 2, most pieces of port terminal equipment are specialized, expensive and exist in relatively small numbers at each terminal. These characteristics will impact any effort to introduce LNG systems into this arena. During the interview process, terminal operators made patent their extreme reluctance to experiment with this equipment. With relatively few units of each vehicle class operating at any given terminal, reliability becomes a critical component of overall operational efficiency and profitability. The high capital costs associated with these equipment classes also contribute to this risk aversion.

While these characteristics do have a negative impact on the feasibility of widespread use of LNG technologies at the terminals, they do not preclude its introduction. As noted, yard tractors represent an exception to many of the characteristics described above. Each terminal has a relatively large population of the vehicles, new units cost only $\$ 40,000-50,000$, and their duty cycles closely resemble conventional LNG applications. This vehicle class provides an excellent, low-risk forum in which to evaluate the in-use suitability of LNG at the Ports. Moreover, by virtue of its high hours of operation and large populations, this class is responsible for a significant share of all emissions from container handling equipment. If LNG was successful in this application, it could easily disperse into other, more specialized parts of the terminal fleets.

\section{Labor Costs and Associated Issues}

The International Longshore and Warehouse Union (ILWU) plays a central role in the workings of both Ports. At present, the position of this union is very strong. As a result, wages among its members are high and the organization has a good deal of authority over operations at 
the individual shipping terminals. This has two clear implications with regard to the use of LNG in the Port setting. Foremost, the labor costs associated with training operating and particularly maintenance personnel on new technologies will act as a deterrent to LNG use at the terminals. This point was made by nearly all of the terminal operators interviewed by CALSTART. A broad range of strategies could be employed to overcome this barrier, including port-sponsored training programs and subsidization of temporary replacement-labor costs. However, policy measures must specifically address this issue if terminal operators are to buy-in to an alternative fuels program.

The other clear implication of the current labor environment is that the ILWU must be at least a tacit partner in the promulgation of any alternative fuels program undertaken by the Ports. This will entail careful design of policy measures so as to minimize any disruptive impact on current labor agreements and maximize benefits to port workers. Reduced on-dock emissions and equipment noise are a direct and immediate benefit of LNG use, and should help to leverage ILWU support for an LNG program. Nonetheless, there will almost undoubtedly be union concerns regarding the fuel's use.

\section{Space Constraints}

Although unlikely to pose a major barrier to LNG use at most terminals, space constraints could add to terminal operators' reluctance to utilize the fuel. On-dock space is both expensive and limited, particularly in grounded shipping terminals. Actual space requirements will depend on specifications of the particular refueling system. However, it must be noted that this represents an additional incremental cost to LNG, given existing fuel systems would likely remain in operation.

\subsubsection{Legislative and Regulatory Action}

Legislative action and the subsequent promulgation of new regulation, emissions standards and funding opportunities play a critical role in shaping the feasibility of LNG use in heavy-duty applications. Appendix $F$ contains a comprehensive listing of the existing and pending legislative measures salient to the present port study. In general, existing measures have provided considerable opportunities to the heavy-duty clean transportation industry and will continue to impact its evolution. Funding from federal, state and local sources has been instrumental in the development and utilization of a variety of low-emission technologies, including LNG. In addition, state and federal emission standards have created performance criteria by which to compare heavy-duty engine technologies and subsequently reward those with the desired emissions characteristics.

Despite these positive impacts, existing efforts have not been sufficient to overcome the capital and operational costs associated with LNG use and stimulate the development of a robust and self-sustaining market for the technologies evaluated here. However, a number of pending measures presented in Appendix $F$ have the potential to significantly alter the economics associated with LNG use. Federal bills HR 970, HR 3766 and Senator Rockefeller's Alternative Fuel Promotion Act all contain provisions that would extend significant tax credits to users and/or sellers of alternative fuels. The latter two would offer a tax credit of $\$ .50 /$ gasoline gallon equivalent of alternative fuel purchased or sold, respectively. This would equate to a credit of roughly $\$ .55 / \mathrm{DEG}$, and would reduce the current price of $\mathrm{LNG}$ in California to approximately \$.28-.47/DEG for off-road applications and \$.68-.87/DEG for on-road ones. At these prices, LNG use would almost certainly result in substantial cost savings for all of the applications discussed here. Tax credits might also be extended to a portion of the construction costs of LNG refueling infrastructure. At present, the prospects of all three bills are uncertain, according to $\mathrm{Mr}$. 
Jeffrey Clarke, Policy and Regulatory Analysis Director for the Natural Gas Vehicle Coalition. However, he also argues that the submission of these bills has heightened congressional awareness of the benefits of and need for alternative fuel technologies.

In California, a number of recent legislative and regulatory actions have occurred that should positively impact LNG use in the state. The aforementioned Moyer Program will provide \$25 million in new funding for emissions reductions from the heavy-duty vehicle sector. Although this funding will not transform the competitive relationship between LNG and diesel as would the above tax credits, it nonetheless represents the single largest funding opportunity for heavy-duty LNG projects in California's history. Moreover, if the program proves successful in achieving cost-effective emissions reductions from this vehicle class it could well be extended and enlarged, according to CARB officials. ${ }^{6}$ The California Energy Commission has also recently announced plans to issue a request for proposals for $\$ 250,000$ in funding dedicated to the development of a LNG liquefaction plant in California. In addition, requests for proposals will also be issued for $\$ 500,000$ in funding for heavy-duty LNG vehicle refueling infrastructure. This latter funding, which is intended to compliment the Moyer Program's vehicle funding, will grant up to $\$ 100,000$ to each of five refueling facilities.

On the regulatory end, there has been considerable activity regarding diesel emissions in California. The Natural Resources Defense Council (NRDC) and the Coalition for Clean Air (CCA), in conjunction with the California attorney general's office recently filed suit against four large supermarket chains, alleging violation of Proposition 65 stipulations. Both the NRDC and CCA have explicitly stated that their intention is to force the utilization of clean fuels, including LNG. This has succeeded to some degree, as defendants have committed to purchasing and operating over 100 new Class 8 LNG tractors. These actions are further strengthened by CARB's recent identification of diesel particulate emissions as a toxic air contaminant (TAC). This ruling could have a dramatic impact on the utilization of LNG as an alternative to diesel-fueled vehicles and engines. While the listing itself carries no proscriptive measures, ARB must now begin the process of determining what further regulatory actions may be necessary to protect the public from exposure to the toxic contaminants from diesel-fueled vehicles and engines. ARB will also develop guidelines to assist risk managers in evaluating the health impact of exposure to these toxic air contaminants. This will clearly heighten public awareness of the health issues associated with diesel use and could result in additional litigation. While this will not result in an overnight shift to cleaner fuels, current diesel-dependent fleets may increase LNG utilization in order to avoid such potential risk and litigation.

\subsubsection{Characteristics of Ports}

Two characteristics of the Ports themselves, as opposed to the operations within them, also have bearing on the feasibility of LNG use. The first of these features has to do with the nature of the relationship between the Port authorities and the various terminal leasees. Under their current lease structures, the Ports are not involved in the day to day operations or environmental management of the terminals. Throughout the data gathering process of the project, Port officials have continually stressed their lack of leverage over and knowledge of the terminal operations. Therefore, even if the Ports identify the need for and basic feasibility of LNG utilization, they have no means of forcing compliance/participation on the part of the terminal operators.

\footnotetext{
${ }^{6}$ CARB workshop on the Carl Moyer Memorial Air Quality Standards Attainment Program, November 1998.
} 
The second critical feature of the Ports is the highly competitive environment in which they must operate and, hopefully, thrive. Roughly $75 \%$ of the containerized cargo passing through the Port of Oakland is discretionary, meaning it could just as easily pass through another port facility. ${ }^{7}$ This percentage is lower in Los Angeles due to the size of the local market; however, at roughly $50 \%$, it is still considerable. ${ }^{8}$ Retaining and ideally expanding their share of this discretionary cargo is critical to the financial well-being of the Ports (and arguably to their surrounding communities as well). This implies that even were the Ports to wield and exercise greater authority over their terminal operators, they would have to do so very judiciously. Any policy that negatively impacts the economic competitiveness of a particular terminal or port could result in a loss of some portion of this discretionary traffic.

There are, however, a range of incentive strategies that the Ports could utilize to encourage the voluntary utilization of low emission technologies such as LNG. Terminals leases typically run five to ten years and are subject to competitive renegotiations. In addition, both Ports are currently undertaking aggressive modernization and expansion programs that will result in the creation of new berths and reconfiguration of existing facilities. Were the Ports to develop and implement an alternative fuels program, incentive strategies could be imbedded into the leases for these new facilities, and into existing leases at the time of renewal.

\subsubsection{Competing Technologies}

At present, LNG is the most promising low-emission technology for heavy-duty applications, delivering dramatic reductions in NOx and PM emissions while closely matching the performance characteristics of conventional diesel systems. There are, however, a broad range of technologies and fuels under development or in the early stages of testing that could challenge the primacy of LNG as a low-emission, heavy-duty technology. Although it would undoubtedly take some time for even the most advanced of these technologies to penetrate the port sector, they do have the ability to impact the long-term viability of LNG use and for this reason are discussed here.

\section{Fuel Cell Technology}

Fuel cells are electrochemical devices that convert chemical fuels into electrical energy. The fuel cell reaction is a highly efficient, clean reaction combining hydrogen with oxygen and emitting water vapor as its only byproduct.

Fuel cells come in a variety of different configurations, with the cells generally being classified based on the electrolyte that is used. The electrolyte is one of three key components of a fuel cell: the other two being the anode, or negative electrode, and the cathode, or positive electrode. There are a number of different kinds of fuel cells that are being considered for transportation applications ranging from automobiles to heavy trucks and even marine vessels. Of these, the proton-exchange membrane (PEM) fuel cell is considered the leading candidate for transportation applications. PEM fuel cells are being looked at by most of the major automotive companies, and numerous demonstration cars have been built. On the heavy-duty side, PEM fuel cells have been used to power transit buses and are being studied as an option for propulsion power in heavy trucks. Two major stumbling blocks currently remain for fuel cells, cost and fuel choice. The cost has been falling dramatically, and many experts predict that fuel cells will become competitive with currently available technology sometime in the next 5-15 years. The fuel choice

\footnotetext{
${ }^{7}$ Multitrans Transportation Consultants, Intermodal Report, prepared for the Metropolitan Transportation Commission, December 1994.

${ }^{8}$ Per conversation with Jeff Leung, Public Affairs Officer, Port of Los Angeles, February 1999.
} 
is another issue entirely. Conventional PEM fuel cells are capable of using only hydrogen as a fuel. To use other fuels, a reformer must be included to convert complex hydrocarbon fuels to hydrogen rich gas that can be used by a fuel cell.

In general, fuel cells remain at least 5-15 years from commercialization, depending in large part on the amount of research that is devoted to the technology. Fuel cells are fuel flexible, when reformers are considered, and capable of running on natural gas. Consequently, while fuel cells are competitive long-term with dedicated LNG engines, natural gas infrastructure can be complimentary to fuel cell use.

\section{Hybrid and Electric Technologies}

Hybrids

A hybrid vehicle utilizes an engine assisted by an energy storage device to propel the vehicle. Some of the energy storage devices under development include batteries, flywheels, and ultracapacitors. This shared propulsion of a vehicle results in reduced emissions and increased fuel economy. This is achieved a number of ways; a smaller engine can be used because the energy storage device provides additional energy needed under load conditions, the engine is optimized at steady state, and regenerative breaking can be used to store energy normally lost.

The development of hybrid vehicles is dictated by the development of the different component technologies. Each of the components are at different stages of development. One of the most commonly used energy storage devices are batteries. At this time only lead-acid, nickel-cadmium and nickel-metal hydride batteries are fully commercialized. In addition to batteries, flywheels and ultracapacitors are alternative energy storage devices under development. Both of these technologies are in prototype phases.

\section{Electric}

Pure electric powered vehicles utilize many of the same components as hybrid vehicles. Because both types of vehicles use electrical energy, many of the components being developed for electric vehicles and hybrid vehicles can be used on the different vehicles without much difficulty.

One big advantage for pure electric vehicles is that there are no tail-pipe emissions associated with the technology. However, the weight and short-life of current battery technology make pure electric heavy-duty vehicles difficult. There are some small electric transit buses in use, but the energy requirements, and weight limits of larger trucks make battery powered electric propulsion difficult to achieve.

\section{Diesel Technologies}

Currently there is considerable activity in the diesel industry to develop and commercialize new fuels and technologies that will meet upcoming emission standards. Because of the entrenched position of diesel technology and infrastructure, these new technologies have a strong possibility of dominating the Class 8 , clean technology market. If these technologies are commercialized, it will make it difficult for other developing technologies and alternative fuels to compete. The developing diesel technologies generally fall into two categories, fuel technologies and vehicle technologies.

\section{Fuel Technologies}

There are three main diesel fuel options that are cleaner than conventional diesel, biodiesel, dimethyl ether (DME) and synthetic diesel. Biodiesel is generally blended with regular diesel and results in increased NOx emissions, but decreased hydrocarbon, carbon monoxide and sulfur 
emissions. Currently the price of biodiesel is two to three times higher than conventional diesel. ${ }^{9}$ The fuel also has different corrosive properties and could cause corrosion problems. Dimethyl ether (DME) can be synthesized from a variety a sources including, natural gas, renewable feedstock and waste. DME results in lower NOx, particulate and toxic emissions, but may cause higher carbon monoxide and hydrocarbon emissions. ${ }^{10}$ The use of DME as a vehicle fuel is still under development but it is estimated that it would cost about three times the price of conventional diesel. ${ }^{11}$ The last major alternative diesel fuel under development is synthetic diesel, which is synthesized from natural gas, coal and biomass resources. This fuel is converted to a liquid through the Fischer-Tropsch process. The fuel can be blended with conventional diesel or used alone. Some early use of the fuel in California has shown that it does not compromise fuel efficiency. Synthetic diesel costs about $10 \%$ more than traditional diesel and can result in minor NOx reductions and measurable reductions in particulates, hydrocarbons and $\mathrm{CO}^{12}$

\section{Vehicle Technologies}

More advanced electronic controls are becoming a cornerstone for many of the technology advances for diesel engines. Electronic controls enable much more precise control of the fuel injection system. This control allows for improved emissions reductions with only minor fuel economy penalties. Most of these changes result in NOx reductions but can also result in higher particulate emissions. Other methods of reducing NOx include cooling turbocharger air and exhaust gas recirculation (EGR). Catalysts are another method of reducing emissions from diesel engines. Diesel oxidation catalysts primarily reduce particulate matter from diesel exhaust. Lean NOx catalysts are being developed specifically to reduce NOx. The main problem with catalyst technologies is that they can become clogged and therefore less effective. Diesel particulate traps can also be used to reduce emissions. Particulate traps reduce exhaust by filtering particulate matter from the exhaust stream. The use of traps can result in decreased fuel economy and they tend to have durability and reliability problems.

Another option for controlling diesel emission is a high-pressure direct injection technology utilizing natural gas and diesel being developed by Westport Innovations and the University of British Columbia. The system uses diesel as a pilot for the natural gas fuel. Because the system burns primarily natural gas, there are reductions in $\mathrm{NOx}, \mathrm{CO}$ and particulate emissions. Also, the system retains all of the diesel engine characteristics including power and efficiency. If this technology proves to be viable for heavy-duty vehicles, the incremental cost of the vehicle technology should be lower than dedicated CNG or LNG engines, but the cost of the infrastructure would remain the same.

In all likelihood, some combination of these technologies will be necessary if heavy-duty diesel systems are to meet the 2004 emission standards. At present, there is still considerable uncertainty within the diesel engine community as to whether the standards can actually be met, and if so, at what cost. If, in fact, this impact is considerable, as some analysts suggest it will be, LNG systems may become more economically viable.

\footnotetext{
${ }^{9}$ DieselNet Technology Guide, BioDiesel paper, "www.dieselnet.com", December 1998.

${ }^{10}$ DieselNet Technology Guide, Dimethyl Ether paper, "www.dieseinet.com", December 1998.

"DieselNet Technology Guide, Dimethyl Ether paper, "www.dieselnet.com", December 1998.

${ }^{12}$ California Energy Commission, Synthetic Diesel Fuel Fact Sheet, "www.energy.ca.gov", October 1998.
} 


\subsubsection{Ancillary Benefits}

\section{Noise Reductions}

In addition to the previously discussed emissions reductions, a number of ancillary benefits are frequently attributed to LNG use in heavy-duty applications. One of the most tangible of these is the reduced operating noise associated with LNG engine systems, particularly dedicated ones. The John Deere Corporation has published data indicating a $10 \%$ noise differential between natural gas and diesel versions of the same engine. Although data is not available for all the engines presented in this report, these figures are very likely representative of dedicated engines as a whole. Reduced operating noise has a number of important benefits. Most obviously, work area safety is increased and the potential for on-the-job hearing damage is diminished. Several terminal operators interviewed by CALSTART indicated that worker's compensation claims involving hearing damage had increased significantly in recent years and were becoming a cause for concern. In addition to safety, reduced operating noise may allow for increased operational hours in some applications. The ability to start refuse collection earlier in the morning because of reduced noise from natural gas engines was apparently a major factor in the recent decision by the City of Frankfurt, Germany to convert its entire refuse and street cleaning fleet to LNG. $^{13}$

\section{Public Relations}

Natural gas engine systems also result in significantly less visible pollution than diesel ones. Although this attribute is probably of greatest benefit to transit vehicles, reduced visible pollution can play an important role in shaping the surrounding communities' perceptions of the environmental impact of port operations.

Public relations and publicity benefits are considered to be among the most important ancillary benefits to LNG use. Companies employing the technologies garner considerable media interest, which may translate into economic benefits as well as insulation against potential emissionsrelated litigation. In the case of the Ports, efforts to encourage LNG use could help to improve community relations and provide leverage in efforts to secure community support for expansion and modernization efforts. Even more critically, proactive and meaningful initiatives to decrease diesel emissions could provide a bulwark against the type of legal action visited upon supermarket distribution facilities.

\section{Emissions Trading}

Within the South Coast Air Basin, certain emissions reductions achieved through the utilization of LNG technologies can exchanged under the Mobile Source Emission Reduction Credit (MSERC) program, established through the SCAQMD and CARB. This program, which went into effect in 1991, allows qualifying reductions to be used as alternatives to emissions controls on industrial sources, to meet or delay compliance with stationary source requirements, to offset emissions from new or temporary sites or to comply with trip reduction requirements. MSERCs also have pecuniary value and can be traded, sold, or banked for future use.

The guidelines for the MSERC program stipulate several fundamental criteria for validating mobile sources emission reduction credits. For emission reductions to qualify for credits, the following conditions must be met:

1. The reductions must not be required by law or regulation, or otherwise assumed to occur as part of a regional air quality plan.

2. The reductions must be real, and quantified to an acceptable degree of certainty.

\footnotetext{
${ }^{13}$ Kestin, Martin, Downstream LNG Vehicle Markets in Germany, delivered at "LNG: Prospecting Downstream Markets" conference, May 1998.
} 
3. In order to be used as stationary source offsets or to replace other emission reduction requirements, the mechanism used to obtain mobile source emission reduction credits must be enforceable and legally binding.

4. The life of the reduction must be reasonably established, and commensurate with the proposed use of the credit.

In other words, the emission reductions must be "surplus", "quantifiable", "enforceable" and "permanent" (e.g., old high-polluting vehicles must be permanently retired when replaced by cleaner vehicles). In addition, it is critical to note that emissions reductions generated from publicly funded projects are generally not considered tradable. Therefore potential users must weigh the comparative value of accepting public funding versus trading emissions reductions.

Although various opportunities for generating MSERCs exist, the guidelines describe two that would be of particular relevance to the use of LNG at the Port of Los Angeles. These programs are: 1) retrofitting light, medium, and heavy-duty vehicles to low-emission configurations, and 2) purchasing new, reduced-emission heavy-duty vehicles. Many operators at the Port of Los Angeles could be eligible for MSERCs if they supplant diesel vehicles with clean fuel alternatives such as LNG. The amount of credits generated is determined by the total emission reduction resulting from vehicle replacement (or scrappage). The net emissions reduction is the difference between the emissions of the new vehicle and the replaced vehicle. Certification or baseline emission standards are usually used as a proxy for the replaced vehicle emissions.

NOx emissions are the most valuable among the criteria pollutants presently being traded. Market values are highly variable; however, current NOx prices are in the range of $\$ 1,000-\$ 2,000 /$ ton reduced/year. Although this is a significant amount, most potential LNG users will find it more cost-effective to pursue public funding for their LNG vehicle projects and forego emissions trading. If public is not available, however, emissions trading could help to defray the current cost penalties associated with LNG use.

\subsubsection{Safety Issues}

The lack of familiarity with LNG equipment and fueling can lead to misperceptions of the relative safety of the technology. Because LNG is a cryogenic fuel and is typically maintained under low pressure (30-150 psig) at temperatures of -128 to -260 degrees Fahrenheit, it requires different handling, storage and general safety procedures than those associated with conventional fuels like gasoline and diesel. According to a recent qualitative risk assessment undertaken by INEEL ${ }^{14}$, the principal safety issues associated with LNG use in transportation applications are as follows:

- Cryogenic Hazards - contact with skin can cause burns, breathing LNG vapors during evaporation can cause lung damage, some structural metals can be damaged by exposure to LNG

- Chemical Hazards - natural gas is non-toxic and non-carcinogenic in all forms; however, it can be an asphyxiant if air is displaced and oxygen levels fall below $15 \%$

- Combustion Hazards - natural gas is combustible when the methane volume fraction is between $5-15 \%$. However, the risk of combustion is generally considered to be less than for gasoline or diesel. Because of its cryogenic state, LNG evaporates rapidly on exposure to air and is therefore less prone to pooling than conventional fuels.

- Pressure hazards - LNG is typically maintained at relatively low pressures. However, if the fuel is allowed to warm and volume remains constant, pressure can rise in the storage vessel. For this reason, pressure release valves that allow venting of the fuel are an integral part of all LNG systems.

\footnotetext{
${ }^{14}$ Siu, Nathan, et. al., Qualitative Risk Assessment for an LNG Refueling Station and Review of Relevant Safety Issues, INEEL, February 1998.
} 
Clearly, it will be necessary to ensure that all personnel in contact with LNG fuel and technology receive proper training. However, there is no reason to believe that risks associated with either the fuel or its associated technology exceed those of conventional fuels or negatively impact the feasibility of its use in the port setting.

\subsubsection{Permitting}

Although it should not be a major barrier to LNG utilization at the Ports, permitting is commonly identified as a bottleneck in the path towards construction and operation of refueling facilities. LNG stations are built to existing construction standards and design protocols. However, because there have been so few stations built in California, permitting authorities do not have a great deal of familiarity and comfort with these systems. Moreover, individual counties and cities may have particular requirements above and beyond state and federal standards. As a result, most stations built within California have experienced significant delays associated with the permitting process.

Given the greater degree of unfamiliarity with small-scale liquefaction systems, it can only be imagined that permitting difficulties would be even more severe with this technology. With either system, however, the Ports should be in a position to facilitate the process and act as a liaison between the various building code and safety enforcement officials, and those wishing to utilize the systems. Experience has shown, however, that it is prudent to expect delays in this phase of a LNG project.

\subsubsection{Summary of Additional Factors Affecting Feasibility}

This section has highlighted a broad range of factors that could impact the feasibility of LNG use in heavy-duty port vehicle and equipment applications. Although these variables generally fall outside of the traditional parameters of analysis (i.e. economic, environmental and technical), they are critical to this port-specific study. Figure 4-12 summarizes the impact of these diverse factors. 
Figure 4-12: Other Factors Impacting Feasibility

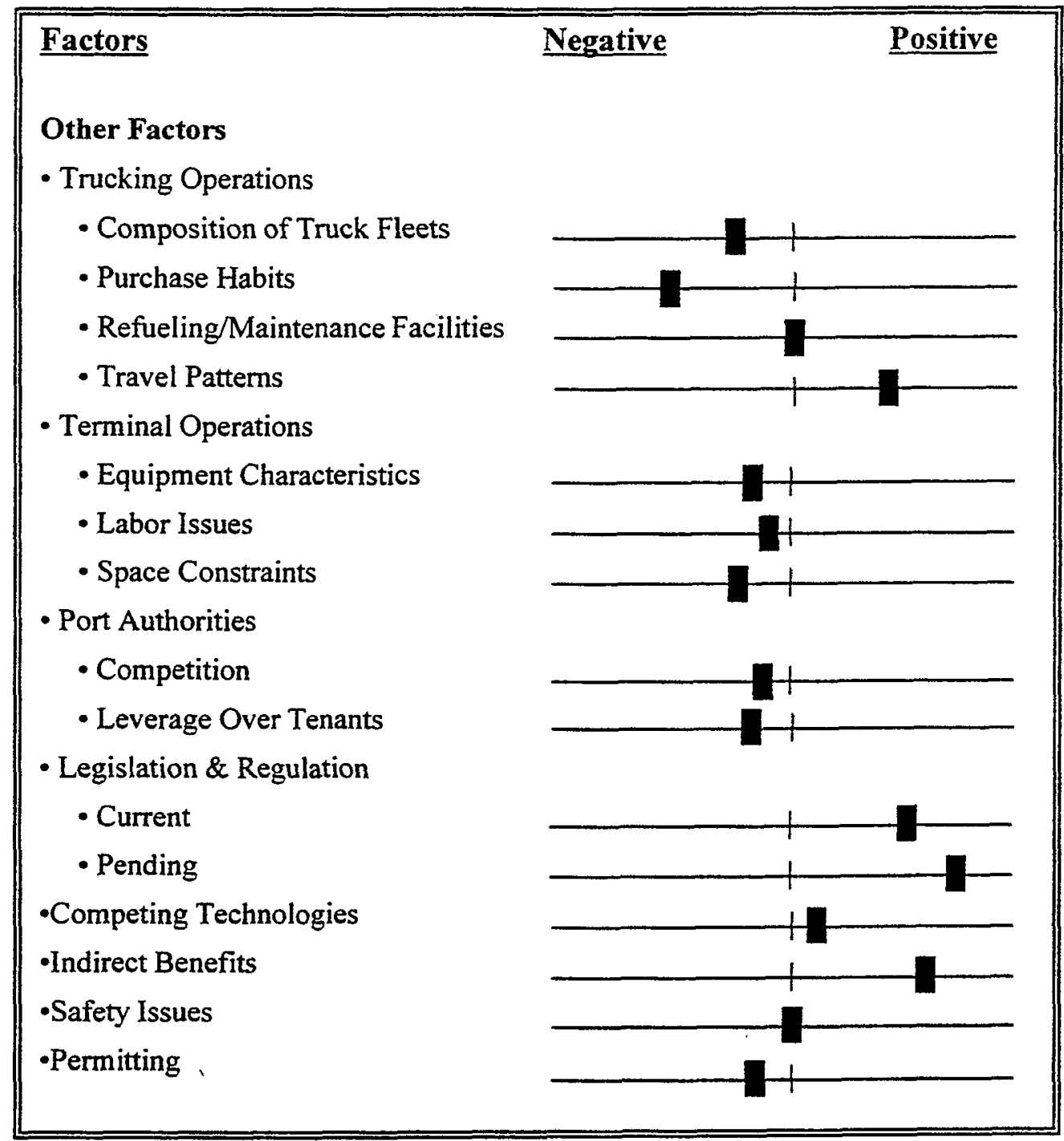

\subsection{Feasibility Summary}

The preceding analysis indicates that there are a broad range of factors that could potentially impact the feasibility of LNG use in heavy-duty vehicle operations at the Ports of Los Angeles and Oakland. Figure 4-13 below reviews these factors, and characterizes the strength and nature of their impact. 
Figure 4-13: Feasibility Overview: Key Variables and Their Impacts

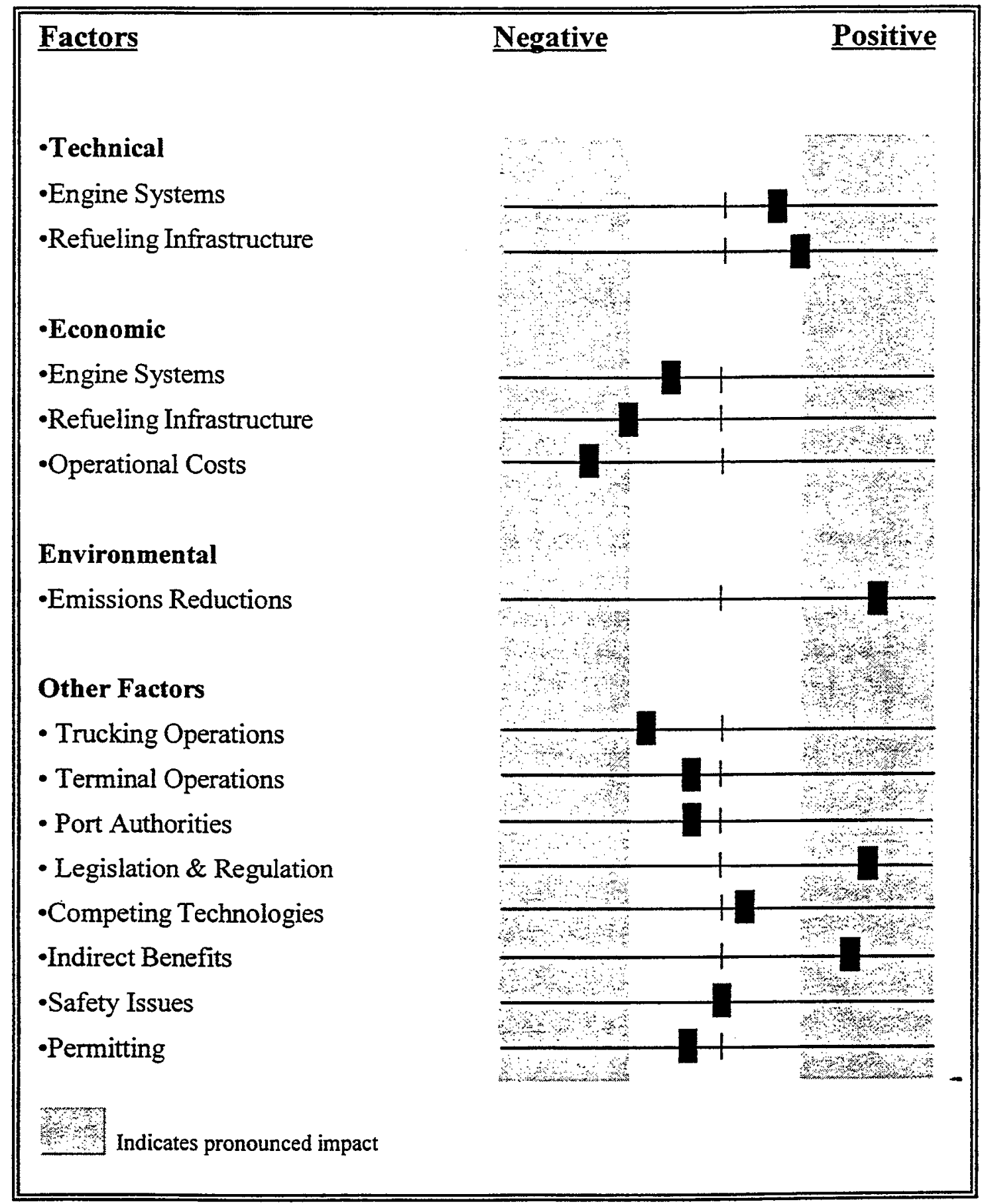

The basic conclusion to which this analysis points is that, given current conditions, LNG use at the Ports would be technologically feasible and environmentally beneficial; but economically and logistically problematic. Though this response may seem equivocal, the variety, complexity and mutability of variables involved preclude a definitive assessment of the overall feasibility of 
utilizing LNG in heavy-duty port vehicle applications. Rather, the analysis identifies a number of critical barriers and benefits to the fuel's use in this particular setting (indicated by gray shading in Figure 4-13).

\section{Critical Barriers}

Although all of the factors listed in Table 4-13 have the ability to affect the utilization of LNG at the Ports and would need to be considered in any effort to introduce the fuel, the current economics of LNG use are clearly the most critical barrier identified in this study. Incremental vehicle and refueling infrastructure costs, efficiency losses, and most importantly, relative fuel prices all work against LNG use. Unless mitigated, these factors will almost certainly prevent LNG penetration of the port setting.

Many characteristics of port operators and port operations also work against the introduction and use of LNG. Most important among these are the high percentage and economic profile of owner/operators in port trucking, the current equipment purchase habits of the trucking sector, logistical concerns regarding refueling and maintenance of LNG trucks and terminal equipment, and lack of leverage that the Ports have over various tenants operators. Although it is very unlikely that the success or failure of a LNG program at the Ports would hinge on any single one of these factors, all would have to be addressed in policy design and implementation.

\section{Critical Benefits and Positive Characteristics}

The substantial NOx and PM emissions reductions that would result from the supplantation of diesel with LNG represent the critical benefit associated with the alternative fuel's use at the Ports. Moreover, the analysis has shown that even limited penetration of LNG would result in marked emissions reduction, particularly among off-road terminal vehicles. In addition to improving local air quality, LNG use could provide an important strategic tool in preventing litigation associated with diesel emissions and securing community support for modification or expansion of port facilities and operations.

The current regulatory environment and legislative agendas also appear to support LNG use. In addition to the recent Proposition 65 lawsuits and toxic air contaminant listing in California, both of which appear to increase the liability associated with concentrated diesel fuel consumption, new funding sources are available to defray the cost of using LNG technology in port applications. If successful, current initiatives to secure federal tax credits for alternative use would dramatically alter the economic landscape for LNG.

Despite having a number of characteristics that could impede the successful introduction of LNG, the Ports and their operators also have a range of positive qualities with respect to the fuel's use. Travel patterns suggest that limited LNG refueling infrastructure would be able serve much of the trucking community's needs. And though their leverage over tenants and operators may be limited, as landowners both Ports are in a position to encourage and facilitate LNG utilization through a variety of incentive measures. Finally, not only does each port represent a powerrful and high profile focal point of regional economic activity, they and their operators are also large, geographically concentrated markets for technology and services. As a result, even limited commitments by the operations evaluated in this study to use LNG technology could stimulate commercial provision of refueling and maintenance services.

\section{Mitigating Barriers and Leveraging Benefits}

The preceding chapter has identified and characterized the impact of a broad range of variables that shape the potential for LNG use in the Port setting. Among these, a number of critical barriers and benefits emerged that could individually have a significant influence on LNG 
utilization. With very few exceptions these many variables and the degree of their impact, critical and otherwise, are highly mutable. Ultimately then, the feasibility of LNG use at the Ports will depend on the(ir) willingness and ability to mitigate the principal barriers and capitalize upon the key benefits associated with the fuel and its accompanying technologies. The following chapter discusses a variety of strategies that could be utilized to this effect. 


\section{Mitigating Barriers, Leveraging Opportunities}

Though the previous chapters have identified and attempted to characterize the impact of a broad range of factors relating to the overall feasibility of LNG use in the Port setting, they have not produced a definitive conclusion on the subject. This is hardly surprising. The Ports are a highly competitive environment, suggesting that if the case for LNG use was an open and shut one, numerous operators would already be utilizing the fuel and capitalizing on its advantages. Conversely, if the case against LNG use was patent, there would be little cause for study. The fact is that the evidence is highly mixed. In certain respects, the Port environment appears wellsuited to utilize this clean burning alternative fuel. Operations (and hence fuel demand) are highly concentrated. Suitable LNG technologies exist to satisfy the demands of most Port duty cycles. Moreover, tremendous synergies exist between the various operations, synergies that could be catalyzed through the overarching governance of the Port Authorities. On top of this are various environmental considerations: the increasing liability associated with concentrated diesel use; the substantial emissions from current equipment; and dramatic emissions reductions that could be achieved with the use of LNG technologies.

On the other hand, there are also serious barriers to LNG's use in this setting. Based strictly on an energy equivalent fuel cost comparison of diesel and LNG, it does not appear economically practical to use the alternative fuel at present. The economic picture worsens with the necessary inclusion of engine efficiency penalties, and worsens still more if potential users are left to assume the costs of the LNG engine systems, refueling infrastructure, personnel training and potential reliability penalties. Some logistical and operational characteristics of the Ports also present obstacles to the fuel's use. The composition of the port trucking population, its reliance on used equipment, concerns over maintenance and refueling of LNG trucks and terminal vehicles and uncertainties regarding the ability of Port Authorities to encourage alternative fuel vehicle use among their tenants and operators all represent hurdles to the successful use of LNG.

Though the barriers listed above are clearly serious ones, serious enough to have stymied any current use of LNG at the Ports, few of them are fixed and their impacts even less so. Feasibility, at least with respect to LNG use at the Ports, is a dynamic condition. Moreover, it is one over which the Port Authorities and other interested parties have a good deal of control. The following sections will discuss ways in which the critical barriers at the Ports can be mitigated and the potential benefits of LNG use realized. Although these measures are presented individually, the successful introduction of LNG into port trucking and terminal operations would likely require a well-coordinated and aggressively administered combination of these initiatives.

\subsection{Mitigation Measures}

\section{Action: Encourage development of local liquefaction facilities}

\section{Barriers Addressed: Fuel costs}

Although the economics of LNG utilization are dependent on a wide range of factors, including the cost of $L N G$ engine and refueling technologies, relative engine efficiencies and maintenance costs, the most critical variable is clearly the price relationship between LNG and diesel fuel. These is no reliable evidence to suggest that diesel prices will rise significantly in the near future (although current prices do represent a historical low, when adjusted for inflation). The price of LNG, however, appears to be far more mutable. 
As previously discussed (see Figure 3-1), LNG prices are determined by three principal factors; feedstock gas price, liquefaction cost and transportation charges, all of which are considered very stable. Together, feedstock and liquefaction costs typically range from \$.30-.35/LNG gallon. Transportation of LNG fuel to California adds anywhere from \$.10-.20/LNG gallon, depending on the source, the exact destination and whether a full tanker load is transported. This results in California LNG prices of roughly \$.45-.55/LNG gallon, pre-tax. As previously noted, this price does not appear to offer sufficient economic incentive to encourage the fuel's use, and in some port applications, would result in serious operational cost penalties. Assuming that diesel prices stay relatively constant, elimination or at least significant reduction of transportation charges through the local production of LNG appears the only realistic, near-term means of obtaining the fuel at an economically competitive price. Moreover, given the capital costs, permitting difficulties and lengthy construction times associated with large-scale liquefaction facilities, this local production would likely have to take the form of relatively small-scale systems.

Given the experimental nature of these technologies, there are obviously a number of uncertainties and questions surrounding small-scale liquefaction. Of these, the most critical involve facility siting, feedstock gas sources, development timeframes and, most importantly, final fuel costs. Some of these issues could be addressed through further study, but others will require in-use experience. Chapter 3 presented information on a variety of small-scale liquefaction systems currently under development or in the prototype stage. Several of these systems appear quite promising and may in fact offer the potential for low-cost supply of LNG. To that end, the Ports, other government agencies and private industry could work together to successfully demonstrate and deploy one or more of these small-scale liquefaction technologies at or near the Ports.

Should on-port liquefaction prove feasible (given space constraints and permitting issues), the Ports can facilitate the siting by working with private industry to determine appropriate and convenient locations. From an economic standpoint, providing no- or low-cost space for a facility would reduce overall production costs for LNG from a small-scale liquefaction facility. Regardless of whether the facility is located on Port property, the Ports can work to ensure that the demand for the fuel is existent, as discussed under other mitigation measures in this chapter.

From technology research and development funding to infrastructure siting incentives and permitting, a number of other government agencies can play a role in deploying small-scale liquefaction technologies at or in the vicinity of the Ports. Brookhaven National Laboratory has funded small-scale liquefaction technology development (Brookhaven is providing funding for development of the Institute of Gas Technology system discussed in Chapter 3), and INEEL is working with PG\&E and So. Cal. Gas. to deploy small-scale liquefaction technology that it has developed. In addition, the CEC recently announced that it plans to issue a request for proposals for $\$ 250,000$ in funding toward the development of a $L N G$ plant within California, as well as a request for proposals for $\$ 500,000$ to fund up to five heavy-duty vehicle alternative fuel vehicle refueling sites.

As noted in Chapter 3, most of the small-scale liquefaction systems are in the developmental or prototype stage. Further research and development funding could be devoted to improve the efficiency and cost-effectiveness of small-scale liquefaction, or to support the coupling of smallscale liquefaction technology with low-cost feedstock gas sources, such as landfills. Funding such as that from the CEC could help off-set the costs associated .with installing LNG infrastructure, either in conjunction with small-scale liquefaction or as a stand-alone LNG fuel storage and dispensing system. 
Other government agencies will also play a role in permitting small-scale liquefaction technologies. As discussed in Chapter 4 , permitting issues regarding small-scale liquefaction could create delays in approval for such facilities. State- and local-agency efforts to establish a structured or streamlined permitting process for small-scale liquefaction facilities would help to eliminate currently anticipated delays.

As noted, two of California's largest gas utilities, PG\&E and So Cal Gas, are already cooperatively evaluating the technological and economic feasibility of developing a network of small-scale $(\sim 10,000 / \mathrm{LNG}$ gallons per day) liquefaction facilities in California based on technology developed at INEEL. Initially, the LNG would primarily be used for PG\&E's vehicle fleet; however, commercial transportation applications could also represent an important market and help spur the program's actualization and growth. At present, the organizations involved are attempting to form a limited liability corporation (LLC) and expect to have an agreement in place by the end of March. Assuming an agreement is reached, two full-scale prototypes are scheduled to be built by the end of 2000 , one in each of the utilities' service areas. ${ }^{1}$

The other businesses identified in Chapter 3 as working on small-scale liquefaction could also actively work to demonstrate and deploy their technology at or in the vicinity of the Ports. Data from this report suggests that any company that can demonstrate a small-scale liquefaction facility capable of producing LNG at $\$ 0.35-\$ 0.40$ per gallon, the price ceiling for LNG to compete with diesel, will create a significant economic opportunity for itself and could help catalyze LNG use at the Ports.

The Ports could provide an ideal forum in which to evaluate and refine these technologies, whether in conjunction with PG\&E and So Cal Gas' on-going efforts or through a demonstration program of its own design. Regardless of the program's exact configuration, small-scale liquefaction could provide the economic cornerstone for a larger effort to encourage and facilitate the utilization of LNG in the port setting.

\section{Action: Provide priority access to low-emission, alternative fuel vehicles}

Barriers Addressed: Operational costs (indirectly)

As detailed in Chapter 2, waiting time at the shipping and rail terminals, and the number of container turns completed per day are more critical determinants of profitability for port truckers than cost per mile of operation. Establishing a reliable and functional priority access system for alternative fuel vehicles may be the single most cost-effective means of encouraging LNG use at the ports. The additional revenue from completion of even one additional short-haul container carry per day would almost certainly outweigh any operational cost penalties associated with LNG use. The following scenario provides an illustration of this potential.

\footnotetext{
${ }^{1}$ Per conversation with Brian Stokes, Senior Research Associate, PG\&E, February 1999.
} 
- Assuming the average port trucker travels, on average, 250 miles per day and in doing so, uses approximately 45 gallons of diesel fuel costing $\$ 1.15 /$ diesel gallon, his daily fuel costs are approximately $\$ 52.00$. Were the same trucker to use LNG, gain priority access to the terminals and complete one additional 50 mile trip, for which he is paid $\$ 40.00$ (an extremely conservative estimate), his daily mileage would increase to 300 and his daily fuel use to 50 diesel equivalent gallons. Assuming LNG costs $\$ .50 / \mathrm{LNG}$ gallon, pre tax, or $\$ 1.16 / \mathrm{DGE}$, and that the driver suffers a $15 \%$ efficiency penalty, his daily fuel costs would increase to approximately $\$ 67.00$. In other words, the additional revenue would more than off-set the increased fuel costs. Assuming conservatively, that the daily revenue gain was only $\$ 20$, this would still result in an additional $\$ 5,000$ in annual revenue.

As part of CALSTART's survey effort, trucking operators were asked to identify what they thought would be the most effective means of encouraging alternative fuel use among their cohort group. Table 5-1 below presents the findings. Clearly, priority access emerges as the most appealing strategy to the trucking community.

Table 5-1: Preferred Means of Encouraging AFV Use

\begin{tabular}{|c|c|c|c|c|c|}
\hline & $\begin{array}{c}\text { Preferential } \\
\text { access/priority } \\
\text { lanes for } \\
\text { alternative fuel } \\
\text { vehicles }\end{array}$ & $\begin{array}{c}\text { Subsidization } \\
\text { of equipment } \\
\text { cost }\end{array}$ & $\begin{array}{c}\text { Infrastructure } \\
\text { provision } \\
\text { and/or } \\
\text { subsidization } \\
\text { of fuel cost }\end{array}$ & $\begin{array}{c}\text { Other } \\
\text { (mandates, } \\
\text { used vehicle } \\
\text { market, weight } \\
\text { waiver) }\end{array}$ & $\begin{array}{c}\text { Nothing port } \\
\text { could do }\end{array}$ \\
\hline $\begin{array}{c}\text { Port of Los } \\
\text { Angeles }\end{array}$ & $62 \%$ & $26 \%$ & $4 \%$ & $8 \%$ & 0 \\
\hline $\begin{array}{c}\text { Port of } \\
\text { Oakland }\end{array}$ & $49 \%$ & $31 \%$ & $3 \%$ & $3 \%$ & $14 \%$ \\
\hline
\end{tabular}

A priority access program would not be without challenges or costs, however. Perhaps the most difficult aspect would be effective enforcement of the system. In terms of vehicles, this would require that alternative fuel units have some form of secure but easily recognizable identification. On the terminal end, it would be necessary to ensure that priority access actually be granted, both at the terminal gate and inside the yard. This would obviously require the participation and support of terminal managers as well as the various labor groups operating at the port. Despite these challenges, such a system could represent an inexpensive and low-risk means of encouraging LNG use at the Ports. Moreover, there is some precedent for priority access. According to numerous trucking operators, particular terminals and trucking operators already negotiate priority access arrangements.

\section{Action: Encourage development of retail LNG refueling infrastructure on port- controlled property \\ Barriers Addressed: Infrastructure costs, scarcity of centrally fueled truck fleets}

Refueling infrastructure has traditionally posed one of the critical constraints to the utilization of LNG in transportation applications. The high cost of the technology, especially when assumed by an individual fleet, and the reluctance of commercial providers to assume the expense and risk of providing retail refueling facilities are the principal contributors to this effect. Even relatively well-funded efforts such as the Interstate Clean Transportation Corridor. have been unable to overcome this barrier. The small percentage of trucking operations with on-site fueling would appear to make this barrier even more severe at the Ports. And yet the Ports may, in fact, provide a unique opportunity to overcome this obstacle. 
Given their dual roles as landlords and policy planners, the Port authorities are in an ideal position to facilitate the development of conveniently located retail/commercial LNG dispensing facilities. By providing low- or no-cost space for refueling infrastructure, soliciting commercial fuel provision and at the same time initiating various policies to encourage LNG use, the Ports could simultaneously address both fuel providers' and users' concerns. This would be particularly effective if the Ports could obtain commitments from a number of port operators to use LNG vehicles and present this packaged demand to a commercial provider prior to station construction. Beyond the heavy-duty vehicles evaluated in this study, there are a number of other vehicles and equipment pieces operating at the Ports that could potentially utilize natural gas, in compressed or liquefied form. Port-authority fleets, tugs, pilot boats, ferries and switcher locomotives all represent potential applications for natural gas fuels. While further analysis would be necessary to determine the feasibility of these applications, it is critical to note that other units utilizing liquid or compressed natural gas at the Ports would help to aggregate demand and spur both local fuel provision and liquefaction. LNG station providers indicate that technology to produce compressed natural gas from LNG is available and could be implemented in conjunction with a LNG station, albeit at an additional cost.

Alternatively, the Ports could themselves operate a publicly accessible LNG refueling station. Under this scenario, the Ports would then have the option of controlling LNG prices and, if necessary, setting them artificially low to catalyze early use. The costs of operating the station and subsidizing the fuel could then be recovered through a nominal per container or per entry tax on conventional vehicle operations. Figures 5-1 and 5-2 below give an indication of the fuel demand that would be associated with various levels of LNG utilization at the both ports. (See Appendix $G$ for complete calculations.) For the purposes of this example, yard tractors are the only terminal application considered.

This action would benefit not only port operators, but other current and potential users as well. Port fueling facilities could be linked to current Interstate Clean Transportation Corridor efforts, as well as local refuse and transit applications. By making stations easily accessible to non-port operators, the Ports could also increase the facilities' throughput and economic viability.

Figure 5-1: Potential LNG Fuel Demand, Port of Los Angeles

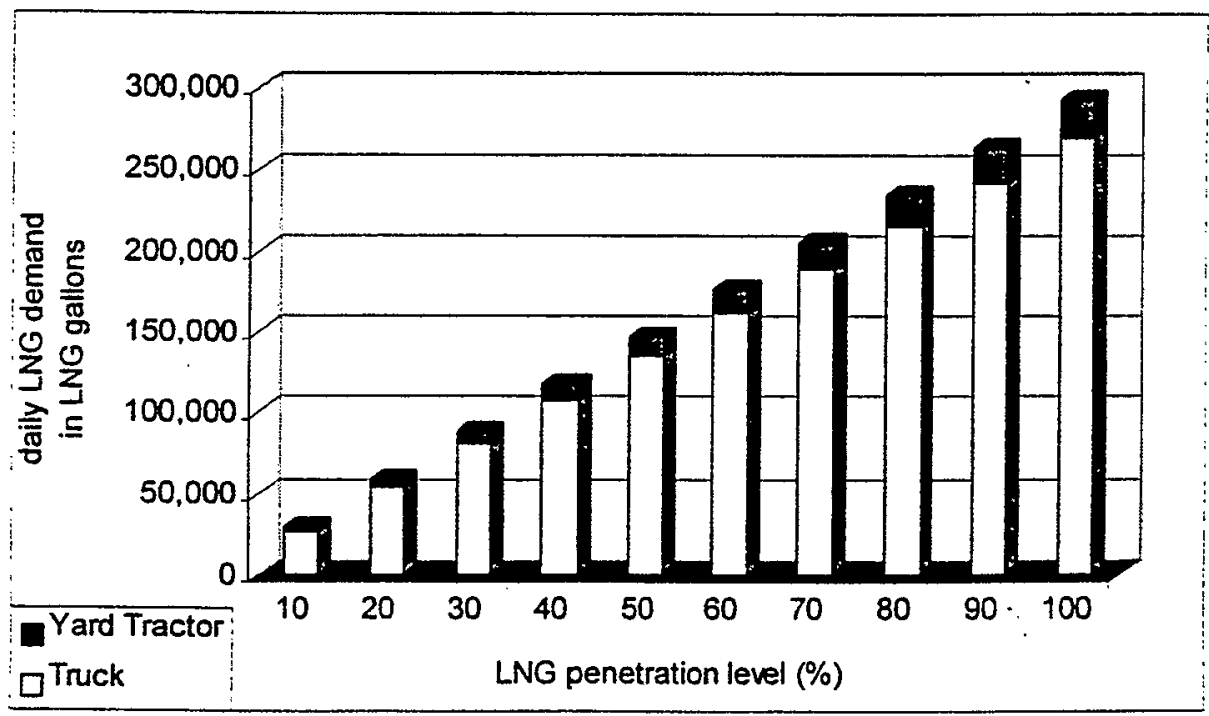


Figure 5-2: Potential LNG Fuel Demand, Port of Oakland

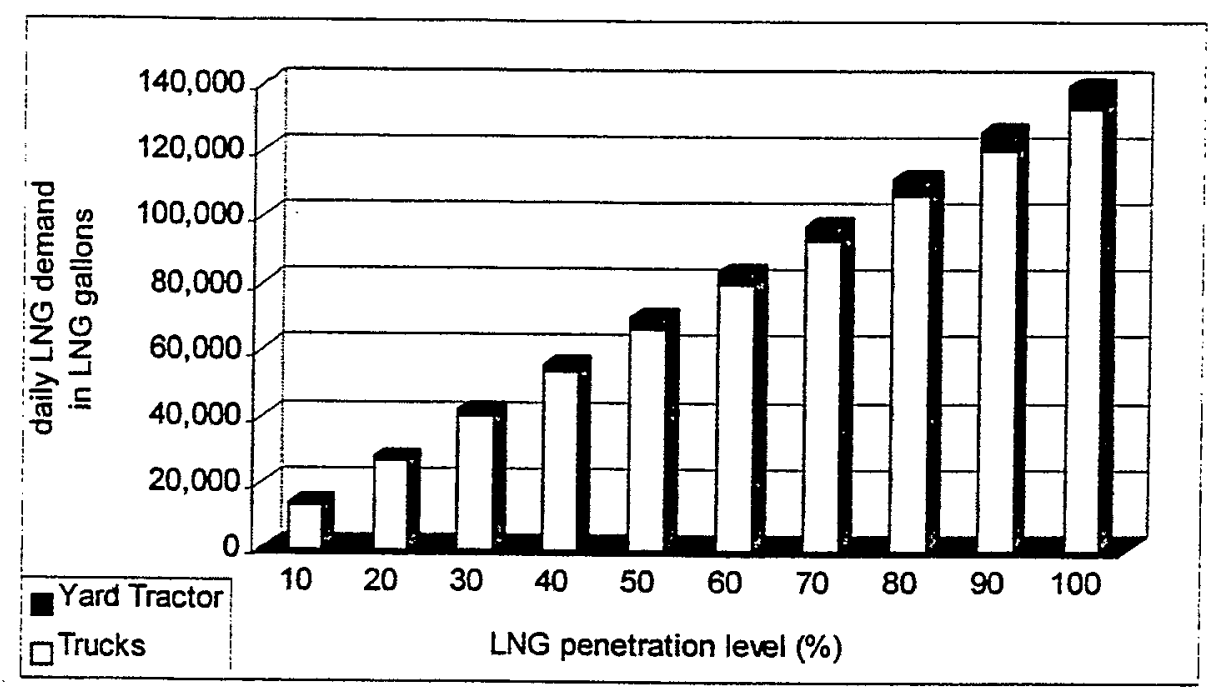

Action: Explore wet hosing, in conjunction with local LNG liquefaction, as an alternative to LNG refueling emplacements for port terminals Barriers Addressed: Infrastructure costs, space constraints

Due to time constraints and the off-road status of port terminal equipment, these units could not utilize a shared refueling facility (except perhaps between contiguous berths). Each terminal using LNG would therefore be required to construct and operate its own fueling facility. As earlier noted, space constraints and system costs would make this a difficult undertaking, particularly if a terminal was only evaluating the fuel and its associated technology. An alternative approach would be to develop a mobile refueling service that operated in conjunction with local liquefaction and stationary refueling facilities. In mobile fueling, also known as wethosing, an on-road fuel tanker brings fuel to the facility and discharges directly to waiting vehicles, as opposed to an interim holding tank. The process, which reduces both infrastructure costs and the liability associated with on-site fuel storage tanks, is already quite common among the diesel-powered trucking fleets at the ports. Moreover, terminals frequently use a similar system, though fuel tankers remain on-site and refuel from stationary storage tanks.

PCI Clean Fuels, an Oakland-area industrial gas supplier, owns and operates a 5,000/LNG gallon mobile fueling vehicle, suggesting that such a system is at least technologically feasible for LNG. In the case of port use, however, it would be imperative that the system as a whole be highly efficient and exceptionally reliable. Additionally, such a wet-hosing system would only-be realistic where LNG was produced locally at a variety of locations, thereby ensuring a secure fuel supply and minimal transportation costs.

\section{Action: Incorporate incentives for AFV-use into port lease structures} Barriers Addressed: Operational costs, lack of leverage over leasees and port operators, competitive concerns Although the Ports and even local $\mathrm{AQMD}$ officials might be reluctant to mandate alternative fuel use or emissions reductions at the terminals, for fear of compromising competitiveness, port authorities could incorporate a variety of incentives into their lease agreements. As earlier noted, 
a substantial portion of each Port's container traffic is discretionary and could be shipped to another port if necessary. By providing rent reductions or rebates for the use of low emission alternative fuels, the construction of on-site refueling infrastructure and the achievement of emission reductions, the Ports could help to defray at least some of the cost of LNG use, without adversely affecting the competitiveness of their operations or those of their leasees. Such incentives could be incorporated into all leases on renewal. However, current modernization and expansion programs at both Ports provide particularly strong opportunities to leverage AFV-use. On-going projects at both Ports will result in new, state-of-the-art berths, rail facilities and container handling space, all of which could be designed to facilitate the use of alternative fuels, such as LNG.

\section{Action: Lobby congressional representatives and port associations to support tax} credits for alternative fuel consumption and infrastructure development

\section{Barriers Addressed: fuel and infrastructure costs}

A number of measures are currently pending in Congress that would dramatically alter the economics of alternative fuel use. The Rockefeller and Ensign bills detailed in Appendix $F$ both seek to provide a $\$ .50 /$ gasoline gallon equivalent $(\$ .55 / \mathrm{DEG})$ tax credit for alternative fuels, as well as limited tax credits for infrastructure. Although the two measures differ in approach, the passage of either bill would make LNG use extremely cost-effective in all of the applications evaluated within this study. Both ports should aggressively lobby their congressional representatives to support the notion of tax credits for alternative fuels. In addition, the Ports could use their influence within various port and maritime associations to create an agenda for evaluating and supporting alternative fuel use in these settings. These national organizations could then reinforce the lobbying efforts of individual ports.

Although ports in general have yet to come under real scrutiny regarding their emissions, it is extremely unlikely that this will continue. Already, many areas of the country are moving to regulate airports as point sources for emissions. Given their operational and spatial similarities, this would also be the expected trend for ports. Proactive attempts by the maritime and shipping industries to formulate their own emissions reduction agenda could forestall more onerous regulation by federal, state and local authorities, as well as litigation from community and environmental groups. By helping to enhance the viability of alternative fuel use, Ports expand their options for achieving cost-effective emissions reductions.

\section{Action: Establish buyer's cooperative to assist potential users in procuring state} and federal funding and to coordinate LNG equipment purchases (new and used) Barriers Addressed: Incremental cost of LNG equipment, purchase habits of port trucking operators

The price of both new LNG vehicles and LNG repowering is sensitive to order volume. Were the ports to actively encourage the utilization of LNG in the trucking community, a cooperative buyers program that consolidated smaller orders from disparate companies could reduce the eost of LNG systems. Even if sufficient funding were available from regulatory agencies, this reduced cost would increase both the cost-effectiveness of emissions reductions and the likelihood of further funding becoming available.

In addition to coordinating purchases, such an organization could assume the role of maintaining and disseminating information on funding opportunities, as well as aiding in the preparation of funding applications. The time and resources necessary to learn about and respond to funding opportunities could themselves be a barrier to many of the operations servicing the Ports. By providing or at least coordinating the assembly of this information, the Ports would greatly 
enhance the likelihood of LNG technologies being adopted. Moreover, the Port authorities may. be able to 'package' funding applications in such a way as to maximize their cost-effectiveness and competitiveness.

\section{Action: Establish revolving loan fund for LNG vehicle purchases}

Barrier Addressed: Purchase habits of port trucking operators, incremental cost of LNG vehicles

Based strictly on cost-effectiveness of emissions reductions, most LNG vehicle projects suggested within this report would qualify for funding under the Moyer Program. However, this program and other existing ones managed by regulatory agencies are only designed to cover the incremental cost of low emission technologies. Given the current reliance on used equipment among port truckers, incremental cost coverage may not be sufficient to encourage the use of LNG technologies among much of this group. A revolving, low-interest loan fund could be established to help defray the overall cost of purchasing new LNG vehicles, as well as LNG infrastructure. Such a fund could prove critical in ensuring equitable access to other LNG incentive measures (priority access, LNG refueling) which, in the absence of a loan fund, might only be utilized by those in the highest tiers of the trucking and shipping sectors.

\section{Action: Focus early outreach and funding efforts on most promising operations, notably, well-capitalized trucking fleets purchasing new(er) vehicles and employing staff drivers, and terminal operators \\ Barrier Addressed: high percentage of owner/operators, purchase habits of port trucking operators}

Even if a low-interest, revolving loan program were established it is still unlikely that many owner/operators would switch from their present equipment to LNG systems. One of the critical findings of this study, however, is that the port trucking community is more diverse than previously assumed. There are, in fact, a number of trucking operations at both Ports that purchase new vehicles, employ staff drivers and are closely attuned to various operational costs. Although the Ports should make every effort to ensure the accessibility and equity of any alternative fuel vehicle program, the fact remains that well-capitalized fleets appear better suited for initial LNG purchases. Therefore, the ports should identify particularly well-suited operations and focus outreach efforts on these entities.

Well-capitalized, early adopters could also help to provide a beachhead for LNG introduction. Typically, these fleets sell vehicles after 5-6 years of use, in order to reduce maintenance costs and equipment downtime. If they could be encouraged to use LNG systems, their used vehicles could then be sold to other port operators, helping to foster a second-hand LNG vehicle market.

A targeted approach might also prove effective for the terminal operations; although here, the focus should be more on vehicle type than any particular operator. Yard tractors clearly represent the most viable entry point for LNG in both the shipping and rail terminals. Assuming utilizafion of $L N G$ is successful in this application, terminal operators could leverage this experience and apply the technology to more technically challenging applications. 
Action: Coordinate and subsidize training of local mechanics in LNG technologies Barrier Addressed: Low percentage of trucking operations with on-site maintenance facilities and personnel, high cost of training maintenance personnel

The relatively small percentage of trucking operators with on-site maintenance facilities and the high cost of training terminal mechanics could both be addressed through Port-sponsored training of maintenance personnel. As part of an overall program to encourage LNG use within the trucking community, the Ports should ensure that at least some portion of commercial mechanics currently servicing the truck fleets are trained on the technologies, prior to their arrival in the port arena. The Ports and other interested parties should consider assuming the cost of such training, in order to allay the concerns of the trucking community.

The cost of training maintenance personnel appears to be an even more critical issue for shipping and rail terminal operators. Because this labor is very effectively organized, and hence expensive, terminal operators may be unwilling to shoulder the cost burden of training them on a new technology, particularly if there are not overwhelming economic benefits associated with its use. The Ports and engine manufacturers could work with both the terminal operators and the labor unions in order to ensure maintenance personnel are adequately trained at the least possible cost to the former group.

\subsection{Summary of Key Mitigation Strategies}

Although there are significant obstacles to the utilization of LNG in the Port setting, most of these factors are conditional. This chapter has presented a number of strategies by which the Ports and other interested parties could mitigate, to varying degrees, the most serious of these barriers. The critical barriers and their corresponding mitigation strategies are summarized below in Table 5-2. Clearly; these barriers are not exhaustive. Chapter 4 presented myriad factors that could impact the feasibility of LNG use in the port setting. A number of the factors discussed there, including technological refinement, safety perceptions and permitting issues, would be important to address within the framework of an alternative fuel program; however, the obstacles discussed above emerged as the most critical. Moreover, many of the mitigation strategies discussed in this chapter would also address these ancillary concerns.

Each of the mitigation strategies discussed would likely represent an important element in any attempt to introduce LNG to the Ports. However, no single measure, even the presence of lowcost, locally liquefied LNG would be sufficient to overcome the numerous obstacles that have been detailed in previous sections of this report. Rather, these measures are intended to be used in concert, as part of a larger effort to reduce the emissions impact of current port operations. Ultimately, one of the greatest strengths of the Ports, with respect to the utilization of LNG or any other alternative fuel, is their ability to design and implement, in conjunction with local air quality and government agencies, a broad-based incentive program. Currently, this abilify is latent. As a result, present conditions do not appear to overwhelmingly favor the introduction of LNG. However, if the Ports were to implement an aggressive package of mitigation and incentive strategies, these conditions could be significantly altered.

Realistically, the wholesale implementation of mitigation and incentive measures discussed herein may not be practical in the short-term. As an initial effort, however, the Ports, in conjunction with others, could pursue the implementation of one or more demonstration projects that package mitigation measures. One example would be the construction of a small-scale liquefaction facility with storage and fuel dispensing equipment, in conjunction with the 
establishment of priority access for LNG trucks. In addition to their emissions benefits, such demonstrations would also provide useful data on operational costs in port settings. As indicated in Chapter 3, engine efficiency penalties, assumed at $5 \%$ for dual-fuel and $15 \%$ for dedicated LNG engines in this study, have varied considerably in LNG vehicles currently in use. Finally, well-planned and executed demonstrations could also help alleviate concerns of trucking operators regarding the use of new technology.

\section{Table 5-2: Critical Barriers and Mitigation Strategies}

\begin{tabular}{|c|c|}
\hline Potential Mitigation Measure & Barrier(s) Addressed \\
\hline $\begin{array}{l}\text { Encourage development of local, small-scale } \\
\text { LNG production }\end{array}$ & Fuel costs \\
\hline $\begin{array}{l}\text { Provide priority access to low-emission } \\
\text { AFVs }\end{array}$ & General LNG economics \\
\hline $\begin{array}{l}\text { Encourage development of retail LNG } \\
\text { refueling infrastructure on port-controlled } \\
\text { property }\end{array}$ & $\begin{array}{l}\text { Infrastructure costs } \\
\text { Lack of centrally fueled truck fleets }\end{array}$ \\
\hline $\begin{array}{l}\text { Explore wet-hosing as an alternative to } \mathrm{LNG} \\
\text { refueling emplacements on port terminals }\end{array}$ & $\begin{array}{l}\text { Infrastructure costs } \\
\quad \text { Space constraints }\end{array}$ \\
\hline $\begin{array}{l}\text { Incorporate incentives for AFV use into port } \\
\text { lease structures }\end{array}$ & $\begin{array}{l}\text { General LNG economics } \\
\text { Reluctance to compromise } \\
\text { competitiveness of port operations } \\
\text { Lack of leverage over terminal leasees }\end{array}$ \\
\hline $\begin{array}{l}\text { Lobby congressional representatives and } \\
\text { port associations to support tax credits of } \\
\text { AFVs }\end{array}$ & $\begin{array}{l}\text { Fuel costs } \\
\text { Infrastructure costs }\end{array}$ \\
\hline $\begin{array}{l}\text { Establish buyer's cooperative to assist } \\
\text { potential users in procuring funding and to } \\
\text { coordinate LNG equipment purchases }\end{array}$ & $\begin{array}{l}\text { Incremental cost of LNG equipment } \\
\text { Purchase habits of port operators } \\
\text { Composition of port trucking population }\end{array}$ \\
\hline $\begin{array}{l}\text { Establish revolving loan fund for AFV and } \\
\text { infrastructure purchases }\end{array}$ & $\begin{array}{l}\text { Purchase habits of port operators } \\
\text { Incremental cost of LNG vehicles and } \\
\text { infrastructure }\end{array}$ \\
\hline $\begin{array}{l}\text { Focus outreach on most promising } \\
\text { applications }\end{array}$ & $\begin{array}{l}\text { Composition of port trucking population } \\
\text { Purchase habits of port operators } \\
\text { Capital costs and scarcity of port } \\
\text { terminal equipment }\end{array}$ \\
\hline $\begin{array}{l}\text { Coordinate and subsidize training of local } \\
\text { mechanics on LNG technologies }\end{array}$ & $\begin{array}{l}\text { Low percentage of operations with on- } \\
\text { site maintenance facilities } \\
\text { High cost of training terminal } \\
\text { maintenance personnel }\end{array}$ \\
\hline
\end{tabular}




\section{Conclusions and Recommendations}

The Seaport Liquid Natural Gas Study has attempted to evaluate the potential for using LNG in a variety of heavy-duty vehicle and equipment applications at the Ports of Los Angeles and Oakland. Specifically, this analysis has focused on the handling and transport of containerized cargo to, from and within these two facilities. In terms of containerized cargo throughput, Los Angeles and Oakland are the second and sixth busiest ports in the U.S., respectively, and together handle nearly 4.5 million TEUs per year. ${ }^{1}$ At present, the landside handling and transportation of containerized cargo is heavily dependent on diesel-powered, heavy-duty vehicles and equipment, the utilization of which contributes significantly to the overall emissions impact of port-related activities.

Emissions from diesel units have been the subject of increasing scrutiny and regulatory action, particularly in California. In the past two years alone, particulate matter from diesel exhaust has been listed as a toxic air contaminant by $C A R B$, and major lawsuits have been filed against several of California's largest supermarket chains, alleging violation of Proposition 65 statutes in connection with diesel emissions from their distribution facilities. CARB has also indicated that it may take further regulatory action relating to the TAC listing. In spite of these developments and the very large diesel emissions associated with port operations, there has been little AFV penetration in these applications. Nearly all port operators interviewed by CALSTART expressed an awareness of the issues surrounding diesel use; however, none appeared to be taking proactive steps to address them. Furthermore, while a less controversial issue than emissions, the dominance of diesel fuel use in heavy-duty vehicles contributes to a continued reliance on imported fuels. The increasing concern regarding diesel use, and the concurrent lack of alternative fuel use and vigorous emissions reduction activity at the Ports provide both the backdrop and the impetus for this study.

The other critical motivation is the significant advances that have been seen in the alternative fuel technology sector. Refinements of existing AFV technologies and introductions of new ones continue to expand the potential range of applications for these lower emission systems. Collectively, these conditions give rise to a series of critical questions which this report has attempted to answer:

- What are the salient characteristics of port container-handling operations with respect to alternative fuel use?

- What is the current state of LNG technology?

- Given the state of the LNG marketplace and the unique features of port operations, is the utilization of this low-emission, alternative fuel technology feasible in this particular setting?

- What are the critical barriers to and benefits of LNG's use in the port applications evaluated here?

- And finally, assuming that the benefits merit such action, what steps could be taken to overcome the critical barriers to LNG use?

The key findings regarding each of the questions are summarized below.

\footnotetext{
${ }^{1}$ Based on 1997 data supplied by the American Association of Port Authorities, Alexandria, Virginia.
} 


\subsection{Key Findings}

\subsubsection{Port Operations}

The land-side container handling operations at the Ports are composed of three main elements: the rail operations, shipping terminal operations and trucking operations. For the purposes of this analysis, the first two have generally been discussed in tandem, due to the similarity in the heavyduty equipment being utilized at the facilities.

\section{Port Trucking}

The port-related trucking sector is diverse group, composed of a variety of economically and operationally differentiated firms. Some of the more salient and prevalent characteristics shared by both Ports' trucking populations include a heavy reliance on owner/operators as opposed to company vehicles and drivers; a focus on container carries as opposed to operational costs as the critical determinant of company and driver profitability; the predominance of vehicles 10 years or older, with the mean vehicle age being 13 years; and the relatively low percentage of operations with on-site maintenance and refueling capabilities. In addition, it was found that the vast majority of port truckers purchase their vehicles used.

Although daily mileage varies greatly by day and by operation type, the average daily VMT reported by truckers at the Ports of Los Angeles and Oakland was 272 and 235 miles, respectively. Assuming a 250-day work year, the trucks servicing the two Ports are travelling approximately 68,000 and 58,750 miles annually. Typically, those fleets with higher percentages of staff drivers have higher daily and annual mileage. With regard to trip ranges, over $80 \%$ of all truck trips at both ports are less than 100 miles, one way, with approximately $50 \%$ being less than 50 miles. Moreover, all ship-to-rail transfers are considerably shorter, with the longest being roughly 20 miles.

At present, there is no alternative fuel usage within either Port's trucking community. Several operators were familiar with LNG systems and had even evaluated their potential use, but concluded that it was not economically practical given current conditions.

\section{Port Terminal Operations}

A wide variety of heavy-duty diesel-powered equipment is utilized in container-handling operations at the Ports' shipping and rail terminals. This equipment ranges from exotic $\$ 1.5$ million transtainers, to versatile reach stackers, to the more commonplace yard tractors. In general, terminal equipment is characterized by high capital costs, high annual hours of operation and demanding duty cycles. All refueling and nearly all equipment maintenance is performed onsite by union labor. Due to their large capital costs, most units are replaced with great infrequency, and usually only upon obsolescence. However, engine rebuilding and repowering are commonplace.

Terminal operators frequently described themselves as risk averse, at least with respect to their equipment choices. Because relatively few units of each type are found on a given terminal, equipment downtime can hamper operations and be extremely costly. Therefore, reliability and familiarity are highly valued. This said, all terminal operations are very cost conscious and would be receptive to a technology that could offer proven cost savings. The other critical characteristic of terminal operations is their off-road status. This allows these facilities to utilize 'red' diesel, which is free from all on-road excise taxes. Because of their substantial fuel consumption, most of these operations are also able to secure volume discounts. Typical fuel costs at the rail and shipping terminals average \$.55-.70/gallon. 
At present, there is very limited use of altemative fuels in heavy-duty applications at the terminals, although propane is used extensively in light- and medium-duty forklifts and yard vehicles. Propane yard tractors are currently being used to varying degrees by two shipping terminals, one at each of the Ports.

\subsubsection{LNG: Technology and Marketplace}

\section{Engine Systems}

A wide range of LNG engines are commercially available at present, with several new highpower systems scheduled to arrive on the market over the next one to two years. The various systems are currently in use in transit, refuse, line-haul and pick-up/delivery trucking applications around the country. At present, transit is the largest user and LNG's share in that market is increasing, relative to both $\mathrm{CNG}$ and diesel.

Despite considerable price decreases over the last five years, the incremental cost of LNG engines and on-board full storage systems remain substantial in comparison to conventional diesel units, typically ranging from $\$ 20,000-40,000$. New funding programs within California will help to ameliorate the impact of these incremental costs, but it remains a barrier to LNG use in many applications.

Two other issues arise with respect to LNG engine technology. Both dedicated and dual-fuel systems are inherently less efficient than diesel, with optimum efficiencies typically projected at $85 \%$ and $95 \%$ that of their diesel counterparts, respectively. Obviously, these efficiency penalties have a negative effect on LNG operational economics. Moreover, actual efficiencies from in-use testing have shown a significant degree of variability and often fall short of these optimum standards. The reliability of natural gas systems has also shown some variability. Although natural gas engines offer the potential for reduced maintenance costs and longer life, many projects have witnessed higher equipment downtimes, relative to diesel units. Testing, refinement and accumulated experience should diminish the impact of these variables; however, their present impact on overall operational economics is uncertain.

\section{Refueling Infrastructure}

LNG infrastructure, while increasingly sophisticated and user-friendly, continues to carry a very significant incremental cost over diesel systems. As a result, private stations remain scarce and retail ones non-existent. Moreover, unlike with engine costs, infrastructure funding is difficult to obtain due to the indirect nature of its associated emissions reductions. Nonetheless, some public money is available, with the CEC recently announcing $\$ 500,000$ in new infrastructure funding for fiscal year 1999.

\section{Fuel Costs}

The LNG used in transportation applications in California is produced primarily in Kansas, Wyoming and Colorado and therefore subject to considerable transport charges. As a result, while at the source costs are only $\$ .30-.35 / \mathrm{LNG}$ gallon, most California operations pay between $\$ .45-.55 / \mathrm{LNG}$ gallon for the fuel. Even with the recent opening of a new liquefaction facility on the California/Arizona border, this price appears stable. Converted to a diesel gallon equivalent, the price of LNG, including California sales tax, is \$.83-1.02/DEG, compared to the \$.55$.70 /$ gallon that off-road operators currently pay for their red diesel. If federal and state excise taxes are factored in, the price of $\mathrm{LNG}$ rises to $\$ 1.23-1.42 / \mathrm{DEG}$, compared to the retail diesel price of \$1.15-1.20/gallon presently found in California. 
LNG prices in California do not offer any operational cost incentive to utilize the fuel. Moreover, the prices above do not take into account the energy efficiency penalties inherent to natural gas engines.

\section{Small-Scale Liquefaction}

Small-scale local liquefaction is garnering increasing interest as an alternative to the longdistance transportation of LNG from traditional Rocky Mountain and Mid-Western sources. CALSTART presented information on a number of these systems that are currently under development or in a variety of prototype and commercialization stages. Although no small-scale liquefiers are currently in full operation, at least one system appears to be commercially available. Moreover a limited partnership between INEEL, PG\&E and So. Cal. Gas is developing plans to build a series of 10,000 LNG gallons/day systems in California. Two full-scale prototypes are expected to be built by the end of 2000 , one in each of the respective utilities' service areas.

\subsubsection{Assessing Feasibility, Identifying Barriers and Benefits}

Theoretically, assessing the feasibility of LNG use at the Ports should be as easy as juxtaposing findings from the technology and port operations chapters of this study. When this exercise is undertaken, however, as it is in Chapter 4 generally and Figure 4-13 specifically, the findings are inconclusive. Under current conditions, LNG use appears to be technologically feasible and environmentally beneficial, but economically questionable and logistically problematic. Unfortunately, the variety, complexity and mutability of factors involved preclude a more definitive response. Rather, what emerges from the analysis are a number of critical barriers to and benefits of utilization of LNG in this particular arena, as well as strategies to address LNG implementation.

\section{Critical Barriers}

At present, economic considerations represent the single most critical barrier to LNG use in the heavy-duty vehicle applications at the two ports. The incremental costs of refueling infrastructure and engine systems, engine efficiency penalties relative to diesel units and, most importantly, relative fuel prices all contribute to the fuel's economic disadvantage. Even in the absence of other factors, these cost issues are powerful enough to prevent the penetration of LNG into the port setting, unless aggressively mitigated.

Unfortunately, certain characteristics of port operations and operators also present obstacles to the introduction of LNG. Among these, the most important appear to be the predominance and, more specifically, the economic profile of owner/operators in port trucking, the current vehicle purchase habits of the trucking sector, logistical concerns regarding refueling and maintenance of LNG trucks and terminal equipment, and the Ports' lack of leverage over their tenants' operations. Although it is unlikely that the success or failure of a port LNG program would hinge on any one of these factors, each would require some consideration in policy design and implementation.

\section{Critical Benefits}

The very substantial reductions in criteria pollutant emissions that would result from the replacement of diesel with LNG represents the most obvious and important near-term benefit to the fuel's use in the port setting. Moreover, even limited utilization of the fuel would result in significant and cost-effective emissions reductions, particularly in the off-road sector. While emissions reductions have tremendous value in and of themselves, they could also be of great 
strategic import to the Ports and their operators. Emissions reductions generated from low emission vehicle technologies such as LNG could provide emissions offsets for expansion projects, establish a bulwark against potential diesel emissions litigation and help to improve community relations.

Within California, regulatory activity and new public funding resources also provide impetus and means for utilizing low-emissions heavy-duty technologies such as LNG. The recent Proposition 65 lawsuits and the TAC listing have created a climate of uncertainty surrounding diesel fuel, particularly at sites of concentrated use. At the same time, a variety of new funding sources are available to defray the cost of using LNG technology in heavy-duty applications. Both the new Moyer Program and new funding from the CEC could greatly aid in the introduction of LNG to the Ports. Pending federal initiatives to provide tax credits for LNG fuel consumption and infrastructure development could have an even greater impact. If passed, these measures would make the economics of LNG use extremely attractive.

Finally, despite a range of attributes that present obstacles to LNG use, the Ports and their operators also have a number of characteristics that are amenable to the fuel and its associated technologies. The highly concentrated travel patterns of port truckers and the hub function of the Ports imply that only limited infrastructure would be necessary to serve most of the trucking communities' fueling needs. Moreover, because the truck populations serving the Ports are so large, even limited commitments from a number of operators could quickly accumulate to form a substantial aggregate demand. If packaged by the Port, this demand could be used to lure retail LNG fuel provision to the vicinity of the Ports, thereby negating the need for costly company refueling systems. Packaging demand and initiating aggressive efforts to encourage the use of LNG could lead to a range of additional benefits unique to the port environment. Because the Ports and their operators represent such large and geographically concentrated markets for technology and services, there is a far greater opportunity to catalyze the commercial provision of refueling, maintenance and even liquefaction systems. Moreover, as landowners, facility managers and commercial enterprises, the Port authorities are in a unique position to both facilitate and benefit from such developments.

\subsubsection{Mitigation Measures}

The numerous barriers detailed in this report and the absence of any clear and directed efforts to encourage alternative fuel use at the Ports have created a set of conditions in which it would be economically questionable and logistically problematic to utilize LNG in the applications evaluated here. Under the circumstances it is in no way surprising that neither LNG nor any other low emission alternative fuel are found in common use at the Ports. These conditions, however, as well as the key variables that shape them, are highly mutable. Ultimately, the feasibility of LNG use in the port setting is dependent less on present conditions than on the willingness and ability of the Ports and other relevant parties to devise means of mitigating the principal barriers and capitalizing on the key benefits associated with the fuel and its accompanying technologies.

Though the necessary conditions would be difficult to achieve, it is not unreasonable to expect that LNG use at the Ports could be economically and logistically viable, and even self-sustaining. This would require a broad-based and concerted effort on the part of both the Ports and other interested parties, such as regulatory agencies and planning agencies, within their respective regions. Some of the most promising measures that could be taken to foment and aid the successful utilization of LNG include the following:

- the development of local, small-scale liquefaction facilities;

- the granting of priority terminal access to low-emission alternative fuel vehicles;

Seaport Liquid Natural Gas Study - Final Report 
- the provision of retail LNG refueling infrastructure on port-controlled property;

- the incorporation of AFV-use incentives into port lease structures;

- and the establishment of a buyer's cooperative to assist in funding procurement and to coordinate new and used LNG equipment purchases.

Other measures that might also be effective in enabling LNG use include the establishment of a low-interest revolving loan fund for AFV purchases, subsidized training for local mechanics on LNG technology and exploration of wet-hosing as an alternative to on-terminal LNG refueling infrastructure. In addition to these efforts, the Ports should lobby their congressional representatives and trade associations to support federal initiatives granting tax credits for AFV use and infrastructure development.

Given the substantial barriers to LNG use, no individual measure listed above would likely be sufficient to enable the successful use of LNG at the Ports. Rather, the Ports would need to work in conjunction with local, state and federal government agencies, labor groups, port operators and other interested parties to create a broad policy framework and implementation strategy. Such a program would necessarily include many of these measures, as well as others generated in the planning process.

\subsection{Recommendations}

Based upon these findings, it is clear that the use of LNG at the Ports faces significant obstacles and it would be premature for the Ports to promote the exclusive utilization of the fuel and its associated technology at this time. This study has shown that under present conditions, use of the fuel in heavy-duty applications would not be cost-effective and would face some significant logistical obstacles. On the other hand, it does appear technically feasible to use LNG technology in place of diesel in these applications. Moreover, there would very likely be substantial benefits to doing so, particularly with regard to emissions of several criteria pollutants.

Ultimately, the magnitude of the potential emissions reductions, the heightened focus on diesel and the apparent conditionality of many of the current barriers all suggest that it is worthwhile to attempt to address these barriers, and premature to dismiss the fuel as a viable alternative. Towards this end, several critical steps could be taken that would benefit the Ports and their surrounding communities, without committing them to a particular technology pathway. These are as follows:

- Most notably, both Ports should move immediately to develop general alternative fuel incentive programs, incorporating provisions such as priority access for AFVs and AFV-friendly lease agreements. Such measures are critical if low-emission technologies are to find application at the Ports.

- The Ports should carefully monitor the evolving liability risks associated with concentrated diesel fuel use. This information should be shared with tenants in an on-going strategy group dedicated to addressing air quality issues at the Ports.

- The Ports should begin to identify those fleets and operations that might prove more receptive and amenable to utilizing non-conventional, low-emission technologies. These potential early-adopters should be given the opportunity to help shape incentive programs and encouraged to work with the Ports in developing appropriate demonstration projects.

- The Ports, in conjunction with regulatory and planning agencies, should design modernization and expansion projects in such a way as to facilitate and encourage the utilization of low-emission technologies such as LNG. Many of the barriers and 
mitigation strategies (priority lanes for low emission vehicles, space constraints, etc.) are best addressed during facility construction or modification.

- The Ports should capitalize on new and existing funding sources, and initiate a variety of technology evaluation projects. Stemming from earlier discussions, an extremely viable project could be the testing of a small-scale liquefaction system in conjunction with a LNG vehicle or equipment application. Such a project would be exceptionally valuable in assessing the ability of small-scale systems to deliver on their potential for low-cost local LNG production. Alternatively, the Ports could attempt to coordinate with PG\&E and So. Cal. Gas' on-going small-scale liquefaction program, concentrating their efforts on finding appropriate vehicle and equipment users.

For the most part, this study has focused on actions that could be taken by the Ports themselves as part of an effort to encourage the use of LNG within the operations associated with their facilities. It should be recognized, however, that while the Ports' potential influence is substantial, the viability of LNG use in this setting will ultimately be determined by a broad range of actors and variables. Should the introduction of LNG or other alternative fuels into the Ports heavy-duty vehicle operations be desired, for emissions or energy security reasons, then it is incumbent upon other government agencies to support these efforts through either technology development assistance or incentives.

The analysis has shown that, technically, LNG could be used at the Ports and to great environmental effect, but that current economic and logistical barriers make the utilization of LNG and the subsequent realization of these potential benefits very difficult. However, many of the barriers and drivers are or will be shaped by forces beyond the control of the Ports-forces such as changing oil prices or new emissions requirements stemming from revised regional air quality management and state implementation plans. Though there impact is uncertain, these variables have the potential to significantly improve the feasibility of LNG use and argue for continuing to evaluate $\mathrm{LNG}$ as an alternative to diesel in the port setting.

Many organizations, including but not limited to regional and state air quality regulators, regional planning organizations, port operators, and environmental and community groups have a stake in both air quality issues and the economic health of the Ports. Ensuring and improving the present status of both measures will require a cooperative effort between these various actors. The effort to introduce low emission technologies into the Ports provides an ideal foundation upon which to build this cooperative relationship. 


\section{This page intentionally left blank}




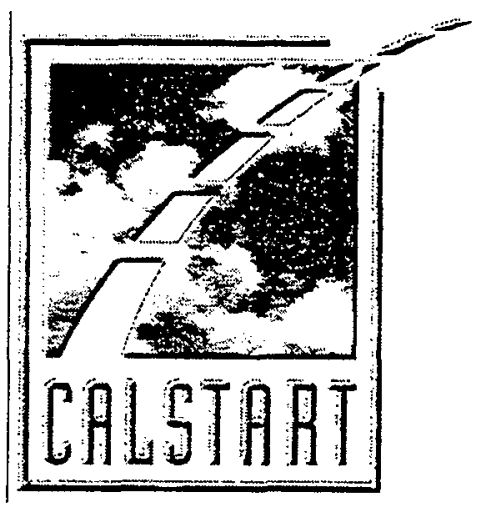

APPENDICES 


$$
1
$$




\section{APPENDIX A - Current U.S. LNG Refuse Hauler \& Trucking Programs}

\begin{tabular}{|c|c|c|c|c|c|c|c|c|c|c|}
\hline & Program Company/Agency & $\begin{array}{c}\text { Statel } \\
\text { Country }\end{array}$ & Fuel & $\begin{array}{c}\text { Number of } \\
\text { Vehicles }\end{array}$ & $\begin{array}{l}\text { Type of } \\
\text { Vehicle }\end{array}$ & $\begin{array}{l}\text { Vehicle } \\
\text { class }\end{array}$ & $\begin{array}{l}\text { Service Sch.l } \\
\text { Application }\end{array}$ & $\begin{array}{l}\text { Chassis } \\
\text { Manufacturer }\end{array}$ & $\begin{array}{c}\text { Engine } \\
\text { Manufacturer }\end{array}$ & $\begin{array}{l}\text { Engine } \\
\text { Model }\end{array}$ \\
\hline \multirow{15}{*}{$\begin{array}{l}\text { Class } 8 \\
\text { Tractors }\end{array}$} & Raley's Groceries, Sacramento & $\overline{C A}$ & LNG & 8 & Tractor-Trailer & 8 & Urban fleet & Kenworth & Cummins & L10-300G \\
\hline & Con-Way Western Express & $\mathrm{CA}$ & LNG & 2 & Tractor-Trailer & 8 & & Ford & Cummins & C Series \\
\hline & Ace Hardware, Irwindale & $\mathrm{CA}$ & LNG & 1 & Tractor-Trailer & 8 & Urban fleet & & & \\
\hline & Overnite Transportation, LA & $\mathrm{CA}$ & LNG & 1 & Tractor-Trailer & 8 & Urban fleet & & & \\
\hline & Houston Airgas & TX & LNG & 2 & Tractor-Trailer & 8 & & Freightliner & $\overline{D D C}$ & \begin{tabular}{|l|} 
Series \\
$50 G$ \\
\end{tabular} \\
\hline & UPS, Houston & TX & LNG & 2 & Tractor-Trailer & 8 & Urban fleet & & & \\
\hline & Detroit Diesel Corp, Detroit & MI & LNG & 1 & Tractor-Trailer & 8 & Urban fleet & Kenworth & $\overline{D D C}$ & \\
\hline & Gordon Foods, Brighton & MI & LNG & 1 & Tractor-Trailer & 8 & Urban fleet & & & \\
\hline & Roadway Express, Copley & $\mathrm{OH}$ & LNG & 6 & Tractor-Trailer & 8 & Urban fleet & & & \\
\hline & Overnite Transp., Richmond & VA & LNG & 1 & Tractor-Trailer & 8 & Urban fleet & Ford CF-7000 & Cummins & $\overline{B 5.9}$ \\
\hline & Perrier Group, Ontario & $\overline{C A}$ & LNG/DF & 8 & Tractor-Trailer & 8 & Urban fleet & & Power Systems & $\begin{array}{l}\text { 6: } C-10 / \\
\text { 2: } C-12\end{array}$ \\
\hline & Trucking Unlimited, Anaheim & $\overline{C A}$ & LNG/DF & 2 & Tractor-Trailer & 8 & Long-haul & & Power Systems & $\mathrm{C}-12$ \\
\hline & Jack B. Kelley, Fontana & $\mathrm{CA}$ & LNG/DF & 2 & Tractor-Trailer & 8 & Urban fleet & Navistar & Power Syslems & $3176 \mathrm{~B}$ \\
\hline & Lucky Stores, Buena Park & $\mathrm{CA}$ & LNG/DF & 1 & Traclor-Trailer & 8 & Urban fleet & & Power Systems & $\mathrm{C}-12$ \\
\hline & H.E.B. Grocery & $\overline{T X}$ & LNG/DF & 18 & Traclor-Trailer & 8 & Urban fleet & Ford & Power Systems & $\mathrm{C}-10$ \\
\hline \multirow{5}{*}{$\begin{array}{l}\text { Refuse } \\
\text { Haulers }\end{array}$} & City of Sacramento & $\overline{C A}$ & LNG & 2 & Refuse Haulers & & Refuse Haulers & & & \\
\hline & Waste Management & & LNG & 4 & Refuse Haulers & & Refuse Haulers & Mack & Mack & E7G-325 \\
\hline & BFI, Allanta & $\overline{G A}$ & LNG & 4 & Refuse Haulers & & Refuse Haulers & Peterbuilt 320 & Cummins & $L \overline{10-260}$ \\
\hline & William H. Martin, Inc. & $\overline{P A}$ & LNG & 7 & Refuse Haulers & & Refuse Haulers & Mack & Mack & E7G-325 \\
\hline & Taormina Industries, LA & $\overline{C A}$ & LNG/DF & 26 & Refuse Haulers & & Refuse Haulers & & Power Systems & $3176 \mathrm{~B}$ \\
\hline
\end{tabular}




\section{This page intentionally left blank}




\title{
APPENDIX B - Cost-effectiveness Calculations for Emission Reductions
}

\author{
Example 1 - Repower of Typical Port Vehicle (1988 Model Year) with Power Systems C12 \\ dual-fuel
}

CARB Annual Emission Reduction Calculation

Emission Reduction $=[($ Baseline NOx $)-($ Reduced NOx $)]($ Conversion Factor $)($ Annual Miles $)(\%$ operated in California)

Where,

Baseline NOx emissions $=$ CARB established emission level from existing engine: $6.0 \mathrm{~g} / \mathrm{bhp}$-hr

Reduced NOx emissions $=$ CARB certified NOx emission level from a new LNG engine: $2.5 \mathrm{~g} / \mathrm{bhp}$-hr

Conversion factor $\quad=2.6 \mathrm{bhp}$-hr $/ \mathrm{mile}$

Annual miles traveled $=63,000$ miles

$\%$ operated in California $=100 \%(1.0)$

Annual NOx reductions for above scenario are -

$((6.0-2.5) \mathrm{g} / \mathrm{bhp}-\mathrm{hr})(2.6 \mathrm{bhp}-\mathrm{hr} / \mathrm{mile})(63,000 \mathrm{miles} /$ year $)(1.0)=737,100 \mathrm{~g} /$ year $=.8125$ tons $/$ year

\author{
CARB Cost Effectiveness Calculation \\ Cost effectiveness $=[($ Capital Recovery Factor $)($ Incremental Repower Cost $)] /($ Annual NOx Reduction) \\ For purposes of this scenario, \\ Capital recovery factor $=.173$ (assumes project life of 7years and interest rate of $5 \%$ ) \\ Incremental repower cost $=\$ 55,000$ \\ Cost-effectiveness for above scenario is - \\ $[(.173)(\$ 55,000)] /(.8125$ tons NOx $)=\$ 11,710 /$ ton NOx reduced - would be considered cost-effective
}

\section{Example 2 - New LNG tractor purchased instead of new diesel vehicle (high end port trucking fleet)}

CARB Annual Emission Reduction Calculation

Emission Reduction $=[($ Baseline NOx $)-($ Reduced NOx $)]($ Conversion Factor $)($ Annual Miles $)(\%$ operated in California)

Where,

Baseline NOx emissions = CARB certified emission level from new diesel engine: $4.0 \mathrm{~g} / \mathrm{bhp}-\mathrm{hr}$

Reduced NOx emissions $=$ CARB certified NOx emission level from a new LNG engine: $2.5 \mathrm{~g} / \mathrm{bhp}$-hr

Conversion factor $\quad=2.6 \mathrm{bhp}-\mathrm{hr} / \mathrm{mile}$

Annual miles traveled $=87,500$ miles

$\%$ operated in California $=100 \%(1.0)$

Annual NOx reductions for above scenario are -

$((4.0-2.5) \mathrm{g} / \mathrm{bhp}-\mathrm{hr})(2.6 \mathrm{bhp}-\mathrm{hr} / \mathrm{mile})(87,500 \mathrm{miles} /$ year $)(1.0)=341,250 \mathrm{~g} /$ year $=.3761$ tons $/$ year 
CARB Cost Effectiveness Calculation

Cost effectiveness $=[($ Capital Recovery Factor $)($ Incremental Repower Cost $)] /$ (Annual NOx Reduction)

For purposes of this scenario,

Capital recovery factor $=.13$ (assumes project life of 10 years and interest rate of $5 \%$ )

Incremental cost $\quad=\$ 30,000$

Cost-effectiveness for above scenario is -

$[(.13)(\$ 30,000)] /(.376$ ltons NOx $)=\$ 10,369 /$ ton NOx reduced - would be considered cost-effective

Example 3 - Repowering of yard tractor to LNG (1994 model year) using Cummins B5.9G

CARB Annual Emission Reduction Calculation

Emission Reduction $=[($ Baseline NOx $)-($ Reduced NOx $)]($ Conversion Factor $)($ Annual Miles $)(\%$ operated in California)

Where,

Baseline NOx emissions = CARB established emission level from existing engine: $11.0 \mathrm{~g} / \mathrm{bhp}-\mathrm{hr}$

Reduced NOx emissions $=$ CARB certified NOx emission level from a new LNG engine: $2.5 \mathrm{~g} / \mathrm{bhp}-\mathrm{hr}$

Conversion factor $\quad=18.5 \mathrm{hp}-\mathrm{hr} / \mathrm{gal}$

Annual miles traveled $=7,000$ gallons $(3500 \mathrm{hrs} . \times 2.0 \mathrm{mpg})$

$\%$ operated in California $=100 \%(1.0)$

Annual NOx reductions for above scenario are -

$((11.0-2.5) \mathrm{g} / \mathrm{bhp}-\mathrm{hr})(18.5 \mathrm{bhp}-\mathrm{hr} / \mathrm{gal})(7,000 \mathrm{gal} /$ year $)(1.0)=1,100,750 \mathrm{~g} /$ year $=1.213$ tons $/$ year

CARB Cost Effectiveness Calculation

Cost effectiveness $=[($ Capital Recovery Factor $)($ Incremental Repower Cost $)] /($ Annual NOx Reduction $)$

For purposes of this scenario,

Capital recovery factor $=.173$ (assumes project life of 7years and interest rate of $5 \%$ )

Incremental repower cost $=\$ 28,000$

Cost-effectiveness for above scenario is -

$[(.173)(\$ 28,000)] /(1.213$ tons NOx $)=\$ 5332 /$ ton NOx reduced - would be considered cost-effective. 


\section{APPENDIX C - Cost Parity Model Inputs}

\section{Truck Fleet Operating Scenario for Evaluating Conversion to $\mathrm{LNG}^{\dagger}$}

Fleet Characteristics

\begin{tabular}{|c|c|c|c|c|}
\hline Characteristic & unit & Default & User Input & Assumptions and Notes \\
\hline Number of trucks in Candidate Fleet & - & 12 & 35 & \multirow{12}{*}{ Existing fleet uses Diesel No. 2.} \\
\hline Annual Mileage Accumulation per truck & $\mathrm{mi} /$ truck/yr & 90,000 & 65,000 & \\
\hline Length of a truck's operating day & hrs & & & \\
\hline in-service days per year & $\mathrm{d} /$ truck/yr & 260 & 250 & \\
\hline Implied average operating speed & $\mathrm{mi} / \mathrm{hr}$ & 33 & (output) & \\
\hline fleet average fuel economy & mi/gallon & 7.50 & 6.50 & \\
\hline on-board fuel capacity & gal/truck & 125 & & \\
\hline Delivered cost of diesel fuel & $\$ /$ gallon & & & \\
\hline Applicable sales tax rate on fuel & $\%$ & $7.75 \%$ & $8.25 \%$ & \\
\hline \multicolumn{4}{|l|}{$\begin{array}{l}\text { Applicable diesel fleet fueling scenario } \\
\text { Fleet-owned fueling facility } \\
\text { Fuel Vendor's fueling facility } \\
\text { On-site fueling service }\end{array}$} & \\
\hline Incremental travel to fueling facility & mi/fill & 0 & - & \\
\hline Truck driver labor + fringe benefits & $\$ / \mathrm{hr}$ & 30 & & \\
\hline
\end{tabular}

\section{Characteristics of the planned LNG fleet operation}

\begin{tabular}{|c|c|c|c|c|}
\hline Characteristic & unit & Default & $\begin{array}{l}\text { User } \\
\text { Input }\end{array}$ & Assumptions and Notes \\
\hline Delivered LNG fuel cost & $\$ /$ gal & 0.400 & & $\begin{array}{l}\text { Sat. liquid at } 14.7 p s i a . \text { Exclude } \\
\text { taxes. }\end{array}$ \\
\hline Incremental travel to LNG fueling facility & miffill & 1 & 0 & \\
\hline LNG dispenser cool-down time & $\min / f i l l$ & 10 & 0 & \\
\hline \multicolumn{5}{|l|}{ Incremental LNG truck capital } \\
\hline Diesel Pilot Ignition (PI) engine & \$/truck & 30,000 & & \\
\hline Spark Ignition (SI) engine & \$/truck & 45,000 & & \\
\hline \multicolumn{5}{|l|}{ Cost Sharing by outside organizations } \\
\hline Incremental LNG truck capital - PI & $\$ /$ truck & 30,000 & & \\
\hline Incremental LNG truck capital - SI & \$/truck & 45,000 & & \\
\hline Fueling facility capital & \$/facility & & 500000 & \\
\hline LNG sold to other customers & gallons/mo & 0 & & $\begin{array}{l}\text { Hold time of assumed } 6.0 \mathrm{~K} \text { gal } \\
\text { tank is } 3.5 \mathrm{~d} \text {. }\end{array}$ \\
\hline Interest rate for amortizing capital costs & $\% / y r$ & $8.0 \%$ & $5 \%$ & - \\
\hline Truck replacement life in fleet service & yr & 8 & & \\
\hline Cost to repower engine to diesel for salvage-PI & \$/truck & 2,000 & $\overline{0}$ & $\begin{array}{l}\text { Needed for diesel-equivalent } \\
\text { salvage value. }\end{array}$ \\
\hline Cost to repower engine to diesel for salvage-SI & \$/truck & 7,500 & 0 & $\begin{array}{l}\text { Needed for diesel-equivalent } \\
\text { salvage value. }\end{array}$ \\
\hline Salvage value of used LNG tanks & \$/truck & 2,000 & 0 & \\
\hline Availability loss for LNG maintenance & $\%$ & $5 \%$ & $0 \%$ & Relative to diesel maintenance. \\
\hline
\end{tabular}

† From LNG/diesel cost parity model developed for the Sacramento Metropolitan Air Quality Management District by Arcadis, Geraghty and Miller. 


\section{This page intentionally left blank}




\section{APPENDIX D - LNG to Diesel Gallon Equivalent Price Conversion}

Calculating retail, diesel gallon equivalent price for $L N G$ from delivered $L N G$ price

Formula is as follows:

Diesel equivalent retail price of $L N G=[($ pre-tax LNG price $+.119+.01) \times 1.7)] \times 1.0825$

Where:

Pre-tax $L N G$ price is given in $\$ / L N G$ gallon

$.119=$ federal excise tax/LNG gallon

$.01=$ state excise tax $/ \mathrm{LNG}$ gallon

$1.7=$ energy equivalency factor

$1.0825=$ state and local sales tax

Sample calculation:

Pre-tax LNG price $=.50 / \mathrm{LNG}$ gallon

Diesel equivalent retail price of $L N G=[(.50+.119+.01) \times 1.7)] \times 1.0825=\$ 1.16 / D E G$ 


\section{This page intentionally left blank}




\title{
APPENDIX E - Emissions Calculations
}

\section{Port of Los Angeles - On-road Emissions Calculations}

Emissions and potential emissions reductions from port-related trucking operations were calculated using standard ARB methodology provided in the Carl Moyer program guidelines for on-road heavy-duty vehicles. Each criteria pollutant is calculated separately, as are diesel and LNG emissions. In these calculations the ARB $2.6 \mathrm{bhp}-\mathrm{hr} / \mathrm{mile}$ conversion factor is used to convert emissions from grams per brake horsepower-hour into grams per mile. This conversion factor was developed specifically for heavy-duty line haul trucks based upon their particular dutycycle. LNG engine emission calculations were based upon emission levels from the Caterpillar C12 LNG engine during the ARB certification process. All vehicles are assumed to be operating $100 \%$ in California.

In order to more accurately assess current diesel vehicle emissions, emission factors (ARB standards) for various model years (MY) were used to reflect the variety in vehicle ages found at the port. Reflecting the fleet composition reported by survey results, $74 \%$ of the vehicles were calculated using pre-1990 standards, 19\% using 1991-93 standards, and 7\% using the 1994+ standards.

\author{
Emission Calculation \\ Annual Emission $=[($ annual mileage $)($ emission std. $)($ conv. factor $)(\%$ operated in CA $)]$ \\ where, \\ Annual Mileage $\quad=68,000$ miles (based upon daily mileage of 272 miles) \\ Emission Standard $\quad=$ certified emission level from new diesel engine (according to model year) or emission \\ level reported for CAT C12 LNG engine during certification process (see Table 4-5), in \\ Conversion Factor \\ g/bhp-hr \\ $\%$ Operated in CA $\quad=1$ (i.e., $100 \%$ )
}

Results were then converted to tons by dividing by 907,200 grams. Each MY result was then multiplied by the corresponding fleet composition percent, and then totaled to obtain port-related trucking emissions. 
Diesel Trucking Calculations

\begin{tabular}{|c|c|c|}
\hline \multicolumn{3}{|c|}{ pre-1990 Vehicle Colemission Calculations } \\
\hline $\begin{array}{c}\text { daily mileage * } \\
272\end{array}$ & $\begin{array}{c}\text { work days } / y r= \\
250\end{array}$ & $\begin{array}{c}\text { annual mileage } \\
68,000\end{array}$ \\
\hline $\begin{array}{cc}\text { emission std * } & \text { bhp-hr/mile } \\
15.5 & 2.6\end{array}$ & $\begin{array}{c}\text { annual mileage }= \\
68,000\end{array}$ & $\begin{array}{c}\text { emissions }(g / y r) \\
2,740,400\end{array}$ \\
\hline $\begin{array}{l}\text { grams/yr I } \\
2,740,400\end{array}$ & $\begin{array}{c}\text { grams/ton } \\
907,200\end{array}$ & $\begin{array}{l}\text { tons/yr } \\
3.02\end{array}$ \\
\hline
\end{tabular}

\begin{tabular}{|c|c|c|c|}
\hline \multicolumn{4}{|c|}{ 1997-1993 Venice cotemission calculations } \\
\hline & $\begin{array}{c}\text { dally mileage * } \\
272\end{array}$ & $\begin{array}{c}\text { work days/yt }= \\
250\end{array}$ & $\begin{array}{c}\text { annual mileage } \\
68,000\end{array}$ \\
\hline \multirow{2}{*}{$\begin{array}{c}\text { emission std } \\
15.5\end{array}$} & ${ }^{*}$ bhp-hr/mile* & annual mileage $=$ & emissions $(g / y)$ \\
\hline & 2.6 & 68,000 & $2,740,400$ \\
\hline & grams/yr ! & grams/ton & tons/yr \\
\hline & $2,740,400$ & 907,200 & 3.02 \\
\hline
\end{tabular}

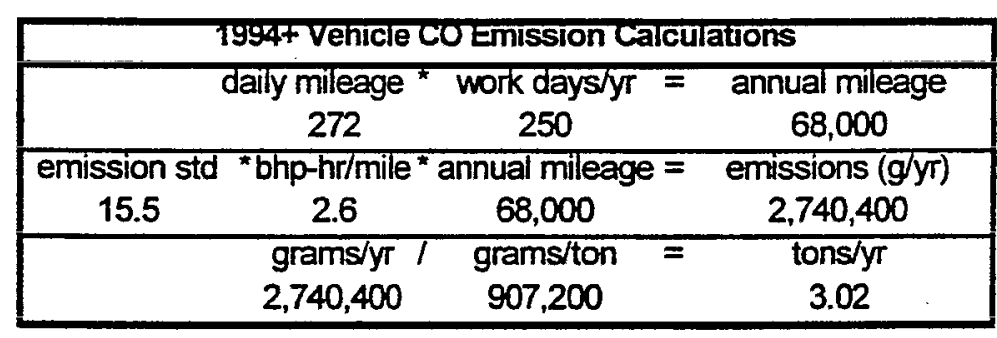

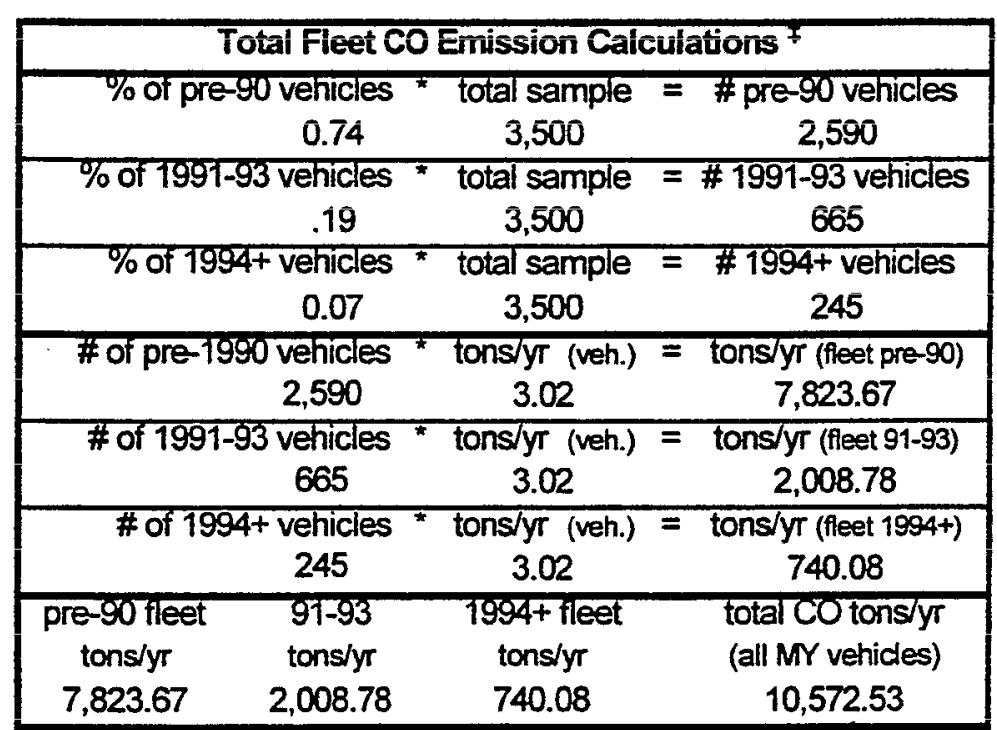

$\mp$ Sample Fleet is estimated from available data 


\begin{tabular}{|c|c|c|c|}
\hline \multicolumn{4}{|c|}{ pre-1990 Vehicle NhHAC Emission Calculations } \\
\hline & $\begin{array}{c}\text { daily mileage * } \\
272\end{array}$ & $\begin{array}{c}\text { work days/yr }= \\
250\end{array}$ & $\begin{array}{c}\text { annual mileage } \\
68,000\end{array}$ \\
\hline \multirow{2}{*}{$\begin{array}{c}\text { emission st } \\
0.5\end{array}$} & $d^{*} \mathrm{bhp}-\mathrm{hr} / \mathrm{mile}{ }^{*}$ & annual mileage $=$ & emissions ( $g / y r)$ \\
\hline & 2.6 & 68,000 & 88,400 \\
\hline & grams/yr I & grams/ton & tons/yr \\
\hline & 88,400 & 907,200 & 0.10 \\
\hline
\end{tabular}

\begin{tabular}{|c|c|c|c|}
\hline \multicolumn{4}{|c|}{ 1991-1993 Venicle NivifC Emission Calculations } \\
\hline & dally mileage * & work days/yr = & annual mileage \\
\hline & 272 & 250 & 68,000 \\
\hline emission & $\mathrm{d}^{*} \mathrm{bhp}-\mathrm{hr} / \mathrm{mile} \mathrm{e}^{*}$ & annual mileage $=$ & emissions ( $g / y r)$ \\
\hline 0.5 & 2.6 & 68,000 & 88,400 \\
\hline & $\begin{array}{c}\text { grams/yr } / \\
88,400\end{array}$ & $\begin{array}{c}\text { grams/ton } \\
907,200\end{array}$ & $\begin{array}{c}\text { tons/yr } \\
0.10\end{array}$ \\
\hline
\end{tabular}

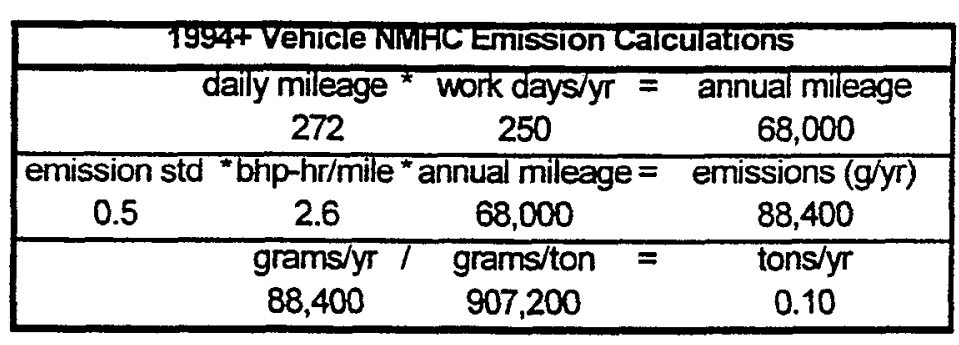

\begin{tabular}{|c|c|c|c|}
\hline \multicolumn{4}{|c|}{ Total Fleet NMHC Emission Calculations ${ }^{+}$} \\
\hline \multicolumn{2}{|c|}{$\%$ of pre-govehicies } & total sample & = \#pre-90 vehicies \\
\hline & 0.74 & 3,500 & 2,590 \\
\hline \multicolumn{2}{|c|}{$\%$ of $7997-93$ vehicles } & total sample & $=\# 1991-93$ vehicles \\
\hline \multicolumn{2}{|c|}{.19} & 3,500 & 665 \\
\hline \multicolumn{2}{|c|}{$\%$ of $1994+$ vehicles } & total sample & $=\# 1994+$ vehicles \\
\hline & 0.07 & 3,500 & 245 \\
\hline \multicolumn{2}{|c|}{ \# of pre-1990 vehicles } & tons/yr (veh.) & $=$ tons/yr (fleet pre-90) \\
\hline \multicolumn{2}{|c|}{2,590} & 0.10 & 252.38 \\
\hline \multirow{2}{*}{\multicolumn{2}{|c|}{$\begin{array}{r}\text { \# of 1991-93 vehicles } \\
665\end{array}$}} & tons/yr (veh.) & $=$ tons/yr (fleet 91-93) \\
\hline & & 0.10 & 64.80 \\
\hline \multicolumn{2}{|c|}{ \# of $1994+$ vehicles } & tons/yr (veh.) & $=$ tons/yr (fleet 1994t) \\
\hline & 245 & 0.10 & 23.87 \\
\hline $\begin{array}{l}\text { pre-90 fleet } \\
\text { tons } / y \text { r }\end{array}$ & $\begin{array}{l}91-93 \\
\text { tons/yr }\end{array}$ & $\begin{array}{l}1994+\text { fleet } \\
\text { tons/yr }\end{array}$ & $\begin{array}{l}\text { total HC tons/yr } \\
\text { (all MY vehicles) }\end{array}$ \\
\hline 252.38 & 64.80 & 23.87 & 341.05 \\
\hline
\end{tabular}

$\ddagger$ Sample Fleet is estimated from available data 


\begin{tabular}{|c|c|c|c|}
\hline \multicolumn{4}{|c|}{ pre-1990 Vehicle Nox Emission Calculations } \\
\hline & $\begin{array}{l}\text { dally mileage } \\
272\end{array}$ & $\begin{array}{c}\text { work days/yr = } \\
250\end{array}$ & $\begin{array}{c}\text { annual mileage } \\
68,000\end{array}$ \\
\hline $\begin{array}{l}\text { emission std } \\
6\end{array}$ & $\begin{array}{c}\text { bhp-hr/mile } \\
2.6\end{array}$ & $\begin{array}{c}\text { annual mileage }= \\
68.000\end{array}$ & $\begin{array}{c}\text { emissions }(g / y r) \\
1,060,800\end{array}$ \\
\hline & $\begin{array}{l}\text { grams/yr } \\
1,060,800\end{array}$ & $\begin{array}{c}\text { grams/ton } \\
907,200\end{array}$ & $\begin{array}{c}\text { tons } / y r \\
1.17\end{array}$ \\
\hline
\end{tabular}

\begin{tabular}{|c|c|c|c|}
\hline \multicolumn{4}{|c|}{ 1991-1993 Vehicle Nox Emission Calculations } \\
\hline & $\begin{array}{l}\text { dally mileage } \\
272\end{array}$ & $\begin{array}{l}\text { work days } / y r= \\
250\end{array}$ & $\begin{array}{c}\text { annual mileage } \\
68,000\end{array}$ \\
\hline emission std & bhp-hr/mile & annual mileage $=$ & emissions ( $g / y r)$ \\
\hline 5 & 2.6 & 68,000 & 884,000 \\
\hline & grams/yr & grams/ton & tons/yr \\
\hline & 884,000 & 907,200 & 0.97 \\
\hline
\end{tabular}

\begin{tabular}{|c|c|c|c|}
\hline \multicolumn{4}{|c|}{ 1994+Veficie NOX Emission Calculations } \\
\hline & $\begin{array}{l}\text { dally mileage } \\
272\end{array}$ & $\begin{array}{c}\text { work days } / y T= \\
250\end{array}$ & $\begin{array}{c}\text { annual mileage } \\
68,000\end{array}$ \\
\hline $\begin{array}{c}\text { emission std } \\
5\end{array}$ & $\begin{array}{c}\text { bhp-hr/mile } \\
2.6\end{array}$ & $\begin{array}{c}\text { annual mileage }= \\
68,000\end{array}$ & $\begin{array}{c}\text { emissions }(g / y r) \\
884,000\end{array}$ \\
\hline & $\begin{array}{l}\text { grams/yr } \\
884,000\end{array}$ & $\begin{array}{c}\text { grams/ton } \\
907,200\end{array}$ & $\begin{array}{l}\text { tons/yr } \\
0.97\end{array}$ \\
\hline
\end{tabular}

\begin{tabular}{|c|c|c|c|}
\hline \multicolumn{4}{|c|}{ Total Fleet NOx Emission Calculations ${ }^{7}$} \\
\hline$\%$ of & e-90vehicles & total sample & $=$ \# pre-90 vehicies \\
\hline & 0.74 & 3,500 & 2,590 \\
\hline$\%$ of 19 & 1-93 vehicles & total sample & $=\# 1991-93$ vehicles \\
\hline & .19 & 3,500 & 665 \\
\hline$\%$ of & $94+$ veficles & total sample & $=$ \# 1994+vehicles \\
\hline & 0.07 & 3,500 & 245 \\
\hline \#orpre & 990 vehicles & tons/yr (veh.) & $=$ tons/yr (fleet pre-90) \\
\hline & 2,590 & 1.17 & $3,028.52$ \\
\hline \# of 19 & 1-93 vehicies & tons/yr (veh.) & $=$ tons/yr (fieet 91-93) \\
\hline & 665 & 0.97 & 647.99 \\
\hline \# of 1 & $94+$ vehicles & tons/yr (veh.) & $=$ tons/yr (fleet 1994+) \\
\hline & 245 & 0.97 & 238.73 \\
\hline pre-90 tleet & $91-93$ fleet & $7994+$ fleet & total Nox tons/yr \\
\hline tons/yr & tons/yr & tons/yr & (all MY vehides) \\
\hline $3,028.52$ & 647.99 & 238.73 & $3,915.25$ \\
\hline
\end{tabular}

$¥$ Sample Fleet is estimated from available data

E-4 


\begin{tabular}{|c|c|c|c|}
\hline \multicolumn{4}{|c|}{ pre-1990 Vehicle PMI Emission Calculations } \\
\hline & $\begin{array}{l}\text { dally mileage } \\
272\end{array}$ & $\begin{array}{l}\text { work days } / y T= \\
250\end{array}$ & $\begin{array}{c}\text { annual mileage } \\
68,000\end{array}$ \\
\hline emission std & bhp-hr/mile & annual mileage $=$ & emissions $(g / y r)$ \\
\hline 0.6 & 2.6 & 68,000 & 106,080 \\
\hline & grams/yr & grams/ton & tons/yr \\
\hline & 106,080 & 907,200 & 0.12 \\
\hline
\end{tabular}

\begin{tabular}{|c|c|c|c|}
\hline \multicolumn{4}{|c|}{ 1991-1993 Venicle Plin emission Calculations } \\
\hline & $\begin{array}{c}\text { dally mileage } \\
272\end{array}$ & $\begin{array}{c}\text { work days/yr }= \\
250\end{array}$ & $\begin{array}{c}\text { annual mileage } \\
68,000\end{array}$ \\
\hline emission std & * bhp-hr/mile * & annual mileage $=$ & emissions $(g / y r)$ \\
\hline 0.25 & 2.6 & 68,000 & 44,200 \\
\hline & $\begin{array}{c}\text { grams/yr } \\
44,200\end{array}$ & $\begin{array}{c}\text { grams/ton } \\
907,200\end{array}$ & $\begin{array}{l}\text { tons/yr } \\
0.05\end{array}$ \\
\hline
\end{tabular}

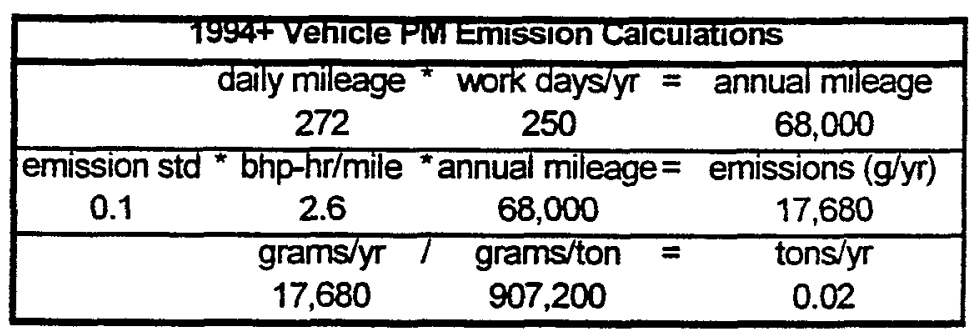

\begin{tabular}{|c|c|c|c|}
\hline \multicolumn{4}{|c|}{ Total Fleet PM Emission Calculations ${ }^{*}$} \\
\hline \multicolumn{4}{|c|}{$\%$ of pre-90 vehicles " total sample $=$ \# pre-90 vehicles } \\
\hline & 0.74 & 3,500 & 2,590 \\
\hline \multicolumn{4}{|c|}{$\%$ of $1997-93$ venicles } \\
\hline & .19 & 3,500 & 665 \\
\hline \multicolumn{4}{|c|}{ \% of $1994+$ vehicles " total sample $=\# 1994+$ vehicles } \\
\hline & 0.07 & 3,500 & 245 \\
\hline \multicolumn{2}{|c|}{ \# of pre-1990 vehicles } & tons/yr (veh.) & $=$ tons/yr (fieet pre-90) \\
\hline & 2,590 & 0.12 & 302.85 \\
\hline \multicolumn{2}{|c|}{ \# of 1991-93 vehicles } & tons/yr (veh.) & $=$ tons/yr (fleet 91-93) \\
\hline \multirow{2}{*}{\multicolumn{2}{|c|}{$\frac{665}{\text { \# of 1994+ vehicles }}$}} & 0.05 & 32.40 \\
\hline & & tons/yr (veh.) & $=$ tons/yT (fleet 1994+) \\
\hline & 245 & 0.02 & 4.77 \\
\hline $\begin{array}{l}\text { pre-90 fleet } \\
\text { tons/yr }\end{array}$ & $\begin{array}{l}97-93 \text { fleet } \\
\text { tons/yr }\end{array}$ & $\begin{array}{l}\text { 1994+ fleet } \\
\text { tons/yr }\end{array}$ & $\begin{array}{l}\text { total PM tons/yT } \\
\text { (all MY vehicles) }\end{array}$ \\
\hline 302.85 & 32.40 & 4.77 & 340.03 \\
\hline
\end{tabular}

¥ Sample Fleet is estimated from available data 


\section{LNG Trucking Calculations}

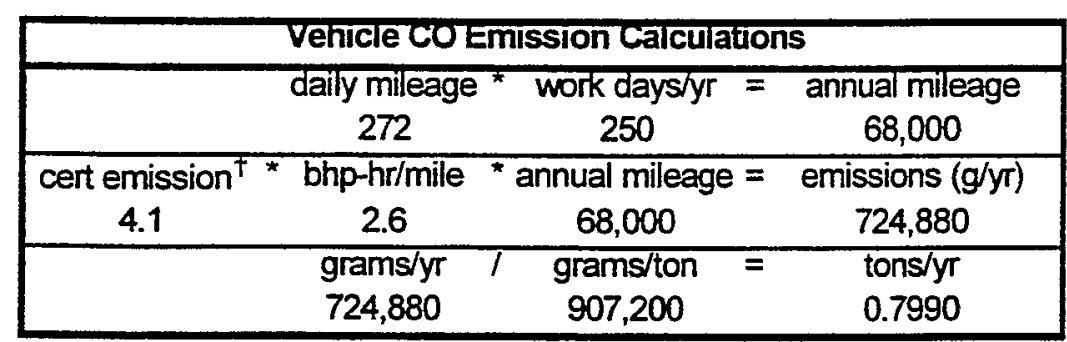

Total Fleet CO Emission Calculations *

\# of fleet venicles emission factor total Nox emissions

(total fleet) * $\quad$ (tons/yr) $=$ (fleet-tons/year)
3,500
0.7990
$2,796.60$

\begin{tabular}{|c|c|c|c|}
\hline \multicolumn{4}{|c|}{ Vehicle NIVIACEmission Calculations } \\
\hline & $\begin{array}{c}\text { dally mileage * } \\
272\end{array}$ & $\begin{array}{c}\text { work days } / y r= \\
250\end{array}$ & $\begin{array}{c}\text { annual mileage } \\
68,000\end{array}$ \\
\hline $\begin{array}{c}\text { cert emission } \\
0.5\end{array}$ & $\begin{array}{c}\text { bhp-hr/mile * } \\
26\end{array}$ & $\begin{array}{c}\text { annual mileage }= \\
68.000\end{array}$ & $\begin{array}{c}\text { emissions }(g / y \tau) \\
88,400\end{array}$ \\
\hline & $\begin{array}{c}\text { grams/yr } \\
88,400\end{array}$ & $\begin{array}{c}\text { grams/ton } \\
907,200\end{array}$ & $\begin{array}{l}\text { tonsiyr } \\
0.0974\end{array}$ \\
\hline
\end{tabular}

Total Fleet NMHC Emission Calculations *

\# of fleet vehicles emission factor total Nox emissions

(total fleet) * (tons/yr) = (fleet-tons/year)

$\begin{array}{lll}3,500 & 0.0974 & 341.05\end{array}$

I Sample Fleet is estimated from available data

t Obtained from Caterpillar (PSA) C12 LNG engine during certification process 


\begin{tabular}{|c|c|c|c|c|}
\hline \multicolumn{5}{|c|}{ Vehicle Nox Emission Calculations } \\
\hline & $\begin{array}{l}\text { dally mileage * } \\
272\end{array}$ & $\begin{array}{c}\text { work days/yr } \\
250\end{array}$ & & $\begin{array}{c}\text { annual mileage } \\
68,000\end{array}$ \\
\hline $\begin{array}{c}\text { cert emission }{ }^{\dagger} \\
2.4\end{array}$ & $\begin{array}{c}\text { bhp-hr/mile * } \\
2.6\end{array}$ & $\begin{array}{c}\text { annual mileage } \\
68,000\end{array}$ & & $\begin{array}{c}\text { emissions }(g / y r) \\
424,320\end{array}$ \\
\hline & $\begin{array}{l}\text { grams/yr } \\
424,320\end{array}$ & $\begin{array}{c}\text { grams/ton } \\
907,200\end{array}$ & $\equiv$ & $\begin{array}{l}\text { tons/yr } \\
0.4677\end{array}$ \\
\hline
\end{tabular}

\begin{tabular}{|c|c|c|}
\hline \multicolumn{3}{|c|}{ Total Fleet NOx Emission Calculations ${ }^{+}$} \\
\hline $\begin{array}{c}\text { \# of fleet vehicles } \\
\text { (total fleet) } \\
3,500\end{array}$ & $\begin{array}{c}\text { emission factor } \\
\text { (tons/yr) } \\
0.4677\end{array}$ & $\begin{array}{c}\text { total NOx emissions } \\
=\quad \text { (fleet-tons/year) } \\
1,637.04\end{array}$ \\
\hline
\end{tabular}

\begin{tabular}{|c|c|c|c|c|}
\hline \multicolumn{5}{|c|}{ Venicle Plutemission Calculations } \\
\hline & $\begin{array}{l}\text { daily mileage } \\
272\end{array}$ & $\begin{array}{c}\text { work days/yr } \\
250\end{array}$ & & $\begin{array}{c}\text { annual mileage } \\
68,000\end{array}$ \\
\hline cert emission & bhp-hr/mile & annual mileage & & emissions (g/yr) \\
\hline 0.1 & 2.6 & 68,000 & & 17,680 \\
\hline & $\begin{array}{c}\text { grams/yr } \\
17,680\end{array}$ & $\begin{array}{l}\text { grams/ton } \\
907,200\end{array}$ & $=$ & $\begin{array}{l}\text { tons/yr } \\
0.0195\end{array}$ \\
\hline
\end{tabular}

Total Fleet PM Emission Calculations ${ }^{*}$

\# of fleet vehicles emission factor total PM emissions

(total fleet) * (tons/yr) = (fleet-tons/year)

$3,500 \quad 0.0195 \quad 68.21$

¥ Sample Fleet is estimated from available data

t Obtained from Caterpillar (PSA) C12 LNG engine during certification process 


\section{Port of Oakland - On-road Emissions Calculations}

Emissions and potential emissions reductions from port-related trucking operations were calculated using standard ARB methodology provided in the Carl Moyer program guidelines for on-road heavy-duty vehicles. Each criteria pollutant is calculated separately, as are diesel and LNG emissions. In these calculations the ARB $2.6 \mathrm{bhp}-\mathrm{hr} / \mathrm{mile}$ conversion factor is used to convert emissions from grams per brake horsepower-hour into grams per mile. This conversion factor was developed specifically for heavy-duty line haul trucks based upon their particular dutycycle. LNG engine emission calculations were based upon emission levels from the Caterpillar C12 LNG engine during the ARB certification process. All vehicles are assumed to be operating $100 \%$ in California.

In order to more accurately assess current diesel vehicle emissions, emission factors (ARB standards) for various model years (MY) were used to reflect the variety in vehicle ages found at the port. Reflecting the fleet composition reported by survey results, $74 \%$ of the vehicles were calculated using pre-1990 standards, 19\% using 1991-93 standards, and 7\% using the 1994+ standards.

\section{Emission Calculation}

Annual Emission $=[($ annual mileage $)($ emission std. $)($ conv. factor $)(\%$ operated in CA $)]$

where,

Annual Mileage

Emission Standard

Conversion Factor

$\%$ Operated in CA

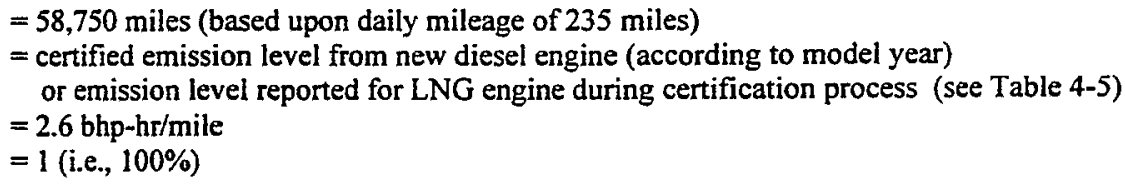

Results were then converted to tons by dividing by 907,200 grams. Each MY results were then multiplied by the corresponding percent of fleet composition, and then totaled to obtain portrelated trucking emissions. 
Diesel Trucking Calculations

\begin{tabular}{|c|c|c|c|}
\hline \multicolumn{4}{|c|}{ pre-1990 Vehicle CO Emission Calculations } \\
\hline & $\begin{array}{c}\text { dally mileage } \\
235\end{array}$ & $\begin{array}{c}\text { work days/yr } \\
250\end{array}$ & $\begin{array}{c}=\text { annual mileage } \\
58,750\end{array}$ \\
\hline $\begin{array}{c}\text { emission std } \\
15.5\end{array}$ & $\begin{array}{l}\text { bhp-hr/mile } \\
2.6\end{array}$ & $\begin{array}{c}\text { annual mileage } \\
58,750\end{array}$ & $\begin{array}{c}\text { emissions }(g / y r) \\
2,367,625\end{array}$ \\
\hline & $\begin{array}{l}\text { grams/yr } \\
2,367,625\end{array}$ & $\begin{array}{c}\text { grams/ton } \\
907,200\end{array}$ & $\begin{array}{c}\text { tons } / y r \\
2.61\end{array}$ \\
\hline
\end{tabular}

\begin{tabular}{|c|c|c|c|}
\hline \multicolumn{4}{|c|}{ 1991-1993 Vehicle Cotemission Calculations } \\
\hline & $\begin{array}{l}\text { daily mileage * } \\
\qquad 235\end{array}$ & $\begin{array}{c}\text { work days/yr }= \\
250\end{array}$ & $\begin{array}{c}\text { annual mileage } \\
58,750\end{array}$ \\
\hline $\begin{array}{c}\text { emission std } \\
15.5\end{array}$ & $\begin{array}{c}\text { bhp-hr/mile } \\
2.6\end{array}$ & $\begin{array}{c}\text { annual mileage }= \\
58,750\end{array}$ & $\begin{array}{c}\text { emissions ( } g / \mathrm{yr}) \\
2,367,625\end{array}$ \\
\hline & $\begin{array}{c}\text { grams/yr } \\
2,367,625\end{array}$ & $\begin{array}{c}\text { grams/ton } \\
907,200\end{array}$ & $\begin{array}{c}\text { tons/yr } \\
2.61\end{array}$ \\
\hline
\end{tabular}

\begin{tabular}{|c|c|c|c|}
\hline \multicolumn{4}{|c|}{ T9947 Venicle Colemission Calculations } \\
\hline & $\begin{array}{c}\text { dally mileage * } \\
\qquad 235\end{array}$ & $\begin{array}{c}\text { work daysyr }= \\
250\end{array}$ & $\begin{array}{c}\text { annual mileage } \\
58,750\end{array}$ \\
\hline $\begin{array}{c}\text { emission std } \\
15.5\end{array}$ & $\begin{array}{c}\text { bhp-hr/mile * } \\
2.6\end{array}$ & $\begin{array}{c}\text { annual mileage }= \\
58,750\end{array}$ & $\begin{array}{c}\text { emissions ( } g / \mathrm{yr}) \\
2,367,625\end{array}$ \\
\hline & $\begin{array}{c}\text { grams/yr } \\
2,367,625\end{array}$ & $\begin{array}{c}\text { grams/ton } \\
907,200\end{array}$ & $\begin{array}{c}\text { tons/yr } \\
2.61\end{array}$ \\
\hline
\end{tabular}

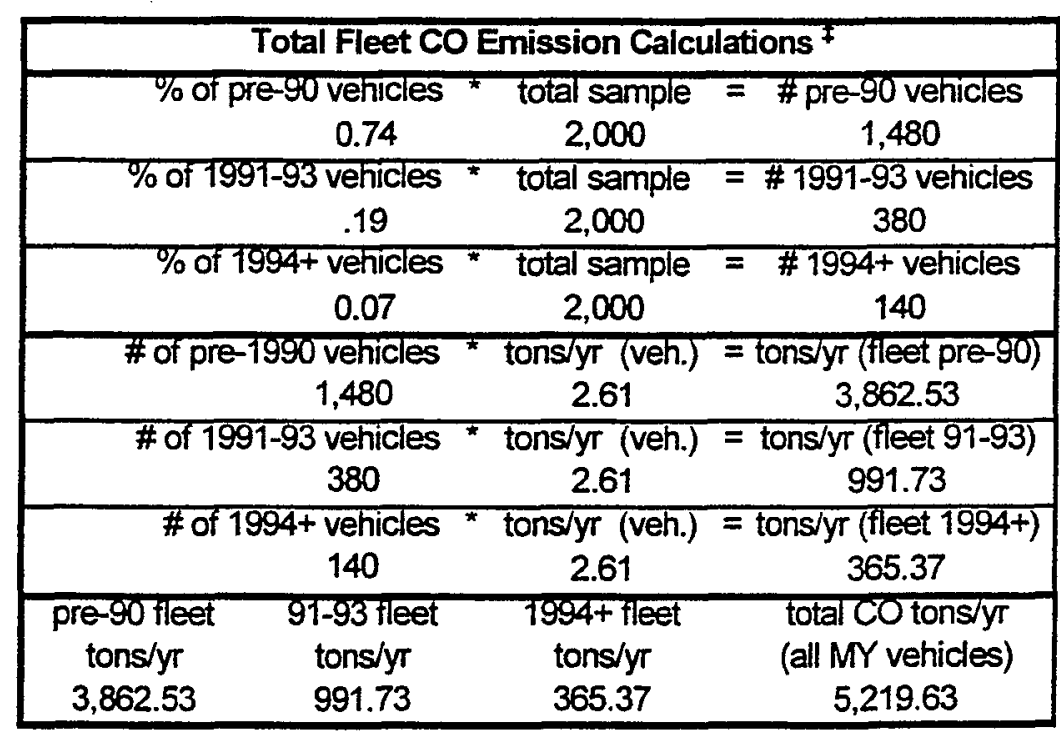

$\mp$ Sample Fleet is estimated from available data 


\begin{tabular}{|c|c|c|c|}
\hline \multicolumn{4}{|c|}{ pre-1990Vehicle NMHC Emission Calculations } \\
\hline & dally mileage & work days/yr $=$ & annual mileage \\
\hline & 235 & 250 & 58,750 \\
\hline emission std & bhp-hr/mile & annual mileage $=$ & emissions $(g / y r)$ \\
\hline \multirow[t]{3}{*}{0.5} & 2.6 & 58,750 & 76,375 \\
\hline & grams/yr & grams/ton & tons/yr \\
\hline & 76,375 & 907,200 & 0.08 \\
\hline
\end{tabular}

\begin{tabular}{|c|c|c|c|}
\hline \multicolumn{4}{|c|}{ 1991-1993Vehicle NiritC Emission Calculations } \\
\hline & dally mileage & work days/yr $=$ & annual mileage \\
\hline & 235 & 250 & 58,750 \\
\hline emission std & bhp-hrimile & annual mileage $=$ & emissions $(g / y r)$ \\
\hline \multirow{3}{*}{0.5} & 2.6 & 58,750 & 76,375 \\
\hline & grams/yr & grams/ton & tons/yr \\
\hline & 76,375 & 907,200 & 0.08 \\
\hline
\end{tabular}

\begin{tabular}{|c|c|c|c|}
\hline \multicolumn{4}{|c|}{ 1994+ Vehicle NinfC Emission Calculations } \\
\hline & daily mileage ${ }^{*}$ & work days/yr = & annual mileage \\
\hline & 235 & 250 & 58,750 \\
\hline emission sta & bhp-hr/mile * & annual mileage $=$ & emissions $(g / y r)$ \\
\hline 0.5 & 2.6 & 58,750 & 76,375 \\
\hline & $\begin{array}{c}\text { grams/yr } \\
76,375\end{array}$ & $\begin{array}{c}\text { grams/ton } \\
907,200\end{array}$ & $\begin{array}{c}\text { tons/yr } \\
0.08\end{array}$ \\
\hline
\end{tabular}

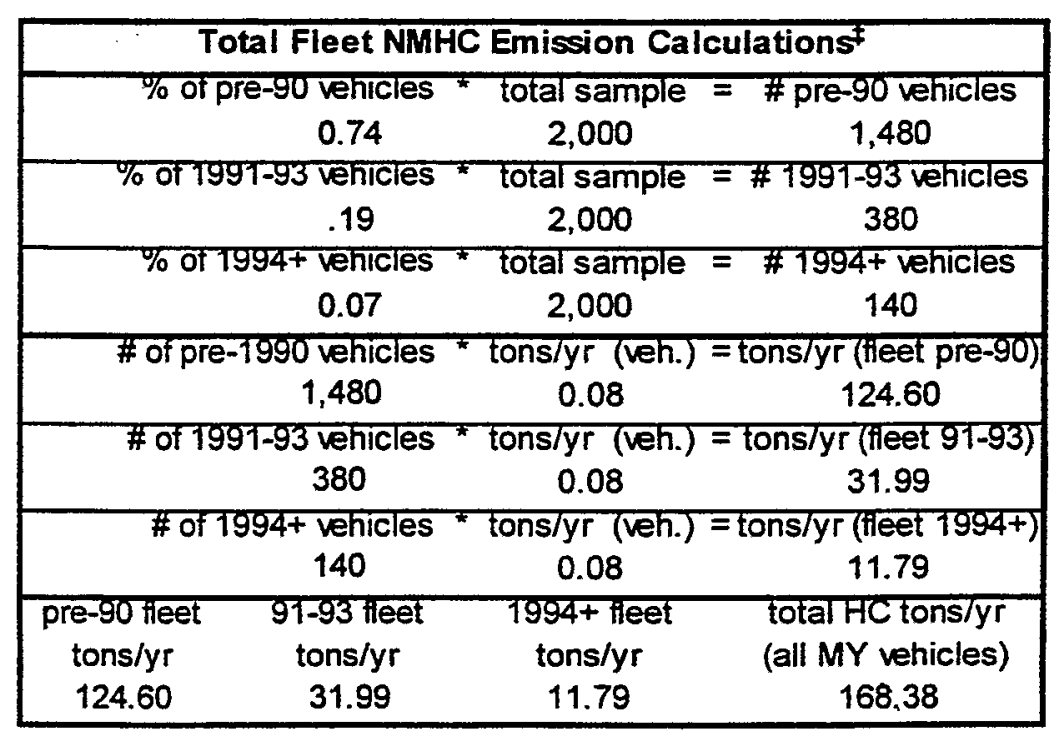

$\mp$ Sample Fleet is estimated from available data

E-10

Seaport Liquid Natural Gas Study - Final Report 


\begin{tabular}{|c|c|c|c|}
\hline \multicolumn{4}{|c|}{ pre-1990 Vehicle Nox Emission Calculations } \\
\hline & $\begin{array}{c}\text { daily mileage } \\
235\end{array}$ & $\begin{array}{c}\text { work days/yr = } \\
250\end{array}$ & $\begin{array}{c}\text { annual mileage } \\
58,750\end{array}$ \\
\hline $\begin{array}{c}\text { emission std } \\
6\end{array}$ & $\begin{array}{c}\text { bhp-hr/mile } \\
2.6\end{array}$ & $\begin{array}{c}\text { annual mileage }= \\
58,750\end{array}$ & $\begin{array}{c}\text { emissions }(g / y r) \\
916,500\end{array}$ \\
\hline & $\begin{array}{l}\text { grams/yr } \\
916,500\end{array}$ & $\begin{array}{c}\text { grams/ton } \\
907,200\end{array}$ & $\begin{array}{l}\text { tons/yr } \\
1.01\end{array}$ \\
\hline
\end{tabular}

\begin{tabular}{|c|c|c|c|}
\hline \multicolumn{4}{|c|}{ 1991-1993Venicle NOX Enission Calculations } \\
\hline & $\begin{array}{c}\text { daily mileage } \\
235\end{array}$ & $\begin{array}{c}\text { work days/yr }= \\
250\end{array}$ & $\begin{array}{c}\text { annual mileage } \\
58,750\end{array}$ \\
\hline $\begin{array}{c}\text { emission std } \\
5\end{array}$ & $\begin{array}{c}\text { bhp-hr/mile } \\
2.6\end{array}$ & $\begin{array}{c}\text { annual mileage }= \\
58,750\end{array}$ & $\begin{array}{c}\text { emissions }(g / y r) \\
763,750\end{array}$ \\
\hline & $\begin{array}{l}\text { grams/yr } \\
763,750\end{array}$ & $\begin{array}{l}\text { grams/ton } \\
907,200\end{array}$ & $\begin{array}{l}\text { tons/yr } \\
0.84\end{array}$ \\
\hline
\end{tabular}

\begin{tabular}{|c|c|c|c|}
\hline \multicolumn{4}{|c|}{ 1994+ Venicle Nox Emission Calculations } \\
\hline & $\begin{array}{c}\text { dally mileage } \\
235\end{array}$ & $\begin{array}{c}\text { work days } / y T= \\
250\end{array}$ & $\begin{array}{c}\text { annual mileage } \\
58,750\end{array}$ \\
\hline $\begin{array}{c}\text { emission std } \\
5\end{array}$ & $\begin{array}{c}\text { bhp-hr/mile } \\
2.6\end{array}$ & $\begin{array}{c}\text { annual mileage }= \\
58,750\end{array}$ & $\begin{array}{c}\text { emissions ( } g / y r) \\
763,750\end{array}$ \\
\hline & $\begin{array}{l}\text { grams/yr } \\
763,750\end{array}$ & $\begin{array}{c}\text { grams/ton } \\
907,200\end{array}$ & $\begin{array}{l}\text { tons } / \mathrm{yr} \\
0.84\end{array}$ \\
\hline
\end{tabular}

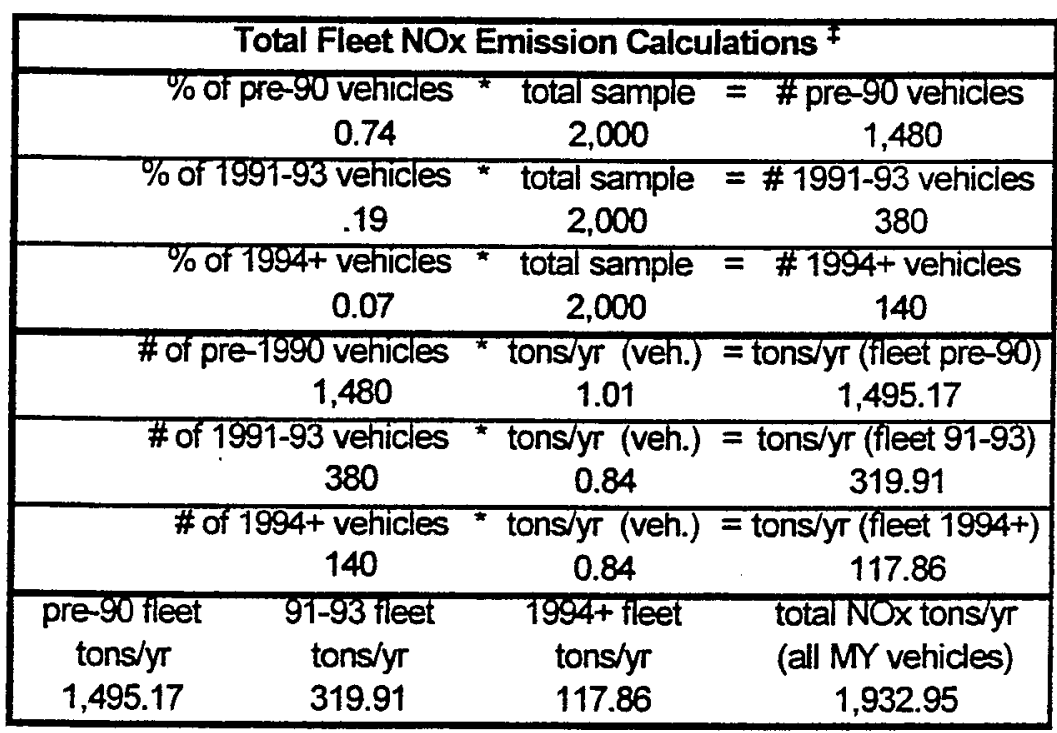

¥ Sample Fleet is estimated from available data 


\begin{tabular}{|c|c|c|c|}
\hline \multicolumn{4}{|c|}{ pre-1990 Vehicle PlM Emission Calculations } \\
\hline & $\begin{array}{c}\text { dally mileage } \\
235\end{array}$ & $\begin{array}{c}\text { work days } / y r= \\
250\end{array}$ & $\begin{array}{c}\text { annual mileage } \\
58,750\end{array}$ \\
\hline $\begin{array}{l}\text { emission std } \\
0.6\end{array}$ & $\begin{array}{c}\text { bhp-hr/mile } \\
2.6\end{array}$ & $\begin{array}{c}\text { "annual mileage }= \\
58,750\end{array}$ & $\begin{array}{c}\text { emissions }(g / y r) \\
91,650\end{array}$ \\
\hline & $\begin{array}{c}\text { grams/yr } \\
91,650\end{array}$ & $\begin{array}{c}\text { grams/ton } \\
907,200\end{array}$ & $\begin{array}{c}\text { tons/yr } \\
0.10\end{array}$ \\
\hline
\end{tabular}

\begin{tabular}{|c|c|c|c|}
\hline \multicolumn{4}{|c|}{ T991-1993 venice Pin EmIssion Calculations } \\
\hline & $\begin{array}{c}\text { dally mileage } \\
235\end{array}$ & $\begin{array}{c}\text { work days } / y r= \\
250\end{array}$ & $\begin{array}{c}\text { annual mileage } \\
58,750\end{array}$ \\
\hline $\begin{array}{c}\text { emission std } \\
0.14\end{array}$ & $\begin{array}{c}\text { bhp-hr/mile } \\
2.6\end{array}$ & $\begin{array}{c}\text { annual mileage }= \\
58,750\end{array}$ & $\begin{array}{c}\text { emissions }(g / y r) \\
21,385\end{array}$ \\
\hline & $\begin{array}{c}\text { grams/yr } \\
21,385\end{array}$ & $\begin{array}{c}\text { grams/ton } \\
907,200\end{array}$ & $\begin{array}{c}\text { tons/yr } \\
0.02\end{array}$ \\
\hline
\end{tabular}

\begin{tabular}{|c|c|c|c|}
\hline \multicolumn{4}{|c|}{ T994+Vehice PlWEmission Calculations } \\
\hline & $\begin{array}{l}\text { dally mileage } \\
235\end{array}$ & $\begin{array}{c}\text { work days } / y r= \\
250\end{array}$ & $\begin{array}{c}\text { annual mileage } \\
58,750\end{array}$ \\
\hline $\begin{array}{c}\text { emission std } \\
0.05\end{array}$ & $\begin{array}{c}\text { bhp-hr/mile } \\
2.6\end{array}$ & $\begin{array}{c}\text { annual mileage }= \\
58,750\end{array}$ & $\begin{array}{c}\text { emissions }(g / y r) \\
7,638\end{array}$ \\
\hline & $\begin{array}{c}\text { grams/yr } \\
7,638\end{array}$ & $\begin{array}{c}\text { grams/ton } \\
907,200\end{array}$ & $\begin{array}{l}\text { tons/yr } \\
0.01\end{array}$ \\
\hline
\end{tabular}

\begin{tabular}{|c|c|c|c|}
\hline \multicolumn{4}{|c|}{ Total Fleet PM Emission Calculations F } \\
\hline \multirow{2}{*}{\multicolumn{2}{|c|}{$\begin{array}{c}\% \text { of pre-90 vehicles } \\
0.74\end{array}$}} & total sample & $=$ \#pre-90 venicles \\
\hline & & 2,000 & 1,480 \\
\hline \multicolumn{2}{|c|}{ \% of 1991-93 vehicles } & total sample & $=\#$ 1991-93 vehicles \\
\hline \multicolumn{2}{|c|}{.19} & 2,000 & 380 \\
\hline \multicolumn{2}{|c|}{$\%$ of $1994+$ vehicles } & total sample & \# 1994+ vehicles \\
\hline \multicolumn{2}{|c|}{0.07} & 2,000 & 140 \\
\hline \multirow{2}{*}{\multicolumn{2}{|c|}{$\begin{array}{c}\text { \# of pre-1990 vehicles } \\
1,480\end{array}$}} & tons/yr (veh.) & $=$ tons $/ y$ (fleet pre-90) \\
\hline & & 0.10 & 149.52 \\
\hline \multicolumn{4}{|c|}{ \# of 1991-93 vehicles ${ }^{*}$ tons/yr (veh.) $=$ tons/yr (fleet 91-93) } \\
\hline & 380 & 0.02 & 8.96 \\
\hline \multicolumn{4}{|c|}{ \# of 1994+ vehicles ${ }^{*}$ tons/yr (veh.) $=$ tons/yr (fleet 1994+) } \\
\hline & 140 & 0.01 & 1.18 \\
\hline $\begin{array}{c}\text { pre-90 fleet } \\
\text { tons/yr } \\
149.52\end{array}$ & $\begin{array}{c}91-93 \text { fleet } \\
\text { tons/yr } \\
8.96\end{array}$ & $\begin{array}{c}\text { T994+fleet } \\
\text { tons/yr } \\
1.18\end{array}$ & $\begin{array}{c}\text { total PM tons/yr } \\
\text { (all MY vehicles) } \\
159.65\end{array}$ \\
\hline
\end{tabular}

$\mp$ Sample Fleet is estimated from available data

E-12 


\section{LNG Trucking Calculations}

\begin{tabular}{|c|c|c|c|}
\hline \multicolumn{4}{|c|}{ Vehicle COEmission Calculations } \\
\hline & $\begin{array}{l}\text { dally mileage * } \\
235\end{array}$ & $\begin{array}{c}\text { work days } / y T= \\
250\end{array}$ & $\begin{array}{c}\text { annual mileage } \\
58,750\end{array}$ \\
\hline $\begin{array}{c}\text { cert emission }^{\dagger} \\
4.1\end{array}$ & $\begin{array}{c}\text { "bhp-hr/mile * } \\
2.6\end{array}$ & $\begin{array}{c}\text { annual mileage }= \\
58,750\end{array}$ & $\begin{array}{c}\text { emissions }(g / y r) \\
626,275\end{array}$ \\
\hline & $\begin{array}{l}\text { grams/yr } / \\
626,275\end{array}$ & $\begin{array}{c}\text { grams/ton } \\
907,200\end{array}$ & $\begin{array}{l}\text { tons/yr } \\
0.6903\end{array}$ \\
\hline
\end{tabular}

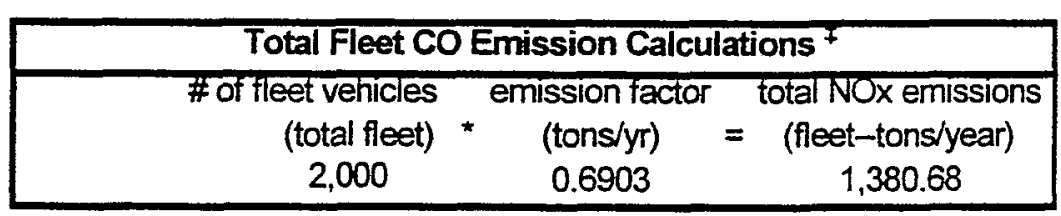

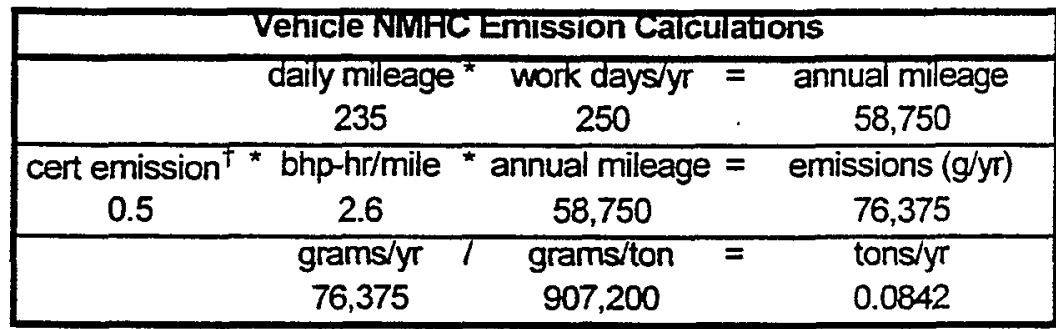

\begin{tabular}{|c|c|c|}
\hline \multicolumn{3}{|c|}{ Total Fleet NMHC Emission Calculations * } \\
\hline $\begin{array}{c}\text { \# of fleet vehicles } \\
\text { (total fleet) } \\
2,000\end{array}$ & $\begin{array}{c}\text { emission factor } \\
\text { (tons/yr) } \\
0.0842\end{array}$ & $\begin{array}{l}\text { total NOx emissions } \\
=\quad \begin{array}{c}\text { (fleet-tons/year) } \\
168.38\end{array}\end{array}$ \\
\hline
\end{tabular}

¥ Sample Fleet is estimated from available data

t Obtained from Caterpillar (PSA) C12 LNG engine during certification process 


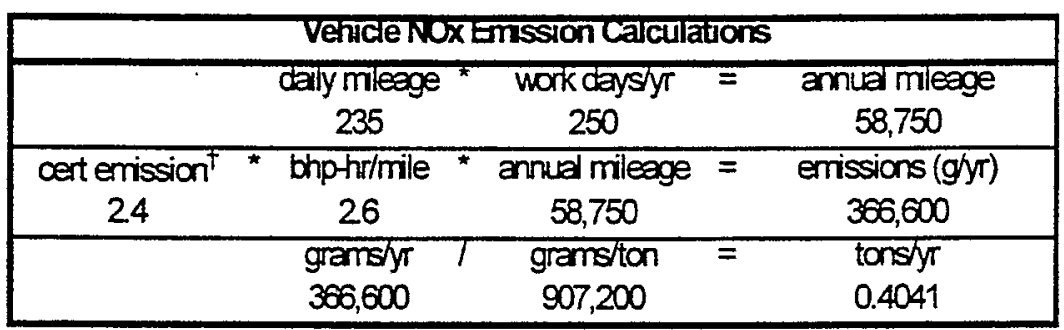

\begin{tabular}{|c|c|c|}
\hline \multicolumn{3}{|c|}{ Total Fleet NOx Emission Calculations ${ }^{T}$} \\
\hline $\begin{array}{l}\text { \#a flect vericles } \\
\text { (tota fleet) } \\
2,000\end{array}$ & $\begin{array}{c}\text { emsson factar } \\
\text { (tonsiyr) } \\
0.4041\end{array}$ & $\begin{array}{c}\text { toal } \\
=\quad \text { (flect-tonsisyear) } \\
808.20\end{array}$ \\
\hline
\end{tabular}

\begin{tabular}{|c|c|c|c|}
\hline \multicolumn{4}{|c|}{ Venucle Pillemssion Cacuations } \\
\hline & $\begin{array}{l}\text { dally mileage * } \\
235\end{array}$ & $\begin{array}{c}\text { work dayshr }= \\
250\end{array}$ & $\begin{array}{c}\text { annua mileage } \\
58,750\end{array}$ \\
\hline $\begin{array}{l}\text { cert emission } \\
0.1\end{array}$ & $\begin{array}{c}\text { bhp-hrimile } \\
26\end{array}$ & $\begin{array}{c}\text { annua mileage }= \\
58,750\end{array}$ & $\begin{array}{c}\text { emissions (gyr) } \\
15,275\end{array}$ \\
\hline & $\begin{array}{c}\text { gramsyr } \\
15,275\end{array}$ & $\begin{array}{l}\text { grams/ton } \\
907,200\end{array}$ & $\begin{array}{l}\text { tonsiyr } \\
0.0168\end{array}$ \\
\hline
\end{tabular}

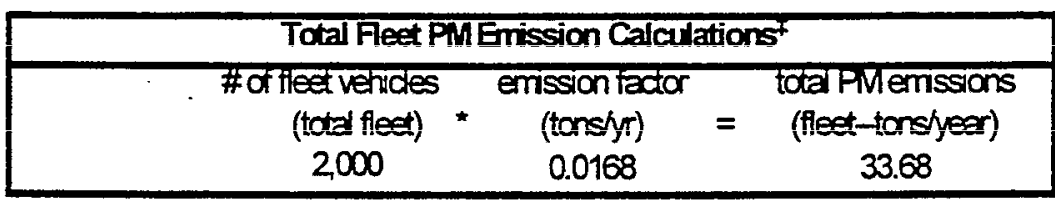

¥ Sample Fleet is estimated fromavalable data t Ottained from Caterpiller (PSA) C12 LVG engine during certification process 


\section{Port of Los Angeles - Off-road Emissions Calculations}

Emissions and potential emissions reductions from port-related terminal equipment were calculated using standard ARB methodology provided in the Carl Moyer program guidelines for off-road equipment. Each criteria pollutant is calculated separately, as are diesel and LNG emissions. In these calculations the ARB $18.5 \mathrm{hp}$-hr/gal energy consumption factor is used to convert emissions from grams per horsepower-hour into grams per gallon. This conversion factor was developed by the ARB specifically for off-road equipment. LNG engine emission calculations were based upon emission levels from the ARB certification process of various available LNG engines, according to the necessary horsepower requirements. LNG engines used include the Cummins B5.9G (for up to $225 \mathrm{hp}$ ), Cummins 8.3G (225-300 hp) and the CAT C10 $(300+\mathrm{hp})$. All equipment is assumed to be operating $100 \%$ in California.

\section{Emission Calculation}

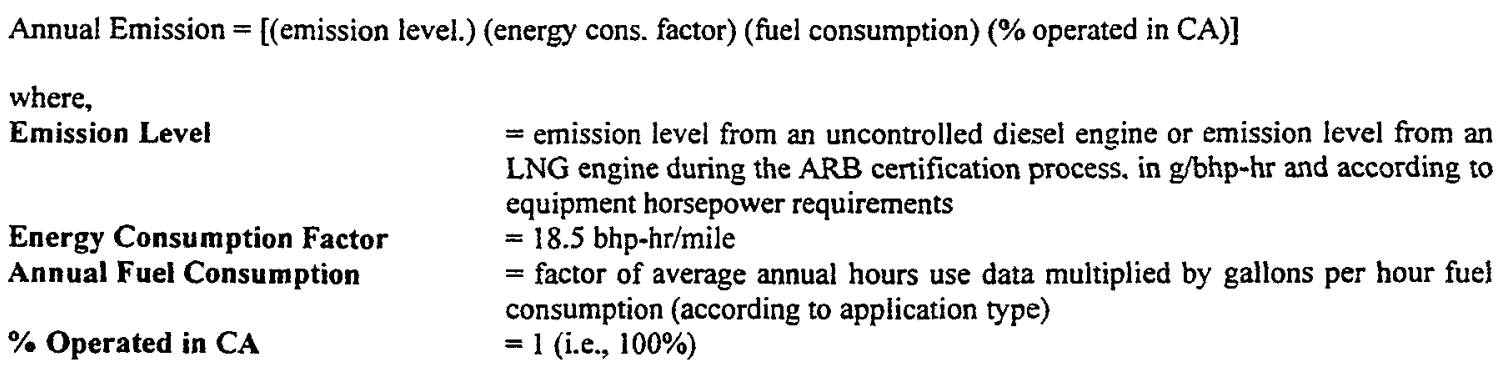
LNG engine during the ARB certification process. in $g / b h p-h r$ and according to equipment horsepower requirements

Energy Consumption Factor Annual Fuel Consumption $=18.5 \mathrm{bhp}-\mathrm{hr} / \mathrm{mile}$

$=$ factor of average annual hours use data multiplied by gallons per hour fuel consumption (according to application type)

$\%$ Operated in CA $=1$ (i.e., $100 \%)$

Results were then converted to tons by dividing by 907,200 grams. 


\begin{tabular}{|c|c|c|c|c|c|c|c|c|c|c|}
\hline \multicolumn{11}{|c|}{ Port of Los Angeles Terminal Equipment - Characteristics and CO Emissions } \\
\hline & \multirow[b]{2}{*}{$\begin{array}{c}\text { Typical } \\
\text { HP }\end{array}$} & \multirow{2}{*}{$\begin{array}{c}\text { Avg. } \\
\text { Annual } \\
\text { Hours } \\
\text { Use }^{2}\end{array}$} & \multirow{2}{*}{$\begin{array}{c}\text { Actual } \\
\text { Vehicle } \\
\text { Count }\end{array}$} & \multirow{2}{*}{$\begin{array}{c}\text { Total \# } \\
\text { Vehicles } \\
\text { (extrap.) }\end{array}$} & \multicolumn{3}{|c|}{ per each vehicle (tons/yaar) } & \multicolumn{3}{|c|}{ total fleet(tonshyear) } \\
\hline & & & & & $\begin{array}{c}\text { Diesel } \\
\text { Emissions }\end{array}$ & $\begin{array}{l}\text { Natural Gas } \\
\text { Emissions }\end{array}$ & $\begin{array}{c}\text { CO } \\
\text { Reductions } \\
\text { (NG vs Diesel) }\end{array}$ & $\begin{array}{c}\text { Diesel } \\
\text { Emissions }\end{array}$ & $\begin{array}{l}\text { Natural Gas } \\
\text { Emissions }\end{array}$ & $\begin{array}{c}\text { CO } \\
\text { Reductions } \\
\text { (NG vs Diesel) }\end{array}$ \\
\hline SHIPPING & & & & & & & & & & \\
\hline Transtainer & 300 & 500 & 12 & 18 & 0.11 & 0.00 & 0.11 & 2.02 & 0.01 & 2.01 \\
\hline Top Pick & 275 & 2400 & 17 & 25 & 0.55 & 0.18 & 0.37 & 13.70 & 4.40 & 9.30 \\
\hline Side Pick & 225 & 750 & 13 & 19 & 0.13 & 0.12 & 0.01 & 2.44 & 2.27 & 0.17 \\
\hline Heavy Forklift & 275 & 1000 & 8 & 12 & 0.17 & 0.06 & 0.12 & 2.06 & 0.66 & 1.39 \\
\hline Yard Tractor & 200 & 2500 & 270 & 405 & 0.29 & 0.27 & 0.02 & 115.63 & 107.37 & 8.26 \\
\hline Diesel Generator & 220 & 4750 & 3 & 4 & 2.17 & 2.01 & 0.15 & 8.68 & 8.06 & 0.62 \\
\hline RAIL & & & & & & & & & & \\
\hline Straddle Crane & 300 & 5900 & 25 & 42 & 1.32 & 4.45 & -3.13 & 55.59 & 186.97 & -131.38 \\
\hline Reach Stacker & 300 & 2300 & 3 & 5 & 0.41 & 1.39 & -0.98 & 2.06 & 6.94 & -4.88 \\
\hline Side Pick & 225 & 6000 & 6 & 10 & 1.03 & 0.95 & 0.07 & 10.28 & 9.54 & 0.73 \\
\hline Heavy Forklift & 275 & 700 & 2 & 3 & 0.12 & 0.04 & 0.08 & 0.36 & 0.12 & 0.24 \\
\hline Yard Tractor & 200 & 5600 & 164 & 273 & 0.64 & 0.59 & 0.05 & 174.59 & 162.11 & 12.47 \\
\hline
\end{tabular}

- Hours use data for Shipping deser generator and Rail heavy forklit obtained from Port of Oakland cota

- Extrapolations for Shipping based on 4 of 6 terminals samplect, extrapolations for Rail based on 3 of 5 terminals

- Cakculations based on 7\% LPG (30) and 93\% desel (375) feet verides

A Aso indudes fippers, packers and wedges

- Natural gas emissions based on Cummins 85.9G engine for HP up to 225, Cummins Ca.3G for HP up to 300, and CAT C10 tor 300 HP and over

\begin{tabular}{|c|c|c|c|c|c|c|c|c|c|c|}
\hline \multicolumn{11}{|c|}{ Port of Los Angeles Terminal Equipment - Characteristics and NMHC Emissions } \\
\hline & \multirow[b]{2}{*}{$\begin{array}{c}\text { Typical } \\
\text { HP }\end{array}$} & \multirow{2}{*}{$\begin{array}{l}\text { Avg } \\
\text { Anmual } \\
\text { Hours } \\
\text { Use" }\end{array}$} & \multirow{2}{*}{$\begin{array}{c}\text { Actual } \\
\text { Vehicle } \\
\text { Count }\end{array}$} & \multirow{2}{*}{$\begin{array}{c}\text { Total \# } \\
\text { Vehicies } \\
\text { (extrap.) }^{\text {b }}\end{array}$} & \multicolumn{3}{|c|}{ per each vehicle(tonsiyear) } & \multicolumn{3}{|c|}{ total fleet(tonsyear) } \\
\hline & & & & & $\begin{array}{c}\text { Diesel } \\
\text { Emissions }\end{array}$ & $\begin{array}{l}\text { Natural Gas } \\
\text { Emissions }\end{array}$ & $\begin{array}{c}\text { NMHHC } \\
\text { Reductions } \\
\text { (NG vs Diesel) }\end{array}$ & $\begin{array}{c}\text { Diesol } \\
\text { Emissions }\end{array}$ & $\begin{array}{l}\text { Natural Gas } \\
\text { Emissions }\end{array}$ & $\begin{array}{c}\text { NMritC } \\
\text { Reductions } \\
\text { (NG vs Diesel) }\end{array}$ \\
\hline SHIPFING & & & & & & & & & & \\
\hline Transtainer & 300 & 500 & 12 & 18 & 0.046 & 0.056 & 0.194 & 0.826 & 1.009 & -0.184 \\
\hline Top Pick & 275 & 2400 & 17 & 25 & 0.196 & 0.117 & 0.930 & 4.894 & 2.937 & 1.958 \\
\hline Side Pick & 225 & 750 & 13 & 19 & 0.046 & 0.005 & 0.291 & 0.872 & 0.087 & 0.785 \\
\hline Heavy Forklift & 275 & 1000 & 8 & 12 & 0.061 & 0.037 & 0.387 & 0.734 & 0.440 & 0.294 \\
\hline Yard Tractor & 200 & 2500 & 270 & 405 & 0.102 & 0.010 & 0.969 & 41.295 & 4.129 & 37.165 \\
\hline Diesel Genera & 220 & 4750 & 3 & 4 & 0.775 & 0.077 & 1.840 & 3.100 & 0.310 & 2.790 \\
\hline$R$ RA/L & & & & & & & & & & \\
\hline Straddle Cran & 300 & 5900 & 25 & 42 & 0.541 & 0.662 & 2.286 & 22740 & 27.793 & -5.053 \\
\hline Reach Stacke & 300 & 2300 & 3 & 5 & 0.169 & 0.206 & 0.891 & 0.844 & 1.032 & -0.188 \\
\hline Side Pick & 225 & 6000 & 6 & 10 & 0.367 & 0.037 & 2.325 & 3.671 & 0.367 & 3.304 \\
\hline Heavy Forklift & 275 & 700 & 2 & 3 & 0.043 & 0.026 & 0.271 & 0.128 & 0.077 & 0.051 \\
\hline Yard Tractor & 200 & 5600 & 164 & 273 & 0.228 & 0.023 & 2.170 & 62.352 & 6.235 & 56.117 \\
\hline
\end{tabular}

- Hours use data for Shipping diesel generator and Rail heavy forklift obtained from Port of Oakland data

- Extrapolations for Shipping based on 4 of 6 teminals sampled; extrapolations for Rail based on 3 of 5 terminals

- Calculations based on 7\% LPG (30) and 93\% diesel (375) fleet vehicles

- Also includes fippers, packers and wedges

- Natural gas emissions based on Cummins 859G engine for HP up to 225. Cummins C8.3G for HP up to 300, and CAT C10 for 300 HP and over 


\begin{tabular}{|c|c|c|c|c|c|c|c|c|c|c|}
\hline \multicolumn{11}{|c|}{ Port of Los Angeles Terminal Equipment - Characteristics and NOx Emissions } \\
\hline & \multirow[b]{2}{*}{$\begin{array}{l}\text { Typical } \\
\text { HP }\end{array}$} & \multirow{2}{*}{$\begin{array}{l}\text { Avg. } \\
\text { Annual } \\
\text { Hours } \\
\text { Use }\end{array}$} & \multirow{2}{*}{$\begin{array}{c}\text { Actual } \\
\text { Vehicle } \\
\text { Count }\end{array}$} & \multirow{2}{*}{$\begin{array}{c}\text { Total \# } \\
\text { Vehicles } \\
\text { (extrap.) }\end{array}$} & \multicolumn{3}{|c|}{ per each vehicle (tons/year) } & \multicolumn{3}{|c|}{ total fleet (tonsyyear) } \\
\hline & & & & & $\begin{array}{c}\text { Diesel } \\
\text { Emissions }\end{array}$ & $\begin{array}{l}\text { Natural Gas } \\
\text { Emissions }\end{array}$ & $\begin{array}{c}\text { NOx } \\
\text { Reductions } \\
\text { (NG vs Diesel) }\end{array}$ & $\begin{array}{l}\text { Diesel } \\
\text { Emissions }\end{array}$ & $\begin{array}{l}\text { Natural Gas } \\
\text { Emissions }\end{array}$ & $\begin{array}{c}\text { NOx } \\
\text { reductions } \\
\text { (NG vs Diesel) }\end{array}$ \\
\hline SHIPPING & & & & & & & & & & \\
\hline Transtainer & 300 & 500 & 12 & 18 & 0.663 & 0.122 & 0.194 & 11.930 & 2.202 & 9.727 \\
\hline Top Pick & 275 & 2400 & 17 & 25 & 2.349 & 0.352 & 0.930 & 58.730 & 8.810 & 49.921 \\
\hline Side Pick & 225 & 750 & 13 & 19 & 0.551 & 0.083 & 0.291 & 10.461 & 1.569 & 8.892 \\
\hline Heavy Forklift & 275 & 1000 & 8 & 12 & 0.734 & 0.110 & 0.387 & 8.810 & 1.321 & 7.488 \\
\hline Yard Tractore & 200 & 2500 & 270 & 405 & 1.224 & 0.184 & 0.969 & 495.536 & 74.330 & 421.205 \\
\hline Diesel Generator & 220 & 4750 & 3 & 4 & 9.299 & 1.395 & 1.840 & 37.196 & 5.579 & 31.616 \\
\hline RAIL & & & & & & & & & & \\
\hline Straddle Crane & 300 & 5900 & 25 & 42 & 7.820 & 1.444 & 2.286 & 328.461 & 60.639 & 267.822 \\
\hline Reach Stacker & 300 & 2300 & 3 & 5 & 2.439 & 0.450 & 0.891 & 12.195 & 2.251 & 9.943 \\
\hline Side Pick & 225 & 6000 & 6 & 10 & 4.405 & 0.661 & 2.325 & 44.048 & 6.607 & 37.440 \\
\hline Heavy Forklift & 275 & 700 & 2 & 3 & 0.514 & 0.077 & 0.271 & 1.542 & 0.231 & 1.310 \\
\hline Yard Tractor & 200 & 5600 & 164 & 273 & 2.741 & 0.411 & 2.170 & 748.222 & 112.233 & 635.989 \\
\hline
\end{tabular}

- Hours use data for Shipping desel generator and Rail heavy forkift obtained from Port of Oakland data

b Extrapolations for Shipping based on 4 of 6 terminals sampled; extrapolations for Rail based on 3 of 5 terminals

c Cakculations based on 7\% LPG (30) and $93 \%$ desel (375) fleet vehicles

- Also includes flippers, packers and wedges

- Natural gas emissions based on Curmins 85.9G engine for HP up to 225, Cummins Ca 3 G for HP up to 300, and CAT C10 for 300 HP and over

\begin{tabular}{|c|c|c|c|c|c|c|c|c|c|c|}
\hline \multicolumn{11}{|c|}{ Port of Los Angeles Terminal Equipment - Characteristics and PM Emissions } \\
\hline & \multirow[b]{2}{*}{$\begin{array}{c}\text { Typical } \\
\text { HP }\end{array}$} & \multirow{2}{*}{$\begin{array}{l}\text { Avg } \\
\text { Annual } \\
\text { Hours } \\
\text { Used }\end{array}$} & \multirow{2}{*}{$\begin{array}{l}\text { Actual } \\
\text { Vehicle } \\
\text { Count }\end{array}$} & \multirow{2}{*}{$\begin{array}{c}\text { Total \# } \\
\text { Vehicles } \\
\text { (extrap.) }^{b}\end{array}$} & \multicolumn{3}{|c|}{ per each vehicle (tons/yoar) } & \multicolumn{3}{|c|}{ total fleet(torsatyour) } \\
\hline & & & & & $\begin{array}{c}\text { Diesol } \\
\text { Emissions }\end{array}$ & $\begin{array}{l}\text { Natural Gas } \\
\text { Emissions }\end{array}$ & $\begin{array}{c}\text { PM } \\
\text { Roductions } \\
\text { (NG vs Diesol) }\end{array}$ & $\begin{array}{l}\text { Diesol } \\
\text { Emissions }\end{array}$ & $\begin{array}{c}\text { Natural Gas } \\
\text { Emissions }\end{array}$ & $\begin{array}{c}\text { PM } \\
\text { Roductions } \\
\text { (NG ve Diesel) }\end{array}$ \\
\hline SHIPPING & & & & & & & & & & \\
\hline Transtainer & 300 & 500 & 12 & 18 & 0.031 & 0.003 & 0.194 & 0.551 & 0.055 & 0.496 \\
\hline Top Pick & 275 & 2400 & 17 & 25 & 0.117 & 0.004 & 0.930 & 2.937 & 0.098 & 2.839 \\
\hline Side Pick & 225 & 750 & 13 & 19 & 0.028 & 0.001 & 0.291 & 0.523 & 0.017 & 0.506 \\
\hline Heavy Forklift & 275 & 1000 & 8 & 12 & 0.037 & 0.001 & 0.387 & 0.440 & 0.015 & 0.426 \\
\hline Yand Tractor & 200 & 2500 & 270 & 405 & 0.061 & 0.002 & 0.969 & 24.777 & 0.826 & 23.951 \\
\hline Diesel Generator & 220 & 4750 & 3 & 4 & 0.465 & 0.015 & 1.840 & 1.860 & 0.062 & 1.798 \\
\hline RAIL & & & & & & & & & & \\
\hline Straddle Crane & 300 & 5900 & 25 & 42 & 0.361 & 0.036 & 2.286 & 15.160 & 1.516 & 13.644 \\
\hline Reach Stackerd & 300 & 2300 & 3 & 5 & 0.113 & 0.011 & 0.891 & 0.563 & 0.056 & 0.507 \\
\hline Side Pick & 225 & 6000 & 6 & 10 & 0.220 & 0.007 & 2.325 & 2.202 & 0.073 & 2.129 \\
\hline Heavy Forklift & 275 & 700 & 2 & 3 & 0.026 & 0.001 & 0.271 & 0.077 & 0.003 & 0.075 \\
\hline Yard Tractor & 200 & 5600 & 164 & 273 & 0.137 & 0.005 & 2.170 & 37.411 & 1.247 & 36.164 \\
\hline
\end{tabular}

- Hours use data for Shipping desel generator and Rail heavy forditit abtained from Port of Oakland data

'Extrapolations for Shipping based on 4 of 6 terminals sampled; extrapolations for Rail based on 3 of 5 terminals

- Cajculations based on $7 \%$ LPG (30) and $93 \%$ diesel (375) fleet venicles

- Also indudes fippers, packers and wodges

- Natural gas emissions based on Curmins 85.9G engine for HP up to 225, Curmins C8.3G for HP up to 300, and CAT CiO for 300 HP and over 


\section{Port of Oakland - Off-road Emissions Calculations}

Emissions and potential emissions reductions from port-related terminal equipment were calculated using standard ARB methodology provided in the Carl Moyer program guidelines for off-road equipment. Each criteria pollutant is calculated separately, as are diesel and LNG emissions. In these calculations the ARB $18.5 \mathrm{hp}-\mathrm{hr} / \mathrm{gal}$ energy consumption factor is used to convert emissions from grams per horsepower-hour into grams per gallon. This conversion factor was developed by the ARB specifically for off-road equipment. LNG engine emission calculations were based upon emission levels from the ARB certification process of various available $L N G$ engines, according to the necessary horsepower requirements. LNG engines used include the Cummins B5.9G (for up to $225 \mathrm{hp}$ ), Cummins 8.3G (225-300 hp) and the CAT C10 $(300+\mathrm{hp})$. All equipment is assumed to be operating $100 \%$ in California.

\section{Emission Calculation}

Annual Emission $=[($ emission level. $)($ energy cons. factor $)($ fuel consumption $)(\%$ operated in CA $)]$

where,

Emission Level

$=$ emission level from an uncontrolled diesel engine or emission level from an LNG engine during the ARB certification process, in $g / b h p-h r$ and according to equipment horsepower requirements

Energy Consumption Factor $=18.5 \mathrm{bhp}-\mathrm{hr} / \mathrm{mile}$

Annual Fuel Consumption

$=$ factor of average annual hours use data multiplied by gallons per hour fuel consumption (according to application type)

\% Operated in CA $=1$ (i.e., $100 \%$ )

Results were then converted to tons by dividing by 907,200 grams. 


\begin{tabular}{|c|c|c|c|c|c|c|c|c|c|c|}
\hline \multicolumn{11}{|c|}{ Port of Cakland Terminal Equipment - Characteristies and NOx Emissions } \\
\hline & \multirow[b]{2}{*}{$\begin{array}{c}\text { Typical } \\
\text { HP }\end{array}$} & \multirow{2}{*}{$\begin{array}{l}\text { Avg. } \\
\text { Annual } \\
\text { Hours } \\
\text { Use" }\end{array}$} & \multirow{2}{*}{$\begin{array}{c}\text { Actual } \\
\text { Vehicle } \\
\text { Count }\end{array}$} & \multirow{2}{*}{$\begin{array}{c}\text { Total \# } \\
\text { Vehicles } \\
\text { (oxtrep. })^{b}\end{array}$} & \multicolumn{3}{|c|}{ per each vehicle (tonsyear) } & \multicolumn{3}{|c|}{ total fleet (tonsiyear) } \\
\hline & & & & & $\begin{array}{c}\text { Diesel } \\
\text { Emissions }\end{array}$ & \begin{tabular}{|c|} 
Natural \\
Gas \\
Emissions
\end{tabular} & $\begin{array}{l}\text { NOx } \\
\text { Reductions } \\
\text { (NG vs Diesef) }\end{array}$ & $\begin{array}{c}\text { Diesel } \\
\text { Emissions }\end{array}$ & $\begin{array}{l}\text { Natural Gas } \\
\text { Emissions }\end{array}$ & $\begin{array}{l}\text { NOx } \\
\text { Reductions } \\
\text { (NG vs Diesef) }\end{array}$ \\
\hline SAIPPING & & & & & & & & & & \\
\hline Transtainer & 300 & 2000 & 8 & 10 & 2.651 & 0.489 & 2.162 & 26.510 & 4.894 & 21.616 \\
\hline Straddle Crane & 300 & 3500 & 5 & 6 & 4.639 & 0.856 & 3.783 & 27.836 & 5.139 & 22.697 \\
\hline Reach Stacker & 300 & 3000 & 6 & 8 & 3.181 & 0.587 & 2.594 & 25.450 & 4.698 & 20.751 \\
\hline Top Pick & 275 & 2550 & 35 & 45 & 2.496 & 0.499 & 1.997 & 112.321 & 22.464 & 89.857 \\
\hline Side Pick & 225 & 1750 & 22 & 28 & 1.285 & 0.257 & 1.028 & 35.972 & 7.194 & 28.778 \\
\hline Heavy Forklift & 275 & 650 & 14 & 18 & $0.4 \pi 7$ & 0.095 & 0.382 & 8.589 & 1.718 & 6.871 \\
\hline Yard Tractor" & 200 & 1950 & 232 & 298 & 0.949 & 0.191 & 0.758 & 282.694 & 56.880 & 225.814 \\
\hline Diesel Generator & 220 & 4750 & 22 & 28 & 9.299 & 1.860 & 7.439 & 260.370 & 52.074 & 208.296 \\
\hline $\begin{array}{c}\text { RAIL } \\
\text { Straddle Crane }\end{array}$ & 300 & 3800 & 6 & 6 & 5.037 & 0.930 & 4.107 & 30.222 & 5.579 & 24.642 \\
\hline Reach Stacker & 300 & 3000 & 5 & 5 & 3.181 & 0.587 & 2.594 & 15.906 & 2.937 & 12.970 \\
\hline Side Pick & 225 & 1400 & 1 & 1 & 1.028 & 0.206 & 0.822 & 1.028 & 0.206 & 0.822 \\
\hline Yand Tractor & 200 & 3500 & 33 & 33 & 1.713 & 0.343 & 1.370 & 56.528 & $\$ 1.306$ & 45.222 \\
\hline
\end{tabular}

- Hours we cata for Rail reach stacker and side picks abtained from Port or LA Rail data

- Extrapolations for Shipping reminal eqpt. are based on 7 of 9 terminals sampled

- Also includes fippers, packers and wedges

- Catculations based on 1\% LPG (2) and $99 \%$ desel (230) fleet vericles

- Natural Gas errissions based on Cummins B5.9G engine for HP up to 225, Cummins CA.3G for HP up to 300, and CAT C10 for $300 \mathrm{HP}$ and over

\begin{tabular}{|c|c|c|c|c|c|c|c|c|c|c|}
\hline \multicolumn{11}{|c|}{ Port of Oakland Terminal Equipment - Characteristics and CO Emissions } \\
\hline & \multirow[b]{2}{*}{$\begin{array}{c}\text { Typical } \\
\text { HP }\end{array}$} & \multirow{2}{*}{$\begin{array}{l}\text { Avg. } \\
\text { Annual } \\
\text { Hours } \\
\text { Use" }\end{array}$} & \multirow{2}{*}{$\begin{array}{c}\text { Actual } \\
\text { Vehicle } \\
\text { Count }\end{array}$} & \multirow{2}{*}{$\begin{array}{c}\text { Total \# } \\
\text { Vohicles } \\
\text { (oxtrep) }\end{array}$} & \multicolumn{3}{|c|}{ per each vehicle (tonsyryar) } & \multicolumn{3}{|c|}{ total fleet (tonstyour) } \\
\hline & & & & & \begin{tabular}{c|} 
Diesel \\
Emissions
\end{tabular} & $\begin{array}{l}\text { Natural Gas } \\
\text { Emissions }\end{array}$ & $\begin{array}{c}c 0 \\
\text { Reductions } \\
\text { (NG vs Diesel) }\end{array}$ & $\begin{array}{c}\text { Diesal } \\
\text { Emissions }\end{array}$ & $\begin{array}{c}\text { Natural Gas } \\
\text { Emissions }\end{array}$ & $\begin{array}{c}\text { CO } \\
\text { Reductions } \\
\text { (NG vs Diesed) }\end{array}$ \\
\hline SHIPPING & & & & & & & & & & \\
\hline Transtainer & 300 & 2000 & 8 & 10 & 0.449 & 1.509 & -1.060 & 4.486 & 15.090 & -10.604 \\
\hline Straddle Crane & 300 & 3500 & 5 & 6 & 0.785 & 2.641 & -1.856 & 4.711 & 15.845 & -11.134 \\
\hline Reach Stacker & 300 & 3000 & 6 & 8 & 0.538 & 1.811 & -1.272 & 4.307 & 14.487 & -10.180 \\
\hline Top Pick & 275 & 2550 & 35 & 45 & 0.582 & 0.187 & 0.395 & 26.208 & 8.424 & 17.784 \\
\hline Side Pick & 225 & 1750 & 22 & 28 & 0.300 & 0.278 & 0.021 & 8.394 & 7.794 & 0.600 \\
\hline Hoavy Forklift & 275 & 650 & 14 & 18 & 0.111 & 0.036 & 0.076 & 2.004 & 0.644 & 1.360 \\
\hline Yard Tractor & 200 & 4950 & 232 & 298 & 0.223 & 0.207 & 0.016 & 66.360 & 61.620 & 4.740 \\
\hline Diesel Generator & 220 & 4750 & 22 & 28 & 2.170 & 2.015 & 0.155 & 60.753 & 56.414 & 4.340 \\
\hline RAVIL & & & & & & & & & & \\
\hline Stradole Crane & 300 & 3800 & 6 & 6 & 0.852 & 2.867 & -2.015 & 5.114 & $17.203-$ & -12.089 \\
\hline Reach Stacker & 300 & 3000 & 5 & 5 & 0.538 & 1.811 & -1.272 & 2.692 & 9.054 & -6.362 \\
\hline Side Pick & 225 & 1400 & 1 & 1 & 0.240 & 0.223 & 0.017 & 0.240 & 0.223 & 0.017 \\
\hline Yard Tractor & 200 & 3500 & 33 & 33 & 0.400 & 0.371 & 0.029 & 13.190 & 12.248 & 0.942 \\
\hline
\end{tabular}

- Hours use data for Rail reach stacker and sice pichs obtained from Port of LA Rail data

- Extrapolations for Shipping teminal eqpt. are based on 7 of 9 terminals sampled

- Also inciudes fippers, packers and weches

- Calculations based on 1\% LPG (2) and 99\% desel (230) freet vehicles

- Natural Gas emissions based on Curmins B5.9G engine for HP up to 225, Curmins C8.3G for 1 P up to 300, and CAT.C10 for 300 HP and over 


\begin{tabular}{|c|c|c|c|c|c|c|c|c|c|c|}
\hline \multicolumn{11}{|c|}{ Port of Oakland Terminal Equipment - Charactoristics and PM Emissions } \\
\hline \multirow[b]{2}{*}{$\cdot$} & \multirow[b]{2}{*}{$\begin{array}{c}\text { Typical } \\
\text { HP }\end{array}$} & \multirow{2}{*}{$\begin{array}{c}\text { Avg. } \\
\text { Annual } \\
\text { Hours } \\
\text { Use }\end{array}$} & \multirow{2}{*}{$\begin{array}{l}\text { Actual } \\
\text { Vehicle } \\
\text { Count }\end{array}$} & \multirow{2}{*}{$\begin{array}{l}\text { Total \# } \\
\text { Vehicles } \\
\text { (extrap) }\end{array}$} & \multicolumn{3}{|c|}{ per each vehicle (tonsyour) } & \multicolumn{3}{|c|}{ total fleet (tons/yar) } \\
\hline & & & & & $\begin{array}{c}\text { Diesel } \\
\text { Emissions }\end{array}$ & $\begin{array}{c}\text { Natural } \\
\text { Gas } \\
\text { Emissions }\end{array}$ & $\begin{array}{c}\text { PM } \\
\text { Reductions } \\
\text { (NG vs Diesel) }\end{array}$ & $\begin{array}{c}\text { Diesel } \\
\text { Emissions }\end{array}$ & $\begin{array}{l}\text { Natural Gas } \\
\text { Emissions }\end{array}$ & $\begin{array}{c}\text { PM } \\
\text { Reductions } \\
\text { (NG vs Diesed) }\end{array}$ \\
\hline SHIPPING & & & & & & & & & & \\
\hline Transtainer & 300 & 2000 & 8 & 10 & 0.122 & 0.012 & 0.110 & 1.224 & 0.122 & 1.101 \\
\hline Straddle Crane & 300 & 3500 & 5 & 6 & 0.214 & 0.021 & 0.193 & 1.285 & 0.128 & 1.156 \\
\hline Reach Stacker & 300 & 3000 & 6 & 8 & 0.147 & 0.015 & 0.132 & 1.175 & 0.117 & 1.057 \\
\hline Top Pick & 275 & 2550 & 35 & 45 & 0.125 & 0.004 & 0.121 & 5.616 & 0.187 & 5.429 \\
\hline Side Pick & 225 & 1750 & 22 & 28 & 0.064 & 0.002 & 0.062 & 1.799 & 0.060 & 1.739 \\
\hline Heavy Forklift & 275 & 650 & 14 & 18 & 0.024 & 0.001 & 0.023 & 0.429 & 0.014 & 0.415 \\
\hline Yard Tractord & 200 & 1950 & 232 & 298 & 0.048 & 0.002 & 0.046 & 14.220 & 0.474 & 13.746 \\
\hline Diesel Generator & 220 & 4750 & 22 & 28 & 0.465 & 0.015 & 0.449 & 13.019 & 0.434 & 12.585 \\
\hline RAIL & & & & & & & & & & \\
\hline Straddle Crane & 300 & 3800 & 6 & 6 & 0.232 & 0.023 & 0.209 & 1.395 & 0.139 & 1.255 \\
\hline Reach Stacker & 300 & 3000 & 5 & 5 & 0.147 & 0.015 & 0.132 & 0.734 & 0.073 & 0.661 \\
\hline Side Pick & 225 & 1400 & 1 & 1 & 0.051 & 0.002 & 0.050 & 0.051 & 0.002 & 0.050 \\
\hline Yard Tractor & 200 & 3500 & 33 & 33 & 0.086 & 0.003 & 0.083 & 2.826 & 0.094 & 2.732 \\
\hline
\end{tabular}

- Hours use data for Rail reach stacker and side picks obtained from Port of LA Rail data

- Extrapolations for Shipping terminal eqpt. are based on 7 of 9 terminals sampled

c Also includes flippers, packers and wedges

- Calculations based on 1\% LPG (2) and 99\% diesel (230) fleet vehicles

- Natural Gas emissions based on Curmins B5.9G engine for HP up to 225, Cummins C8.3G for HP up to 300, and CAT C10 for 300 HP and over

\begin{tabular}{|c|c|c|c|c|c|c|c|c|c|c|}
\hline \multicolumn{11}{|c|}{ Port of Oakland Terminal Equipment - Characteristics and NMHC Emissions } \\
\hline & \multirow{2}{*}{$\begin{array}{c}\text { Typical } \\
\text { HP }\end{array}$} & \multirow{2}{*}{$\begin{array}{l}\text { Avg. } \\
\text { Annual } \\
\text { Hours } \\
\text { Use" }\end{array}$} & \multirow{2}{*}{$\begin{array}{c}\text { Actual } \\
\text { Vehiclo } \\
\text { Count }\end{array}$} & \multirow{2}{*}{$\begin{array}{c}\text { Total \# } \\
\text { Vehicies } \\
\text { (extrap) }\end{array}$} & \multicolumn{3}{|c|}{ per each vehicle (tonatyoar) } & \multicolumn{3}{|c|}{ total fleet (tonsycer) } \\
\hline & & & & & $\begin{array}{c}\text { Diesel } \\
\text { Emissions }\end{array}$ & $\begin{array}{l}\text { Natural Gas } \\
\text { Emissions }\end{array}$ & $\begin{array}{c}\text { NMHHC } \\
\text { Reductions } \\
\text { (NG vas Dived) }\end{array}$ & $\begin{array}{c}\text { Dieset } \\
\text { Emissions }\end{array}$ & $\begin{array}{c}\text { Natural Gas } \\
\text { Emissions }\end{array}$ & $\begin{array}{c}\text { NMHC } \\
\text { Reductions } \\
\text { (NG vs Diesol) }\end{array}$ \\
\hline $\begin{array}{l}\text { SHIPPiNG } \\
\text { Transtainer }\end{array}$ & & & & & & & & & & \\
\hline $\begin{array}{l}\text { Transtainer } \\
\text { Straddle Crane }\end{array}$ & 300 & 2000 & 8 & 10 & 0.184 & 0.224 & -0.041 & 1.835 & 2.243 & -0.408 \\
\hline Reach Stacker & 300 & 3500 & 5 & 6 & 0.321 & 0.393 & -0.071 & 1.927 & 2.355 & -0.428 \\
\hline $\begin{array}{l}\text { Reach Stacker } \\
\text { Top Pick }\end{array}$ & 300 & 3000 & 6 & 8 & 0.220 & 0.269 & -0.049 & 1.762 & 2.153 & -0.392 \\
\hline Top Pick & 275 & 2550 & 35 & 45 & 0.208 & 0.125 & 0.083 & 9.360 & 5.616 & 3.744 \\
\hline Side Pick & 225 & 1750 & 22 & 28 & 0.107 & 0.011 & 0.096 & 2.998 & 0.300 & 2.698 \\
\hline Heavy Forklift & 275 & 650 & 14 & 18 & 0.040 & 0.024 & 0.016 & 0.716 & 0.429 & 0.286 \\
\hline Yand Tractor & 200 & 1950 & 232 & 298 & 0.080 & 0.008 & 0.072 & 23.700 & 2.370 & 21.330 \\
\hline Diesel Generator & 220 & 4750 & 22 & 28 & 0.775 & 0.077 & 0.697 & 21.698 & 2.170 & 19.528 \\
\hline $\begin{array}{c}\text { Rall } \\
\text { Straddle Crane }\end{array}$ & 300 & 3800 & 6 & 6 & 0349 & 0426 & $=007$ & 2002 & $x^{-1}$ & \\
\hline Reach Stacker & 300 & 3000 & 5 & 5 & 0.220 & 0.269 & -0.049 & $\begin{array}{l}2.092 \\
1.101\end{array}$ & $\begin{array}{l}2.55 r \\
1.346\end{array}$ & $\begin{array}{l}-0.465 \\
-0.245\end{array}$ \\
\hline Side Pick & 225 & 1400 & 1 & 1 & 0.086 & 0.009 & 0.077 & 0.086 & 0.009 & 0.077 \\
\hline Yard Tractor & 200 & 3500 & 33 & 33 & 0.143 & 0.014 & 0.128 & 4.711 & 0.471 & 4.240 \\
\hline
\end{tabular}

- Hours use data for Rail reach stacker and side picks obtained from Port of LA Rail data

- Extrapolations for Shipoing terminal eqo. are based on 7 of 9 terminals sampled

'Also inctudes fippers, packers and wedges

- Catculations based on 1\% LPG (2) and 99\% desel (230) fleet vetrides

- Natural Gas emissions based on Cummins 85.9G engine for HP up to 225, Cumnins C8.3G for HP up to 300, and CAT C10 for 300 HP and over 


\section{APPENDIX F - Legislation, Regulations and Funding}

Legislative action and the subsequent promulgation of new regulation and funding opportunities also play a critical role in shaping the feasibility of LNG use in heavy-duty applications. The following table details existing and pending legislative measures salient to the present port study.

\section{Existing Federal Legislation}

\begin{tabular}{|c|c|c|}
\hline Sponsor - Legislation & Funding \& Monetary Impacts & Description/Provisions \\
\hline $\begin{array}{l}\text { US Dept. of Trans. and } \\
\text { Caltrans - } \\
\text { Transportation Equity } \\
\text { Act for the 21st } \\
\text { Century (TEA-21) }\end{array}$ & $\begin{array}{l}\$ 8.1 \text { billion over } 6 \text { years (through the } \\
\text { CMAQ program). }\end{array}$ & $\begin{array}{l}\text { TEA } 21 \text { is a continuation and improvement of ISTEA, to help } \\
\text { meet the requirements of the Clean Air Act, and provides for } \$ 8.1 \\
\text { billion over } 6 \text { years. Funds may be allocated for public/private } \\
\text { partnerships and technology developments inciuding, but not } \\
\text { limited to, refueling station construction, incremental vehicle } \\
\text { costs, and retrofit/repower of pre-1993 engines. }\end{array}$ \\
\hline $\begin{array}{l}\text { US EPA - } \\
\text { Clean Air Act } \\
\text { Amendments of } 1990\end{array}$ & None & $\begin{array}{l}\text { Clarifies how areas will be designated as non-attainment and } \\
\text { specifies the types of actions that must be taken to improve an } \\
\text { areas air quality. Certain fleets of } 10 \text { or more vehicles, capable } \\
\text { of being centrally refueled, must purchase a percentage of clean } \\
\text { fuel vehicles (CFV). Vehicles greater than } 8,500 \mathrm{lb} \text {. gww in CA } \\
\text { are subject to the requirements of the Clean Fuel Fleet Program. }\end{array}$ \\
\hline $\begin{array}{l}\text { US EPA - } \\
\text { Energy Policy Act }\end{array}$ & $\begin{array}{l}\text { Federal tax deductions for AFVs; } \\
\$ 2,000 \text { (up to } 10,000 \mathrm{lb} . \mathrm{gvw}) \\
\$ 5,000(10,001-26,000 \mathrm{lb} \mathrm{gvw}) \\
\$ 50,000(26,000+\mathrm{lb} \text {. gvw). } \\
\text { AFV fueling facilities; } \$ 100,000 \text {. }\end{array}$ & $\begin{array}{l}\text { Establishes a comprehensive energy strategy, based on reducing } \\
\text { foreign oil dependence and expanding the utilization of } \\
\text { alternative transportation fuels. Requires certain fleets to } \\
\text { purchase a percentage of AFVs, however vehicles weighing over } \\
8,500 \mathrm{lb} \text {. are not currently covered. Credits may be earned, and } \\
\text { transferred, for fleet AFV purchases above and beyond mandate } \\
\text { requirements. }\end{array}$ \\
\hline $\begin{array}{l}\text { US Dept. of Energy - } \\
\text { Clean Cities Program }\end{array}$ & $\begin{array}{l}\text { Approximately } \$ 10 \text { million in low } \\
\text { interest alternative fuel-related loans } \\
\text { and } \$ 1 \text { million for AFV demonstration } \\
\text { projects and infrastructure annually. }\end{array}$ & $\begin{array}{l}\text { This DOE program provides funds for a wide variety of alternative } \\
\text { fuel vehicle and infrastructure demonstration projects. Current } \\
\text { focus is on connecting designated cities with interstate } \\
\text { infrastructure development. }\end{array}$ \\
\hline
\end{tabular}

Proposed/Pending Federal Legislation

\begin{tabular}{|c|c|c|}
\hline $\begin{array}{l}\text { Sponsor/Bill - } \\
\text { Legis/ation }\end{array}$ & Funding \& Monetary Impacts & Description/Provisions \\
\hline $\begin{array}{l}\text { H.R. } 3466- \\
\text { Empowerment Zone } \\
\text { Clean Fuel Vehic/e Bill }\end{array}$ & A \$.50/gge tax credit for CFVs. & $\begin{array}{l}\text { Provides tax incentives for clean fuel vehicle use by enterprise } \\
\text { zone businesses within empowerment zones and non-attainment } \\
\text { areas. It would also replace the existing EPAct tax deductions for } \\
\text { fueling property and vehicle investments with tax credits, in these } \\
\text { designated areas. }\end{array}$ \\
\hline $\begin{array}{l}\text { H.R. 3376: } \\
\text { Clean Burning Fuels } \\
\text { Incentive Act }\end{array}$ & $\begin{array}{l}\text { A } \$ .50 / g g e \text { (or per } 114,000 \text { Btu) tax } \\
\text { credit for users of certain newly } \\
\text { purchased clean fuel vehicles. }\end{array}$ & $\begin{array}{l}\text { Would provide a federal income tax credit for the use of new } \\
\text { natural gas, methanol and ethanol powered vehicles. The credit } \\
\text { would be } \$ .50 / \mathrm{gge} \text {, or per } 114,000 \mathrm{Btu} \text {. }\end{array}$ \\
\hline $\begin{array}{l}\text { S. 829: } \\
\text { Clean Fuel Vehicle Act } \\
\text { of } 1997\end{array}$ & $\begin{array}{l}\text { Exempts clean-fuel vehicles from liuxury } \\
\text { vehicle tax, reduces LNG tax to parity } \\
\text { with CNG (to about \$.0354/LNG gallon) }\end{array}$ & $\begin{array}{l}\text { Amends the Internal Revenue Code to encourage the production } \\
\text { and use of clean-fuel vehicles. }\end{array}$ \\
\hline $\begin{array}{l}\text { H.R. 970: } \\
\text { The Natural Gas } \\
\text { Vehicle Incentives Act } \\
\text { of } 1997\end{array}$ & $\begin{array}{l}\text { Among numerous tax credits, it includes } \\
50 \% \text { credit for incremental cost of } \\
\text { AFVs. }\end{array}$ & $\begin{array}{l}\text { Amends Federal AFV mandates in favor of an-incentive based } \\
\text { approach, by establishing tax credits for purchase of new AFVs, } \\
\text { fueling infrastructure, and alternative fuels. In addition, it } \\
\text { provides for shorter depreciation of AFVs and related } \\
\text { infrastructure and funding for research, development and } \\
\text { demonstration of AFV technologies. Natural gas use is } \\
\text { emphasized. }\end{array}$ \\
\hline $\begin{array}{l}\text { Rockefeller Bill } \\
\text { Alternative Fuel } \\
\text { Promotion Act }\end{array}$ & $\begin{array}{l}\$ 30,000 \text { in tax deductions for alternative } \\
\text { fueling station installations and a } \\
\$ .50 / \text { per gge tax credit to the sellers of } \\
\text { clean burning alternative fueis used in } \\
\text { AFVs. }\end{array}$ & $\begin{array}{l}\text { This act would provide substantial new incentives for the use of } \\
\text { AFVs in a variety of applications. Providing tax credits to the } \\
\text { seller rather than the user would drive down the cost of LNG fuel, } \\
\text { while simultaneously allowing for distribution of the credit through } \\
\text { production/delivery/marketing chain. The act would also provide } \\
\text { states with the authority to allow single occupant AFVs in high } \\
\text { occupancy vehicle lanes. }\end{array}$ \\
\hline
\end{tabular}




\section{Existing California Legislation}

\begin{tabular}{|c|c|c|}
\hline Sponsor: Legis/ation & Funding \& Monetary /mpacts & Description/Provisions \\
\hline $\begin{array}{l}\text { Local AQMD - } \\
\text { A.B. } 2766\end{array}$ & $\begin{array}{l}\text { The Mobile Source Air Pollution } \\
\text { Reduction Review Committee (through } \\
\text { DMV fees) tentatively has } \$ 11 \text { million } \\
\text { for HD vehicle projects for } 1998-99 \text {. }\end{array}$ & $\begin{array}{l}\text { Aims to reduce mobile source emissions on projects offering } \\
\text { qualitative and non-air quality-related benefits, including HD } \\
\text { vehicles and research, development and demonstration of } \\
\text { advanced low-emission transportation technologies. }\end{array}$ \\
\hline $\begin{array}{l}\text { California Energy } \\
\text { Commission - } \\
\text { Medium \& Heavy Duty AFV } \\
\text { Incentive Program }\end{array}$ & $\begin{array}{l}\$ 250,000 \text { for LNG Liquefaction } \\
\text { Projects; } \$ 575,000 \text { for Heavy Duty } \\
\text { Demonstrations; and } \$ 500,000 \text { for } \\
\text { Heavy Duty Infrastructure to be } \\
\text { awarded in calendar year } 1999 \text {. }\end{array}$ & $\begin{array}{l}\text { Funding is used to defray costs of new and converted vehicle } \\
\text { demonstrations that achieve } 2.5 \mathrm{~g} / \mathrm{bhp} \text {-hr NOx emissions, } \\
\text { infrastructure development with } 14,250 \text { million BTU minimum } \\
\text { throughput, and building of LNG production facilities. } \\
\text { Minimum } 50 \% \text { cost-share is required for most projects. }\end{array}$ \\
\hline $\begin{array}{l}\text { California Energy } \\
\text { Commission - } \\
\text { Transp. Energy } \\
\text { Technologies Advancement } \\
\text { Program (TETAP) } \\
\end{array}$ & $\begin{array}{l}\$ 1,400,000 \text { awarded in } 1997-98 \\
\text { program (with PVEA funds). }\end{array}$ & $\begin{array}{l}\text { TETAP provides up to } 50 \% \text { co-funding of near-term (3-5 } \\
\text { years) transportation research, development and } \\
\text { demonstration projects that have the potential to reduce } \\
\text { emissions and petroleum fuel use by on- or off-road vehicles. }\end{array}$ \\
\hline $\begin{array}{l}\text { ARB, CEC, US DOE, } \\
\text { CALSTART et al. - } \\
\text { Interstate Clean } \\
\text { Transportation Corridor } \\
\text { (ICTC) }\end{array}$ & $\begin{array}{l}\$ 250,000 \text { avg., } \$ 10 \text { million/yr for } \\
\text { California }\end{array}$ & $\begin{array}{l}\text { Seeks to develop refueling infrastructure (focus on LNG) to } \\
\text { support interstate truck traffic between LA, San } \\
\text { Francisco/Sacramento and Salt Lake City, UT. Aims to } \\
\text { assist in air quality and fuel diversification goals and create a } \\
\text { market pull. }\end{array}$ \\
\hline $\begin{array}{l}\text { ARB - } \\
\text { Innovative Clean Air } \\
\text { Technologies }\end{array}$ & $\begin{array}{l}\$ 250,000 \text { avg., } \$ 1 \text { million/yr (requires } \\
50 \% \text { match) }\end{array}$ & $\begin{array}{l}\text { Funds projects which develop and demonstrate technologies } \\
\text { that reduce air pollution and show technical merit, support } \\
\text { CARB objectives \& have potential for job creation in } \\
\text { California. }\end{array}$ \\
\hline $\begin{array}{l}\text { Proposition } 65- \\
\text { Safe Drinking Water and } \\
\text { Toxic Enforcement Act of } \\
1986\end{array}$ & $\begin{array}{l}\text { This action may force large diesel } \\
\text { fleets to re-evaluate alternative fuel } \\
\text { technologies as current and future } \\
\text { suits are filed, alleging violation of } \\
\text { Prop. } 65 \text { stipulations. }\end{array}$ & $\begin{array}{l}\text { Requires public notification of presence and/or use of } \\
\text { chemicals known by the State of Califomia to cause cancer, } \\
\text { birth defects or other reproductive harm, shifting the burden } \\
\text { of proof from the regulatory agency to the business and } \\
\text { forcing the latter develop altemative practices, test new } \\
\text { products, and meet overall compliance with Prop. } 65 \text { 's } \\
\text { requirements. }\end{array}$ \\
\hline $\begin{array}{l}\text { ARB August } 1998- \\
\text { formal listing of Diesel } \\
\text { particulate emissions as a } \\
\text { Toxic Air Contaminant } \\
\text { (TAC) }\end{array}$ & $\begin{array}{l}\text { As with Prop. } 65 \text {, the TAC listing of } \\
\text { diesel may result in increased } \\
\text { regulation and/or litigation, forcing } \\
\text { diesel-dependent operations to re- } \\
\text { consider increased AFV use. }\end{array}$ & $\begin{array}{l}\text { The TAC listing of diesel particulate emissions will increase } \\
\text { awareness, and possibly litigation, regarding the health } \\
\text { issues associated with diesel use. ARB will also begin the } \\
\text { process of assessing the need for additional guidelines, } \\
\text { regulations, and other opportunities to reduce further public } \\
\text { exposure to toxic air contaminants from diesel-fueled vehicles } \\
\text { and engines. }\end{array}$ \\
\hline $\begin{array}{l}\text { Local Air Districts \& ARB - } \\
\text { Carf Moyer Heavy Duty } \\
\text { Vehicle Program }\end{array}$ & $\begin{array}{l}\$ 25 \text { million in funding to be spent in } \\
\text { the upcoming year. }\end{array}$ & $\begin{array}{l}\text { Funding will be used to reduce diesel emissions by } \\
\text { purchasing new and replacing existing } \mathrm{HD} \text { vehicles and off- } \\
\text { road equipment with certified and cost effective low-emission } \\
\text { technologies. Focus is on reducing NOx and PM emissions } \\
\text { from diesel vehicles greater than } 14,000 \mathrm{gw} \text { and equipment } \\
\text { over } 50 \mathrm{hp} \text {. Funds will be administered by the air districts on } \\
\text { a } \$ .5 / 1 \text { match. }\end{array}$ \\
\hline $\begin{array}{l}\text { Califomia Petroleum } \\
\text { Violation Escrow Account } \\
\text { Funds }\end{array}$ & $\begin{array}{l}\text { State appropriated over } \$ 1.8 \text { million in } \\
1997\end{array}$ & $\begin{array}{l}\text { In } 1997 \text { over } \$ 4 \text { million was appropriated for the } \\
\text { transportation, technology advancement and } \\
\text { commercialization program. Funds were used to establish } \\
\text { demonstration projects and to purchase alternative fuel } \\
\text { vehicles and related infrastructure. }\end{array}$ \\
\hline
\end{tabular}




\section{APPENDIX G - Estimated Daily LNG Fuel Demand at Various Penetration Levels}

\section{Methodology}

The potential LNG fuel demand at various penetration levels is calculated using operational data drawn from interviews with port trucking and terminal operators. These calculations are presented in the tables below. The fuel economy of port trucks is assumed to be $6.0 \mathrm{mpg}$, while that of yard tractors is $2.0 \mathrm{gph}$. Because of the substantial difference between the annual hours of operation for rail and shipping terminal yard tractors (see Table 2-8), a weighted average has been used to generate the potential fuel demand for this vehicle category. For the purposes of this exercise, no energy efficiency penalties have been factored into total LNG fuel consumption calculation. Depending on the type of engines being used, actual fuel demand would be at least $5-15 \%$ higher than presented here.

\section{Port of Los Angeles - Yard Tractors}

\begin{tabular}{|c|c|c|c|c|c|c|c|c|c|}
\hline penetration & $\begin{array}{c}\text { est.\# } \\
\text { vehicles }\end{array}$ & & $\begin{array}{c}\text { fuel } \\
\text { econon } \\
\text { (gph) }\end{array}$ & & $\begin{array}{l}\text { avg. daily } \\
\text { use (hours) }\end{array}$ & $\begin{array}{c}\text { diesel fuel } \\
\text { consumptio } \\
\text { (gallons) }\end{array}$ & & $\begin{array}{l}\text { energy } \\
\text { equivalency } \\
\text { factor }\end{array}$ & $\begin{array}{c}\text { LNG fuel } \\
\text { consumption } \\
\text { (gallons) }\end{array}$ \\
\hline $10 \%$ & 68 & $x$ & 2.0 & $x$ & 10.3 & 1,397 & $x$ & 17 & 2,374 \\
\hline $20 \%$ & 136 & $x$ & 2.0 & $x$ & 10.3 & 2,793 & $x$ & 1.7 & 4,749 \\
\hline $20 \%$ & 203 & $\mathbf{x}$ & 2.0 & $x$ & 10.3 & 4,190 & $x$ & 17 & 7,123 \\
\hline $40 \%$ & 271 & $x$ & 2.0 & $x$ & 10.3 & 5,587 & $x$ & 1.7 & 9,497 \\
\hline $50 \%$ & 339 & $x$ & 20 & $x$ & 10.3 & 6,983 & $x$ & $\times 17 \%=$ & 11,872 \\
\hline $60 \%$ & 407 & $x$ & 2.0 & $x$ & 10.3 & 8,380 & $x$ & 1.7 & 14,246 \\
\hline $70 \%$ & 475 & $\mathrm{x}$ & 2.0 & $x$ & 10.3 & 9777 & $x$ & $17=$ & 16,620 \\
\hline $80 \%$ & 542 & $x$ & 2.0 & $x$ & $10.3=$ & $=11,173$ & $x$ & $1.7=$ & 18,995 \\
\hline $90 \%$ & 610 & $x$ & 2,0 & $x$ & 10.3 & $12 ; 570=$ & $x$ & $17 \%$ & 21,3697 \\
\hline $100 \%$ & 678 & $x$ & 2.0 & $x$ & $10.3=$ & 13,967 & $x$ & $1.7=$ & 23,744 \\
\hline
\end{tabular}

\section{Port of Oakland - Yard Tractors}

\begin{tabular}{|c|c|c|c|c|c|c|c|c|c|}
\hline penetration & $\begin{array}{c}\text { est. \# } \\
\text { vehicles }\end{array}$ & & $\begin{array}{c}\text { fuel } \\
\text { econon } \\
\text { (gph) }\end{array}$ & & $\begin{array}{l}\text { avg. daily } \\
\text { use (hours) }\end{array}$ & $\begin{array}{l}\text { diesel fut } \\
\text { consumpti } \\
\text { (gallons) }\end{array}$ & & $\begin{array}{l}\text { energy } \\
\text { equivalency } \\
\text { factor }\end{array}$ & $\begin{array}{l}\text { LNG fuel } \\
\text { consumption } \\
\text { (gallons) }\end{array}$ \\
\hline $10 \%$ & 33 & $x$ & 20 & $x$ & 5.9 & 391 & & -17 & $<664$ \\
\hline $20 \%$ & 66 & $x$ & 2.0 & $x$ & $5.9=$ & 781 & $x$ & 1.7 & 1,328 \\
\hline $30 \%$ & 99 & $x$ & 20 & $x$ & 599 & 1,172 & $x$ & 17 & 1,992 \\
\hline $40 \%$ & 132 & $x$ & 2.0 & $x$ & $5.9=$ & 1,562 & $x$ & 1.7 & 2,656 \\
\hline $50 \%$ & 166 & $x$ & 207 & $x$ & 5.9 & 1,953 & $x$ & $17 \%$ & 3,320 \\
\hline $60 \%$ & 199 & $x$ & 2.0 & $x$ & 5.9 & 2,343 & $x$ & 1.7 & 3,984 \\
\hline $70 \%$ & 232 & $x$ & 20 & $x$ & 59 & 2734 & $x$ & $1: 7$ & 4,648 \\
\hline $80 \%$ & 265 & $x$ & 2.0 & $x$ & 5.9 & 3,125 & $x$ & 1.7 & 5,312 \\
\hline $90 \%$ & 298 & $x$ & 20 & $x$ & 5.9 & 3,515 & $x^{3}$ & 17 & 5,976 \\
\hline $100 \%$ & 331 & $x$ & 2.0 & $x$ & 5.9 & 3,906 & $\mathrm{x}$ & 1.7 & 6,640 \\
\hline
\end{tabular}


